October 2004

\title{
Atmospheric Dispersal and Deposition of Tephra from a Potential Volcanic Eruption at Yucca Mountain, Nevada
}

Prepared for:

U.S. Department of Energy

Office of Civilian Radioactive Waste Management

Office of Repository Development

1551 Hillshire Drive

Las Vegas, Nevada 89134-6321

Prepared by:

Bechtel SAIC Company, LLC

1180 Town Center Drive

Las Vegas, Nevada 89144

Under Contract Number

DE-AC28-01RW12101 


\section{DISCLAIMER}

This report was prepared as an account of work sponsored by an agency of the United States Government. Neither the United States Government nor any agency thereof, nor any of their employees, nor any of their contractors, subcontractors or their employees, makes any warranty, express or implied, or assumes any legal liability or responsibility for the accuracy, completeness, or any third party's use or the results of such use of any information, apparatus, product, or process disclosed, or represents that its use would not infringe privately owned rights. Reference herein to any specific commercial product, process, or service by trade name, trademark, manufacturer, or otherwise, does not necessarily constitute or imply its endorsement, recommendation, or favoring by the United States Government or any agency thereof or its contractors or subcontractors. The views and opinions of authors expressed herein do not necessarily state or reflect those of the United States Government or any agency thereof. 
QA: QA

\author{
Atmospheric Dispersal and Deposition of Tephra from a Potential \\ Volcanic Eruption at Yucca Mountain, Nevada \\ MDL-MGR-GS-000002 REV 01
}

October 2004 
7022855188

rUL CUD DIUE
T-784 P. $002 / 002$ F-120

\section{Mode signature PagejGhange Higtoary}

Fegro $\overline{\text { ni }}$

1. Toul Pager 224

\section{Typo of Liatheunalieal Medal \\ $x$ Pranose Model}

Abstretion theded

Syatem Moded

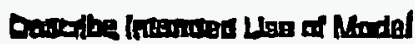

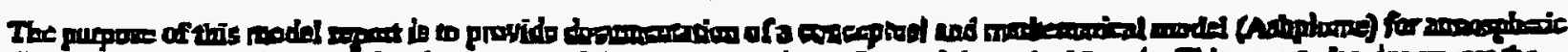

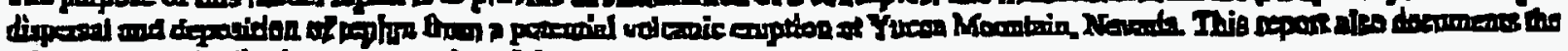

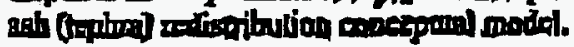

\section{The}

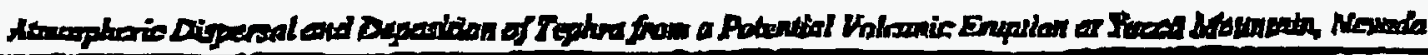

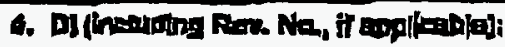

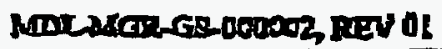

\begin{tabular}{l}
\hline 5. Trobe Appoundeos \\
Nine
\end{tabular}

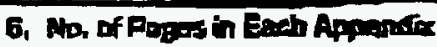

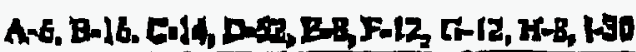

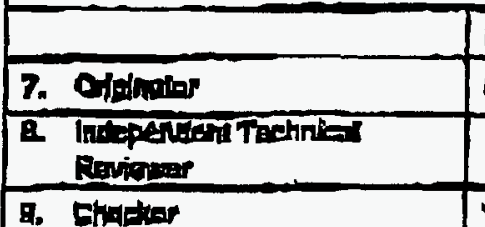

10. 망

11. Resporside Manegathand

22 Raeponsiols Werrigor

12. Fornoms

Fingad Hang
Slonahro

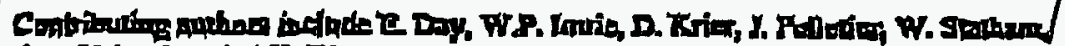

CA Vilention, sed R, wholles

Change Heany

\begin{tabular}{|c|c|}
\hline \multicolumn{2}{|r|}{ Change Heany } \\
\hline 14. Revian N/an & 15. Cordedpon of Cronge \\
\hline 0 & Lnivialioser \\
\hline DI & 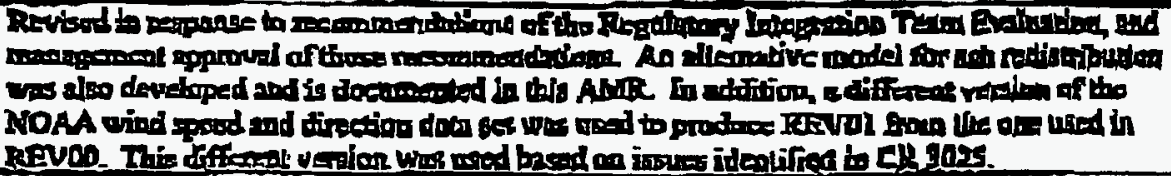 \\
\hline
\end{tabular}


INTENTIONALLY LEFT BLANK 


\section{CONTENTS}

Page

ACRONYMS AND ABBREVIATIONS xiii

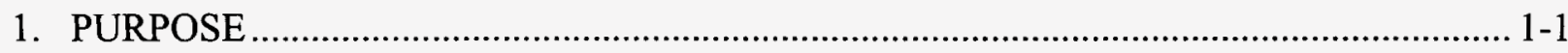

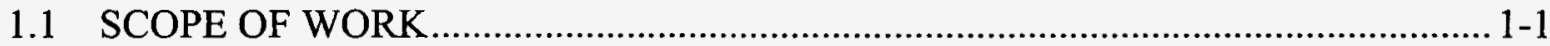

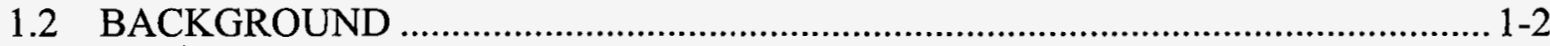

1.2.1 Previous Use and Documentation ........................................................... 1-2

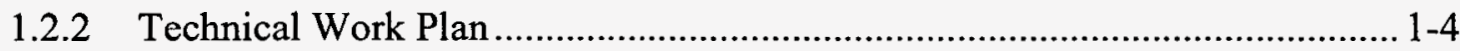

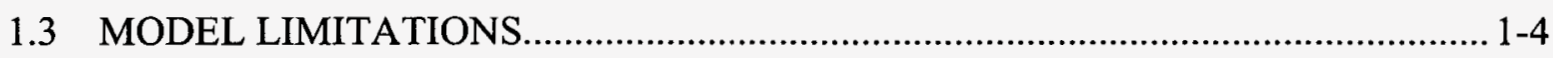

1.3.1 Ashplume Model Limitations............................................................ 1-4

1.3.2 Ash Redistribution Model Limitations................................................ 1-6

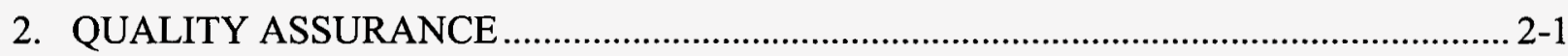

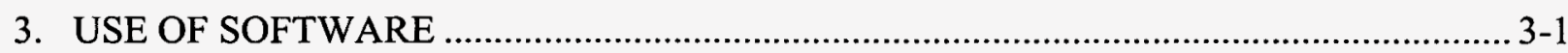

3.1 SOFTWARE TRACKED BY CONFIGURATION MANAGEMENT ..................... 3-1

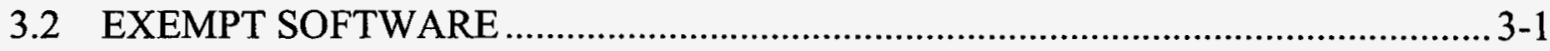

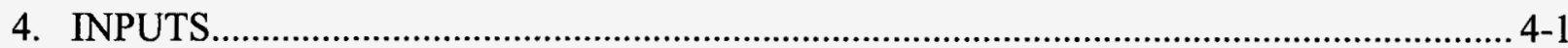

4.1 DATA, PARAMETERS, AND OTHER MODEL INPUTS .................................. $4-1$

4.1.1 Data .......................................................................................... 4-1

4.1.2 Parameters and Parameter Uncertainty ................................................ 4-3

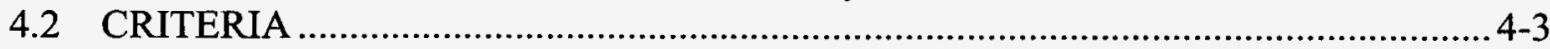

4.2.1 Criteria for Ashplume Model ...................................................................... 4-4

4.2.2 Criteria for Ash Redistribution Model ........................................................ 4-6

4.3 CODES, STANDARDS, AND REGULATIONS ............................................. 4-8

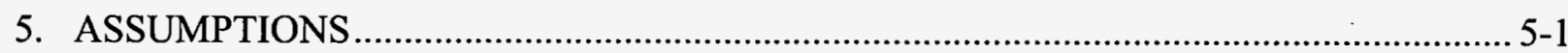

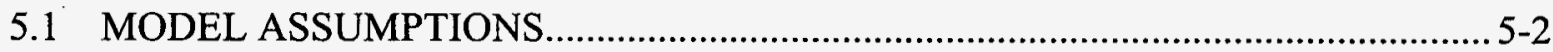

5.1.1 Ashplume Representation of the Conceptual Model...................................5-2

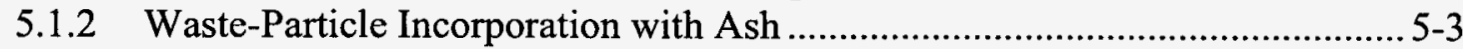

5.1.3 Tephra Sheet Distribution for Ash Redistribution Model ................................. 5-4

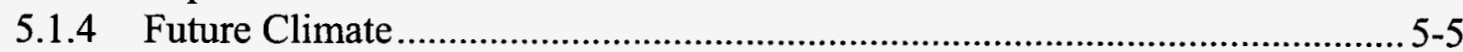

5.1.5 Ash-Sediment Mixing during Fluvial Transport .......................................... 5-5

5.1.6 Stability of Channels on the Upper Fortymile Wash Alluvial Fan .................. 5-5

5.1.7 Initial Redistributed Ash is Undiluted.................................................. 5-6

5.1.8 No Eolian Transport of Waste to the RMEI ............................................5-6

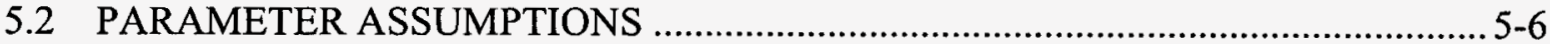

5.2.1 Future Wind Speed and Direction ........................................................ 5-6

5.2.2 Wind Speed and Direction Remain Constant During an Eruptive Event......... 5-8

5.2.3 Ashplume Utilization of Wind Speed and Direction.......................................5-8

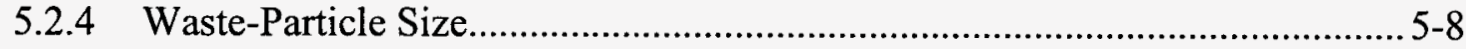

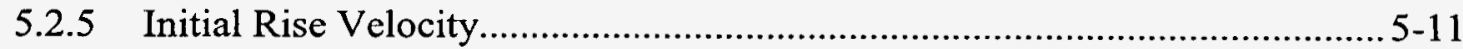

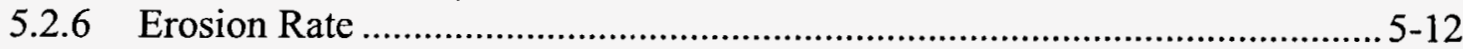




\section{CONTENTS (Continued)}

Page

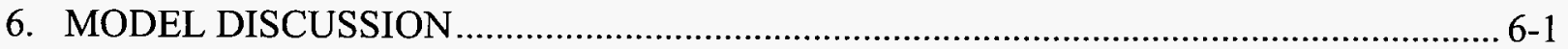

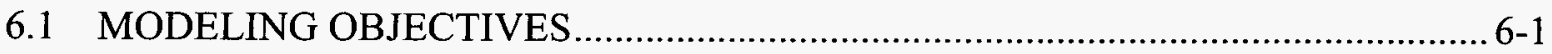

6.1.1 Objectives of the Ashplume Model ....................................................... 6-2

6.1.2 Objectives of the Ash Redistribution Conceptual Model............................... 6-2

6.2 FEATURES, EVENTS, AND PROCESSES INCLUDED IN THE MODEL............ 6-3

6.3 BASIS OF CONCEPTUAL MODELS ......................................................... 6-3

6.3.1 Basis of Ashplume Conceptual Model .................................................... 6-3

6.3.2 Basis of Ash Redistribution Model ............................................................. 6-5

6.4 CONSIDERATION OF ALTERNATIVE CONCEPTUAL MODELS ..................... 6-8

6.4.1 Consideration of Alternative Conceptual Models for Airborne Transport of

Tephra.

6.4.1.1

Gaussian-Plume Model

$6-8$

6.4.1.2

PUFF

6-8

6.4.1.3 Gas-Thrust Code.

$6-9$

6.4.1.4 Alternative Igneous Source Term Model

6.4.2 Consideration of Alternative Conceptual Model for Ash Redistribution....... 6-10

6.4.3 Summary of Alternative Conceptual Models ................................................. 6-10

6.5 ASH DISPERSAL CONCEPTUAL MODEL DESCRIPTION ............................. 6-11

6.5.1 Mathematical Description of the Base-Case Conceptual Model.................... 6-11

6.5.2 Core Model Inputs................................................................................ 6-18

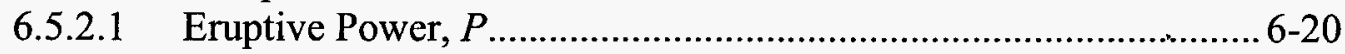

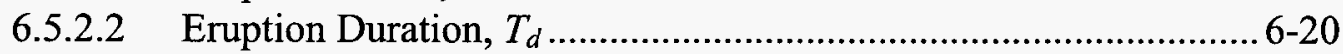

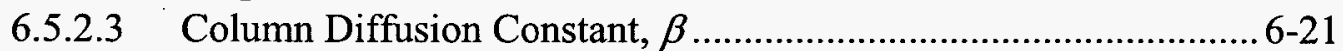

6.5.2.4 Mean Ash Particle Diameter, $d$................................................ 6-22

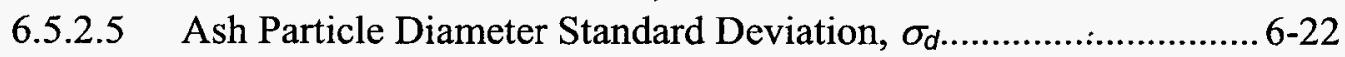

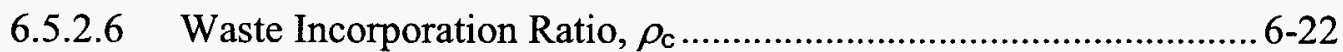

6.5.2.7 Wind Speed, $u$.................................................................... 6-23

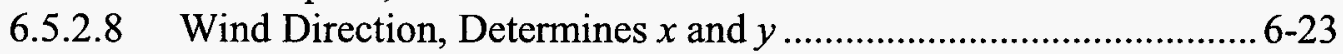

6.5.2.9 Mass of Waste Available for Incorporation, $U$.......................... 6-23

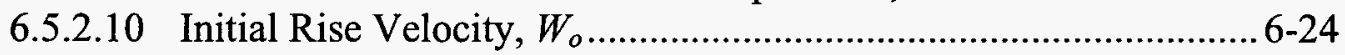

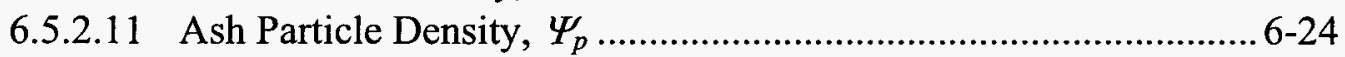

6.5.2.12 Ash Particle Shape Factor, $F$................................................ 6-25

6.5.2.13 Air Density, $\Psi$ a .................................................................... 6-25

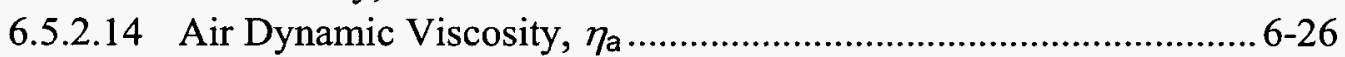

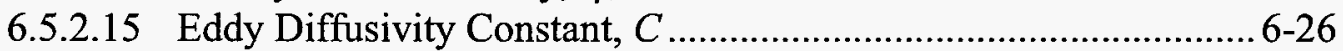

6.5.2.16 Waste Particle Size (Minimum, Mode, Maximum) ...................... 6-26

6.5.3 Other Model Inputs ............................................................................ 6-27

6.5.3.1 Grid Location and Spacing for the $X$ and $Y$ Axes, $X_{\min }, X_{\max }$,

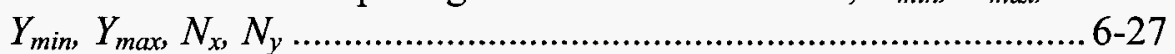

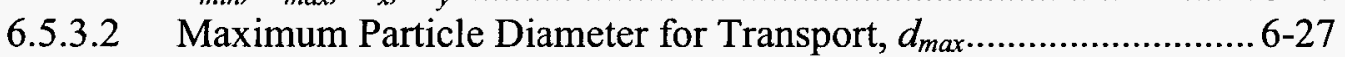

6.5.3.3 Minimum Height of Eruption Column, $H_{\min }$................................. 6-28

6.5.3.4 Threshold Limit on Ash Accumulation, Ash Cutoff ...................... 6-28 


\section{CONTENTS (Continued)}

Page

6.5.4 Summary of the Computational Model

6-28

6.6 ASH REDISTRIBUTION CONCEPTUAL MODEL DESCRIPTION................... 6-29

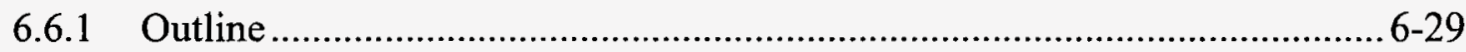

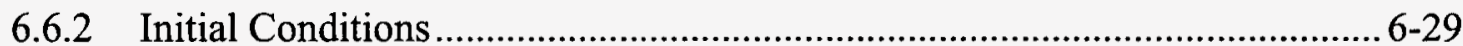

6.6.3 Tephra Redistribution and Dilution........................................................ 6-29

6.6.4 Rates of Surficial Processes in Fortymile Wash ...................................... 6-31

6.6.5 Equilibrium on The Fortymile Wash Alluvial Fan .....................................6-31

6.6.6 Model Outcome 1: Primary Tephra Deposition at the RMEI Location......... 6-31

6.6.7 Model Outcome 2: Primary Tephra Deposition Upstream in

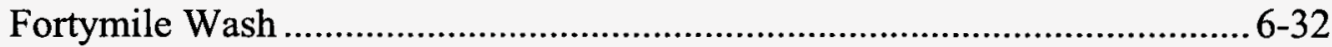

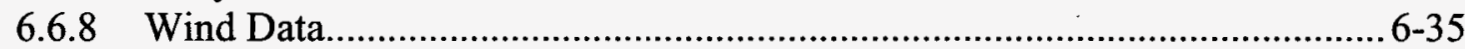

6.7 MODEL RESULTS AND ABSTRACTIONS ............................................... 6-36

6.7.1 Waste-Form Concentrations in Ash from an Ash Plume $18 \mathrm{~km}$

from a Vent...............................................................................6.6.6.

6.7.2 Ash Redistribution Model Abstraction.................................................... 6-40

6.7.2.1 Model Description ................................................................ 6-40

6.7.2.2 Formulation .......................................................................... 6-40

6.7.2.3 Interchannel-Divide Areas ....................................................... 6-42

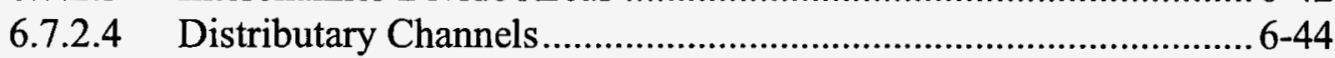

6.7.2.5 Model Parameters.................................................................6.6.45

6.7.2.5.1 Areal weights for channels and interchannel

divides ............................................................... 6-46

6.7.2.5.2 Ash erosion rate from interchannel divide areas........ 6-46

6.7.2.5.3 Residual concentration factor for waste in soil.......... 6-46

6.7.2.5.4 Time for ash dilution in channels.............................. 6-47

6.7.2.5.5 Thickness of residual contaminated soil layer ............. 6-47

6.7.2.5.6 Distribution of contamination within soil layer......... 6-47

7. MODEL VALIDATION …................................................................................... 7-1

7.1 VALIDATION PROCEDURES ................................................................... 7-1

7.2 SENSITIVITY ANALYSIS …................................................................... 7-3

7.3 NATURAL ANALOG STUDIES FOR ASHPLUME AND THE ASH

REDISTRIBUTION CONCEPTUAL MODEL .................................................... $7-4$

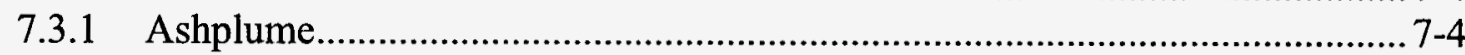

7.3.1.1 Cerro Negro ..................................................................... 7-4

7.3.1.2 Lathrop Wells ......................................................................... 7-5

7.3.1.3 Cinder Cone......................................................................... 7-7

7.3.2 Ash Redistribution................................................................................... 7-8

7.4 INDEPENDENT TECHNICAL REVIEW ..................................................... $7-10$

7.4.1 Ashplume Mathematical Model ........................................................ $7-10$

7.4.2 Ash Redistribution Conceptual Model ............................................... 7-11 


\section{CONTENTS (Continued)}

8. CONCLUSIONS

8.1 SUMMARY OF MODELING ACTIVITY

8.2 MODEL REPORT OUTPUTS

$8-1$

8.3 OUTPUT UNCERTAINTY

9. INPUTS AND REFERENCES ………………........................................................... 9-1

9.1 DOCUMENTS CITED ................................................................................. 9-1

9.2 CODES, STANDARDS, REGULATIONS, AND PROCEDURES ..........................9-10

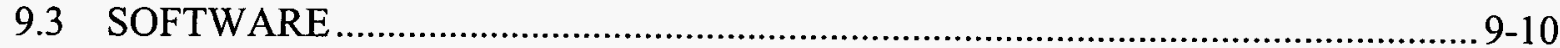

9.4 SOURCE DATA, LISTED BY DATA TRACKING NUMBER ……...................... 9-10

9.5 OUTPUT DATA, LISTED BY DATA TRACKING NUMBER ............................. 9-11

APPENDIX A - QUALIFICATION OF EXTERNAL SOURCES ……............................... A-1

APPENDIX B - KEY TECHNICAL ISSUES, DOE-NRC AGREEMENTS, AND YUCCA MOUNTAIN REVIEW PLAN ACCEPTANCE CRITERIA .........B-1

APPENDIX C - SENSITIVITY STUDIES.......................................................................

APPENDIX D - DESERT ROCK WIND DATA ANALYSES ..................................... D-1

APPENDIX E - INPUT VALUES FOR WASTE FORM CONCENTRATION AT THE RMEI LOCATION ................................................................................ E-1

APPENDIX F -INDEPENDENT TECHNICAL REVIEW OF MDL-MGR-GS 000002 REV 00B

APPENDIX G-CRITERIA FOR INDEPENDENT REVIEW FOR THE ASH REDISTRIBUTION CONCEPTUAL MODEL

APPENDIX H-AN ESTIMATE OF FUEL-PARTICLE SIZES FOR PHYSICALLY DEGRADED SPENT FUEL FOLLOWING A DISRUPTIVE VOLCANIC EVENT THROUGH THE REPOSITORY 


\section{FIGURES}

Page

1-1. Schematic Representation of a Volcanic Eruption at Yucca Mountain, Showing Transport of Radioactive Waste in an Ash Plume

6-1. Wind-Rose Plot for 700-mb Levels at Desert Rock Airport..................................... 6-6

6-2. Fortymile Wash Watershed............................................................................... 6-7

6-3. Illustration of Conceptual Model for Redistribution of Tephra Toward a RMEI for Outcome 2

6-4. Schematic of Decrease in Radionuclide Concentration in Soil

7-1 Comparison of Calculated and Measured Ash Deposition Thickness (cm) for 1995 Cerro Negro Eruption: Isopachs of Model Results from ASHPLUME V 1.4LV and V 2.0 Compared to Observed (Measured) Ash Thickness. $7-5$

7-2. Comparison of Ashplume Results to Lathrop Wells Ash Thickness Observations......... 7-6

7-3. Comparison of Ashplume Results to Cinder Cone Ash Thickness Observations .......... 7-7

7-4. Aerial Photograph Showing Lathrop Wells Drainage System ................................... 7-9

8-1. Wind-Rose Frequency of Occurrences at 3 to $4 \mathrm{~km}$ Above Yucca Mountain............... 8-7 
INTENTIONALLY LEFT BLANK 


\section{TABLES}

Page

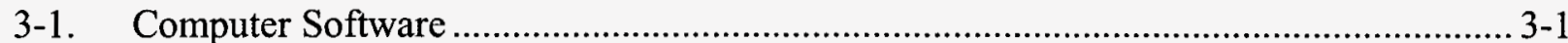

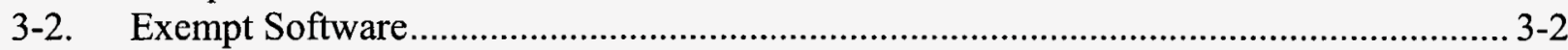

4-1. Data Supporting the Development of Input Parameter Values for the

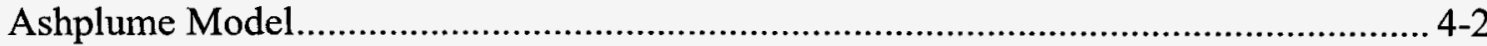

4-2. Site-Specific Data Supporting the Ash Redistribution Conceptual Model.................... 4-3

5-1. Summary of Key Assumptions ................................................................................. 5-1

5-2. Fraction of Hot Particles by Size and Distance from Chernobyl Power Plant ............. 5-10

6-1. Included FEPs for This Model Report ............................................................... 6-3

6-2. Alternative Conceptual Models Considered for Airborne Transport of Tephra........... 6-11

6-3. Inputs for the Ashplume Model ............................................................................ 6-19

6-4. Calculated Concentration of Ash and Waste in the Midline of a Volcanic Plume at a Location $18 \mathrm{~km}$ South of the Repository 6-37

6-5. Ash Redistribution Model Abstraction for the TSPA-LA Model................................ 6-41

7-1. Confidence-Building and Post-Model Development Validation Activities .................. 7-2

7-2. Ash Volume Percentages in Samples of Drainage Channels Near Lathrop

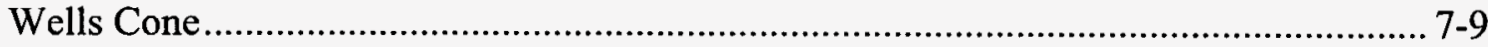

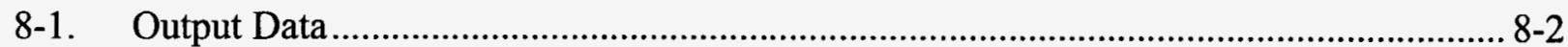

8-2. Input Parameter Values for the ASHPLUME_DLL_LA V2.0 Model for TSPA ............ 8-4

8-3. Wind Speed in Relation to Height Above Yucca Mountain............................................ 8-5

8-4. Wind Direction PDF at 3 to $4 \mathrm{~km}$ Above Yucca Mountain.......................................... 8-6 
INTENTIONALLY LEFT BLANK 


\section{ACRONYMS AND ABBREVIATIONS}

2-D

$\mu \mathrm{m}$

BDCF

$\mathrm{cm}$

CDF

DIRS

DOE

FEPs

g

$\mathrm{g}_{\mathrm{c}}$

$\mathrm{kg}$

$\mathrm{km}$

$\mathrm{m}$

$\mathrm{mm}$

NRC

PDF

RMEI

S

TSPA

TSPA-LA

TSPA-SR

TWP

YMR

YMRP two-dimensional

micrometer

biosphere dose conversion factor

centimeter

cumulative distribution function

Document Input Reference System

U.S. Department of Energy

features, events, and processes

gram

gravitation acceleration constant

kilogram

kilometer

meter

millimeter

U.S. Nuclear Regulatory Commission

probability distribution function

reasonably maximally exposed individual

second

Total System Performance Assessment

Total System Performance Assessment for the License Application Total System Performance Assessment for the Site Recommendation technical work plan

Yucca Mountain region

Yucca Mountain Review Plan 


\section{PURPOSE}

The purpose of this model report is to provide documentation of the conceptual and mathematical model (Ashplume) for atmospheric dispersal and subsequent deposition of ash on the land surface from a potential volcanic eruption at Yucca Mountain, Nevada. This report also documents the ash (tephra) redistribution conceptual model. These aspects of volcanism-related dose calculation are described in the context of the entire igneous disruptive events conceptual model in Characterize Framework for Igneous Activity (BSC 2004 [DIRS 169989], Section 6.1.1). The Ashplume conceptual model accounts for incorporation and entrainment of waste fuel particles associated with a hypothetical volcanic eruption through the Yucca Mountain repository and downwind transport of contaminated tephra. The Ashplume mathematical model describes the conceptual model in mathematical terms to allow for prediction of radioactive waste/ash deposition on the ground surface given that the hypothetical eruptive event occurs. This model report also describes the conceptual model for tephra redistribution from a basaltic cinder cone. Sensitivity analyses and model validation activities for the ash dispersal and redistribution models are also presented. Analyses documented in this model report update the previous documentation of the Ashplume mathematical model and its application to the Total System Performance Assessment (TSPA) for the License Application (TSPA-LA) igneous scenarios. This model report also documents the redistribution model product outputs based on analyses to support the conceptual model. In this report, 'Ashplume' is used when referring to the atmospheric dispersal model and 'ASHPLUME' is used when referencing the code of that model.

Two analysis and model reports provide direct inputs to this model report, namely Characterize Eruptive Processes at Yucca Mountain, Nevada and Number of Waste Packages Hit by Igneous Intrusion.

This model report provides direct inputs to the TSPA, which uses the ASHPLUME software described and used in this model report. Thus, ASHPLUME software inputs are inputs to this model report for ASHPLUME runs in this model report. However, ASHPLUME software inputs are outputs of this model report for ASHPLUME runs by TSPA.

\subsection{SCOPE OF WORK}

The scope of this report is limited to descriptions of models for atmospheric dispersal of contaminated tephra after a violent Strombolian eruption of the type that could occur in the Yucca Mountain region (YMR) (BSC 2004 [DIRS 169980], Section 6.3) and for redistribution of the contaminated tephra after the volcanic eruption. If such an eruption were to intersect the repository, the possibility exists for wastes to become entrained in the eruptive mixture and be transported via the same mechanisms as the ash plume. Although other eruption types that include nonviolent as well as violent phases exist, the violent Strombolian eruption has the greatest potential to erupt ash and waste particles higher into the atmosphere, thus increasing the potential distance of dispersal (BSC 2004 [DIRS 169980], Section 6.1.3.2).

Figure 1-1 is a schematic representation of a possible future volcanic eruption at Yucca Mountain, showing transport of radioactive waste in an ash plume. In Figure 1-1, the scope of the Ashplume conceptual model includes only the eruptive ash plume, convective/dispersive 
transport of contaminated ash particles downwind, and deposition on the ground surface. The Ashplume mathematical model may be used to evaluate ash and waste concentration (areal density) at any one point or multiple points on the surface relative to the volcanic vent. The ash redistribution conceptual model is used to describe the erosion and subsequent deposition of contaminated ash. The north-south orientation and 18-km distance shown in Figure 1-1 are for illustration purposes only.

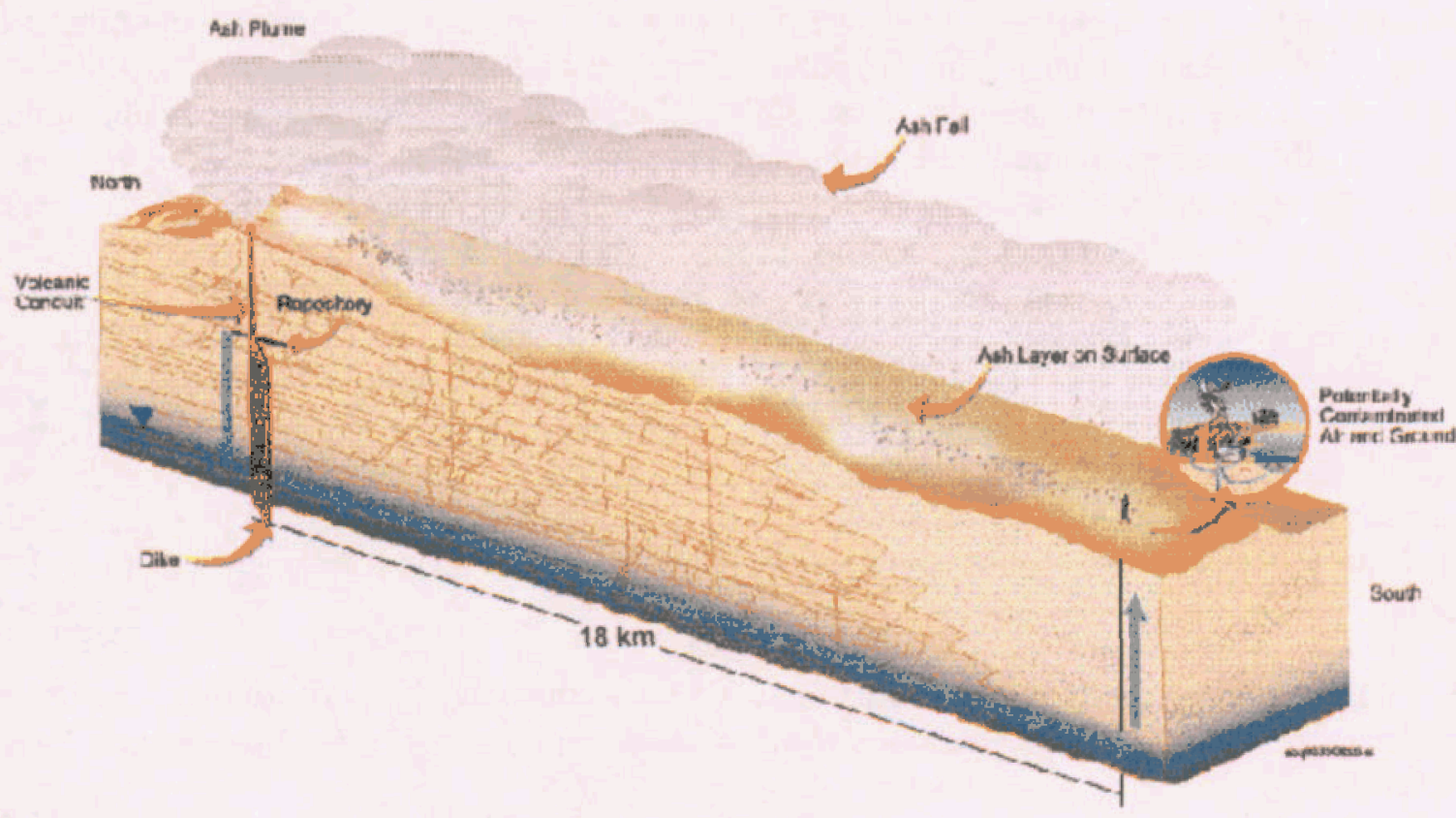

NOTE: For illustration purposes only.

Source: Modified from CRWMS M\&O (2000 [DIRS 153246], Figure 3.10-5).

Figure 1-1. Schematic Representation of a Volcanic Eruption at Yucca Mountain, Showing Transport of Radioactive Waste in an Ash Plume

\subsection{BACKGROUND}

The following sections discuss both the ash dispersal model used for past Yucca Mountain TSPA analyses and the ash redistribution conceptual model and present the objectives of this report as defined by the Technical Work Plan: Igneous Activity Assessment for Disruptive Events (BSC 2004 [DIRS 171403]) for this activity.

\subsubsection{Previous Use and Documentation}

The ASHPLUME Version 1.0-A Code for Contaminated Ash Dispersal and Deposition, Technical Description and User's Guide (Jarzemba et al. 1997 [DIRS 100987]) implements the mathematical model of atmospheric dispersal and deposition of tephra of Suzuki (1983 [DIRS 100489]) for estimation of the areal density of tephra deposits on the surface of the Earth following a volcanic eruption. The code includes estimation of the areal density of spent 
fuel particles incorporated into tephra particles due to a volcanic event that intersects the repository.

For the Total System Performance Assessment for the Site Recommendation (TSPA-SR) (CRWMS M\&O 2000 [DIRS 153246]), the original Jarzemba et al. (1997 [DIRS 100987]) ASHPLUME V 1.0 code was modified to incorporate eruptive parameters developed from natural analog volcanoes that would be representative of any future volcanic event in the YMR. This modified version of the code, known as ASHPLUME V1.4LV-dll, was used as a component of the TSPA-SR model and was incorporated as a dynamically linked library directly within the TSPA-SR model. For current work, ASHPLUME_DLL_LA V 2.0 ([BSC 2003 [DIRS 166571]) is used for calculations within the TSPA-LA. As described below, ASHPLUME_DLL_LA V2.0 is essentially the same as previous versions of the code but employs a modified set of input parameters that are based on those data analyzed within the revision to the scientific analysis report Characterize Eruptive Processes at Yucca Mountain, Nevada (BSC 2004 [DIRS 169980]).

The main difference between ASHPLUME 1.4LV (BSC 2002 [DIRS 161296]) and ASHPLUME_DLL_LA V2.0 ([BSC 2003 [DIRS 166571]) lies in the formulation of eruption column height. ASHPLUME 1.4LV uses an empirical relationship between volume and column height that was determined to be less accurate than the use of eruptive power to calculate mass discharge rate and, subsequently, column height (as is implemented in ASHPLUME_DLL_LA $\mathrm{V} 2.0$ ). This new version of the code is more consistent with the state of practice among volcanologists. A form of ASHPLUME V2.0 (CRWMS-M\&O 2001 [DIRS 152844]), compiled for use on the Windows NT 4.0 platform, was used for the model validation and sensitivity studies presented in Section 7; this form of the code differs insignificantly from ASHPLUME_DLL_LA V2.0, which has been compiled to run on the Windows 2000 platform for TSPA. The change in the code from ASHPLUME 1.4LV (BSC 2002 [DIRS 161296]) to ASHPLUME_DLL_LA V2.0 (BSC 2003 [DIRS 166571]) and ASHPLUME V2.0 (CRWMS-M\&O 2001 [DIRS 152844]) produces slightly higher calculated column heights than in ASHPLUME 1.4LV, and, therefore, a new set of wind data collected at Desert Rock (near Mercury, Nevada) (NOAA 2004 [DIRS 171035]) was used to calculate wind speed and direction up to a height of $13 \mathrm{~km}$. This data set replaces the Nevada Test Site data (Quiring 1968 [DIRS 119317]) that were used for the TSPA-SR (CRWMS M\&O 2000 [DIRS 153246]).

Parameterization for the atmospheric dispersal model used in all ASHPLUME versions was documented in Igneous Consequence Modeling for the TSPA-SR (BSC 2001 [DIRS 157876], Section 6.1.2). Tephra deposit thicknesses were simulated using ASHPLUME V1.4LV (BSC 2002 [DIRS 161296]) and ASHPLUME V2.0 (CRWMS M\&O 2001 [DIRS 152844]), and compared with actual tephra deposit thicknesses from the 1995 eruptive event at the Cerro Negro volcano in Nicaragua was documented in CRWMS M\&O (2000 [DIRS 152998]). The purpose of this model report is to consolidate and update documentation of the Ashplume conceptual and mathematical models, including parameterization and validation for ASHPLUME_DLL_LA V2.0 (BSC 2003 [DIRS 166571]).

It should be noted that the ash redistribution conceptual model was new and not used in the TSPA-SR; however, output from analyses supporting this model will be used in the TSPA-LA. 


\subsubsection{Technical Work Plan}

- This model report is governed by the Technical Work Plan: Igneous Activity Assessment for Disruptive Events (BSC 2004 [DIRS 171403]), Work Package ADEM03. The technical work plan (TWP) specifies the activities to be carried out in consolidating and updating the documentation of the Ashplume conceptual and mathematical models.

The ASHPLUME code was not used to quantitatively assess the sensitivity of the erupted ash/waste distributions due to the conceptualization of the magma/waste form interaction. However, these effects are assessed in the assumptions and model conceptualization sections (Sections 5.1.2, 5.2.4, 6.3, and 6.5).

\subsection{MODEL LIMITATIONS}

\subsubsection{Ashplume Model Limitations}

A mathematical model is generally considered to be a mathematical description of a conceptual model that approximates the behavior of a system, process, or phenomenon with determinable limits of uncertainty. The Ashplume mathematical model is an approximation of the physical systems involved in the atmospheric dispersal and deposition of contaminated tephra (ash and waste particles) associated with a possible future volcanic eruption through the repository at Yucca Mountain. Limitations inherent in all mathematical representations of complex geologic processes include: (1) incomplete knowledge of details of a highly complex and heterogeneous natural process involving localized regions of the Earth's crust; (2) use of a mathematical representation that approximates, but does not specifically represent, every detail of the process; and (3) lack of comprehensive data describing every aspect of the complex, heterogeneous geologic natural process being represented. As a result of these limitations, the model provides predictive capability but does not provide an exact representation of the process.

The Ashplume model for Yucca Mountain is based on a model of Suzuki (1983 [DIRS 100489]) that Jarzemba et al. (1997 [DIRS 100987]) refined to represent violent Strombolian-type eruptions. Strombolian eruption involves ejection of magma into the atmosphere as a ballistic fountain of $\mathrm{cm}$-sized scoria fragments from which $\mu \mathrm{m}$ - and $\mathrm{mm}$-size ash is elutriated in a rising convective plume above the fountain. Whereas the fountain develops a cone of potentially contaminated scoria around the vent orifice, the convective plume provides a source for distal transport of potentially contaminated ash downwind over a wide area. Fallout of ash from the plume forms a ground layer that generally thins with distance from the vent and is subject to redistribution by wind and water erosion. The Strombolian-type eruption is considered to be the most typical of the type of eruption possible in the YMR (BSC 2004 [DIRS 169980]). A Strombolian eruption includes violent phases as well as phases that are less violent, in which more effusive eruption dominates (BSC 2004 [DIRS 169980], Section 6.3.3). With increasing violence of a Strombolian eruption, a larger fraction of the magma is fragmented to ash sizes, and a greater proportion of the magma contributes to the convective plume. The Ashplume model is limited to representation of the convective plume only and, thus, best models violent Strombolian eruptions. Accounting for overall mass on energy balance is not explicitly provided in the model results. 
The Ashplume model solves diffusive transport (by atmospheric turbulence and wind) of particles distributed in a column (plume) of a height determined by the heat flux (power) of the column source. The duration of this transport for individual particles is the fallout time for particles governed by their terminal fall velocity (a function of their individual size, density, and shape factor) and their upward velocity in the plume. One limitation of the model is that Ashplume assumes a linear decrease in the plume's rise velocity from its initial rise velocity at the vent to zero at the top of the plume, but a buoyancy-driven velocity profile is not calculated.

Another limitation of the Ashplume model is its inability to accurately represent the transport of ash particles of mean diameter less than approximately 15 micrometers $(\mu \mathrm{m})$ (Jarzemba et al. 1997 [DIRS 100987], Section 2.1). This cutoff in mean particle diameter is generally accepted to be the lower limit for the importance of gravitational settling. For particle sizes less than about $15 \mu \mathrm{m}$, atmospheric turbulence would tend to keep the particles aloft longer than would be predicted by the model. Because the typical mean diameter of ash particles after an eruption is generally much larger than $15 \mu \mathrm{m}$ (see Section 6.5.2.4), the model described here is applicable to calculating the distribution of the majority of potential ash and radionuclide releases from a possible future eruption at Yucca Mountain. For the small number (approximately 10 percent) of model realizations in which the mean particle size is $<30 \mu \mathrm{m}$, the effect of the model limitation is to overpredict the deposition of these fine particles in the YMR, leading to conservative predictions of ash and waste areal densities at the reasonably maximally exposed individual (RMEI). A related limitation is that Ashplume does not consider ash particle aggregation within the plume or removal of particles from the plume by rainfall. These processes would tend to increase the deposition of particles from the plume, and could either increase or decrease the ash/waste deposition in the RMEI location.

The Ashplume mathematical model uses the simplification that wind speed is assumed to be constant throughout the atmospheric column. This assumption is discussed further in Section 5 . This limitation is accommodated within the TSPA models by treating wind speed as an uncertain parameter. In addition, wind-speed data are taken from the upper altitudes reached by the ash plume where the majority of ash is dispersed from the eruptive column of a violent Strombolian eruption. The full range of wind speeds from near zero to the maximum winds observed at the higher altitudes is represented in the wind-speed distribution used in the TSPA-LA analyses. This stochastic treatment of wind speed produces a mean result in ash deposition that captures the uncertainty that exists in future wind speeds at all altitudes of the vertical eruptive column. Wind direction and wind speed are treated in a similar manner within the TSPA implementation of the dispersion model. The Ashplume mathematical model limits wind direction to a single value for a given realization of the model. However, in the TSPA, wind direction is also treated stochastically so that the distribution of wind direction and velocity, as a function of height, reflects the wind directions actually observed near the Yucca Mountain site.

The final limitation of the Ashplume model is its sensitivity to eruptive power and initial rise velocity, which are, in turn, functions of total erupted volume and duration. These parameters (power and initial rise velocity) are uncertain. ASHPLUME 1.4 LV (BSC 2002 [DIRS 161296]) calculated these parameters from the theoretical relationship of conduit radius to magma ascent velocity given by Wilson and Head (1981 [DIRS 101034], p. 2977), and, in that version, the initial rise velocity was termed as the "eruption velocity at the vent." Because the actual eruption velocity at the vent in Strombolian eruptions is also a function of magma volatile 
content and the initial plume rise velocity is only weakly linked to eruption velocity, the previous relationship is not valid. ASHPLUME_DLL_LA V2.0 (BSC 2003 [DIRS 166571]) must assume a conservative condition in which all the magma is fragmented and enters the convective plume (violent Strombolian) such that the initial plume rise velocity can be derived using a relationship between power, duration, and conduit diameter. This relationship is defined in Section 6.5.1, Equation 6-7, and the derivation of the initial rise velocity is discussed specifically in Section 6.5.2.10.

In spite of these limitations, the Ashplume model is considered to be appropriate, although conservative, for the analysis of the volcanic direct release scenario because the model includes those parameters that apply specifically to conditions of maximum entrainment of contaminated ash in an eruption column, dispersal of that ash downwind, and deposition of the ash at specified locations on the Earth's surface. The appropriateness of the model and the development of specific parameters are explained in detail in Section 6.

\subsubsection{Ash Redistribution Model Limitations}

The conceptual model of tephra redistribution following a hypothetical eruption at Yucca Mountain does not have a mathematical basis. However, simple calculations were completed to provide an abstraction of that conceptual model for use in the TSPA-LA. The ash redistribution conceptual model describes surficial processes that modify and distribute tephra that has been deposited from a hypothetical volcanic eruption at Yucca Mountain. This model is described in Sections 6.3.2 and 6.6.

On account of uncertainties, lack of data and avoidance of mathematical complexity that does not provide value commensurate with the model purpose, there are recognized limitations to the ash redistribution model. Among the limitations are:

- It is only appropriate for erosion when climatic conditions are similar to the present climate, or those included in Future Climate Analysis (BSC 2004 [DIRS 170002]).

- It emphasizes fluvial erosion and deposition, but does not specifically identify eolian deposition except as part of total deposition.

- There is insufficient analog tephra dilution data to make dilution a useful process for TSPA-LA measurements. The initial conditions for model outcomes producing tephra fall predominantly in the Fortymile Wash watershed include post eruptive transport of the more mobile ash and waste from Fortymile Wash to the RMEI before stability occurs on the fan surfaces.

- The redeposition of waste on the interchannel divides by sheet flooding is not represented by the model. The low frequency of these events, and the dilution of waste that would occur in the redistributed material, support this simplification.

- The long-term geologic dynamics of fan interchannel divides and channel interactions are not represented. 
The abstraction of the ash redistribution conceptual model (Section 6.7.2) is included in the TSPA model. However, it is now known that the simplified representation of redistribution and erosion in this model provides multiple accounting for waste mass, and the resulting degree of conservatism is more pronounced when primary ash layer is thin. For this reason, an alternative model is presented in Appendix I, and is proposed for post TSPA-LA usage. 
INTENTIONALLY LEFT BLANK 


\section{QUALITY ASSURANCE}

This report is classified in the Q-List (BSC 2004 [DIRS 168361]) as Safety Category 1 because of its importance to waste isolation, as defined in AP-2.22Q, Classification Analyses and Maintenance of the Q-List. The results of this report are important to the demonstration of compliance with the post-closure performance objectives prescribed in 10 CFR 63.113 [DIRS 156605]. Development of this model report and the supporting activities has been determined to be subject to the Yucca Mountain Project quality assurance program (BSC 2004 [DIRS 171403], Section 8.1), Work Package ADEM03. Approved quality assurance procedures identified in the TWP (BSC 2004 [DIRS 171403], Section 4) have been used to conduct and document the activities described in this model report. The TWP also identifies the methods used to control the electronic management of data (BSC 2004 [DIRS 171403], Section 8.4).

This report documents a conceptual and mathematical model of atmospheric dispersal and subsequent deposition of contaminated tephra from a potential volcanic eruption at Yucca Mountain, and a conceptual model for subsequent redistribution of tephra by surficial processes. This report contributes to the analysis and modeling data used to support performance assessment; the conclusions do not directly impact engineered features important to safety, as defined in AP-2.22Q, Classification Analyses And Maintenance Of The Q-List.

The modeling activities documented in this model report were performed with no variances to work described in the TWP (BSC 2004 [DIRS 171403]). 
INTENTIONALLY LEFT BLANK 


\section{USE OF SOFTWARE}

\subsection{SOFTWARE TRACKED BY CONFIGURATION MANAGEMENT}

The sequence of versions showing the evolution of the ASHPLUME software is provided in Table 3-1. ASHPLUME_DLL_LA V 2.0 (BSC 2003 [DIRS 166571]) was used for the calculation of initial ash/fuel concentrations, which are described in Section 6.7 of this model report. ASHPLUME V 2.0 (CRWMS M\&O 2001 ([DIRS 152844]) is the version used in this model report for the validation activities in Section 7. Both versions were obtained from Software Configuration Management and are appropriate for each application. Also, GoldSim V8.01 SP1 (Golder Associates 2003 [DIRS 166572]) was used (Table 3-1) to estimate the mean concentrations of radioactive waste in the tephra sheet at $18 \mathrm{~km}$ from a hypothetical vent (Section 6.7.1 and Appendix E). These qualified codes were adequate for their intended uses and were used only within the range of validation as required by LP-SI.11Q-BSC, Software Management.

Table 3-1. Computer Software

\begin{tabular}{|l|l|l|l|}
\hline \multicolumn{1}{|c|}{$\begin{array}{c}\text { Software } \\
\text { Title/Version } \\
\text { (V) }\end{array}$} & $\begin{array}{c}\text { Software } \\
\text { Tracking Number } \\
\text { (STN) }\end{array}$ & \multicolumn{1}{c|}{ Code Usage } & $\begin{array}{c}\text { Computer: } \\
\text { Type, Platform, } \\
\text { and Location }\end{array}$ \\
\hline $\begin{array}{l}\text { ASHPLUME V 2.0 } \\
\text { (CRWMS-M\&O 2001 } \\
\text { [DIRS 152844) }\end{array}$ & $10022-2.0-00$ & $\begin{array}{l}\text { This version is used in validation studies as } \\
\text { described in Section 7.3.1 of this report. }\end{array}$ & $\begin{array}{l}\text { PC, Windows NT } \\
4.0\end{array}$ \\
\hline $\begin{array}{l}\text { ASHPLUME_DLL_LA } \\
\text { (BSC 2003 }\end{array}$ & $11117-2.0-00$ & $\begin{array}{l}\text { This version is used for TSPA-LA } \\
\text { calculations and calculation of initial ash/fuel } \\
\text { areal concentrations for the ash } \\
\text { redistribution conceptual model described in } \\
\text { Section 6.7. } \\
\text { Parameterization developed in this model } \\
\text { report will directly feed this version of the } \\
\text { software for TSPA-LA usage. }\end{array}$ & PC, Windows 2000 \\
\hline $\begin{array}{l}\text { ASHPLUME 1.4LV } \\
\text { (BSC 2002 } \\
\text { [DIRS 161296]) }\end{array}$ & $10022-1.4$ LV-02 & $\begin{array}{l}\text { This version is used, along with V2.0, for } \\
\text { comparison of calculated and measured ash } \\
\text { deposition thickness for 1995 Cerro Negro } \\
\text { eruption (see Section 7.3.1.1). }\end{array}$ & PC, Windows 2000 \\
\hline $\begin{array}{l}\text { GoldSim } \\
\text { V 8.01 Service Pack 1 } \\
\text { (Golder Associates } \\
\text { 2002 [DIRS 166572]) }\end{array}$ & $10344-8.01$ SP1-00 & $\begin{array}{l}\text { In conjunction with ASHPLUME_DLL_LA V } \\
\text { 2.0, this software was used for probabilistic } \\
\text { simulations (Section 6.7.1 and Appendix E). }\end{array}$ & PC, Windows 2000 \\
\hline
\end{tabular}

\subsection{EXEMPT SOFTWARE}

Commercial, off-the-shelf software used in support of this model report is listed in Table 3-2. This software is exempt from the requirements of LP-SI.11Q-BSC, Software Management. Formulas, inputs, and outputs are documented in the appropriate scientific notebooks. 
Table 3-2. Exempt Software

\begin{tabular}{|l|l|l|}
\hline $\begin{array}{c}\text { Software Name and } \\
\text { Version (V) }\end{array}$ & \multicolumn{1}{|c|}{ Description } & $\begin{array}{c}\text { Computer and Platform } \\
\text { Identification }\end{array}$ \\
\hline Microsoft Excel, 2000 & $\begin{array}{l}\text { The commercial software, Microsoft Excel 2000, was used } \\
\text { for plotting graphs and statistical calculations. Only built-in } \\
\text { standard functions in this software were used. No } \\
\text { software routines or macros were used with this software } \\
\text { to prepare this report. }\end{array}$ & PC, Windows 2000/NT \\
\hline Microsoft Access, 2000 & $\begin{array}{l}\text { The commercial software, Microsoft Access 2000, was } \\
\text { used for unit conversions and data segregation. Only } \\
\text { built-in standard query functions in this software were } \\
\text { used. No software routines or macros were used with this } \\
\text { software to prepare this report. }\end{array}$ & PC, Windows 2000 \\
\hline
\end{tabular}




\section{INPUTS}

\subsection{DATA, PARAMETERS, AND OTHER MODEL INPUTS}

This section discusses data, parameters, and inputs to the modeling activities that are documented in this report. External data used as direct input have been qualified as documented in Appendix A.

\subsubsection{Data}

Sources for data supporting the development of input parameters to the Ashplume model, and documented in this report, are listed in Table 4-1. These data are used to develop primary model inputs as described in Section 6.5.2. Ash physical characteristics required as inputs to the Ashplume model are developed in the scientific analysis report Characterize Eruptive Processes at Yucca Mountain, Nevada (BSC 2004 [DIRS 169980]). The report provides information about natural volcanic systems and the parameters that can be used to model their behavior and is appropriate for use as input to the ash dispersion model documented in this report.

The wind speed cumulative distribution functions (CDFs) and wind direction probability distribution functions (PDFs) appropriate for use in modeling a potential future volcanic eruption in the YMR are developed in this model report from data provided in Upper Air Data: Desert Rock, Nevada, 1978-1995 (NOAA 2004 [DIRS 171035]). The development of the CDFs and PDFs from the raw climatological data is described in Sections 6.5.2.7 and 6.5.2.8.

The waste-particle-size distribution used as input to this model report is supported by documentation included in Appendix H. Air physical characteristics are taken from the CRC Handbook of Chemistry and Physics (Lide 1994 [DIRS 147834]).

Data sources providing input for the development of parameters used in the ash redistribution conceptual model documented in this report are identified in Table 4-2. These data provide the technical basis for the bounding model described in Section 6.7.2.

The qualification status of the input sources is provided in the Technical Data Management System and listed in the Document Input Reference System (DIRS) database. Data from external sources are used as direct input to the development of this model report. The data from these sources have been justified per requirements of AP-SIII.10Q, and are considered to be qualified for intended use. These justifications are documented in Appendix A. 
Table 4-1. Data Supporting the Development of Input Parameter Values for the Ashplume Model

\begin{tabular}{|c|c|c|}
\hline Data Description & Source & Section Where Discussed/Used \\
\hline Eddy diffusivity & Suzuki 1983 [DIRS 100489] & Table 6-3, 6.5.2.1 \\
\hline Waste Incorporation ratio & $\begin{array}{l}\text { Jarzemba et al. } 1997 \\
\text { [DIRS 100987] }\end{array}$ & Table 6-3, 6.5.1(Eq.6-9); 6.5.2.6 \\
\hline Column diffusion constant & $\begin{array}{l}\text { Jarzemba et al. } 1997 \\
\text { [DIRS 100987] }\end{array}$ & Table 6-3, Table 8-2, 6.5.2.3 \\
\hline Air physical characteristics (air viscosity) & Lide 1994 [DIRS 147834] & Table 6-3, 6.5.2.14, Table 8.2 \\
\hline Air physical characteristics (air density) & Lide 1994 [DIRS 147834] & Table 6-3, 6.5.2.13; Table 8.2 \\
\hline Wind speed & $\begin{array}{l}\text { NOAA 2004[DIRS } \\
\text { 171035] }\end{array}$ & $\begin{array}{l}\text { 6.5.2.7; 6.5.3.8; Tables 6-3, 8-2, 8-3, } \\
\text { Appendix D }\end{array}$ \\
\hline Wind direction & $\begin{array}{l}\text { NOAA } 2004 \\
\text { [DIRS 171035] }\end{array}$ & $\begin{array}{l}\text { 6.5.2.8; 6.5.3.8; Tables 6-3, 8-2, 8-4, } \\
\text { Figure 8-1, Appendix D }\end{array}$ \\
\hline Specific heat capacity of magma & Drury 1987 [DIRS 156447] & 6.5.2.1 \\
\hline $\begin{array}{l}{ }^{137} \mathrm{Cs} \text { values for the Fortymile Wash } \\
\text { alluvial fan }\end{array}$ & $\begin{array}{l}\text { LA0308CH831811.002 } \\
\text { [DIRS 164853] }\end{array}$ & 6.7.2.3 \\
\hline Specific heat capacity of magma & Bacon 1977 [DIRS 165512] & 6.5.2.1 \\
\hline $\begin{array}{l}\text { Median number of waste packages } \\
\text { calculated to be hit by a magmatic conduit }\end{array}$ & $\begin{array}{l}\text { SN0402T0503303.004 } \\
\text { [DIRS 167515] }\end{array}$ & 6.7 .1 \\
\hline Eruptive mass flux & $\begin{array}{l}\text { Detournay et al. } 2003 \\
\text { [DIRS 169660] }\end{array}$ & 6.5.1 (Eq. 6-7b), 6.5.2.1 \\
\hline $\begin{array}{l}\text { Ash weight percentages in samples of } \\
\text { drainage channels near the Lathrop Wells } \\
\text { cone }\end{array}$ & $\begin{array}{l}\text { LAO405CH831811.001 } \\
\text { [DIRS 169998] }\end{array}$ & Table 7-2 \\
\hline $\begin{array}{l}\text { Eruptive volume based upon the estimated } \\
\text { eruption volumes of Quaternary volcanoes } \\
\text { in the YMR }\end{array}$ & $\begin{array}{l}\text { LA0407DK831811.001 } \\
\text { [DIRS 170768] }\end{array}$ & 6.5 .1 (Eq. 6-7b), 6.5.2.1 \\
\hline $\begin{array}{l}\text { Duration of a single explosive phase } \\
\text { constituting a violent Strombolian eruptive } \\
\text { event }\end{array}$ & $\begin{array}{l}\text { LA0407DK831811.001 } \\
\text { [DIRS 170768] }\end{array}$ & Table 6-3, 6.5.2.2, Table 8-2 \\
\hline Basaltic magma density & $\begin{array}{l}\text { LA0407DK831811.001 } \\
\text { [DIRS 170768] }\end{array}$ & $6.5 .2 .10,6.5 .2 .11$ \\
\hline $\begin{array}{l}\text { Conduit diameter } \\
\text { (eruptive vent diameter) }\end{array}$ & $\begin{array}{l}\text { LA0407DK831811.001 } \\
\text { [DIRS 170768] }\end{array}$ & 6.5 .2 .10 \\
\hline $\begin{array}{l}\text { Clast characteristics (ash particle shape } \\
\text { factor) }\end{array}$ & $\begin{array}{l}\text { LA0407DK831811.001 } \\
\text { [DIRS 170768] }\end{array}$ & Table 6-3, 6.5.2.12, Table 8-2 \\
\hline $\begin{array}{l}\text { Ash particle density at minimum particle } \\
\text { size }\end{array}$ & $\begin{array}{l}\text { LA0407DK831811.001 } \\
\text { [DIRS 170768] }\end{array}$ & Table 6-3, Table 8-2, 6.5.2.11 \\
\hline $\begin{array}{l}\text { Ash particle density at maximum particle } \\
\text { size }\end{array}$ & $\begin{array}{l}\text { LA0407DK831811.001 } \\
\text { [DIRS 170768] }\end{array}$ & Table 6-3, Table 8-2, 6.5.2.11 \\
\hline $\begin{array}{l}\text { Log ash particle size at minimum ash } \\
\text { density }\end{array}$ & $\begin{array}{l}\text { LA0407DK831811.001 } \\
\text { [DIRS 170768] }\end{array}$ & Table 6-3, Table 8-2, 6.5.2.11 \\
\hline $\begin{array}{l}\text { Log ash particle size at maximum ash } \\
\text { density }\end{array}$ & $\begin{array}{l}\text { LA0407DK831811.001 } \\
\text { [DIRS 170768] }\end{array}$ & Table 6-3, Table 8-2, 6.5.2.11 \\
\hline Mean ash particle diameter & $\begin{array}{l}\text { LA0407DK831811.001 } \\
\text { [DIRS 170768] }\end{array}$ & Tables 6-3, 8-2, 6.5.2.4, 6.7.2.2 \\
\hline Ash particle diameter standard deviation & $\begin{array}{l}\text { LA0407DK831811.001 } \\
\text { [DIRS 170768] }\end{array}$ & Table 6-3, 6.5.2.5, Table 8-2 \\
\hline
\end{tabular}


Table 4-2. Site-Specific Data Supporting the Ash Redistribution Conceptual Model

\begin{tabular}{|l|l|l|}
\hline \multicolumn{1}{|c|}{ Data Description } & \multicolumn{1}{|c|}{ Source } & \multicolumn{1}{c|}{ Data Tracking Number } \\
\hline $\begin{array}{l}\text { Ash weight percentages in samples } \\
\text { of drainage channels near the } \\
\text { Lathrop Wells cone }\end{array}$ & Harrington 2003 [DIRS 164775] & $\begin{array}{l}\text { DTN: LA0405CH831811.001 } \\
\text { [DIRS 169998] }\end{array}$ \\
\hline $\begin{array}{l}{ }^{137} \text { Cs values for the Fortymile Wash } \\
\text { alluvial fan }\end{array}$ & Harrington 2003 [DIRS 164775] & $\begin{array}{l}\text { DTN: LA0308CH831811.002 } \\
\text { [DIRS 164853] }\end{array}$ \\
\hline
\end{tabular}

\subsubsection{Parameters and Parameter Uncertainty}

The TSPA model, of which Ashplume is a component, uses Monte Carlo simulation as a method for mapping uncertainty in model parameters and future system states, expressed as probability distributions, into predictions of model output (BSC 2003 [DIRS 166296]). Large uncertainties exist in Ashplume model input parameters due to the uncertainty of future atmospheric conditions at the time of the hypothetical eruption and uncertainty in the characterization of the physical attributes of a future eruption. Ashplume model parameters that contain uncertainty and may significantly affect the results of TSPA calculations are developed in this model report as probability distributions for compatibility with the Monte Carlo methods used in the TSPA model.

Development of parameters used in the Ashplume model is documented in Section 6.5 .2 of this report. Sampled parameters used in the ash redistribution conceptual model are documented in Section 6.7 .2 of this report.

The erosion rates developed in this report and used in the ash redistribution conceptual model are based on a 50-plus year record of ${ }^{137} \mathrm{Cs}$ (by-products of hydrogen bomb surface tests in the Pacific); therefore, considerable uncertainty is associated with the use of these rates for long-term (i.e., 10,000 years) erosion of the Fortymile Wash alluvial fan. Future climate variability may affect the rates of erosion. Although considerable uncertainty is associated with the long-term erosion rates, the product range provided is considered reasonable for the regulatory time frame. As long as climate variations remain within projected limits, erosion rates are expected to remain nearly the same as current rates.

\subsection{CRITERIA}

The general requirements to be satisfied by the TSPA are stated in 10 CFR 63.114 [DIRS 156605]. Technical requirements to be satisfied by the TSPA are identified in the Yucca Mountain Project Requirements Document (Canori and Leitner 2003 [DIRS 166275]). The acceptance criteria that will be used by the Nuclear Regulatory Commission (NRC) to determine whether the technical requirements have been met are identified in the Yucca Mountain Review Plan, Final Report (NRC 2003 [DIRS 163274]). In cases where subsidiary criteria are listed in the YMRP for a given criterion, only the subsidiary criteria addressed by this scientific analysis

are listed. Where a subcriterion includes several components, only some of those components may be addressed. Details of how the criteria and key technical issues have been addressed in this report are provided in Appendix B. 


\subsubsection{Criteria for Ashplume Model}

The Yucca Mountain Review Plan, Final Report (NUREG-1804; NRC 2003 [DIRS 163274]) associates the integrated subissue of airborne transport of radionuclides with the requirements listed in 10 CFR 63.114(a)-(c) and (e)-(g) [DIRS 156605]. NUREG-1804 (NRC 2003 [DIRS 163274], Section 2.2.1.3.11.3) describes the acceptance criteria that the NRC will use to evaluate the adequacy of information addressing the airborne transport of radionuclides in the license application. NUREG-1804 (NRC 2003 [DIRS 163274], Section 2.2.1.3.13.3) describes the acceptance criteria that the NRC will use to evaluate the adequacy of information addressing redistribution of radionuclides in soil in the license application.

YMRP Section 2.2.1.3.11, Integrated Subissue: Airborne Transport of Radionuclides (NRC 2003 [DIRS 163274])

\section{Acceptance Criterion 1: System Description and Model Integration Are Adequate}

1. Total system performance assessment adequately incorporates important design features, physical phenomena, and couplings, and uses consistent and appropriate assumptions throughout the airborne transport of radionuclides abstraction process.

2. Models used to assess airborne transport of radionuclides are consistent with physical processes generally interpreted from igneous features in the Yucca Mountain region and/or observed at active igneous systems.

3. Models account for changes in igneous processes that may occur from interactions with engineered repository systems.

4. Guidance in NUREG-1297 and NUREG-1298 (Altman et al. 1988 [DIRS 103597]; Altman et al. 1988 [DIRS 103750]), or in other acceptable approaches for peer review and data qualification is followed.

\section{Acceptance Criterion 2: Data Are Sufficient for Model Justification}

1. Parameter values used in the license application to evaluate airborne transport of radionuclides are sufficient and adequately justified. Adequate descriptions of how the data were used, interpreted, and appropriately synthesized into the parameters are provided.

2. Data used to model processes affecting airborne transport of radionuclides are derived from appropriate techniques. These techniques may include site-specific field measurements, natural analog investigations, and laboratory experiments.

3. Sufficient data are available to integrate features, events, and processes, relevant to airborne transport of radionuclides into process-level models, including site-specific determination of appropriate interrelationships and parameter correlations.

4. Where sufficient data do not exist, the definition of parameter values and associated conceptual models is based on appropriate use of expert elicitation conducted, in 
accordance with NUREG-1563 (Kotra et al. 1996 [DIRS 100909]). If other approaches are used, the U.S. Department of Energy adequately justifies their use.

Acceptance Criterion 3: Data Uncertainty is Characterized and Propagated through the Model Abstraction

1. Models use parameter values, assumed ranges, probability distributions, and bounding assumptions that are technically defensible, reasonably account for uncertainties and variabilities, and do not result in an under-representation of the risk estimate.

2. Parameter uncertainty accounts quantitatively for the uncertainty in parameter values derived from site data and the available literature (i.e., data precision), and the uncertainty introduced by model abstraction (i.e., data accuracy).

3. Where sufficient data do not exist, the definition of parameter values and associated uncertainty is based on appropriate use of expert elicitation conducted in accordance with NUREG-1563 (Kotra et al. 1996 [DIRS 100909]). If other approaches are used, the U.S. Department of Energy adequately justifies their use.

\section{Acceptance Criterion 4: Model Uncertainty is Characterized and Propagated through the Model Abstraction}

1. Alternative modeling approaches to airborne transport of radionuclides are considered and are consistent with the available data and current scientific understandings, and the results and limitations are appropriately considered in the abstraction.

2. Uncertainties in abstracted models are adequately defined and documented, and effects of these uncertainties are assessed in the total system performance assessment.

3. Consideration of conceptual model uncertainty is consistent with available site characterization data, laboratory experiments, field measurements, natural analog information and process-level modeling studies; and the treatment of conceptual model uncertainty does not result in an under representation of the risk estimate.

\section{Acceptance Criterion 5: Model Abstraction Output is Supported by Objective Comparisons}

1. Models implemented in the airborne transport of radionuclides abstraction provide results consistent with output from detailed process-level models and/or empirical observations (laboratory and field testings and/or natural analogs).

2. Inconsistencies between abstracted models and comparative data are documented, explained, and quantified. The resulting uncertainty is accounted for in the model results.

The Yucca Mountain Review Plan (NUREG-1804, NRC 2003 [DIRS 163274] associates the integrated subissue of redistribution of radionuclides in soil with the requirements listed in 
10 CFR $63.114(1)(\mathrm{a})-(\mathrm{c}),(\mathrm{e})-(\mathrm{g})$, and 63.305 as they relate to the redistribution of radionuclides in soil abstraction.

\subsubsection{Criteria for Ash Redistribution Model}

YMRP Section 2.2.1.3.13, Redistribution of Radionuclides in Soil (NRC 2003 [DIRS 163274])

\section{Acceptance Criterion 1: System Description and Model Integration Are Adequate}

1. Total system performance assessment adequately incorporates important features, physical phenomena and couplings between different models, and uses consistent and appropriate assumptions throughout the abstraction of redistribution of radionuclides in the soil abstraction process.

2. The total system performance assessment model abstraction identified and describes aspects of redistribution of radionuclides in soil that are important to repository performance, including the technical bases for these descriptions. For example, the abstraction should include modeling of the deposition of contaminated material in the soil and the determination of the depth distribution of the deposited radionuclides.

3. Relevant site features, events, and processes have been appropriately modeled in the abstraction of redistribution of radionuclides, from surface processes, and sufficient technical bases are provided.

4. Guidance in NUREG-1297 and NUREG-1298 (Altman et al. 1988 [DIRS 103597]; Altman et al. 1988 [DIRS 103750]), or other acceptable approaches for peer reviews is followed.

\section{Acceptance Criterion 2: Data Are Sufficient for Model Justification}

1. Behavioral, hydrological, and geochemical values used in the license application are adequately justified (e.g., irrigation and precipitation rates, erosion rates, radionuclide solubility values, etc.). Adequate descriptions of how the data were used, interpreted, and appropriately synthesized into the parameters are provided.

2. Sufficient data (e.g., field laboratory, and natural analog data are available to adequately define relevant parameters and conceptual models necessary for developing the abstraction of redistribution of radionuclides in soil in the total system performance assessment.

\section{Acceptance Criterion 3: Data Uncertainty Is Characterized and Propagated Through the Model Abstraction}

1. Models use parameter values, assumed ranges, probability distributions, and bounding assumptions that are technically defensible, reasonably account for uncertainties and variabilities, do not result in an under-representation of the risk estimate, and are consistent with the characteristics of the reasonably maximally exposed individual in 10 CFR Part 63 [DIRS 156605]. 
2. The technical bases for the parameter values and ranges in the total system performance assessment abstraction are consistent with data from the Yucca Mountain region [e.g., Amargosa Valley survey (Cannon Center for Survey Research, 1997)], studies of surface processes in the Fortymile Wash drainage basin: applicable laboratory testings: or other valid sources of data. For example, soil types, crop types, plow depths, and irrigation rates should be consistent with current farming practices, and data on the airborne particulate concentration should be based on the resuspension of appropriate material in a climate and level of disturbance similar to that which is expected to be found at the location of the reasonably maximally exposed individual, during the compliance time period.

3. Uncertainty is adequately represented in parameters for conceptual models, process models, and alternative conceptual models considered in developing the total system performance assessment abstraction of redistribution of radionuclides in soil, either through sensitivity analyses, conservative limits, or bounding values supported by data, as necessary. Correlations between input values are appropriately established in the total system performance assessment.

4. Parameters or models that most influence repository performance based on the performance measure and time period of compliance, specified in 10 CFR Part 63 [DIRS 156605], are identified.

5. Where sufficient data do not exist, the definition of parameter values and conceptual models on appropriate uses of other sources, such as expert elicitation, are conducted in accordance with appropriate guidance, such as NUREG-1563 (Kotra et al. 1996 [DIRS 100909]).

\section{Acceptance Criterion 4: Model Uncertainty is Characterized and Propagated Through the Model Abstraction}

1. Alternative modeling approaches of features, events, and processes are considered and are consistent with available data, and current scientific understanding, and the results and limitations are appropriately considered in the abstraction.

2. Sufficient evidence is provided that alternative conceptual models of features, events, and processes have been considered; that the preferred models (if any) are consistent with available data (e.g., field, laboratory, and natural analog) and current scientific understanding; and that the effect on total system performance assessment of uncertainties from these alternative conceptual models has been evaluated.

3. Consideration of conceptual model uncertainty is consistent with available site characterization data, laboratory experiments, field measurements, natural analog information and process-level modeling studies; and the treatment of conceptual model uncertainty does not result in an under-representation of the risk estimate. 


\section{Acceptance Criterion 5: Model Abstraction Output Is Supported by Objective Comparisons}

1. Models implemented in the abstraction provide results consistent with output from detailed process-level models and/or empirical observations (e.g., laboratory testing, field measurements, and/or natural analogs).

\subsection{CODES, STANDARDS, AND REGULATIONS}

No other codes, standards or regulations other than those referenced in Section 4.2 apply to this model report. 


\section{ASSUMPTIONS}

This section describes the assumptions applicable to the use of the Ashplume and Ash Redistribution models. Each assumption listed is followed by a rationale for use, confirmation status, and a disposition in this report. Assumptions are grouped within this section according to whether they apply to the conceptual or mathematical model or to the model parameters. A summary of the described assumptions is provided in Table 5-1. Assumptions made in source documents are not discussed in this report.

Table 5-1. Summary of Key Assumptions

\begin{tabular}{|c|c|c|}
\hline Item \# & Assumption & Summary Comment on Impact \\
\hline \multicolumn{3}{|c|}{ MODEL ASSUMPTIONS } \\
\hline 5.1 .1 & $\begin{array}{l}\text { Volcanic eruption is violent Strombolian } \\
\text { for entire duration }\end{array}$ & $\begin{array}{l}\text { Enhances the potential for ash and waste dispersal by } \\
\text { transport in convective plume. }\end{array}$ \\
\hline 5.1 .2 & $\begin{array}{l}\text { All waste particles smaller than a defined } \\
\text { fraction of ash particles are transported by } \\
\text { ash and dispersed }\end{array}$ & $\begin{array}{l}\text { This is a conceptual assumption to ensure that waste and } \\
\text { ash particles are appropriately paired, according to a } \\
\text { particle size ratio, to provide reasonable waste transport to } \\
\text { atmosphere. Sensitivity analysis indicates that impact of } \\
\text { this assumption is small. }\end{array}$ \\
\hline 5.1 .3 & $\begin{array}{l}\text { RMEI hazard paths from ash redistribution } \\
\text { are bounded by two model outcomes } \\
\text { dependent on primary ash thickness at } \\
\text { RMEI location }\end{array}$ & $\begin{array}{l}\text { The two model outcomes are the basis for product outputs } \\
\text { from the redistribution conceptual model for the TSPA. } \\
\text { Other possible model outcomes (e.g., where tephra are } \\
\text { deposited west of Yucca Mountain) would result in exposure } \\
\text { to a RMEl less than that of the two outcomes outlined } \\
\text { above. }\end{array}$ \\
\hline 5.1 .4 & $\begin{array}{l}\text { Future climate changes will have little } \\
\text { impact on Fortymile Wash alluvial fan }\end{array}$ & $\begin{array}{l}\text { If climate changes to a wetter period the pluvial period is } \\
\text { projected to have about } 11 / 2 \text { to } 2 \text { times the current annual } \\
\text { precipitation. However this is seen to require no adjusted } \\
\text { use of current data since the expected effects would include } \\
\text { more vegetation and this will result in less ash being derived } \\
\text { from the hillslopes. Therefore, this assumption is expected } \\
\text { to have little effect on the model outcome. }\end{array}$ \\
\hline 5.1 .5 & $\begin{array}{l}\text { Fluvial transport and mixing of ash with } \\
\text { sediment can be scaled from other analog } \\
\text { sites }\end{array}$ & $\begin{array}{l}\text { Mixing of sediments while in transport down drainage } \\
\text { channels is a fundamental sedimentary process and as } \\
\text { such can be scaled from analog data for drainage basins } \\
\text { where the process has not yet been measured. }\end{array}$ \\
\hline 5.1 .6 & $\begin{array}{l}\text { The channels of the alluvial fan in area of } \\
\text { the RMEI are stable for the regulatory } \\
\text { period }\end{array}$ & $\begin{array}{l}\text { Because the channels on the upper (northern) part of the } \\
\text { fan are moderately incised it is highly unlikely for the } \\
\text { channels to be moved. Thus, when flow moves through } \\
\text { these channels, material in the channels will be moved } \\
\text { downstream to be replaced by other material as the flood } \\
\text { wanes. Since the areal proportion of channels is expected } \\
\text { to remain relatively constant, the actual location of these } \\
\text { channels does not matter in the Ash Redistribution model. }\end{array}$ \\
\hline 5.1 .7 & Initial redistributed tephra is undiluted & $\begin{array}{l}\text { Data are insufficient for accurate prediction of mixing of ash } \\
\text { and sediment. Therefore, no credit is taken for dilution. } \\
\text { This assumption maximizes transport of ash in channels to } \\
\text { RMEl area. }\end{array}$ \\
\hline 5.1 .8 & $\begin{array}{l}\text { Eolian erosion transports waste out of } \\
\text { RMEl area without redeposition in RMEI } \\
\text { area }\end{array}$ & $\begin{array}{l}\text { The net loss of waste in the RMEI area is offset by the } \\
\text { presence of a persistent layer of low contamination in the } \\
\text { model. Therefore the effect of this assumption is thought to } \\
\text { be small. }\end{array}$ \\
\hline
\end{tabular}


Table 5-1. Summary of Key Assumptions (Continued)

\begin{tabular}{|c|c|c|}
\hline Item \# & Assumption & Summary Comment on Impact \\
\hline \multicolumn{3}{|c|}{ PARAMETER ASSUMPTIONS } \\
\hline 5.2 .1 & $\begin{array}{l}\text { Wind data from Desert Rock station near } \\
\text { Mercury, Nevada, acceptably } \\
\text { approximates future wind conditions }\end{array}$ & $\begin{array}{l}\text { Global climate model studies with available paleoclimate } \\
\text { information support the assumption of little change to } \\
\text { long-term average wind patterns. Post-glacial qualitative } \\
\text { trends include a lessening of frequency for northerly winds } \\
\text { from the repository towards the RMEI }\end{array}$ \\
\hline 5.2 .2 & $\begin{array}{l}\text { Wind speed and direction are constant } \\
\text { during an eruptive event }\end{array}$ & $\begin{array}{l}\text { Gives maximum distribution along centerline of wind } \\
\text { direction, and toward the RMEI for corresponding wind } \\
\text { conditions }\end{array}$ \\
\hline 5.2 .3 & $\begin{array}{l}\text { Tephra dispersal is dictated by the wind } \\
\text { speed and direction at the top of the } \\
\text { eruption plume }\end{array}$ & $\begin{array}{l}\text { Use of wind speed and direction corresponding with the top of } \\
\text { plume results in high (conservative) dispersal of ash and } \\
\text { waste }\end{array}$ \\
\hline 5.2 .4 & $\begin{array}{l}\text { All waste intersected in eruptive event is } \\
\text { dispersed as fine particulate of near } \\
\text { fuel-form grain size }\end{array}$ & $\begin{array}{l}\text { Appropriate analog data from igneous extrusion through } \\
\text { engineered systems are lacking. This assumption places a } \\
\text { high (conservative) proportion of waste into the dispersed } \\
\text { plume and uses a median particle size that corresponds with } \\
\text { a range that was reported as representing a high hot particle } \\
\text { size fraction at } 20 \mathrm{~km} \text { from the Chernobyl Power Plant }\end{array}$ \\
\hline 5.2 .5 & $\begin{array}{l}\text { Initial rise velocity of particles in plume is } \\
\text { the minimum velocity necessary to supply } \\
\text { eruptive thermal power to a convective } \\
\text { plume. }\end{array}$ & $\begin{array}{l}\text { This assumption maximizes the dispersal of ash and waste in } \\
\text { a high convective plume that is transported downwind. }\end{array}$ \\
\hline 5.2 .6 & $\begin{array}{l}\text { Net soil erosion for the regulatory period } \\
\text { will be similar to that assessed from } \\
50 \text {-year cesium tracer data }\end{array}$ & $\begin{array}{l}\text { Produces realistic rate of erosion occurring over the last } \\
50 \text { years and should remain the same unless large-scale } \\
\text { climate changes occur in this time interval. }\end{array}$ \\
\hline
\end{tabular}

\subsection{MODEL ASSUMPTIONS}

\subsubsection{Ashplume Representation of the Conceptual Model}

Assumption: The Ashplume model assumes that volcanic eruptions in the YMR are violent Strombolian for the entire duration of the explosive phase. Erupted magma is presumed to be fragmented and dispersed in the convective plume for the entire duration of the eruption. This assumption is conservative in that it maximizes the potential for ash and waste dispersal during Strombolian activity. (Note that violent Strombolian does not reach the dispersive potential of more violent types of events that are not associated with the YMR, such as Vulcanian/Surtseyan [hydrovolcanic] eruptions or eruptive phases.) The validity of this assumption received support from the Igneous Consequences Peer Review Panel (Detournay et al. 2003 [DIRS 169660], Section 4.2).

Rationale: This assumption is considered to be conservative because normal Strombolian activity is dominated by short-duration bursts that throw relatively coarse fragments of melt out of the vent on ballistic trajectories, where most of the fragments are deposited immediately around the vent with only a very small fraction of finer particles rising higher and being dispersed by wind to form minor fallout sheets (BSC 2004 [DIRS 169980], Section 6.3.3.6.1). In contrast, the Ashplume model represents the most violent type of Strombolian activity, in which the near-vent ballistic 
component is minimal and tephra dispersal in a wind-blown convective plume dominates, according to the conceptual model (Jarzemba et al. 1997 [DIRS 100987], p. 2-1). Clearly, this assumption maximizes the dispersal for contaminants for Strombolian activity. Uncertainties associated with the nature of violent Strombolian eruptive phases are their duration (the length of time the volcanic eruption is occurring), eruption power (the heat flux carried by the tephra), and the initial velocity of tephra entering the plume (BSC 2004 [DIRS 169980], Section 6.3.3.4). These uncertainties are included in the model through the development of distribution functions for these parameters. For historic eruptions, the uncertainties can be bounded by measurements of the volume of erupted material; such measurements for YMR analogs are used to provide realistic bounds on input parameters (Section 6.5.2).

Confirmation Status: It is conservative to assume that an eruptive event can be modeled as being in the violent Strombolian phase during the entire period of eruption because typical eruptions include only a minor component, if any, of violent Strombolian activity. Most of a typical eruption is less energetic. No further confirmation is required.

Where Used: This assumption is used in Section 6.3 to support the conceptual model for the volcanic eruption release.

\subsubsection{Waste-Particle Incorporation with Ash}

Assumption: The mathematical formulation of the Ashplume model makes the simplifying assumption that all waste particles with diameters less than a certain fraction of the diameter of ash particles, determined by the incorporation ratio (Section 6.5), are attached to ash particles for transport. The model also contains the assumption that any waste particles too large for incorporation are not transported downwind.

Rationale: There is no physical basis for this mathematical construct, but the assumption is consistent with the conceptualization that all waste material in canisters intersected by an eruptive conduit is incorporated into the magma (and, subsequently, into the eruption column). This mathematical formulation is required to transport an ash particle corrected for the density of the waste particle. It is reasonable to assume that small ash particles cannot host large waste particles for transport. A limiting factor must be introduced into the mathematical model to represent a reasonable waste/ash fraction. In this mathematical simplification, waste-particle size distributions and ash-particle size distributions are appropriately paired to ensure a reasonable fraction of waste is transported in the eruption.

Confirmation Status: This assumption is consistent with the conceptual model of ash/waste interaction. Confirmation of this mathematical construct would be very difficult through laboratory test. Based on the relative insensitivity of the Ashplume model to this parameter (Appendix C), it is not identified as requiring further work for confirmation. 
Where Used: This assumption is used in Section 6.5 in the development of the Ashplume mathematical model.

\subsubsection{Tephra Sheet Distribution for Ash Redistribution Model}

Assumption: That potential hazard paths characterizing maximum potential exposure to the RMEI can be represented by two bounding model outcomes for tephra sheet distribution and orientation, and that these outcomes can be distinguished by a criterion of minimum primary ash deposition as calculated by Ashplume.

Rationale: The possible orientation of tephra sheets from a basaltic volcanic eruption centered on Yucca Mountain suggests that the two model outcomes representing maximum potential exposure to the RMEI are: Outcome 1, in which the tephra sheet covers the location of the RMEI, and Outcome 2, in which the tephra sheet is located within the Fortymile Wash drainage basin upstream from the RMEI location. The properties of the Outcome 1 tephra sheet at the RMEI location are consistent with the waste concentrations and ash thickness calculated from ASHPLUME_DLL_LA V 2.0 (BSC 2003 [DIRS 166571]) and presented in Table 6-4 of Section 6.7.1. Properties of an Outcome 2 tephra sheet located in the Fortymile Wash drainage basin assume that available ash from the eruption, other than that forming the cinder cone, is deposited within the drainage basin and is available for redistribution primarily by fluvial processes. The two model outcomes are the basis for product outputs from the redistribution conceptual model for the TSPA. Other possible model outcomes (e.g., where tephra are deposited west of Yucca Mountain) would result in exposure to a RMEI less than that of the two outcomes outlined above.

The assumed criterion for distinction between model outcomes 1 and 2 is based on ash thickness at the RMEI location as first calculated by the Ashplume code within the TSPA GoldSim model. Outcome 1 is defined as including eruptive events where the calculated primary tephra thickness at the RMEI location is greater than or equal to the minimum mean ash particle size, $0.001 \mathrm{~cm}$. All other events are defined as Outcome 2.

Confirmation Status: The two outcomes represent hazard paths that likely characterize maximum potential exposure to the RMEI in that ash deposited to the northeast is consistent with prevailing wind direction and is the most likely direction of any ash plume in a hypothetical eruption in the vicinity of Yucca Mountain including one located at Yucca Mountain. The deposition of ash to the south directly on the location of the RMEI would be the exceptional case as a northerly wind direction is uncommon (see Figure 6-1).

It is possible that the simplified bounding definition could classify as Outcome 1 some events in which an approximately westerly wind placed the primary tephra upstream of the RMEI location, but also provided sufficient thickness at the RMEI location to satisfy categorization as Outcome 1. This would result in omitting an upstream waste redistribution source to the RMEI location. The possibility of this sort of hybrid event is accounted for in the initial conditions for Outcome 1.Westerly winds are infrequent; however, for reason of this potential shortcoming, the alternative ash redistribution 
model (see Appendix I) identifies an option for using wind direction sectors, rather than primary tephra thickness, to select initial conditions for ash redistribution.

Where Used: This assumption is used in Section 6.6.1 of this report to support the ash redistribution conceptual model.

\subsubsection{Future Climate}

Assumption: The climate through much of the regulatory period will be similar to today's climate and, even with a projected increase in annual precipitation, will have relatively little impact on the Fortymile Wash alluvial fan.

Rationale: See Future Climate Analysis (BSC 2004 [DIRS 170002]). If climate changes to a wetter period the pluvial period is projected to have about $1 \frac{1 / 2}{2}$ to 2 times the current annual precipitation. However this is seen to require no adjusted use of current data since the expected effects would include more vegetation and this will result in less ash being derived from the hillslopes.

Confirmation Status: No confirmation needed.

Where Used: Section 6.6

\subsubsection{Ash-Sediment Mixing during Fluvial Transport}

Assumption: Fluvial transport and the mixing of basaltic ash with other sediment through the Fortymile Wash drainage system can be adequately described by scaling analog data from other sites.

Rationale: Mixing of sediments while in transport down drainage channels is a fundamental sedimentary process and as such can be scaled from analog data for drainage basins where the process has not yet been measured.

Confirmation Status: None required

Where Used: Section 6.6

\subsubsection{Stability of Channels on the Upper Fortymile Wash Alluvial Fan}

Assumption: The channels on the upper fan at the RMEI location are stable through the regulatory period.

Rationale: The upper fan of Fortymile Wash is close to being in equilibrium. The channels are slightly incised below the fan surface and, as such, sediment will pass through the channels during floods without modifying them. Thus, these channels are considered as stable features of the upper fan surface.

Confirmation Status: None required for this conceptual model.

Where Used: Section 6.6 


\subsubsection{Initial Redistributed Ash is Undiluted}

Assumption: Initial redistributed tephra is assumed to be undiluted, and this is an upper bound of the process. The lower bound would be a well-mixed sediment with no ash remaining incorporated.

Rationale: The lack of dilution data from younger analog volcanoes precludes its use in TSPA so the default upper bound is used.

Confirmation Status: None required for this conceptual model.

Where Used: Section 6.6

\subsubsection{No Eolian Transport of Waste to the RMEI}

Assumption: Eolian erosion process is assumed to transport waste out of the RMEI area without redeposition in the RMEI area.

Rationale: The rate of deposition by eolian processes is not known. It is difficult to adequately measure and to model in a meaningful predictive manner. While this assumption results in a continual loss of contamination from the interchannel divide areas, the presence of a persistent low (1 percent) concentration of waste in these areas is designed, in part, to account for the continued remobilization of waste in the RMEI area.

Confirmation Status: None required for this conceptual model.

Where Used: Section 6.6

\subsection{PARAMETER ASSUMPTIONS}

\subsubsection{Future Wind Speed and Direction}

Assumption: Data characterizing variability in wind speed and wind direction under present climatic conditions in the YMR are provided in Upper Air Data: Desert Rock, Nevada, 1978-1995 (NOAA 2004 [DIRS 171035]; and Appendix D, this document) data from the Desert Rock station near Mercury, Nevada, which are assumed to be acceptable approximations of variability in wind speed and direction for future wind conditions. Conceptually, this assumption corresponds to an assumption that climatic change will not significantly affect wind speed and direction. The magnitude of short-term variability in wind speed and direction, which is included in the data that characterize present wind conditions, is presumed to be significantly greater than long-term variability introduced by potential future climatic changes.

Rationale: Justification for future wind conditions in future climates is based on the observation that the magnitude of short-term variability in meteorological phenomena is great compared to changes in long-term averages. Emphasis for relatively brief volcanic events is appropriately placed on the short-term variability rather than on long-term averages in wind patterns. 
Additional support for the reasonableness of this assumption comes from examination of published modeling studies of past climatic conditions that may be reasonable analogs for future climatic conditions at Yucca Mountain. Kutzbach et al. (1993 [DIRS 119269], p. 60) have modeled global climates at 3,000-year intervals during the last 18,000 years, using general circulation models with available paleoclimatic information used to define boundary conditions. Resolution of the model is extremely coarse (grid blocks are 4.4 degrees latitude by 7.5 degrees longitude (Kutzbach et al. 1993 [DIRS 119269], p. 60)), and results are not intended to be interpreted at local scales. However, model results (presented at a regional scale) provide qualitative information about modeled wind speeds and directions for the southwestern United States. Model results are provided for 18,000 years ago, at the end of the last major glaciation of northern North America, at 12,000, 9,000, and 6,000 years ago and also for present conditions. Climatic conditions at these times span the range of conditions that might reasonably occur during a future transition from the present climate to a glacial climate.

Modeled surface winds for the southwestern United States in winter and summer show a slightly stronger westerly component (away from the location of the RMEI south of the repository) 18,000 years ago than at present and are essentially unchanged from the present at 12,000, 9,000, and 6,000 years ago (Kutzbach et al. 1993 [DIRS 119269], Figures 4.6 and 4.8). Modeled winter (January) winds at the 500 -millibar (mb) pressure isobars (about $5.5-\mathrm{km}$ altitude) blow strongly from the west at all times and were somewhat stronger at 18,000 years ago than at present (Kutzbach et al. 1993 [DIRS 119269], Figure 4.14). Modeled summer (July) winds at $500 \mathrm{mb}$ are weaker and less consistent, blowing from the southwest and west at 18,000 and 12,000 years ago and at the present and from the northwest 9,000 and 6,000 years ago (Kutzbach et al. 1993 [DIRS 119269], Figure 4.15).

The information relevant to the assumption discussed here is that significant changes in the Kutzbach et al. (1993 [DIRS 119269]) modeled wind speeds and directions in the southwestern United States are not dramatic during the modeled transition from glacial to interglacial climates. The largest changes, occurring during full glacial conditions 18,000 years ago, appear qualitatively to correspond to a decrease in the relative frequency of winds blowing toward the RMEI location south of Yucca Mountain. Therefore, these changes are reasonably and conservatively neglected, and variability in present wind conditions is assumed to characterize variability adequately in future conditions.

Confirmation Status: None required.

Where Used: This assumption is used to justify the distributions of future wind speed and direction that are recommended for use in the TSPA-LA analyses. The recommended wind direction and wind speed distribution functions are discussed in Section 6.5. Functionally, the assumption means that individual values of wind speed and direction can be sampled for time zero from distributions based on present data, and the same values can then be used for all time steps for each realization. 


\subsubsection{Wind Speed and Direction Remain Constant During an Eruptive Event}

Assumption: Wind speed and direction are assumed to be constant during an eruptive event.

Rationale: This assumption prevents short-term variations in wind speed and direction from spreading the ash plume over a broader area and results in both a maximum quantity and maximum concentrations of waste at the centerline of the plume. This is a reasonable simplification, given the relatively short duration of violent eruptive events.

\section{Confirmation Status: None required.}

Where Used: This assumption is used in Section 6.5.

\subsubsection{Ashplume Utilization of Wind Speed and Direction}

Assumption: The Ashplume model assumes that the wind speed and direction that dictate tephra dispersal are those that occur at the top of the plume.

Rationale: Wind speed and wind direction vary with altitude above the ground, and, thus, tephra dispersed from the plume at different altitudes follows trajectories governed by altitude-dependent wind vectors. The column diffusion constant $(\beta)$ determines which locations in the column contribute the most tephra dispersal. This constant was presumed to be a $\log$-uniform distribution from 0.01 to 0.5 (Jarzemba et al. 1997 [DIRS 100987], p. 4-1) without justification (for the distribution type) other than it spans more than one order of magnitude. Because violent Strombolian eruptions typically form an anvil-shaped plume, most particles must rise to near the plume top before dispersal down wind. This suggests that large values of $\beta$ are common such that the distribution is likely uniform, as is implemented in this report. With a uniform distribution of beta between 0.01 and 0.5 , the majority (about 80 percent) of violent Strombolian eruptions are modeled with $\beta$ greater or equal to 0.1 , a level at and above which Suzuki (1983 [DIRS 100489], Figure 6) showed dominant dispersal from the upper half of the column. Hence, the wind speed and direction near the top of the plume are appropriate and maximize dispersal for modeled eruptions. This assumption is considered to be reasonable and consistent with the intended use of the Ashplume model.

Confirmation Status: None required.

Where Used: This assumption is used in Section 6.5.

\subsubsection{Waste-Particle Size}

Assumption: For the purpose of estimating waste-particle diameters in the eruptive environment, all waste is assumed to be unaltered commercial spent fuel physically disaggregated to a size range that approximately relates to fuel form grain size. 
Rationale: This assumption is considered reasonable for analyses of the 10,000-year post-closure performance period as specified in 10 CFR 63 [DIRS 156605].

Experimental evidence is lacking for processes, including fragmentation, from magmatic melt interaction with spent nuclear fuel in a volcanic eruption. The U.S. Department of Energy (DOE) performance assessments (Reamer 1999 [DIRS 119693], p. 82) have all assumed that the waste package fails upon contact with basaltic magma, therefore exposing the fuel form to the magma. Characterize Eruptive Processes at Yucca Mountain, Nevada (BSC 2004 [DIRS 169980], Section 6.3.3.5) discusses potential mechanisms of magmatic interaction with the waste packages and spent fuel form and observes that fuel form oxidation is a likely interaction process.

Dike/Drift Interactions (BSC 2004 [DIRS 170028], Section 6.4.8) considers that magmatic interaction with waste form could form molten and solid oxide solution complexes with some of the magmatic mineral constituents; however, chemically unchanged waste form is assumed due to lack of data on the mineral phases that could form. If chemical assimilation into the magmatic melt, rather than the assumption of physical disaggregation to fine particle size, were assumed for the Ashplume modeling purpose the proportion of waste available for atmospheric dispersion would be smaller (less conservative) by an approximate factor of three. This would be the case since a major proportion of the waste, assimilated in the magma, would then allocate to cone and lava flow material rather than with the eruptive plume column ash. Glass waste form would be more readily expected to be assimilated with the magmatic melt; therefore, on account of both aspects, the assumption basis for treating all waste as fragmented particulate is conservative but reasonable.

If partly or wholly assimilated into the magma melt, the unaltered glass waste forms are likely to have particle diameters comparable to those of the ash particles, which are larger than the values used for spent fuel. Given the conceptualization that waste particles are transported by combining with ash particles of larger sizes (see Assumption 5.1.2), the assumption to treat all waste as unaltered commercial spent fuel is also conservative but reasonable. The assumption that the waste form is unaltered prior to being disturbed in a volcanic event is reasonable for analyses of the 10,000-year post-closure performance period, given the relatively small number of waste packages expected to fail under nominal conditions during that period and the expected stability of the waste form within the undisturbed waste packages.

The assumed mechanism for disaggregation of spent fuel form to fine particulate, exposed after waste package failure, is based on oxidation of $\mathrm{UO}_{2}$, the primary form of commercial pressurized water reactor fuel (DOE 2003 [DIRS 166027], p. 19). Oxidation rates and the accompanying morphological changes of non-irradiated and irradiated fuel form have been extensively studied (DOE 2003 [DIRS 166027], p. 19), though most reported work seems to be for temperatures below $400^{\circ} \mathrm{C}$, presumably pertaining to spent fuel handling and storage. The chemistry of the uranium oxide system is complex because of the existence of hyperstoichiometric oxides (DOE 2003 [DIRS 166027], p. 20). At lower temperatures, the progressive oxidation of $\mathrm{UO}_{2}$ to the higher valence states involves an incubation period; however, this trends to zero at 
$500^{\circ} \mathrm{C}$ (Dehaudt 2001 [DIRS 164019], p. 376). The same source reports that progression through oxidation states results in structural changes with initial densification (up to a $\mathrm{O}: \mathrm{U}$ ratio of approximately 2.3 ) and subsequent specific volume increases (between $\mathrm{O}: \mathrm{U}$ ratios of approximately 2.3 and 3.0) that lead to intergranular and intragranular decohesion of the fuel grains. At macro level, this has been seen to cause fragmentation to fuel form grain size and even to provide size distributions as small as 0.35 and 0.95 micrometers; however, no work has been found to provide an estimate of the overall size distribution from fuel exposed to the durations, temperatures and forces that are possible during an eruptive event. Sintered $\mathrm{UO}_{2}$ does not readily break into single grains; rather transgranular fracture is common when grinding unirradiated $\mathrm{UO}_{2}$. Also, because fission products tend to accumulate along grain boundaries during irradiation of the fuel (especially as gas bubbles and metal particles), the resulting loss of cohesion between grains allows spent fuel to break into individual grains more readily than does unirradiated $\mathrm{UO}_{2}$.

Simulated accident events have been studied; however, resulting particulate size has not often been reported. Sandoval et al. (1983 [DIRS 156313], p. 46) report a mass median diameter of 210 micrometer for $\mathrm{UO}_{2}$ particle and fume release after penetration by a high-energy device of a full size shipping cask containing depleted $\mathrm{UO}_{2}$ fuel. However this shock circumstance of short duration may not adequately represent the oxidation state fragmentation mechanisms.

In reconstruction of the inhalation dose after the Chernobyl accident, the fractions of hot particles according to distance from the nuclear plant are reported (Mück et al. 2000 [DIRS 170378], Table 5) to be as shown in Table 5-2. This provides an analog of distal size distributions of radionuclide outfall from an accidental thermal source, but not the total particle size distribution from that source.

Table 5-2. Fraction of Hot Particles by Size and Distance from Chernobyl Power Plant

\begin{tabular}{|c|c|c|c|c|}
\hline \multirow{2}{*}{$\begin{array}{l}\text { Distance from } \\
\text { Chernobyl } \\
\text { Nuclear Power } \\
\text { Plant, km }\end{array}$} & \multicolumn{4}{|c|}{ Fraction of Hot Particles with a Given Particle Size } \\
\hline & $0-20 \mu \mathrm{m}$ & $20-50 \mu \mathrm{m}$ & $50-100 \mu \mathrm{m}$ & $100-200 \mu \mathrm{m}$ \\
\hline 4 & - & $12.5 \%$ & $75 \%$ & $12.5 \%$ \\
\hline 10 & 一. & $65 \%$ & $35 \%$ & - \\
\hline 20 & $8 \%$ & $87 \%$ & $5 \%$ & - \\
\hline 37 & $40 \%$ & $60 \%$ & - & 一 \\
\hline 55 & $65 \%$ & $35 \%$ & - & - \\
\hline
\end{tabular}

Source: Mück et al. 2000 [DIRS 170378].

While preparing spent $\mathrm{UO}_{2}$ fuel (approved testing material (ATM) 103: 30MW d/kg-U, Appendix $\mathrm{H}$ ) for corrosion studies, Argonne National Laboratory made assessments of crushed and ground fuel particle size. The estimate of fuel particle size and relationship to natural grain size is provided in Appendix $\mathrm{H}$. The majority (approximately 80 percent) of the size-reduced fuel was reported as being mostly single fuel grains, less than 45 micrometers and averaging 20 micrometers. A midsize range of 45 to 150 micrometers represented 11 percent of the ground fuel while 9 percent 
exceeded 150 micrometers. For the purpose of consideration to volcanic interaction with the repository, the Argonne National Laboratory author of Appendix $\mathrm{H}$ provides a professional judgment of suggested fuel particle size, based on that investigation, experience with observations of fuel, and cited sources. For unaltered fuel the suggested particle diameter range is 1 to 500 micrometers with a mean of 20 micrometers.

From the foregoing, and in the absence of data that more specifically represents interaction of magma with spent fuel, the Ashplume model assumes that fuel in the affected waste packages is available for entrainment in the ash plume as finely-divided particles with diameters in the range of 1 to 500 micrometers, with a mean of 20 micrometers.

Confirmation Status: This assumption is considered reasonable for analyses of 10,000-year performance, as described above. Given the uncertainties in defining test parameters for representation of magmatic interaction with waste form, and the demonstrated relative insensitivity to particle size (Appendix C), no further confirmation activities are planned.

Where Used: This assumption is used in Section 6.5 in describing the waste-particle size distribution.

\subsubsection{Initial Rise Velocity}

Assumption: The initial rise velocity of tephra particles in the plume is assumed to be the minimum velocity required to provide the plume the modeled thermal power. The Ashplume model stipulates that the convective rise velocity of tephra particles linearly decreases from the initial rise velocity at the base of the convective plume to zero at the top of the plume. Because the upward velocity profile of buoyant plumes generally decreases with height to zero at their tops where neutral buoyancy is a complex relationship of plume and atmospheric density profiles and the rate of air entrainment and heating, this assumption represents the model-equivalent of the modeled plume's vertical velocity profile. In order for model-equivalence to give a reasonable numerical approximation, the initial rise velocity is constrained to values that are compatible with the plume height and, thus, eruptive power.

Rationale: Ashplume models a column (plume) instantaneously loaded with hot particles moving at some upward velocity. The height of the column determined by ASHPLUME is fixed by the power (heat flux) provided by erupting magma. The heat flux is directly proportional to the mass flux of magma from the vent, which, for continuity, is determined by the vent area, magma bulk density, and vent velocity. For any given vent area and mass flow rate, the density and velocity of the mixture are inversely related: minimum vent velocity occurs when the magma bulk density is at its maximum (gas-free) value and maximum vent velocity occurs when magma bulk density is at its minimum value. The eruption velocity may briefly exceed the sonic velocity of the mixture within or slightly above the eruptive vent, resulting in sub-atmospheric pressure in the jet; however, the pressure will quickly adjust to atmospheric conditions, which will determine the mixture density and, indirectly, its 
velocity. For the purposes of this study then, the minimum realistic magma bulk density arises when magma volatile components are expanded to atmospheric pressure. Realistic vent velocities fall between these two extremes. Before the magma and gas mixture enters the convective-thrust part of the plume, it rapidly decelerates by its interaction with the atmosphere and gravitational forces in a region known as the gasthrust region (Section 6.3). Because the height of the gas-thrust region is generally less than 10 percent of the total eruptive column height, a convective plume model such as Ashplume that neglects this gas-thrust region is justified (Wilson et al. 1978 [DIRS 162859], p. 1830). The Ashplume model must account for gas expansion and air entrainment as well as the deceleration of tephra in the gas-thrust region while maintaining continuity in order for the column height to eruptive power relationship to hold. Implicit in the convective plume model is that (1) height is solely determined by the convection produced by the supplied thermal power and that (2) the contribution to the plume height by the momentum of gas-thrust region is negligible. This approximation stipulates that the velocity of tephra entering the plume must only be that required to deliver the required power. Thus, for eruptions involving gas expansion, the plume base area must be greater than the vent area by a factor equal to the amount of gas expansion. For plumes of circular cross section, the radius increases by the square root of the gas expansion. As an example, consider a mixture of gas and tephra issuing from a vent of $1-\mathrm{m}$ radius for which the mixture expands by a factor of 200 . The resulting plume would have a radius of approximately $14 \mathrm{~m}$, and its initial velocity would be the minimum vent velocity. This assumption is considered reasonable and consistent with the intended use of the Ashplume model.

Confirmation Status: None required.

Where Used: This assumption is used in Section 6.5.

\subsubsection{Erosion Rate}

Assumption: Net erosion for the regulatory period will be similar to that observed from field studies as assessed by 50 -year ${ }^{137} \mathrm{Cs}$ tracer data.

Rationale: Field measurements of ${ }^{137} \mathrm{Cs}$ on interchannel divides derives erosion rates representative of the last 50 years only (the time since the deposition of ${ }^{137} \mathrm{Cs}$ began) and must be extrapolated for time periods greater than 50 years. In the absence of other local or analog data and consistent with the assumption of relatively stable future climate (Section 5.1.4), the field-measured net erosion rate over 50 years is assumed to apply for the regulatory period. These data are taken from Harrington (BSC 2003 [DIRS 164775]).

Confirmation Status: required for this conceptual model. 


\section{MODEL DISCUSSION}

The potential consequences of an igneous event intersecting the repository (BSC 2004 [DIRS 169989]) require consideration of both the eruption and deposition of pyroclastic material and redistribution of that pyroclastic material after initial deposition. This section presents the objectives, technical bases, and applications of the two models that represent the eruption, deposition, and redistribution of volcanic ash. Section 6.1 presents the modeling objectives. Section 6.2 presents the applicable features, events, and processes addressed by the models. Section 6.3 provides the conceptual basis for the eruptive transport, deposition, and redistribution of waste-contaminated ash from a hypothetical volcanic eruption through a repository at Yucca Mountain. Section 6.4 discusses alternative conceptual models, and Section 6.5 presents the technical basis for application of the ash dispersal and deposition model. Sections 6.6 and 6.7 provide the technical basis for and application of the redistribution of waste-contaminated volcanic ash through sedimentary processes.

The Ashplume mathematical model is implemented for TSPA calculations by computer code ASHPLUME_DLL_LA V2.0 (BSC 2003 [DIRS 166571]). The ASHPLUME_DLL_LA computer code is a component of the TSPA model of the nuclear waste repository at Yucca Mountain. The TSPA model is used to evaluate the performance of the geologic repository in protecting humans and the environment from the risk associated with exposure to spent nuclear fuel and high-level radioactive waste. Within the TSPA, the atmospheric dispersal and deposition of tephra model implemented in the ASHPLUME code is used to predict the ground-level concentration or areal density $\left(\mathrm{g} / \mathrm{cm}^{2}\right)$ of ash and waste after a violent Strombolian eruption that intersects the repository. The waste concentration is then combined with biosphere dose conversion factors (BDCFs) to calculate a radioactive dose to a RMEI. The ash redistribution conceptual model describes the sedimentary processes acting on the tephra sheet after deposition. The concentrations of contaminated ash from sedimentary processes that could redistribute contaminated ash at the RMEI location $(18 \mathrm{~km}$ south of the repository's southern boundary (40 CFR Part 197 [DIRS 165519])) are calculated for different ash-fall deposition realizations. The model is based on several site-specific investigations, including analog studies of ash redistribution and erosional and depositional processes inferred from an analysis of ${ }^{137} \mathrm{Cs}$ data (BSC 2004 [DIRS 169980], Section 6.5.1.3]).

\subsection{MODELING OBJECTIVES}

Two models have been developed to represent the dispersal, deposition, and redistribution processes for volcanic ash contaminated with radioactive waste from a hypothetical eruption through the repository at Yucca Mountain. The overall objectives of these two models are to:

- Represent the processes and the associated potential consequences related to deposition and redistribution of contaminated ash at and near the RMEI location.

- Provide representative abstractions of the models with bounding conditions for inclusion in the TSPA model. 


\subsubsection{Objectives of the Ashplume Model}

The Ashplume conceptual model provides the basis, supported by analog descriptions, for the applicability of using the ASHPLUME code to model volcanic ash and waste dispersal during a hypothetical future volcanic eruption through the repository. Development of the model uses the Eruptive Processes Conceptual Model (BSC 2004 [DIRS 169980], Section 6) and is based on comparison of the expected scenario characteristics with the physical processes modeled by Ashplume.

The Ashplume model implements the conceptual and mathematical model of Suzuki (1983 [DIRS 100489]) for estimation of the areal density of tephra (ash) deposits on the surface of the earth following a violent Strombolian-type volcanic eruption. The computer code, developed by Jarzemba et al. (1997 [DIRS 100987]) from the Suzuki mathematical model, includes estimation of the areal density on the Earth's surface of spent fuel particles incorporated into ash particles due to an eruption that intersects the repository at Yucca Mountain. Areal densities can be converted to deposit thickness by dividing the areal density by the value of settled (deposit) density (typically $1.0 \mathrm{~g} / \mathrm{cm}^{3}$ (BSC 2004 [DIRS 169980])).

ASHPLUME_DLL_LA V 2.0 (BSC 2003 [DIRS 166571]) includes a dynamically linked library module for use as a component of the TSPA GoldSim model to assess risk to the RMEI from exposure to contaminated ash from possible volcanic activity at the Yucca Mountain site. The results of the Ashplume model calculations (tephra and waste areal densities) are used by the TSPA-LA model in conjunction with BDCFs to calculate dose to the RMEI. For compliance demonstration purposes for disruptive scenarios, the TSPA-LA assumes that the dose occurs to an individual who has the same characteristics as the RMEI. ASHPLUME V 2.0 (CRWMS M\&O 2001 [DIRS 152844]) also includes an executable module for stand-alone use, which is applied to making calculations shown in Section 7 of this report. The stand-alone version calls the dynamically linked library module for making the calculations and serves only to format user input parameters for the dynamically linked library. Thus, the following discussions in this report apply equally to both stand-alone and dynamically linked library implementations of ASHPLUME V 2.0.

\subsubsection{Objectives of the Ash Redistribution Conceptual Model}

The objective of the ash redistribution conceptual model is to describe the range of conditions that allow for the transport of waste-contaminated volcanic ash to the location of the RMEI by sedimentary processes that include both eolian and alluvial transport mechanisms. The consequences of a volcanic eruption include consideration of the potential increase in dose at the location of the RMEI from the transport of radioactive-waste-contaminated ash through sedimentary processes. This potential consequence is described in greater detail as a specific disruptive events feature, event, and process (FEP) (FEP 1.2.04.07.0C) (BSC, 2004 [DIRS 170017]). The ash redistribution conceptual model presents the basis for the ash redistribution abstraction, which is a component of the TSPA model. The ash redistribution conceptual model also addresses the conditions for the concentration of radionuclides from the transport of waste-contaminated ash at the location of the RMEI. 


\subsection{FEATURES, EVENTS, AND PROCESSES INCLUDED IN THE MODEL}

The development of a comprehensive list of FEPs potentially relevant to post-closure performance of the Yucca Mountain repository is an ongoing, iterative process based on site-specific information, design, and regulations. Table 6-1 provides a list of igneous-related FEPs (DTN: MO0407SEPFEPLA.000 [DIRS 170760]) that are included in the TSPA-LA through the use of the results of the calculations described in this document. Details of the inclusion or exclusion of disruptive events FEPs are discussed in Features, Events, and Processes: Disruptive Events (BSC, 2004 [DIRS 170017], Sections 6.2.1.7; 6.2.2.2; 6.2.2.3; 6.2.2.6; 6.2.2.7; 6.2.2.8).

For the igneous eruptive scenario, the TSPA-LA assumes that a hypothetical dike propagates upward, intersects the repository, provides a source for magma to enter the repository drifts, and magma and ash, potentially with entrained waste, are released to the surface via an eruptive conduit and redistributed by sedimentary processes. The FEPs listed in Table 6-1 are part of the conceptual basis for such a scenario. However, this report does not provide a direct basis for the inclusion in TSPA-LA of the FEPs listed in Table 6-1, with the exception of parameters developed to address ash redistribution. Rather, this report develops a basis for implementing the FEPs in TSPA-LA by helping to constrain the potential consequences of the listed FEPs. As such, a partial treatment of the included FEPs is provided herein, and the results of this model report and listed FEPs are considered to be implicitly included in the TSPA-LA.

Table 6-1. Included FEPs for This Model Report

\begin{tabular}{|l|l|l|}
\hline FEP Number & \multicolumn{1}{|c|}{ FEP Name } & \multicolumn{1}{|c|}{ Relevant Section of this Model Report } \\
\hline 1.2.04.06.0A & Eruptive conduit to surface intersects repository & Section 6.3.1,6.5.2 \\
\hline $1.2 .04 .07 .0 \mathrm{~A}$ & Ashfall & Section $6.5,6.7,7.3 .1$ \\
\hline 1.2.04.07.0C & Ash redistribution via soil and sediment transport & Sections 6.3.2, 6.6, 6.7.2, 7.3.2, Appendix I \\
\hline
\end{tabular}

\subsection{BASIS OF CONCEPTUAL MODELS}

\subsubsection{Basis of Ashplume Conceptual Model}

The basis for the conceptual model of a Strombolian eruption in the YMR is discussed in Characterize Eruptive Processes at Yucca Mountain, Nevada (BSC 2004 [DIRS 169980], Section 6.3), including details of volcanic eruption characteristics and supporting parameters, values, and distributions. The following discussion develops the conceptual model using information from this source.

A description of the Ashplume conceptual model for the atmospheric dispersal and deposition of contaminated tephra is preceded by an event of a basaltic dike rising through the Earth's crust and intersecting the proposed repository at Yucca Mountain (Figure 1-1). An eruptive conduit, or conduits, can form when a portion of the dike begins to widen and provides a preferential pathway to focus an eruption that penetrates the Earth's surface in a violent Strombolian eruption. If the conduit intersects one or more repository drifts, the canisters located partially or entirely within the conduit provide no further protection to the waste, which will become fragmented and entrained within the rising magma (BSC 2004 [DIRS 170028]). This condition 
is inherent in the input parameter for the amount of waste erupted and is given a technical basis in the Number of Waste Packages Hit by Igneous Intrusion (BSC 2004 [DIRS 170001]) for use in the TSPA-LA (BSC 2002 [DIRS 160313], p. B-8). The Ashplume model begins with the thermal and mass characteristics of the erupted material entering the corrective-thrust part of the eruption column (see below).

Existing data are limited regarding the expected state of the waste particles (e.g., grain size) resulting from a basaltic disruptive event and associated thermal, chemical, and physical processes (e.g., Codell 2003 [DIRS 165503]). The model assumes that fine-grained waste particles are entrained into a mixture of tephra and gas, rather than mixing directly into the magma prior to fragmentation (Section 5.2.4). As described in Section 6.5.1, the waste particle size distribution is paired with an appropriate ash size distribution and an incorporation ratio is used to account for the amount of waste fuel that is transported with the ash. For transport calculations, the paired ash and waste particles are modeled as density-convective ash particles.

A Strombolian eruption is characterized by the eruption of a high-speed column of a gas-pyroclast-waste-particle mixture. The column consists of two regions. The lower region directly above the vent is called the gas-thrust region, and it behaves as a ballistic fountain of tephra moving under the influence of its eruption momentum. The upper region of the column is called the convective-thrust region, in which tephra rise by buoyant convective currents (Self and Walker 1994 [DIRS 162831]). Strombolian eruptions typically vary in eruptive intensity as measured by the degree of magma fragmentation and eruption column height (BSC 2004 [DIRS 169980], Section 6.3.3). When the eruptive intensity reaches a point where a dominant portion of the tephra is carried into the convective-thrust region in a sustained eruption, the eruption is said to be in a violent Strombolian phase (BSC 2004 [DIRS 169980], Section 6.3.3). Hence, a violent Strombolian eruption is one that is dominated by heating of entrained air, and the atmospheric transport of the fragmented magma and gas mixture approximates a thermally buoyant plume.

As the eruptive mixture rises in the plume of a violent Strombolian eruption, it entrains and heats air, which, in turn, reduces the bulk density of the mixture, and the plume becomes buoyant and continues to rise as a plume (BSC 2004 [DIRS 169980], Section 6.3.3). The plume rises to an altitude of neutral buoyancy compared to the surrounding atmosphere, in which it then spreads laterally as an anvil cloud (the initial conditions for the ASHPLUME code calculations) and is transported down wind. Tephra particles fall out from the vertical eruption column and from the anvil cloud according to their settling velocities. Such eruptions produce a fallout sheet of varying thickness extending from the volcanic vent (e.g., Section 7.3.3, Figure 7-4). The thickness of the deposit depends on factors such as particle density, eruptive parameters, wind speed and direction, and distance from the vent (Suzuki 1983 [DIRS 100489]).

The Ashplume mathematical model is based on a two-dimensional (2-D) diffusion model in which only horizontal turbulent diffusion is considered. The movement of air in the atmosphere is relatively random due to the many eddy currents that exist (Suzuki 1983 [DIRS 100489]). The movement of particles within the air mass is treated as random for the same reason. Particles diffuse in the atmosphere in both vertical and horizontal directions, but because the scale of horizontal turbulence is much greater than the scale of the vertical turbulence (Suzuki 1983 [DIRS 100489]), horizontal diffusion is the dominant factor in determining the width of a plume 
as it moves downwind. Therefore, the Ashplume model is based on a 2-D diffusion equation in which only horizontal turbulent diffusivity is considered.

Ashplume is designed to model violent Strombolian eruption behavior as a thermally buoyant plume, calculating the atmospheric dispersal of tephra and its deposition on the ground. Furthermore, Ashplume calculates the entrainment of waste in the erupted plume by an "incorporation ratio," which defines the minimum ash particle size needed to carry a given waste particle size in the plume (Section 6.5.1). By doing so, the fallout of tephra carries fuel particles to where they are deposited on the ground, forming a contaminated fallout deposit. The contaminated fallout has the potential to affect the food and water supplies of the RMEI by direct contamination or by later surface redistribution of fallout deposits, which could be carried to the RMEI location by a number of mechanisms (BSC 2004 [DIRS 169460], Section 6). It is beyond the scope of this report to identify the mechanisms for human exposure due to the described eruptive model. The scope of this conceptual model begins with the intersection of waste by the magma and ends with the ash-waste mixture settling to the ground surface. The Ashplume conceptual and mathematical models are appropriate for estimating the ground-level concentration of waste fuel within the limitations discussed in Section 1.3. Outputs of the Ashplume model include prediction of ash/waste areal densities $\left(\mathrm{g} / \mathrm{cm}^{2}\right)$ at prescribed points surrounding the volcanic vent.

The ground-surface concentration and redistribution of waste, combined with BDCFs, will be used as input to the TSPA model to calculate the dose at the RMEI location. The analysis documented in this model report will improve and clarify the previous documentation of the Ashplume model and its application to TSPA-LA igneous scenarios.

\subsubsection{Basis of Ash Redistribution Model}

The ash redistribution model is a conceptual model that considers two bounding outcomes (see Section 5.1.3) of ash atmospheric dispersion and settlement to the ground as calculated by Ashplume within the TSPA GoldSim model. Abstractions of numeric factors from the conceptual ash redistribution model are provided for use by the TSPA GoldSim code for the purpose of calculating initial ash layer thickness and ground surface concentration at the RMEI location, as well as for calculating changes in these parameters over the regulatory period.

If an eruption were to occur through the repository at Yucca Mountain, radioactive waste particulate could be ejected along with the volcanic ash as attached particles (see Section 6.3.1). Material that is ejected into the atmosphere from a volcanic eruption eventually falls to the ground surface and forms a feature known as a tephra sheet. The depositional process is described in Characterize Eruptive Processes at Yucca Mountain Nevada (BSC 2004 [DIRS 169980], Section 6.3.4). The areal extent and thickness of the tephra sheet primarily depend on the volume of ash ejected, the eruptive power, and the wind speed. The tephra sheet generally decreases in thickness and grain size away from the vent, (Section 7.3 Figures 7-1 and 7-2). After deposition of the tephra sheet, the ash and waste would be available for redistribution by normal sedimentary processes (erosion and deposition) by water and wind.

For an eruption event, the TSPA GoldSim code executes the ASHPLUME code, while also sampling wind direction and velocity, to calculate ash deposition at the RMEI location. As can 
be seen from the wind rose data in Figure 6-1, and the topographical map of Figure 6-2, this sampling will include some results in which little or no ash will deposit at or be redistributed to the RMEI location. For this reason, two bounding outcomes of ash atmospheric dispersion are defined (see Section 5.1.3) as a basis for the conceptual ash redistribution model in order to represent upper bound effects at the RMEI location.

Model Outcome 1 corresponds to cases in which the TSPA-sampled wind direction is toward the RMEI (near northerly wind direction), resulting in ash deposition at the RMEI area. Model Outcome 2 corresponds to cases where tephra is not deposited directly at the RMEI location and the Fortymile Wash watershed is used as the basis for the conceptual model. In this context and for the purposes of the TSPA, Outcome 1 is defined as including eruptions for which there is a non-negligible thickness of ash deposited at the RMEI location quantified as greater than or equal to the minimum ash particle size, $0.001 \mathrm{~cm}$. Realizations in which the primary tephra thickness is less than $0.001 \mathrm{~cm}$ are then treated as examples of Outcome 2. Practically, Outcome 2 corresponds to predominant ash deposition within the Fortymile Wash watershed (consistent with prevailing southwesterly winds), which is then the source for potential downstream redistribution towards the RMEI location.

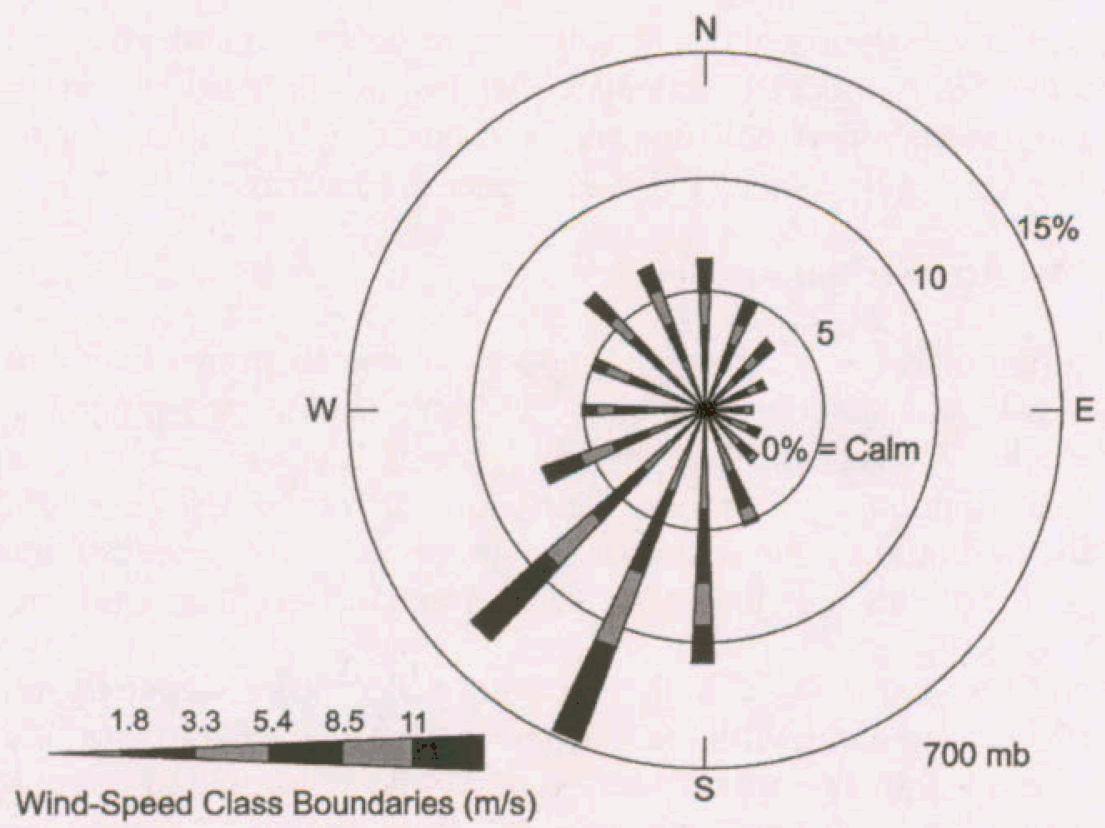

Source: CRWMS M\&O (2000 [DIRS 151945], Figure 6.2-6 b).

NOTE: The diagram shows the frequency of occurrence for each direction from which the wind is blowing.

Figure 6=1. Wind-Rose Plot for 700-mb Levels at Desert Rock Airport 


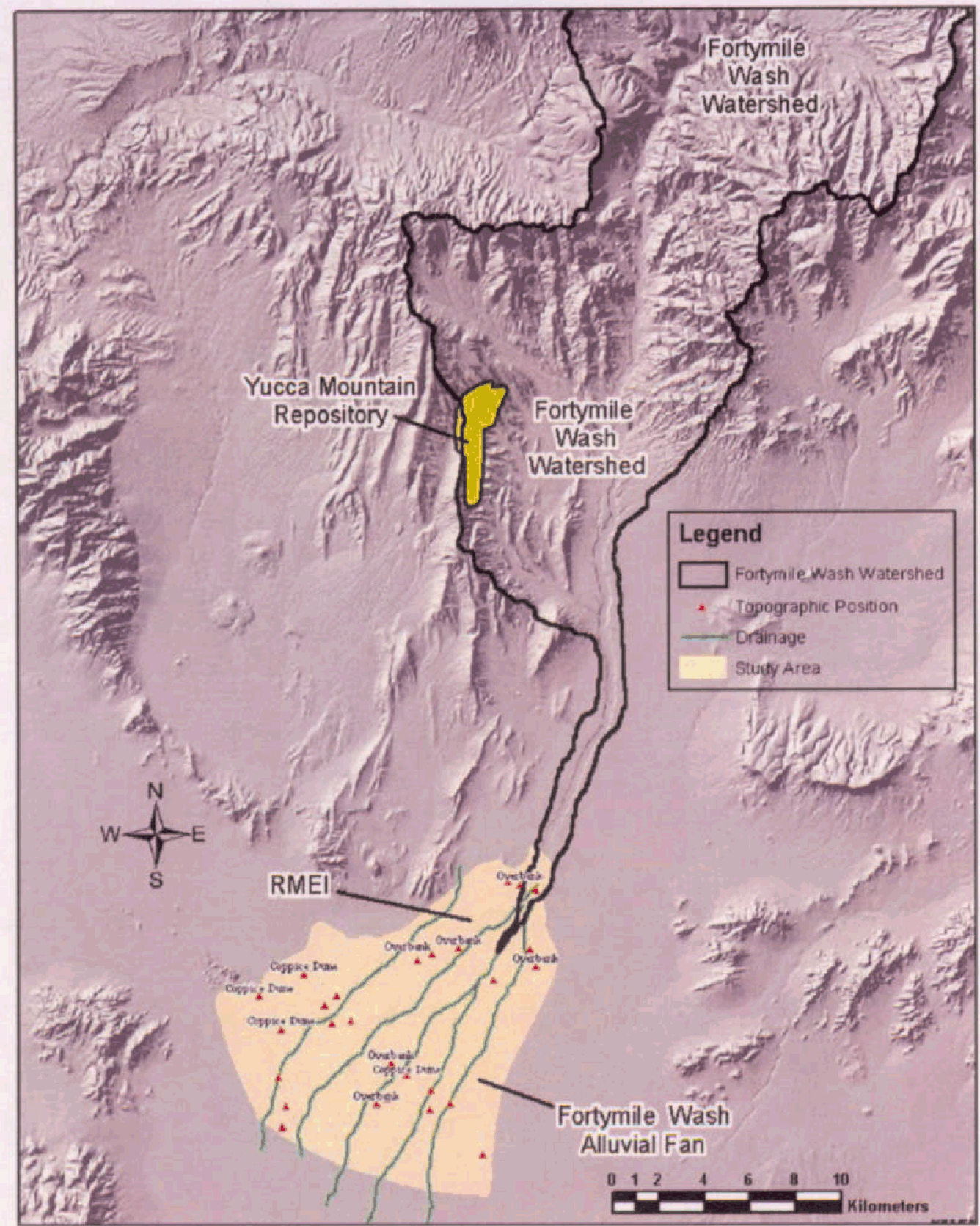

For illustration purposes only.

NOTE: The green-colored areas are distributary channels and equal 18 percent of the total fan area (Planimetered data from 1:100,000 topographic map). The tan areas are interchannel divides and equal 82 percent of the total fan area (Planimetered data measured from 1:100,000 topographic map). The triangles in the diagram are locations of overbank deposits and coppice dunes that form along the channels on the alluvial fan.

Areal weights are calculated in Harrington (2004 [DIRS 171345], p. 77). The portion of the Fortymile Wash watershed upstream of the repository is approximately eight times the area downstream of the repository site.

Figure 6-2. Fortymile Wash Watershed 
Tephra-sheet orientations that correspond with the approximate sector of winds from north easterly to southerly either eliminate ash from reaching the RMEI location or reduce the volume of ash available for redistribution to the RMEI location. It is therefore conservative to force such results to correspond with Outcome 2 if they do not satisfy the criterion of Outcome 1.

For Outcome 1, the initial condition of ground surface ash deposition (at the RMEI location) corresponds to the values calculated by Ashplume and executed by the TSPA GoldSim model. For Outcome 2, the initial conditions at the RMEI location include a transport of ash from the upstream Fortymile Wash basin. In this case the initial conditions are numerically expressed for TSPA, but based on assumption. Assumed initial conditions in Outcome 1 also account for the possibility of a hybrid outcome in which significant ash is deposited at both the RMEI location and in the near portions of Fortymile Wash.

For time steps after the initial condition, the conceptual ash redistribution model estimates the erosion, transport, and redeposition of contaminated ash. Based on local field data (BSC 2004 [DIRS 169980], Section 6.3.4), the model applies a set of parameters that captures the effects of erosion of the initial deposit, mixing and sorting during transport, and the eventual redeposition at the RMEI location (see Section 6.7.2). Since the RMEI location is on the upper delta of the Fortymile Wash alluvial fan (Figure 6-2), the conceptual ash redistribution model parametrically differentiates between alluvial fan channels and interchannel divides.

The outputs of this model are treated as an abstraction for the TSPA-LA model for the purpose of combining with BDCFs to calculate the dose at the RMEI location.

\subsection{CONSIDERATION OF ALTERNATIVE CONCEPTUAL MODELS}

The consideration of alternative conceptual models for each of the two models documented in this report is described in Sections 6.4.1 and 6.4.2. Note that the ash redistribution conceptual model is the first of its kind.

\subsubsection{Consideration of Alternative Conceptual Models for Airborne Transport of Tephra}

Several alternative conceptual models were considered to evaluate the violent Strombolian eruption and transport of the ash/waste mixture. The qualitative evaluations conducted are summarized in the following discussions.

\subsubsection{Gaussian-Plume Model}

Methods used previously to estimate radionuclide dispersal by volcanism (Wescott et al. 1995 [DIRS 100476]) theorize that the ash cloud travels as a Gaussian plume, released at a stack height one half the volcanic column height. Application of the Gaussian-plume model presumes that a plume of contaminants travels in the same direction as the prevailing wind ( $x$-direction) but may be somewhat depressed toward the Earth's surface due to gravitational settling. Contaminant concentration in the plume follows a Gaussian distribution in the dimensions perpendicular to the direction of travel ( $y$ - and $z$-directions).

The Gaussian-plume model does not accurately account for the effects of gravitational settling of volcanic particles with large diameters (i.e., centimeters). This shortcoming could lead to 
predictions of a higher upper limit on the particle-size range for particles dispersed a significant distance downwind than would be the case in reality. The increased particle size would result in the distribution of a larger amount of waste farther downwind than would normally be expected after a basaltic eruption. Based on these factors, the Gaussian-plume alternative conceptual model is excluded from further evaluation because the model does not adequately portray a volcanic eruption column and is not conservative in the distribution of contaminated ash.

\subsubsection{PUFF}

PUFF (Searcy et al. 1998 [DIRS 101015]) was evaluated conceptually based on descriptions in the scientific literature. The PUFF model was developed primarily to predict airborne distribution of ash plumes to aid aircraft navigation near volcanic eruptions. The PUFF conceptual model does not include incorporation of contaminated particles with the ash plume or calculate ground-level concentrations of ash resulting from settling. The PUFF model was excluded from further evaluation because of these limitations.

\subsubsection{Gas-Thrust Code}

Another alternative conceptual model considered was the gas-thrust code that was proposed in the NRC's Igneous Activity Issue Resolution Status Report (Reamer 1999 [DIRS 119693], Section 4.2.2.3). Use of the code would require either the development of an atmospheric transport and deposition model to couple to the gas-thrust code or a code would have to be developed to retrofit the gas-thrust code to an existing atmospheric transport model. The ash-dispersion controlling constant (beta) within the ASHPLUME code has an analogous effect to the gas-thrust code. The parameter beta has the effect of generating a vertical distribution of particles above the volcano. The gas-thrust code is a variation on this concept and falls within the uncertainties associated with the input parameter values used in forming the beta distribution. The gas-thrust alternative conceptual model was excluded from further evaluation because the ASHPLUME code, without modification, uses input parameters that incorporate the vertical distribution of particles above a volcano.

\subsubsection{Alternative Igneous Source Term Model}

The Alternative Igneous Source Term model was developed by Codell (2003 [DIRS 165503]) as an extension of Ashplume to investigate the processes of waste fragmentation and incorporation into the tephra. Despite an in-depth review of thermal, chemical, and physical processes of waste degradation in the presence of magma, there are no reliable means to predict the grain size of incorporated waste, and Codell concludes that one should assume that all waste from damaged waste packages is incorporated homogeneously into the magma/pyroclast medium as a fine-grained material. Codell's (2003 [DIRS 165503]) main improvement over Ashplume is the addition of a complex model for the mixing of ash and fuel particles. While Ashplume uses a fixed incorporation ratio to specify the mixing of fuel and ash by particle size, Codell's (2003 [DIRS 165503]) alternative model allows for a range of fuel concentrations on a given ash particle, following the rule that the fraction of mass of fuel incorporated into ash is proportional to the mass of the ash. To accomplish this, the alternative conceptual model bins the ash-particle-size distribution, develops symbolic "indicator particles" to represent the mass of ash in each bin, and then distributes the available mass of fuel to those indicator particles 
according to a probability function. Therefore, Codell's (2003 [DIRS 165503]) particles range much more widely in density than those used in the current Ashplume model, which produces the possible existence of dense particles that would fall out of the column sooner than is predicted by the current model. However, Codell (2003 [DIRS 165503]) found that the difference in results between Ashplume and the alternative conceptual model was, on average, within a factor of two for fuel concentration and that Ashplume typically predicts higher concentrations, and is, therefore, more conservative. Codell (2003 [DIRS 165503]) concludes that given other, larger, uncertainties in modeling volcanism, Ashplume is credible.

In summary, this alternative model explores aspects of waste incorporation into the magma and ash beyond the scope of previous work. However, despite the detailed analysis of concepts of waste/magma mixing and a complex approach to the mixing of waste and ash particles, the resulting predictions of waste concentration on the ground are not significantly different from the current model and may, therefore, be excluded from consideration.

\subsubsection{Consideration of Alternative Conceptual Model for Ash Redistribution}

The ash redistribution conceptual model is based on observations and laboratory data from field work in Fortymile Wash, on the Fortymile Wash alluvial fan, and from drainages near the Lathrop Wells cone. Specifically, the ash redistribution conceptual model is based on erosion rate data, soil profile data, and surficial processes information collected in the Yucca Mountain area, including sample locations in Fortymile Wash and surrounding the Lathrop Wells cone. The documentation of this ash redistribution conceptual model is the first of its kind. The simplified representation of redistribution and erosion in this model is shown to result in conservatism due to multiple-accounting of waste mass. For this reason, an alternative numerical model is presented in Appendix I, and is proposed for post TSPA-LA usage.

\subsubsection{Summary of Alternative Conceptual Models}

Table 6-2 summarizes the alternative conceptual models considered for use to evaluate the volcanic direct release scenario and the screening status of the alternative models. Based on the screening of the alternative conceptual models considered, the Ashplume model was determined to be the most appropriate model for use in TSPA-LA calculations of atmospheric dispersal and deposition of tephra due to a volcanic eruption through the repository. The Ashplume model was specifically chosen because it incorporates both the ash dispersal and waste incorporation mechanisms required for the TSPA-LA analysis of ash/waste deposition, redistribution, and dose to man. The alternative conceptual models considered in Table 6-2 do not provide the full functionality required for the TSPA-LA analysis.

Development of the ash redistribution conceptual model is based on analog data from sites at and near Yucca Mountain. The documentation of this model is the first of its kind; therefore, no alternative conceptual models have been identified. 
Table 6-2. Alternative Conceptual Models Considered for Airborne Transport of Tephra

\begin{tabular}{|l|l|l|}
\hline $\begin{array}{c}\text { Alternative } \\
\text { Conceptual Model }\end{array}$ & \multicolumn{1}{|c|}{ Key Assumptions } & \multicolumn{1}{c|}{ Screening Assessment and Basis } \\
\hline Gaussian Plume & $\begin{array}{l}\text { Point source, Gaussian distribution of } \\
\text { plume }\end{array}$ & $\begin{array}{l}\text { Excluded-larger particles are not accurately } \\
\text { accounted for in gravitational settling. }\end{array}$ \\
\hline PUFF & $\begin{array}{l}\text { Convection and dispersion of ash from a } \\
\text { volcanic eruption }\end{array}$ & $\begin{array}{l}\text { Excluded-model still in development, waste-fuel } \\
\text { interaction not included, surface concentrations } \\
\text { not available. }\end{array}$ \\
\hline Gas-Thrust & Buoyancy of a vertical erupting column & $\begin{array}{l}\text { Excluded-atmospheric transport not available, } \\
\text { surface concentrations of waste and ash not } \\
\text { available. }\end{array}$ \\
\hline $\begin{array}{l}\text { Alternative Igneous } \\
\text { Source Term }\end{array}$ & $\begin{array}{l}\text { Ashplume plus probability model for size } \\
\text { of waste particles mixing with a given ash } \\
\text { particle }\end{array}$ & $\begin{array}{l}\text { Excluded-results of alternative conceptual } \\
\text { model not significantly different from those of } \\
\text { Ashplume. }\end{array}$ \\
\hline
\end{tabular}

\subsection{ASH DISPERSAL CONCEPTUAL MODEL DESCRIPTION}

The model of atmospheric dispersal and deposition of tephra used in the TSPA-LA and implemented with the Ashplume mathematical model is based on a theoretical model for the dispersion of tephra developed by Suzuki (1983 [DIRS 100489]). Jarzemba et al. (1997 [DIRS 100987]) extended the mathematical model to include the incorporation of waste-fuel particles with tephra particles. This section presents the mathematical formulation of the Suzuki/Jarzemba dispersion model and discusses model inputs developed for use in the TSPA-LA.

\subsubsection{Mathematical Description of the Base-Case Conceptual Model}

The movement of air mass in the atmosphere is relatively random within the scale of eddy motions in wind currents (Suzuki 1983 [DIRS 100489]). Therefore, the dispersion of the ash-waste particles in the atmosphere is treated as random. Particles disperse in the atmosphere in both vertical and horizontal directions. However, the scale of horizontal turbulence is much greater than the scale of vertical turbulence (Suzuki 1983 [DIRS 100489]). Therefore, in the Suzuki (1983 [DIRS 100489]) development of the mathematical model, particle diffusion is considered to be 2-D in the horizontal $x-y$ plane. Particle movement in the third (vertical) direction is accounted for by settling velocity in the Suzuki model.

The underlying 2-D partial differential equation relating the change in concentration, $\partial \xi$, at a point $\mathrm{x}-\mathrm{y}$ (with $\mathrm{x}$ downwind) to wind velocity, $\mathrm{u}$, and an eddy diffusivity constant, $\mathrm{K}$, follows (Suzuki 1983 [DIRS 100489]):

$$
\frac{\partial \xi}{\partial t}=-u \frac{\partial \xi}{\partial x}+\frac{\partial}{\partial x}\left(K \frac{\partial \xi}{\partial x}\right)+\frac{\partial}{\partial y}\left(K \frac{\partial \xi}{\partial y}\right)
$$

By selecting an appropriate value for the diffusivity constant $\mathrm{K}$, Equation 6-1 is appropriate for estimating the 2-D diffusion of particulate matter in the atmosphere downwind from a source of contamination. Because the $\mathrm{x}$ direction is assumed to be aligned with the wind, the $\mathrm{y}$ component of the convective term in Equation 6-1 is zero. 
Suzuki (1983 [DIRS 100489]) developed the mathematical model shown in Equation 6-1 for application to atmospheric dispersal of tephra by applying source conditions and settling velocities suitable for explosive volcanic eruptions that are unlikely, but possible, in the YMR and termed violent Strombolian. Jarzemba et al. (1997 [DIRS 100987]) further developed the model to calculate the concentration of spent-fuel waste particles that become incorporated with ash particles in the case of a hypothetical volcanic eruption through the Yucca Mountain repository. A summary of the mathematical development in Suzuki (1983 [DIRS 100489]) and Jarzemba et al. (1997 [DIRS 100987]) of the ash-waste dispersal model follows.

To derive a solution to Equation 6-1 suitable for application to calculation of tephra dispersion in the atmosphere after a volcanic eruption, Suzuki (1983 [DIRS 100489]) used the following boundary and initial conditions.

- Erupted material (the source boundary) consists of a finite mass of volcanic ash particles contaminated with waste particles.

- The source of tephra particles is described by the distribution of the diameter of the released particles, and the distribution has a single mode.

- Combined ash/waste particles have a probability to diffuse out of the eruption column during upward travel in the column as well as during transport of the plume downwind.

- All particles fall at the terminal velocity and finally accumulate on the ground.

The solution to the mathematical model described in Equation 6-1 is provided by Suzuki (1983 [DIRS 100489]) and can be summarized by the following equation that describes the areal density of accumulated ash on the Earth's surface after an eruption:

$$
X(x, y)=\int_{\rho=\rho_{\min }}^{\rho_{\max }} \int_{z=0}^{H} \frac{5 Q p(z) f(\rho)}{8 \pi C\left(t+t_{s}\right)^{5 / 2}} \exp \left[\frac{-5\left\{(x-u t)^{2}+y^{2}\right\}}{8 C\left(t+t_{s}\right)^{5 / 2}}\right] d z d \rho
$$

where

$X(x, y)=$ mass of ash per unit area accumulated at location $(x, y)$ in $\mathrm{g} / \mathrm{cm}^{2}$

$\rho=$ common logarithm of particle diameter $d$, where $d$ is in $\mathrm{cm}$

$\rho_{\min }=$ minimum value of $\rho$

$\rho_{\max }=$ maximum value of $\rho$

$z \quad=$ vertical distance of particle from ground surface in $\mathrm{km}$

$H \quad=$ height of eruption column above vent in $\mathrm{km}$

$x=x$ coordinate on the surface of the Earth oriented in the same direction as the prevailing wind in $\mathrm{cm}$

$y=y$ coordinate on the surface of the Earth, oriented perpendicular to the direction of the prevailing wind in $\mathrm{cm}$ 
$Q \quad=$ total quantity of erupted material in $\mathrm{g}$

$p(z)=$ distribution function for particle diffusion out of the column within $\pm \mathrm{d} z$ of height $z$

$f(\rho)=$ distribution function for $\log$-diameter of particles within $\pm \mathrm{d} \rho$ of $\rho$ normalized per unit mass

$C=$ constant relating eddy diffusivity and particle fall time in $\mathrm{cm}^{2} / \mathrm{s}^{5 / 2}$

$t \quad=$ particle fall time in $\mathrm{s}$

$t_{s} \quad=$ particle diffusion time in eruption column in $\mathrm{s}$

$u \quad=$ wind speed in $\mathrm{cm} / \mathrm{s}$.

The probability density distribution function for particle diffusion out of the eruption column $p(z)$ is given by (Suzuki 1983 [DIRS 100489]):

$$
p(z)=\frac{\beta W_{0} Y e^{-Y}}{V_{0} H\left\{1-\left(1+Y_{0}\right) e^{-Y_{0}}\right\}}
$$

where

$$
\begin{aligned}
& Y=\frac{\beta W(z)}{V_{0}} \\
& Y_{0}=\frac{\beta W_{0}}{V_{0}} \\
& \beta \quad=\text { a constant controlling diffusion of particles in the eruption column (dimensionless) } \\
& W_{0} \quad=\text { initial particle rise velocity in } \mathrm{cm} / \mathrm{s} \text {, that represents initial rise velocity of the } \\
& \text { convective part of the plume. } \\
& V_{0}=\text { particle terminal velocity at mean sea level in } \mathrm{cm} / \mathrm{s} \\
& W(z)=\text { particle velocity as a function of height }=W_{0}\left(1-\frac{z}{H}\right) \text { in } \mathrm{cm} / \mathrm{s} \text {. }
\end{aligned}
$$

According to Jarzemba et al. (1997 [DIRS 100987]), the definitions of $Y$ and $Y_{0}$ differ from those found in Suzuki (1983 [DIRS 100489]), that is, $Y=\frac{\beta\left(W(z)-V_{0}\right)}{V_{0}}$ and $Y_{0}=\frac{\beta\left(W_{0}-V_{0}\right)}{V_{0}}$, for two reasons:

- The definitions in Suzuki (1983 [DIRS 100489]) lead to negative values of $p(z)$ at heights approaching the top of the column

- $p(z)$ (Equation 6-3) integrated over all column heights does not equal one using the definitions of $Y$ and $Y_{0}$ found in Suzuki (1983 [DIRS 100489]). 
The particle terminal velocity at mean sea level is given by (Suzuki 1983 [DIRS 100489]):

$$
V_{0}=\frac{\psi_{p} g_{c} d^{2}}{9 \eta_{a} F^{-0.32}+\sqrt{81 \eta_{a}^{2} F^{-0.64}+\frac{3}{2} \psi_{p} \psi_{a} g_{c} d^{3} \sqrt{1.07-F}}}
$$

where

$\Psi_{a}, \Psi_{p}=$ density of air and of particles, respectively in $\mathrm{g} / \mathrm{cm}^{3}$

$g_{c}=$ gravitational acceleration constant $=980 \mathrm{~cm} / \mathrm{s}^{2}$

$\eta_{\mathrm{a}}=$ dynamic viscosity of air in $\mathrm{g} /(\mathrm{cm} \cdot \mathrm{s})$

$F=$ shape factor for particles-for an elliptically shaped particle with principal axes $a$, $b$, and $c, F=(b+c) / 2 a$, where $a$ is the longest axis

$d \quad=$ mean particle diameter in $\mathrm{cm}$.

Jarzemba et al. (1997 [DIRS 100987]) define particle density, $\Psi_{p}$ in $\mathrm{g} / \mathrm{cm}^{3}$, to be a function of the particle log-diameter, $\rho_{a}$ in $\mathrm{cm}$, as follows:

$$
\begin{array}{cl}
\Psi_{p}=\Psi_{p}^{\text {high }} & \text { for } \rho_{a}<\rho_{a}^{\text {low }} \\
\Psi_{p}=\Psi_{p}^{\text {low }}+\left(\Psi_{p}^{\text {high }}-\Psi_{p}^{\text {low }}\right)\left(\rho_{a}^{\text {high }}-\rho_{a}\right) /\left(\rho_{a}^{\text {high }}-\rho_{a}^{\text {low }}\right) & \text { for } \rho_{a}^{\text {low }}<\rho_{a}<\rho_{a}^{\text {high }} \\
\Psi_{p}=\Psi_{p}^{\text {low }} & \text { for } \rho_{a}>\rho_{a}^{\text {high }}
\end{array}
$$

where $\Psi_{p}^{\text {high }}, \Psi_{p}^{\text {low }}, \rho_{a}^{\text {high }}$, and $\rho_{a}^{\text {low }}$ are defined by user inputs.

The particle fall time (in s) is given by (Suzuki 1983 [DIRS 100489]):

$$
t=0.752 \times 10^{6}\left[\frac{1-e^{-0.0625 z}}{V_{0}}\right]^{0.926}
$$

For a detailed derivation of Equations 6-2 through 6-6, the reader is referred to Suzuki (1983 [DIRS 100489]).

The height of the eruption column or plume, $H$, used in Equation 6-2, follows buoyant plume theory applied to volcanic eruptions by Wilson et al. (1978 [DIRS 162859]) and discussed in Jarzemba et al. (1997 [DIRS 100987]). In Ashplume, height in $\mathrm{km}$ is given as:

$$
H=0.0082 P^{0.25}
$$

where the eruption column power, $P$, in watts, is determined by the eruption mass flux and heat content:

$$
P=\dot{Q}\left(C_{p} \Delta T E\right)
$$


The parameters in parentheses in Equation 6-7b represent the heat content and its efficiency in adding buoyancy; they are fixed by magma and tephra characteristics. The mass flux, $\dot{Q}$, can be evaluated by assuming a constant eruptive mass flux over the duration of the eruption, which is related to the erupted ash settled volume by equation $6-7 \mathrm{c}$ in which the transformation, for purposes of power calculation, neglects the smaller mass and heat contribution from gas.

$$
\dot{Q}=\frac{Q}{T_{d}}=\frac{V \psi_{s}}{T_{d}}=\psi_{m} W_{0} \pi\left(\frac{d_{c}}{2}\right)^{2}
$$

where

$$
\begin{aligned}
& C_{p}=\text { heat capacity of magma }(\mathrm{J} / \mathrm{kgK}) \\
& \Delta T=\text { temperature difference between magma and ambient }\left({ }^{\circ} \mathrm{C}\right) \\
& E=\text { efficiency factor of heat usage }(1.0 \text { for Equation } 6-7 \mathrm{~b}) \\
& Q=\text { total mass of erupted material }(\mathrm{kg}) \\
& V=\text { ash erupted volume }\left(\mathrm{m}^{3}\right) \\
& T_{d}=\text { eruption duration }(\mathrm{s}) \\
& \psi_{s}=\text { ash settled density }\left(\mathrm{kg} / \mathrm{m}^{3}\right) \\
& \psi_{m}=\text { bulk density of erupting magma and gas mixture }\left(\mathrm{kg} / \mathrm{m}^{3}\right) \\
& W_{0}=\text { initial particle rise velocity }(\mathrm{m} / \mathrm{s}) \\
& d_{c}=\text { effective conduit (vent) diameter }(\mathrm{m}) .
\end{aligned}
$$

Note that the units listed above are for Eq. 6-7a through Eq. 6-7c only. The Ashplume model input parameters of initial rise velocity, power, and duration are linked in Equations 6-7b and 6-7c and determine the plume height in Equation 6-7a; velocity also contributes to the probability density distribution function (Equation 6-3). Accordingly, the basis for selecting these parameters is further discussed in Section 6.5.2. The value for the efficiency factor $(E)$ is assumed to be 1.0 in this analysis, given the uncertainties in values for $C_{p}$ and $\Delta T$ (Heiken et al. 2003 [DIRS 166290], pp. 41 to 42). As already noted, the calculation neglects the mass and thermal content of gas in the plume.

In the Suzuki mathematical model (Suzuki 1983 [DIRS 100489]), the volcanic ash mass is distributed log-normally with particle size:

$$
f\left(\rho^{a}\right)=\frac{1}{\sqrt{2 \pi} \sigma_{d}} \exp \left[-\frac{\left(\rho^{a}-\rho_{\text {mean }}^{a}\right)^{2}}{2 \sigma_{d}^{2}}\right]
$$

where

$$
\begin{array}{ll}
f\left(\rho^{a}\right) & =\text { normalized (per unit mass) probability distribution for log diameter of ash } \\
\rho^{a} & =\text { log-diameter of ash particle size, with particle size in } \mathrm{cm} \\
\rho_{\text {mean }}^{a} & =\text { mean of log-diameter of ash particle size, with particle size in } \mathrm{cm} \\
\sigma_{d} & =\text { standard deviation of log particle size. }
\end{array}
$$


The TSPA analyses for Yucca Mountain require a prediction of spent fuel per unit area on the ground surface as a function of location relative to the volcanic vent (i.e., relative to the repository) after a hypothetical eruption through the repository. It is assumed (Section 5.1.3) that the transport mechanism for waste fuel particles is by attachment to ash particles larger than a certain relative size represented by an incorporation ratio.

The rationale for limiting the amount of fuel mass available for incorporation into a volcanic-ash particle of a given size is that for smaller volcanic-ash particles, an amount of fuel mass will be too large to be incorporated into these small particles. For example, it is unlikely that a $1-\mathrm{cm}$ fuel particle could be incorporated into a $0.5-\mathrm{cm}$ volcanic ash particle. Assuming a cutoff on the ratio of incorporable fuel diameter to volcanic ash diameter of 1:10 is equivalent to assuming an incorporation ratio $\left(\rho_{\mathrm{c}}\right)$ of 1. Mathematically, the incorporation ratio is defined as (Jarzemba et al. 1997 [DIRS 100987]):

$$
\rho_{c}=\log _{10}\left[\frac{d_{\min }^{a}}{d^{f}}\right]
$$

where

$$
\begin{aligned}
& d_{\min }^{a}=\text { minimum ash particle size needed for incorporation in } \mathrm{cm} \\
& d^{f}=\text { fuel particle size in } \mathrm{cm} .
\end{aligned}
$$

Setting the incorporation ratio, $\rho_{c}$ equal to 0.3 , is roughly equivalent to allowing all fuel mass of size less than or equal to one-half of the volcanic-ash particle size to be available for incorporation.

Fuel mass is defined in Jarzemba et al. (1997 [DIRS 100987]) as following a log-triangular distribution function of the log-diameter of fuel particles (specifically, a log-triangular distribution for fuel mass within $\pm \mathrm{d} \rho$ of $\rho^{f}$ normalized per unit mass). The log-triangular distribution is defined in Equation 6-10. It should be noted that an error in the Jarzemba et al. (1997 [DIRS 100987]) presentation of the fuel particle size log-triangular distribution has been corrected here in Equation 6-10 by reversing the sign on the coefficient $k_{2}$.

$$
\begin{array}{rlrl}
m\left(\rho^{f}\right) & =k_{1}\left(\rho^{f}-\rho_{\min }^{f}\right) & \text { for } \rho_{\min }^{f}<\rho^{f} \leq \rho_{\operatorname{mode}}^{f} & \\
& =k_{1}\left(\rho_{\bmod e}^{f}-\rho_{\min }^{f}\right)-k_{2}\left(\rho^{f}-\rho_{\bmod e}^{f}\right) & \text { for } \rho_{\operatorname{mode}}^{f}<\rho^{f} \leq \rho_{\max }^{f} \text { (Eq. 6-10) } \\
& =0 & \text { otherwise }
\end{array}
$$

where

$m\left(\rho^{f}\right)=$ log-triangular distribution of fuel particle size

$\rho^{f}=$ log-diameter of fuel particle size, with particle size in $\mathrm{cm}$ 


$$
\begin{aligned}
& k_{1}=\frac{2}{\left(\rho_{\max }^{f}-\rho_{\min }^{f}\right)\left(\rho_{\operatorname{mode}}^{f}-\rho_{\min }^{f}\right)} \\
& k_{2}=\frac{2}{\left(\rho_{\max }^{f}-\rho_{\min }^{f}\right)\left(\rho_{\max }^{f}-\rho_{\operatorname{mode}}^{f}\right)} \\
& \rho_{\min }^{f}=\text { minimum log-diameter of fuel particle size, with particle size in } \mathrm{cm} \\
& \rho_{\max }^{f}=\text { maximum log-diameter of fuel particle size, with particle size in } \mathrm{cm} \\
& \rho_{\text {mode }}^{f}=\text { mode log-diameter of fuel particle size, with particle size in } \mathrm{cm} .
\end{aligned}
$$

Jarzemba et al. (1997 [DIRS 100987]) determined the fuel fraction (ratio of fuel mass to ash mass) as a function of $\rho^{\mathrm{a}}$ by considering that all fuel particles of size smaller than $\left(\rho^{a}-\rho_{c}\right)$ have the ability to be incorporated simultaneously into volcanic-ash particles of size $\rho^{\mathrm{a}}$ or larger. The fuel fraction as a function of $\rho^{\mathrm{a}}$ is determined by summing all the incremental contributions of fuel mass to the volcanic ash mass from fuel sizes smaller than $\left(\rho^{a}-\rho_{c}\right)$. An expression for the fuel fraction is given as

$$
F F\left(\rho^{a}\right)=\frac{U}{Q} \cdot \int_{\rho=-\infty}^{\rho=\rho^{a}} \frac{m\left(\rho-\rho_{c}\right)}{1-F(\rho)} d \rho
$$

where

$$
\begin{array}{ll}
Q & =\text { the total mass of ash ejected in the event in } \mathrm{g} \\
U & =\text { total mass of fuel ejected in the event in } \mathrm{g} \\
m & =\text { probability density function of fuel particle size } \\
F\left(\rho^{a}\right) & =\text { cumulative distribution of } f\left(\rho^{a}\right) .
\end{array}
$$

Equation 6-11 assumes the resulting contaminated particles follow the same size distribution as the original volcanic ash particles. This assumption seems reasonable because the total mass of volcanic ash erupted will be much greater than the total mass of fuel available for incorporation. Introduction of a relatively small amount of fuel mass into the ash mass is unlikely to alter the size distribution of the ash. The mathematical and computational models do, however, adjust the density of ash particles to account for the incorporation of fuel. The particle density used in the calculation of the terminal velocity of a particle is adjusted as a combined particle in the dispersion calculation. The combined-particle density is adjusted by a statement in the ASHPLUME code: ashden $=$ ashden $\times[1+$ fuel fraction $]$. In this statement, "ashden" represents the ash particle density and "fuel fraction" represents the mass fraction of fuel in the combined particle. The integrand of Equation 6-2 is multiplied by $F F\left(\rho^{a}\right)$ and then recalculated to find the spent fuel density at the $(x, y)$ location. 


\subsubsection{Core Model Inputs}

The values for input parameters to Ashplume are developed from observed, or primary, data from analog volcanoes. This development is based on the approach outlined in BSC 2004 [DIRS 169980], Section 6.3.3.4, but it has been altered to meet the needs of this model abstraction. Self-consistent relationships among eruptive duration, eruptive volume, and vent radius are used in Equation 6-7c to derive values for initial rise velocity and mass flux (see Section 5.2.5 for further discussion). Mass flux is in turn used to derive eruptive power (a primary model input) in Equation 6-7b. Finally, eruptive height, calculated from power, is used to define the atmospheric height bin from which wind speed and direction are sampled. While values for mass flux (or power) and initial eruptive velocity could be chosen from published values, the model is kept self-consistent by the use of appropriate ranges in primary data for the YMR (e.g., eruptive volume, eruptive duration, and vent radius) developed in Characterize Eruptive Processes at Yucca Mountain, Nevada (BSC 2004 [DIRS 169980], Section 6.3.3). In addition, the relationships among the primary data provide upper and lower bounds on the distributions for derived input parameters (Heiken et al. 2003 [DIRS 166290]); for instance, the minimum mass flux is derived from the minimum erupted volume and the maximum eruption duration. These values, combined with reasonable material properties data (ash settled density, magma density, magma specific heat, and temperature difference) provide a firm link between the model performance and primary data. The ash settled density, which is the bulk density of the ash that settles on the ground after an eruption, is provided in DTN: LA0407DK831811.001 [DIRS 170768] as $1.0 \mathrm{~g} / \mathrm{cm}^{3}$. Magma density is also provided in DTN: LA0407DK831811.001 [DIRS 170768]. Note that while eruptive volume is not a direct input parameter for ASHPLUME V 2.0 (CRWMS M\&O 2001 [DIRS 152844]), it is used in the modeling process as one of the primary means to constrain the realism of the combinations of input parameters that define each modeled eruption (Sections 6.5.2.2, 8.2). Once the primary input parameter values have been developed (e.g., eruptive power and duration), they are used within the ASHPLUME code at run time to calculate values for column height (from power) and total mass of ash (from power and duration), among others, for use in transport calculations. Because these values are calculated using equivalent mathematical relationships, the results of the model are consistent with the primary data used to develop the input parameter values.

For the ASHPLUME_DLL_LA V2.0 computer code (BSC 2003 [DIRS 166571]) to calculate the concentration of ash and waste fuel on the ground surface according to Equation 6-2, parameter values must be provided for all of the unknown coefficients in the governing Equations 6-2 to 6-11 (Section 6.5.1). ASHPLUME_DLL_LA V2.0 allows parameters that are distributions to be sampled outside of the ASHPLUME code (within the TSPA-LA GoldSim model). GoldSim then passes the sampled point values for each parameter into the ASHPLUME_DLL_LA V2.0 code. Each realization simulates only one volcanic event at a time, and the single volcanic event in each realization represents the entire output of the volcano as one violent Strombolian eruption. The following sections discuss each of the parameters given in Table 6-3 in more detail and provide the technical basis for the parameter values and distributions. 
Table 6-3. Inputs for the Ashplume Model

\begin{tabular}{|c|c|c|c|}
\hline $\begin{array}{c}\text { Coefficient } \\
\text { (Equation Number) }\end{array}$ & Input Description & $\begin{array}{l}\text { Point Value or } \\
\text { Distribution }\end{array}$ & Data Source \\
\hline$x$ and $y$ (Eq. 6-2) & Determined by wind direction & $\begin{array}{l}\text { Wind direction is a } \\
\text { distribution }\end{array}$ & Based on location of the RMEI \\
\hline$\Psi_{p}^{\text {high }}($ Eq. 6-5) & $\begin{array}{l}\text { Ash particle density at } \\
\text { minimum particle size }\end{array}$ & Point value & $\begin{array}{l}\text { DTN: LA0407DK831811.001 } \\
\text { [DIRS 170768] }\end{array}$ \\
\hline$\Psi_{p}^{\text {low }}($ Eq. 6-) & $\begin{array}{l}\text { Ash particle density at } \\
\text { maximum particle size }\end{array}$ & Point value & $\begin{array}{l}\text { DTN: LA0407DK831811.001 } \\
\text { [DIRS 170768] }\end{array}$ \\
\hline$\rho_{\mathrm{a}}^{\text {high }}$ (Eq. 6- 5) & $\begin{array}{l}\text { Log ash particle size at } \\
\text { minimum ash density }\end{array}$ & Point value & $\begin{array}{l}\text { DTN: LA0407DK831811.001 } \\
\text { [DIRS 170768] }\end{array}$ \\
\hline$\rho_{a}^{\text {low }}(\mathrm{Eq} .6-5)$ & $\begin{array}{l}\text { Log ash particle size at } \\
\text { maximum ash density }\end{array}$ & Point value & $\begin{array}{l}\text { DTN: LA0407DK831811.001 } \\
\text { [DIRS 170768] }\end{array}$ \\
\hline$F$ (Eq. 6-4) & Ash particle shape factor & Point value & $\begin{array}{l}\text { DTN: LA0407DK831811.001 } \\
\text { [DIRS 170768] }\end{array}$ \\
\hline$\Psi_{\mathrm{a}}$ (Eq. 6- 4) & Air density & Point value & Lide 1994 [DIRS 147834] \\
\hline$\eta_{\mathrm{a}}($ Eq. 6-4) & Air viscosity & Point value & Lide 1994 [DIRS 147834] \\
\hline$C$ (Eq. 6-2) & Eddy diffusivity constant & Point value & $\begin{array}{l}\text { Calculated from information in } \\
\text { Suzuki } 1983 \text { [DIRS 100489] }\end{array}$ \\
\hline$d_{\max }$ & $\begin{array}{l}\text { Maximum particle diameter for } \\
\text { transport }\end{array}$ & Point value & $\begin{array}{l}\text { Jarzemba et al. (1997 } \\
\text { [DIRS 100987]) }\end{array}$ \\
\hline$\rho_{\min }^{f}$ (Eq. 6-10) & Minimum waste particle size & Point value & Appendix $\mathrm{H}$ \\
\hline$\rho_{\text {mode }}^{f}(\mathrm{Eq} \cdot 6-10)$ & Mode waste particle size & Point value & Appendix $H$, Section 6.5.2.16 \\
\hline$\rho_{\max }^{f}($ Eq. 6-10) & Maximum waste particle size & Point value & Appendix $\mathrm{H}$ \\
\hline$H_{\min }$ & $\begin{array}{l}\text { Minimum height of eruption } \\
\text { column }\end{array}$ & Point value & $\begin{array}{l}\text { Minimum practical value } \\
\text { (Section } 6.5 .3 .3 \text { ) }\end{array}$ \\
\hline Ash Cutoff & $\begin{array}{l}\text { Threshold limit on ash } \\
\text { accumulation }\end{array}$ & Point value & $\begin{array}{l}\text { Minimum practical value } \\
\text { (Section 6.5.3.4) }\end{array}$ \\
\hline$\beta$ (Eq. 6-3) & Column diffusion constant & Distribution & $\begin{array}{l}\text { Jarzemba et al. } 1997 \\
\text { [DIRS 100987] }\end{array}$ \\
\hline$d$ (Eq. 6-4) & Mean ash particle diameter & Distribution & $\begin{array}{l}\text { DTN: LA0407DK831811.001 } \\
\text { [DIRS 170768] }\end{array}$ \\
\hline$\sigma_{d}$ (Eq. 6-8) & $\begin{array}{l}\text { Ash particle diameter standard } \\
\text { deviation }\end{array}$ & Distribution & $\begin{array}{l}\text { DTN: LA0407DK831811.001 } \\
\text { [DIRS 170768] }\end{array}$ \\
\hline$\rho_{c}($ Eq. 6-9) & Waste incorporation ratio & Point value & $\begin{array}{l}\text { Jarzemba et al. } 1997 \\
\text { [DIRS 100987] }\end{array}$ \\
\hline$U$ (Eq. 6-11) & Mass of waste to incorporate & $\begin{array}{l}\text { Distribution } \\
\text { determined by TSPA } \\
\text { model }\end{array}$ & N/A \\
\hline Wind Direction & Wind direction & Distribution & NOAA 2004 [DIRS 171035] \\
\hline$u$ (Eq. 6-2) & Wind speed & Distribution & NOAA 2004 [DIRS 171035] \\
\hline$W_{o}$ (Eq. 6-3) & Initial rise velocity & Distribution & See Section 6.5.2.10 \\
\hline $\begin{array}{l}P \text { (Eqs. 7a and } \\
6-7 \mathrm{~b})\end{array}$ & Eruptive power & Distribution & See Section 6.5.2.1 \\
\hline$T_{d}$ & Eruption duration & Distribution & $\begin{array}{l}\text { DTN: LA0407DK831811.001 } \\
\text { [DIRS 170768] }\end{array}$ \\
\hline
\end{tabular}




\subsubsection{Eruptive Power, $P$}

Type: $\quad \log$-uniform distribution

Value: $\quad 6.17 \times 10^{8}-5 \times 10^{12}$

Units: watts

The range of eruptive power is a function of settled volumes and eruption duration as shown in Equations $6-7 \mathrm{~b}$ and $6-7 \mathrm{c}$. The heat capacity $(C p)$ used for magma is $1000 \mathrm{~J} /(\mathrm{kg} \cdot \mathrm{K})$ derived as a rounded value from Bacon (1977 [DIRS 165512], Figures 1 and 2) and Drury (1987 [DIRS 156447], Table 2). The range for the event eruptive volume to be expected in the YMR is defined in DTN: LA0407DK831811.001 [DIRS 170768] as $0.004-0.08 \mathrm{~km}^{3}$. The range of eruption duration is discussed below in Section 6.5.2.2. By converting the lowest volume to mass, using the settled density $\left(1.0 \mathrm{~g} / \mathrm{cm}^{3}\right.$; see Section 6.5 .2$)$, and dividing this mass by the longest duration to get eruptive mass flux, the lower limit of eruptive power is set by Equation 6-7b. In contrast, the upper limit of power is set to the value using the maximum mass flux recommendations of the Igneous Consequences Review Panel (Detournay et al. 2003 [DIRS 169660], p. 18). The mass and thermal energy of gas in the plume are neglected. This range in power is consistent with and slightly more conservative than the distribution for eruptive power developed in Jarzemba (1997 [DIRS 100460], Table 2).

\subsubsection{Eruption Duration, $T_{d}$}

Type: log-uniform distribution

Value $1.6 \times 10^{4}-6.48 \times 10^{6}$

Units seconds

The range of eruption durations and rationale for using this range of values is discussed in Characterize Eruptive Processes at Yucca Mountain, Nevada (BSC 2004 [DIRS 169980], Table 7-1; and DTN: LA0407DK831811.001 [DIRS 170768]). The range of values provided in that document spans 0.5 hour to 75 days $\left(1.8 \times 10^{3}\right.$ to $6.48 \times 10^{6}$ seconds) for the duration of a single explosive phase constituting a violent Strombolian eruptive phase, as observed at analogue volcanoes. This range has been revised for use in this model by decreasing the lower bound to 800 seconds, or 0.22 hours. This change was made for consistency among the eruption parameters (Section 6.5.2). Using Equations 6-7b and 6-7c, the minimum eruption duration is derived from the maximum power $\left(5 \times 10^{12} \mathrm{~W}\right)$ and the minimum erupted volume $\left(0.04 \mathrm{~km}^{3}\right)$. The difference between 0.5 hours and 0.22 hours represents a slight change in duration between the field characterization and the model abstraction, but it is considered negligible in light of the uncertainties in characterization of eruption parameters.

Eruption duration is used for two purposes, one during the development of input parameter values, and one within the ASHPLUME code during computation. The range in eruption duration is used to develop the upper and lower bounds for the distribution for mass flux and hence eruptive power, $\mathrm{P}$, using Equations 6-7b and 6-7c (Section 6.5.2); for example, minimum mass flux is a function of minimum volume and maximum duration, while maximum mass flux is derived from maximum volume and minimum duration. Eruption duration is used within ASHPLUME to calculate the total mass erupted, $Q$, for each realization. The actual limits on the range of eruption duration used in each TSPA model realization are established at run-time, 
determined by Equations 8-1a and 8-1b (Section 8.2) such that the total volume of the eruption remains within the bounds provided in DTN: LA0407DK831811.001 [DIRS 170768]. The primary considerations used to verify the realism of each TSPA model realization (Section 8.2) are eruptive power and eruptive volume, two parameters that well characterize the magnitude of violent Strombolian eruptions (BSC 2004 [DIRS 169980], Section 6.3.3.4). While the range of duration developed in a TSPA model realization for a given sampled value of power (Equations 8-1a, 8-1b) may range from about 0.22 hours to three years, the limits of total eruptive volume $\left(0.004\right.$ to $0.08 \mathrm{~km}^{3}$ (DTN: LA0407DK831811.001 [DIRS 170768])) are honored. These end members of the possible range of eruptive duration remain within the range of the duration for the formation of an entire volcano (DTN: LA0407DK831811.001 [DIRS 170768]).

\subsubsection{Column Diffusion Constant, $\beta$}

Type: uniform distribution

Value: $0.01-0.5$

Units: N/A

The column diffusion constant $(\beta)$ is set at a uniform distribution with a minimum value of 0.01 and a maximum value of 0.5 .

The column diffusion constant was discussed by Suzuki (1983 [DIRS 100489], pp. 104 to 107). This parameter affects the distribution of particles vertically in the ash column and helps determine where particles exit the column. The erupted ash cloud is assumed (by Suzuki) to spread axially a distance of half the height. Ashplume takes a beta value and determines the vertical profile of particle sizes in the erupted column that will then be transported down wind. Suzuki discussed beta values of $0.01,0.1$, and 0.5 . The larger beta becomes, the more the particle distribution becomes skewed towards the top of the column. Therefore, a value of 0.5 generates a column particle distribution that contains very few particles in the lower 70 percent of the column, whereas a beta value of 0.01 gives an upwardly decreasing distribution that contains the most particles lower in the column. The beta parameter, in effect, is related to the buoyancy of particles in the eruptive column and determines how high most particles will travel before exiting the column. Suzuki (1983 [DIRS 100489]) suggests that beta values of 0.5 or greater are possible but are not very likely to occur. Jarzemba et al. (1997 [DIRS 100987], p. 4-1) uses a log-uniform distribution for beta that has a minimum value of 0.01 and a maximum value of 0.5 . This range of values spans more than an order of magnitude and encompasses the range that is valid for the Ashplume model. However, in order to simulate the anvil cloud associated with a violent Strombolian eruption properly, samples from the range in beta should be focused toward the upper end of the range; therefore, a uniform (rather than log-uniform) distribution is recommended. 


\subsubsection{Mean Ash Particle Diameter, $d$}

Type: log-triangular distribution

Value: $\quad 0.001-0.01-0.1$

Units: $\mathrm{cm}$

The ash particle diameter is defined within the Ashplume model by two parameters: the mean ash particle diameter and the ash particle diameter standard deviation. The mean ash particle diameter for the volcanic eruption is defined in DTN: LA0407DK831811.001 [DIRS 170768], as a $\log$ triangular distribution with a minimum value of $0.001 \mathrm{~cm}$, a mode value of $0.01 \mathrm{~cm}$, and a maximum value $0.1 \mathrm{~cm}$. The rationale for using this range of mean ash particle diameter is discussed in Characterize Eruptive Processes at Yucca Mountain, Nevada (BSC 2004 [DIRS 169980] Sections 6.3.3 and Section 7.1). The lower end of the distribution is intended to capture the respirable fraction between $0.001 \mathrm{~cm}$ and $0.01 \mathrm{~cm}$ (BSC 2004 [DIRS 169980] Section 6.3.3). For comparison, Jarzemba (1997 [DIRS 100460], p. 137) gives a log-triangular distribution with a minimum of $0.01 \mathrm{~cm}$, a median of $0.1 \mathrm{~cm}$, and a maximum of $10 \mathrm{~cm}$. Although this upper range would account for the larger lapilli sizes and smaller blocks and bombs, these particles would fall on or near the cone and would not contribute much or any mass to the downwind tephra deposit, as is demonstrated by measurements of historic violent Strombolian eruptions (BSC 2004 [DIRS 169980], Table 6-6).

\subsubsection{Ash Particle Diameter Standard Deviation, $\sigma_{d}$}

Type: uniform distribution

Value: $1.3-1.9$

Units: $\quad \log (\mathrm{cm})$

The ash particle diameter standard deviation is discussed in Characterize Eruptive Processes at Yucca Mountain, Nevada (BSC 2004 [DIRS 169980], Section 6.3.5.2) and is derived from analog data. The referenced report (BSC 2004 [DIRS 169980], Table 7-1; and DTN: LA0407DK831811.001 [DIRS 170768]) suggests a uniform distribution from 1 to 3 phi units (phi units are defined to be the negative logarithm in base 2 of the particle diameter in millimeters). This range is equivalent to -1.9 to $-1.3 \log (\mathrm{cm})$, which are the units required by ASHPLUME_DLL_LA V 2.0 (BSC 2003 [DIRS 166571]). The ASHPLUME code requires that values for this parameter be positive, so the absolute value of the size range is used, 1.3 to $1.9 \log (\mathrm{cm})$.

\subsubsection{Waste Incorporation Ratio, $\rho_{c}$}

Type: point value

Value: 0.3

Units: $\quad \mathrm{N} / \mathrm{A}$

The incorporation ratio describes the ratio of ash/waste particle sizes that can be combined for transport. An incorporation ratio of 0.3 was used by Jarzemba et al. (1997 [DIRS 100987], Table 5-1) and is used here (see Section 6.5.1 for additional discussion). An incorporation ratio of 0.3 corresponds to a maximum incorporated waste particle size equal to half the diameter of 
the ash particle (i.e., any waste particles larger than half the ash particle diameter cannot be incorporated into the ash).

The waste mass is distributed among the ash mass based on relative particle sizes. The waste mass is not divided equally among the ash particles. Incorporation of waste particles requires ash particles of a certain size or larger. Thus, larger ash particles will carry more waste mass, and smaller ash particles will carry less or maybe even no waste mass.

\subsubsection{Wind Speed, $u$}

Type: empirical distribution

Value: Tables D-10 through D-22 (Appendix D)

Units: $\mathrm{cm} / \mathrm{s}$

Upper Air Data: Desert Rock, Nevada, 1978-1995 (NOAA 2004 [DIRS 171035]) provides wind speed data for the Desert Rock area for a 16-year period from 1978 to 1993 (see Appendix D). After converting height data to height above Yucca Mountain, data were grouped into 1-km increments from $0 \mathrm{~km}$ up to $13 \mathrm{~km}$. The wind speed data for each height interval were then used to calculate CDFs with bins set to $100 \mathrm{~cm} / \mathrm{s}$ intervals. Appendix D contains a detailed description of the steps required to develop the wind speed CDFs. Although Quiring (1968 [DIRS 119317]) provides wind speed data for the YMR for a seven-year period from 1957 to 1964, those data do not extend to sufficiently high altitudes to address fully the range of potential column heights that Ashplume considers; thus, the data from Desert Rock are more appropriate.

\subsubsection{Wind Direction, Determines $x$ and $y$}

Type: empirical distribution

Value: Tables D-23 through D-35 (Appendix D)

Units: Ashplume degrees

Upper Air Data: Desert Rock, Nevada, 1978-1995 (NOAA 2004 [DIRS 171035]) provides wind direction data for the Desert Rock area for a 16-year period from 1978 to 1993. After converting Desert Rock height data to height above Yucca Mountain, data were grouped into 1-km increments from $0 \mathrm{~km}$ up to $13 \mathrm{~km}$. The wind direction data for each height interval were then used to calculate PDFs and associated wind-rose diagrams, with bins set to 30 -degree intervals. Appendix D contains a detailed description of the steps required to develop the wind direction PDFs. Although Quiring (1968 [DIRS 119317]) provides wind speed data for the YMR for a seven-year period from 1957 to 1964 , those data do not extend to sufficiently high altitudes to address fully the range of potential column heights that Ashplume considers; thus, the data from Desert Rock are more appropriate.

\subsubsection{Mass of Waste Available for Incorporation, $U$}

Value: distribution will be passed to Ashplume; determined by the TSPA-LA model Units: grams

The mass of waste available for incorporation with ash particles is an input for the ASHPLUME V 2.0 code (CRWMS-M\&O 2001 [DIRS 152844]). However, this parameter is not developed 
within this model report. The waste mass depends upon factors such as waste inventory and the number of waste packages disturbed in a volcanic eruption (BSC 2002 [DIRS 170001]). These factors are defined elsewhere in the TSPA-LA model, and the resulting waste mass available is passed to ASHPLUME_DLL_LA V2.0 (BSC 2003 [DIRS 166571]) at run time.

\subsubsection{Initial Rise Velocity, $W_{o}$}

Type: log-uniform distribution

Value: $\quad 1.0-1.2 \times 10^{4}$

Units: $\quad \mathrm{cm} / \mathrm{s}$

Termed "the eruption velocity at the vent" for previous versions of ASHPLUME software, the initial rise velocity is assumed to be the minimum velocity required to provide the modeled power to the plume as described in Section 5.2.5. This velocity is a function of vent velocity. Although vent velocities are shown to be a function of magma volatile content in Characterize Eruptive Processes at Yucca Mountain, Nevada (BSC 2004 [DIRS 169980]), those velocities do not reflect the deceleration of the tephra particles that occurs before their entry into the plume, which must be assumed for application of the Ashplume model. Hence, this distribution must be calculated by Equations 6-7a through 6-7c, using maximum magma bulk density. This calculated distribution is solely a function of eruption power and conduit diameter: the former being a distribution specified in Section 6.5.2.1, and the latter enumerated in DTN: LA0407DK831811.001 [DIRS 170768] as ranging from 50 to $150 \mathrm{~m}$. As stated in Section 5.2.5, the importance of the initial rise velocity is to deliver the thermal mass (power) to the eruption column, and the velocity of the material entering the plume must only be that required to deliver the necessary power. Neglecting the gas-thrust part of the eruption column and given that the heat flux is directly proportional to the mass flux of magma to the vent, the simplest approach to developing the minimum initial rise velocity is to consider the minimum velocity of magma at the vent. This value can be derived from the minimum mass flux and maximum radius; given the ranges in these values (Heiken et al. 2003 [DIRS 166290], p. 41) and a magma density of $2.6 \mathrm{~g} / \mathrm{cm}^{3}$ (DTN: LA0407DK831811.001 [DIRS 170768]), the range in $\mathrm{W}_{0}$ is $0.001-12000 \mathrm{~cm} / \mathrm{s}$. Wilson and Head (1981 [DIRS 101034], p. 2977) report that the minimum practical value for rise speed of basalt in a $0.22-\mathrm{m}$-radius conduit is $0.12 \mathrm{~m} / \mathrm{s}$ $(12 \mathrm{~cm} / \mathrm{s})$; for a conduit in the range of tens of meters in radius (and for the same mass flux), this velocity could drop by an order of magnitude. The minimum value for $W_{0}$ has, therefore, been increased to $1.0 \mathrm{~cm} / \mathrm{s}$ to provide a realistic lower bound while providing appropriate velocity values that successfully deliver the thermal mass to the eruption column. This increase in $W_{0}$ implies that, for minimum mass flux, the maximum effective vent radius is about $27 \mathrm{~m}$, which is within the range of analogous conduit radii (DTN: LA0407DK831811.001 [DIRS 170768]).

\subsubsection{Ash Particle Density, $\Psi_{p}$}

Type: point values

Values: Table 8-2

Units: $\mathrm{g} / \mathrm{cm}^{3}$

The ash particle density used in Equation 6-4 is defined in Equation 6-5. The ash particle density is defined to be a function of particle diameter in Characterize Eruptive Processes at Yucca 
Mountain, Nevada (BSC 2004 [DIRS 169980], Section 6.3.3.6.2). The ASHPLUME_DLL_LA V2.0 (BSC 2003 [DIRS 166571]) code requires inputs for the densities of large and small ash particles. Characterize Eruptive Processes at Yucca Mountain, Nevada defines the densities of ash particles as a function of the magma density. This model report uses a magma density of $2.6 \mathrm{~g} / \mathrm{cm}^{3}$, which is within the range of magma densities reported in DTN: LA0407DK831811.001 [DIRS 170768]. DTN: LA0407DK831811.001 [DIRS 170768] defines the density of a $0.001-\mathrm{cm}$ ash particle to be 80 percent of the magma density $\left(2.08 \mathrm{~g} / \mathrm{cm}^{3}\right)$, whereas a $1.0-\mathrm{cm}$ ash particle has a density of 40 percent of the magma density $\left(1.04 \mathrm{~g} / \mathrm{cm}^{3}\right)$ as a result of the typically greater volume of voids (vesicles) in larger pyroclasts. ASHPLUME requires two sets of values to be entered related to the ash particle density, ash particle density at minimum and maximum particle size (described above) and log ash particle size at minimum and maximum ash density. The particle diameters for input to parameters $\rho_{\mathrm{a}}{ }^{\text {high }}$ and $\rho_{a}{ }^{\text {low }}$ must be entered as $\log$ values, that is, as $\log (\mathrm{cm})$.

\subsubsection{Ash Particle Shape Factor, $F$}

Type: point value

Value: 0.5

Units: N/A

The ash-particle shape factor is a parameter that is used to describe the shape of the ash particles being transported in the model. The shape factor is used in determining the settling velocity according to Equation 6-4. The shape factor $(F)$ is defined as $F=(b+c) / 2 a$, where $a$, $b$, and $c$ are the length of the longest, middle, and shortest axes of the particles. DTN: LA0407DK831811.001 [DIRS 170768] provides a particle shape factor of 0.5 . This parameter applies to the ash and does not apply to the waste. The waste is incorporated into ash particles in order to be transported downwind, and the Ashplume model treats all particles (ash and ash/waste combined) as having the same shape factor.

\subsubsection{Air Density, $\Psi$ a}

Type: point value

Value: 0.001117

Units: $\mathrm{g} / \mathrm{cm}^{3}$

The air density is used in calculating the particle-settling velocity in Equation 6-4. Because the density is nearly constant within the altitude range of interest, air density was selected as a point value (constant). The density was selected at an altitude of $1000 \mathrm{~m}$ above mean sea level and at ambient temperature of $25^{\circ} \mathrm{C}$. The value of $0.001117 \mathrm{~g} / \mathrm{cm} 3$ was taken from Lide (1994 [DIRS 147834]). 


\subsubsection{Air Dynamic Viscosity, $\eta_{a}$}

Type: point value

Value: 0.0001758

Units: $\mathrm{g} /(\mathrm{cm} \cdot \mathrm{s})$

The air viscosity is used in calculating the particle-settling velocity in Equation 6-4. Because the viscosity is nearly constant within the altitude range of interest, air viscosity was selected as a point value (constant). The viscosity was selected at an altitude of $1000 \mathrm{~m}$ above mean sea level and at ambient temperature of $25^{\circ} \mathrm{C}$. The value of $0.0001758 \mathrm{~g} / \mathrm{cm}-\mathrm{s}$ was taken from Lide (1994 [DIRS 147834]).

\subsubsection{Eddy Diffusivity Constant, $C$}

Type: point value

Value: 400

Units: $\quad \mathrm{cm}^{2} / \mathrm{s}^{5 / 2}$

The constant $(\mathrm{C})$ controlling eddy diffusivity relative to particle fall time was modeled by Suzuki (1983 [DIRS 100489], p. 99). The eddy diffusivity (K) of the particles is expressed by Suzuki as a function of the particle fall time, $\mathrm{K}=\mathrm{Ct}^{3 / 2}$, where $\mathrm{t}$ is the particle fall time. This relationship is based on turbulent particle diffusion and the simplification that the particle diffusion time equals the particle fall time (i.e., time to settle to the ground in seconds). The above relationship is obtained from Suzuki (1983 [DIRS 100489], p. 99) because eddy turbulent diffusion occurs over large-scale eddies and can, thus, be related to the particle fall times. The apparent eddy diffusivity $\left(A_{L}\right)$ of particles in the atmosphere is related to the scale of diffusion $(L)$ according to Suzuki (1983 [DIRS 100489], p. 99) by $A_{L}=0.08073 C^{2 / 5} \mathrm{~L}^{6 / 5}$ with $A_{L}$ given in $\mathrm{cm}^{2} / \mathrm{s}$ and $L$ in $\mathrm{cm}$. Suzuki (1983 [DIRS 100489], Figure 6-3) shows a linear relationship between $\log \left(\mathrm{A}_{\mathrm{L}}\right)$ and $\log (\mathrm{L})$ in the atmosphere; the correlation between $\mathrm{L}$ and $\mathrm{A}_{\mathrm{L}}$ is defined as $\mathrm{A}_{\mathrm{L}}=0.887 \mathrm{~L}^{6 / 5}$. Combining these equations yields a constant value for $\mathrm{C}$ of $400 \mathrm{~cm}^{2} / \mathrm{s}^{5 / 2}$, which is the value selected in this model report.

\subsubsection{Waste Particle Size (Minimum, Mode, Maximum)}

Type: point values

Values: 0.0001 minimum, 0.0016 mode, 0.05 maximum

Units: $\quad \mathrm{cm}$

Waste fuel mass is treated as a log-triangular distribution with particle size in the Ashplume model (Equation 6-10). The minimum, mode, and maximum values defining the distribution are fixed values in the TSPA analyses and are provided to the ASHPLUME_DLL_LA V2.0 (BSC 2003 [DIRS 166571]) code in units of $\mathrm{cm}$. The values are converted to $\log (\mathrm{cm})$ within the code. Assumptions providing the minimum (0.0001), mean (0.002), and maximum (0.05) particle diameter in centimeters are discussed in Section 5.2.4. Because ASHPLUME requires a mode value for the log-triangular distribution, the mean value of $0.002 \mathrm{~cm}$ (Section 5.2 .4 ) was converted to a mode value of $0.0016 \mathrm{~cm}$ according to $\mu=(a+b+c) / 3$ where $\mu$ is the $\log$ of the 
mean value, $a$ is the $\log$ of the minimum value, $b$ is the $\log$ of the mode value, and $c$ is the $\log$ of the maximum value (Evans et al. 1993 [DIRS 112115]).

\subsubsection{Other Model Inputs}

Ashplume requires several other input parameters to control code operation that are not directly related to the mathematical model described in this section. These parameters are computational grid locations, maximum particle diameter for transport, minimum height of eruption column considered in transport, threshold limit on ash accumulation, run type, and an option of whether to save particle size information at the grid locations. These additional model inputs are discussed in the following sections.

\subsubsection{Grid Location and Spacing for the $X$ and $Y$ Axes, $X_{\min }, X_{\max }, Y_{\min }, Y_{\max }, N_{x}, N_{y}$}

Any grid (receptor) location can be specified for calculation of ash and fuel concentrations in the ASHPLUME_DLL_LA V 2.0 (BSC 2003 [DIRS 166571]) code. The only limitation is that the volcanic vent location $(0,0)$ cannot be specified. The grid locations are defined by specifying a minimum and maximum $\mathrm{X}$ and $\mathrm{Y}$ location and the number of desired grid locations between the minimum and maximum. These parameters are shown in Table 8-2 in Section 8 for the TSPA-LA model feeds. As an example, to calculate the ash and fuel concentrations at a single point corresponding to the RMEI located approximately $18 \mathrm{~km}$ due south of the repository, the minimum and maximum $\mathrm{X}$ locations would be specified as $0.0 \mathrm{each}$, and the minimum and maximum $Y$ locations would be specified as 0.0 and $-18 \mathrm{~km}$ each, respectively. The number of $\mathrm{X}$ and $\mathrm{Y}$ locations would be specified as 1 and 2, respectively. In the ASHPLUME coordinate system, the point $(0,0)$ corresponds to the volcanic vent, 0 degrees is due east, 90 degrees is due north, 180 degrees is due west, and -90 degrees is due south. The appropriate coordinate transformations are made within the ASHPLUME_DLL_LA V2.0 (BSC 2003 [DIRS 166571]) code to be consistent with Equation 6-2.

\subsubsection{Maximum Particle Diameter for Transport, $d_{\max }$}

The maximum particle diameter that can be transported down wind is specified as $10 \mathrm{~cm}$ in this model report. This parameter is a simple check within the code to limit the maximum size of particles that are considered for transport in the model. BSC (2004 [DIRS 169980], Section 6.3.3.6.1) describes the range in tephra particle sizes observed at Lathrop Wells, Tolbachik, and Cerro Negro volcanoes, which are three of the analogs for a volcano that could possibly form in the YMR. Lathrop Wells ash, at a distance of 1 to $2 \mathrm{~km}$, ranges in size from 0.125 to $8 \mathrm{~mm}$, and grain sizes with significantly greater fine fractions $(<0.125 \mathrm{~mm})$ were noted at Tolbachik and Cerro Negro. BSC (2004 [DIRS 169980], Table 6-6) lists coarsest median grain sizes for Lathrop Wells in the greater than $1-\mathrm{km}$ distance as $1.16 \mathrm{~mm}$ with a standard deviation of 0.57 . Thus, these data support the hypothesis that grain sizes greater than about $1 \mathrm{~cm}$ are not transported a significant distance down wind but, rather, fall ballistically near the cone. Therefore, the use of a $10-\mathrm{cm}$ tephra-size cutoff for transport provides reasonable mathematical efficiency without biasing the model results. 


\subsubsection{Minimum Height of Eruption Column, $H_{\min }$}

This parameter allows the definition of a lower threshold height below which particle transport is not calculated within the code. It represents the lower limit of the inner integral of Equation 6-2. A value of $1 \mathrm{~m}$ is chosen because this is essentially zero, considering the heights of eruption that are simulated from Equation 6-7b. A value identically equal to zero is not numerically possible in the ASHPLUME_DLL_LA V2.0 (BSC 2003 [DIRS 166571]).

\subsubsection{Threshold Limit on Ash Accumulation, Ash Cutoff}

The value of $10^{-10}\left(\mathrm{~g} / \mathrm{cm}^{2}\right)$ selected in this model report defines the lower limit for the calculation of ash accumulation; below this value, the ash-concentration value is set to zero in the ASHPLUME_DLL_LA V2.0 (BSC 2003 [DIRS 166571]) code. This limit is reasonable because any values lower than this will have a negligible effect on model results. This limit is intended to speed code calculations for large grids by eliminating calculations that result in concentrations below this value.

\subsubsection{Summary of the Computational Model}

The Ashplume mathematical model is implemented as a computer code using the standard FORTRAN 77 language. The integrations defined in the mathematical model are solved using standard numerical integration techniques. For use in the TSPA-LA, the ASHPLUME_DLL_LA V2.0 (BSC 2003 [DIRS 166571]) code is implemented directly within the GoldSim software as a dynamically linked library. All model inputs are entered in GoldSim templates and passed directly to the ASHPLUME DLL. Table 8-2 in Section 8 provides a summary of all inputs required by GoldSim and relates Ashplume input parameters to the corresponding GoldSim variable names.

Model results are primarily produced within the TSPA-LA model (GoldSim). The model results presented in this report include the calculation of mean fuel concentration at the RMEI location in Section 6.7.2 and the validation activity in Section 7. The ASHPLUME_DLL_LA V2.0 (BSC 2003 [DIRS 166571]) code is required as a component of the TSPA model of the nuclear waste repository at Yucca Mountain. Within the TSPA-LA, the atmospheric dispersal and deposition of tephra model implemented in the ASHPLUME code is used to predict the ground-level concentration of ash and waste after a violent Strombolian eruption that intersects the repository. The waste concentration is then combined with BDCFs in the TSPA model to calculate an annual dose to a RMEI. Ashplume model results are produced at run time within the TSPA-LA model. The Ashplume model inputs discussed in this section, and summarized in Section 8, are provided as inputs to the TSPA-LA model as GoldSim variables. These variables are passed to the ASHPLUME_DLL_LA V2.0 (BSC 2003 [DIRS 166571]) module at run time, and ASHPLUME calculates ash and fuel deposition in $\mathrm{g} / \mathrm{cm}^{2}$. The ash and fuel deposition values are passed back to the GoldSim model. Limited base-case model results are provided in the calculation of mean fuel concentration at the RMEI location (Section 6.7.1) via 100 realizations of distributed parameter values (except wind direction, which was held constant). Complete base-case model results will be available when the TSPA-LA GoldSim calculations have been performed. 


\subsection{ASH REDISTRIBUTION CONCEPTUAL MODEL DESCRIPTION}

\subsubsection{Outline}

The ash redistribution conceptual model describes the sedimentary processes that occur when contaminated volcanic ash is deposited at, or redistributed to, the location of the RMEI from a hypothetical volcanic eruption through the repository. The conceptual model represents the sedimentary processes affecting the Fortymile Wash alluvial fan, and specifically the effects on the RMEI area at the head of the Fortymile Wash alluvial fan (Figure 6-2). The basis for the ash redistribution conceptual model is provided in Section 6.3.2.

The model applies a set of parameters that captures the effects of erosion of the initial deposit, mixing and sorting during transport, and the eventual redeposition at the RMEI location (Section 6.7.2). The model captures the effects of sedimentary processes leading to redistribution of contaminated ash at the location of the RMEI. The outputs of this conceptual model are treated as an abstraction for the TSPA-LA model.

\subsubsection{Initial Conditions}

As described in Section 6.3.2, the conceptual ash redistribution is based on two bounding conditions, model Outcome 1 and Outcome 2, that are defined by the criterion of minimum ash deposition at the RMEI area. If the specified criterion is met, the tephra-sheet axis is assumed to be sufficiently aligned with the RMEI area that it represents a maximal primary ash outfall at the RMEI area. This corresponds with Outcome 1, and the criterion used to define such a case is that the primary tephra thickness at the RMEI area is greater than or equal to the minimum ash particle size, $0.001 \mathrm{~cm}$. All realizations in which the primary tephra thickness is less than $0.001 \mathrm{~cm}$ are treated as examples of Outcome 2 , in which the primary ash outfall is assumed to be entirely within the Fortymile Wash basin and therefore a source for potential downstream redistribution toward the RMEI location. In the case of Outcome 2, the conceptual ash redistribution model provides TSPA with numerical representation of primary ash transported from the Fortymile Wash basin to the channels and interchannel divides at the RMEI area.

\subsubsection{Tephra Redistribution and Dilution}

The regional trend toward homogeneity of sediment loads with distance from the primary eruptive deposit is fundamental to the conceptual model for ash redistribution (Section 6.3.2). If ash were ejected into the atmosphere from a hypothetical eruption at Yucca Mountain, deposition would likely occur on the flanks of Yucca Mountain and onto adjacent stream channels, washes, or alluvial fans (Figure 6-2) ((BSC 2004 [DIRS 169980], Section 6.3.4). As suggested by sedimentary processes at analog volcanoes, normal sedimentary processes would begin redistributing and diluting the ash and waste shortly after such an eruption.

Given the strong eolian action in the northern Amargosa Valley, where the RMEI is located, it is highly unlikely that tephra would remain unmodified or undiluted for more than a few decades. Alluvial action (e.g., extreme flood events, such as plus 500 years) could also dilute and transport material that was originally deposited on interchannel divide surfaces into runoff channels. For tephra deposited directly onto distributary channel bottoms, the same processes 
are relevant and would be augmented by the additional dilution and redistribution of tephra (e.g., occasional flash floods).

The conditions for tephra fall and redistribution include the two main geomorphic features present at the RMEI location, interchannel divide areas and distributary channels. These features are characteristic of alluvial fans that develop in semi-arid and arid climates.

Shortly after deposition of a tephra sheet, normal sedimentary processes (Folk 1980 [DIRS 164773], Chapter 2) would begin redistributing the ash. Wind and water would begin eroding, transporting, sorting, and depositing the unconsolidated ash and waste in greater or lesser concentrations, depending on the mixing processes. If ash/waste deposition were to occur at the RMEI location, exposure from the radionuclides contained within the redistributed deposits would occur. On this basis, surface redistribution of contaminated tephra deposits is evaluated here for inclusion in the TSPA.

The transport of tephra occurs both by wind and water action; however, while water in a flooding event can transport large amounts and much larger sizes of material in a short period of time, wind is a major source of transport (Bull 1991 [DIRS 102040], pp. 105 to 106), as evidenced by the presence of dunes in the YMR. Transport of tephra by water begins with hillslope erosion processes and continues as sediment moves into drainages, then is transported as bedloads in the drainages that coalesce into larger and larger drainage channels. At junctions of all scales within drainage systems, water and sediment from different channels begin a process of mixing that ultimately leads to a homogeneous sediment containing elements derived from all drainages in the basin (Folk 1980 [DIRS 164773], Chapter 2). Mixing of sediments occurs in all environments where sediment is transported by water or wind, including intermittent as well as perennial stream systems. The mixing in stream channels occurs at higher rates with larger clast sizes in larger drainages and on steeper slopes than in smaller drainages and on lower-gradient landscape surfaces, such as the Fortymile Wash alluvial fan with a longitudinal gradient of one-half degree. Mixing also occurs from wind action by transporting sediment across the landscape. Wind is the major erosional force on the Fortymile Wash fan but also is effective in bringing sand onto the fan where it forms coppice dunes around vegetation on the fan surface. However, during high-intensity storms (summer monsoon-type thunderstorms), the larger, regional drainage channels that form and flow across newly deposited tephra sheets exhibit the same processes as those observed in other streams. Therefore, after small transport distances, even the channels on newly deposited tephra sheets would have well-mixed sediment loads.

In small channels developed on tephra sheets northwest of the Lathrop Wells cone, tephra moves downslope as small debris flows with dimensions typically tens of centimeters wide and tens of meters long. Tephra moves downslope through progressive generations of these small debris flows until it reaches a channel at the base of the slope. The channel may then merge with larger channels. Depending upon initial tephra thickness, each step in the process results in some dilution of the tephra with other material (Harrington 2003 [DIRS 164775], pp. 14 to 16).

In the region around Yucca Mountain, including the Lathrop Wells cone, sediments in drainage channels are mainly volcaniclastic materials, derived from the dominantly silicic Southern Nevada Volcanic field, and eolian quartz sand and silt. Where basaltic tephra from the Lathrop Wells cone has been transported into a drainage channel containing tuff and quartz clasts, the 
tephra component is progressively diluted during transport relative to the total sediment volume. In addition, tephra may be diluted prior to fluvial mobilization due to the infiltration of eolian sand and silt.

The sedimentary depositional system at the Lathrop Wells volcanic cone near Yucca Mountain (Harrington 2003 [DIRS 164775], pp. 14 to 16) was studied to assess the significance of dilution in the ash redistribution conceptual model. The dilution rates (Section 7.3.2) analyzed for the drainages around the Lathrop Wells cone were not included in the abstraction of the ash redistribution conceptual model because the drainage system at Lathrop Wells is very small relative to the Fortymile Wash drainage. In addition, the ash was deposited approximately 77,000 years ago, and the drainage system at the Lathrop Wells cone is most likely nearing equilibrium. Although dilution rates at the Lathrop Wells cone are not necessarily representative of the rates that may be expected from sedimentary processes affecting a young tephra sheet, those dilution rates do demonstrate that the process of dilution can be significant.

\subsubsection{Rates of Surficial Processes in Fortymile Wash}

To understand potential tephra redistribution, it is important to constrain the current rates of surficial processes along the main Fortymile Wash drainage. Fortymile Wash is a major drainage area along the base of the eastern slope of Yucca Mountain. It has an $800-\mathrm{km}^{2}$ drainage basin that includes the entire eastern slope of Yucca Mountain and the Fortymile Wash alluvial fan. In the upper or northern half of the fan, the channels are well defined (Figure 6-2). The drainage pattern is a distributary system where channels are widely spaced, but there is a sizable interchannel area occurring between all pairs of channels. These interchannel divide tracts are more prominent on the upper fan. On the lower fan (not shown in Figure 6-2), they are neither as topographically prominent nor as wide. Estimates of surficial process rates in the Fortymile Wash are based on ${ }^{137}$ Cs concentrations in the sediments (BSC 2004 [DIRS 169980], Section 6.3.4.2). Eolian erosion on the interchannel divides presently occurs at the rate of 0.02 to $0.04 \mathrm{~cm} /$ year.

\subsubsection{Equilibrium on the Fortymile Wash Alluvial Fan}

It must be noted however, that sediment likely moves off the surface slowly, if at all. As sand particles are loosened from the underlying sediment, they likely form coppice dunes anchored to vegetation on the sediment surface. Thus, over time, the net effect on the upper fan interchannel divides is probably a very small net loss, which could be easily replaced by the creation of $A_{v}$ horizons from incoming dust and sand blown onto the surface. With time, and assuming no large (500 to 1000 year) floods occur, the surfaces of the divides are in near equilibrium with the present climate and will change little over this extended period.

\subsubsection{Model Outcome 1: Primary Tephra Deposition at the RMEI Location}

For the relatively less frequent wind directions toward the south, the eruption would result in tephra deposition at the RMEI location. In this case, the deposit would initially blanket both distributary channels and interchannel divide surfaces, which stand several tens of centimeters to a maximum of about $1 \mathrm{~m}$ above the channel fill. 
In the case where tephra is deposited directly at the RMEI location, the following factors will determine the evolution of that deposit with time. Such a deposit is most likely to be thin ( $2 \mathrm{~cm}$ or less, based on the model abstraction presented in Section 6.7.1) and fine grained, consisting of ash-sized particles (less than or equal to $2 \mathrm{~mm}$ ). Tephra deposited on interchannel divide surfaces may be subject to the following processes:

- Removal by wind

- In-situ dilution by eolian sand and silt

- Mechanical and chemical infiltration into the underlying soil profile (see results of the ${ }^{137}$ Cs study in BSC 2004 [DIRS 169980], Section 6.3.4.2).

Extreme (e.g., plus 500 years) flood events could also dilute and transport material that was originally deposited on interchannel divide surfaces into runoff channels. For tephra deposited directly onto distributary channel bottoms, the above processes are relevant as well as the additional dilution and redistribution of tephra by occasional flash floods.

\subsubsection{Model Outcome 2: Primary Tephra Deposition Upstream in Fortymile Wash}

Figure 6-3 illustrates the conceptual model for redistribution of tephra toward the RMEI. Such redistribution would be dominated by fluvial transport down Fortymile Wash and can best be illustrated by considering the time evolution of tephra concentration on the surface at locations (stations) along the wash. Station $\mathrm{A}$ is at the point where Fortymile Wash is closest to the repository, while Stations B and C are progressively downstream, and Station D roughly corresponds to the location of a RMEI at the depositional mouth (alluvial fan) of the wash where it drains into the Amargosa Valley. The plots on the right side of Figure 6-3 conceptually show the relative concentration of tephra on the surface of the wash, averaged across the wash, as a function of time after the initial eruptive deposition of the tephra. These plots are qualitative and do not represent particular data from the YMR or other sites. Note that Figure 6-3 represents both individual flood events and the longer time-averaged behavior of the system.

Immediately after an eruption, the surface concentration of tephra at Station A will be unity, representing the presence of an undisturbed tephra deposit blanketing the wash. With time, this concentration will be reduced as sediment is transported in from upstream sources. Initially, this process will result in upstream-derived sediments being mixed with, or deposited on the surface of, the primary tephra deposit. Eventually, the primary tephra deposit will be locally incised to its base, exposing underlying sediments, and, ultimately, the primary deposit may be completely incised across the entire width of the wash so that no primary deposit remains. At that time, it is likely that tephra will continue to be transported into the wash from the flanks and hillslopes immediately adjacent to the wash (e.g., Yucca Mountain itself) especially where slopes are greater than about 10 percent and tephra can be swept off the slope and into the adjacent drainage channel by short, intense thunderstorms. 


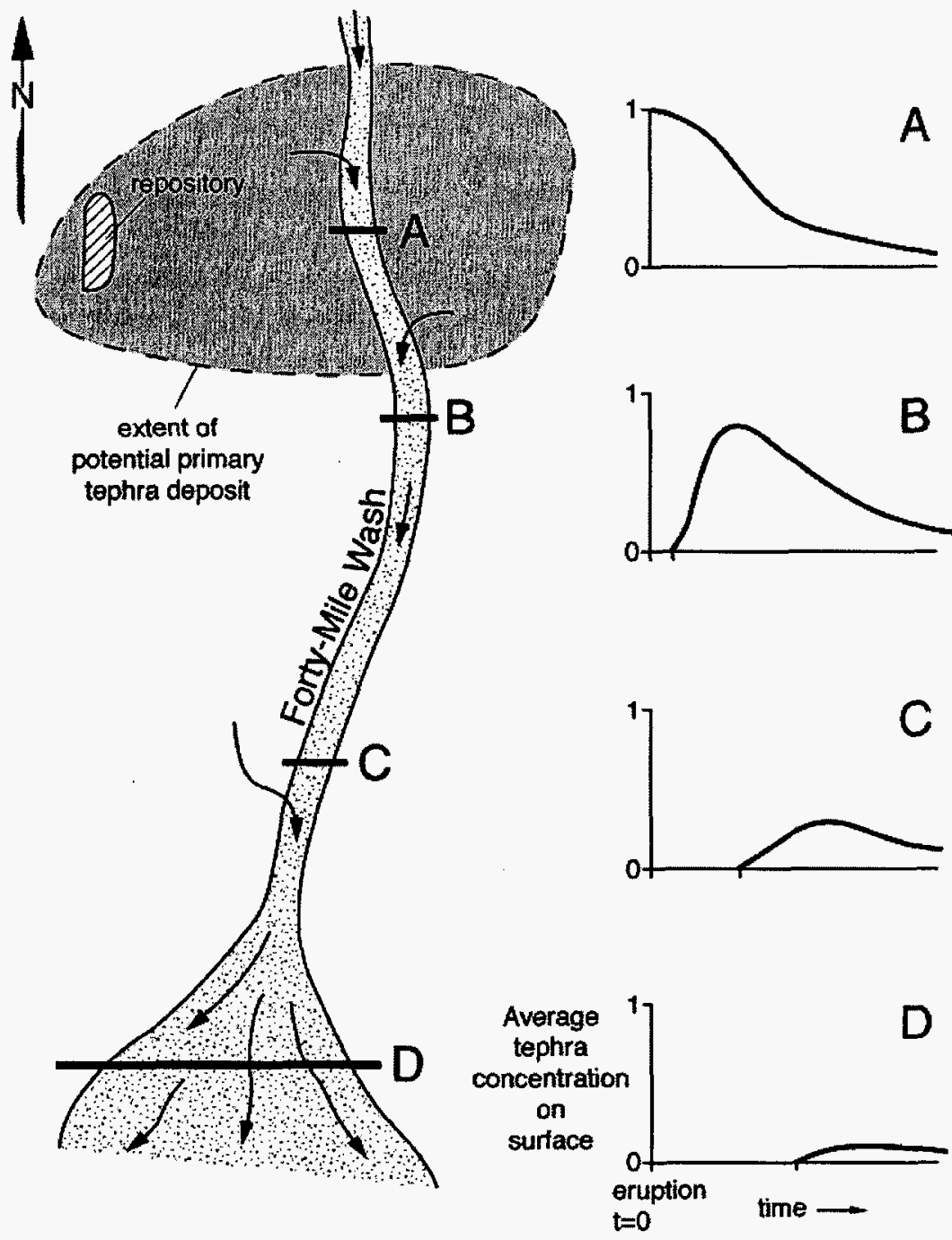

NOTE: For illustration purposes only.

Figure 6-3. Illustration of Conceptual Model for Redistribution of Tephra Toward a RMEl for Outcome 2

Of the hillslopes of Yucca Mountain and Fortymile Wash, greater than 20 percent have slopes greater than 10 percent (see Figure I-1). These commonly are valley side slopes along the Wash and its major tributaries. Slopes that are less steep are likely to be incised first and ash would be removed at a much lower rate, as is observed throughout the Sunset Crater ash depositional area (Harrington 2004 [DIRS 171345], p. 77). Therefore, the average concentration of tephra at Station A will continue to decline very gradually, rather than immediately going to a value of zero, after an initial phase of cutting through the primary deposit.

Station B is not blanketed by the primary tephra deposit, so there will be a period of time between the eruption and the first arrival of tephra via sedimentary processes. The tephra concentration at Station B will increase relatively rapidly as the upstream tephra deposit is incised and that material moves downstream. However, on average, the tephra concentration will peak at some value less than unity because of dilution of the tephra by other sediments from 
sources upstream of the tephra deposit, sediment washed directly off the slopes above the wash near Station B, and by mixing with pre-existing sediments on the floor of the wash. The concentration at Station B will gradually decline but will continue to be fed by tephra washing in from upstream environs (e.g., around Station A).

Stations C and D will experience successively longer lag times between the eruption and first arrival of tephra via the sediment transport system. In addition, the peak concentration at each station will be successively lower due to dilution as described above. The general effect is that of a downstream-propagating tephra "wave" that is progressively diluted, damped, and dispersed. Station D will experience the longest lag time before contaminated tephra arrives, and the lowest peak concentration, but the longest period during which contaminated tephra is being fed to the location.

The processes of sediment transport in a setting such as Fortymile Wash are complex and sporadic and are very difficult to model. For example, introduction of hillslope material directly into the tributary washes and/or main wash might occur during relatively localized, intense thunderstorms, but these are not likely to result in transport far downstream in the wash (see more detailed discussion in Characterize Eruptive Processes at Yucca Mountain Nevada (BSC 2004 [DIRS 169980], Section 6.3.4). Major flood events (e.g., 100-year storms) can mobilize hill-slope material into the wash and additionally transport material downwash many kilometers. The effects, both during individual storm events and integrated over long times and many events, should be dominated by:

- Dilution of tephra by the arrival of upstream-sourced sediments

- Dilution of tephra by material washed from the wash flanks directly into the wash

- Mixing with pre-existing sediments along the bed of the wash.

Also, note that the conceptual plots in Figure 6-3 represent average surface concentration of tephra across the wash - in reality, there may be small sub-channels with very high tephra concentrations while other parts of the wash remain free of tephra. In the alluvial fan area of Fortymile Wash (e.g., Station D), tephra variations across the wash might be especially pronounced as the wash branches into distributary channels separated by higher-standing interchannel divides that might only receive new sediment during extreme (e.g., +500 years) flood events (the distinction between distributary channels and interchannel divides becomes important in determining doses to a RMEI). Vertically, in the uppermost deposits in a channel after an eruption, there might also be tephra-rich layers and tephra-poor layers, reflecting a variety of sediment transport and local depositional mechanisms. In practice, it is not possible to predict such details nor is it necessary to model this level of detail because the average behavior is appropriate for the purposes of the analysis.

Rainstorms at Yucca Mountain can be classed into two types: local, infrequent storms and regional storms that cover very broad areas on scales larger than entire drainage basins (Coe et al. 1997 [DIRS 104691], p. 15). Typically, regional storms have longer durations with periods of heavy rains during part or most of the storms. These storms occur more commonly in winter, although they can occur at any time of the year. 
It is the intense, very localized thunderstorm that would be the likely initiator of movement of the scoria and ash particles from the ridge-top drainage heads into the parallel channels. Undercutting of slopes of scoria and ash could cause sloughing of masses of tephra and result in the addition of disaggregated scoria and ash to the drainage systems. In most localized thunderstorms, water infiltrates into the underlying soil quite rapidly and does not carry its bedload long distances. At Yucca Mountain, these storms seldom feed abundant material into Fortymile Wash (Coe et al. 1997. [DIRS 104691], pp. 24 to 26). To get abundant material into the wash and to transport it a long distance requires the much broader, longer-period regional rainstorms.

It is, therefore, the broad, regional storms that are responsible for moving most, and possibly all, of the sediment through the lower part of Fortymile Wash below Yucca Mountain. The material being moved and mixed is not only the sediment from the east flanks of Yucca Mountain, but includes the entirety of the sediment that is derived from the drainage basin of Fortymile Wash, including the terraces along the length of the wash.

If overall climate in the YMR were to change to wetter weather patterns, there would be several impacts on the landscape, including a major change in the dominant storm type. During wetter conditions associated with future glacial transition climates (see Future Climate Analysis (BSC 2004 [DIRS 170002]), long-duration regional storms would become more frequent, and summer monsoon storms would become less frequent, or perhaps disappear. Regardless of the details of such storms, mixing would still be an effective agent in the dilution of contaminated sediment along the journey to the Fortymile Wash alluvial fan and beyond. Most predictions for increased rainfall in this area project one-and-one-half to two times the modern rate of 25 to $30 \mathrm{~mm}$ (BSC 2004 [DIRS 170002]).

\subsubsection{Wind Data}

A wind-rose diagram of surface winds in Jackass Flats and on the Fortymile Wash fan is shown in Figure 6-1. Prevailing winds are predominantly from the southwest and move material toward the northeast. Frequently, strong winds blow across the fan, pick up the sand and smaller size fractions (some of which may be contaminated), and remove them from the fan and from the Fortymile Wash drainage, thus, reducing the quantity of contaminated surface material on the Fortymile Wash fan.

Although the effects of near-surface wind erosion (Figure 6-1) can be inferred from the ${ }^{137} \mathrm{Cs}$ data (BSC 2004 [DIRS 169980], Table 6-8), there is also evidence of eolian deposition on some surfaces. The presence of coppice dunes along the edges of the interchannel divide areas indicates that vegetation traps some of the eroded materials before the eolian materials can be carried off the divide area. Supporting data for wind transport and deposition of material throughout the Yucca Mountain area include the presence of stratified eolian horizons of fine sand and silt marked by the presence of gas bubble vesicles ( $A_{v}$ horizons). Such vesicular soil horizons are found on most geomorphic surfaces that have been stable for several hundred years, as are many of the surfaces around Yucca Mountain (YMP 1993 [DIRS 100520], pp. 24 to 25). The presence of Big Dune in close proximity to the Fortymile Wash fan, from which material is being removed and deposited almost continuously, clearly demonstrates that this is an area where eolian processes play an important role in landscape modification. Such eolian removal 
processes commonly leave behind a lag of the heavier and coarser-grained materials. Surfaces covered to some degree by these lag materials are similar in origin to the desert pavements that cover most stable geomorphic surfaces in arid environments.

\subsection{MODEL RESULTS AND ABSTRACTIONS}

This section provides results and abstractions on ash dispersal, deposition, and redistribution for use in the TSPA-LA model. Section 6.7.1 presents Ashplume results required to implement selected conditions of the redistribution abstraction in which representative amounts of ash and waste deposited at the RMEI location are required for initial conditions. For purposes of this calculation, 100 simulations of a single eruption were conducted with the wind fixed southward. The resulting mean concentrations of radioactive waste in the tephra sheet were calculated at the location of the RMEI, about $18 \mathrm{~km}$ south of the repository (Section 6.7.1). Section 6.7.2 presents the overall redistribution abstraction, which uses the Ashplume results presented in Section 6.7.1.

\subsubsection{Waste-Form Concentrations in Ash from an Ash Plume $18 \mathrm{~km}$ from a Vent}

This section describes the results of calculations using the ASHPLUME_DLL_LA V2.0 code (BSC 2003 [DIRS 166571]) to estimate the mean concentrations of radioactive waste at a point $18 \mathrm{~km}$ south from a hypothetical vent along the midline of a tephra sheet. For the purposes of this calculation, 100 simulations of a single eruption were conducted using sampled values for all distributed ASHPLUME inputs except wind direction, which was held fixed so that the mid-line of the plume would be the same in each realization. Distributions for the sampled inputs are as described below. Results are presented in Table 6-4 in terms of concentration of ash and waste form per unit area $\left(\mathrm{g} / \mathrm{cm}^{2}\right)$ of ash for each of the 100 realizations. The mean waste concentration, termed the Mean Primary Waste Concentration, incorporates effects of uncertainty in the ASHPLUME inputs and, is the value to be used by the TSPA-LA for certain realizations, time periods, and geomorphic surfaces in the model for redistribution described in Section 6.7.2.

Parameter values used in this calculation were chosen using the base-case values and ranges of values presented in Section 6.5.2. For those values with a distribution $\left(\beta, d, \sigma_{d}, W_{0}, P, T_{d}\right.$, and $u$ ), 100 realizations were generated randomly from these distributions by implementing the ASHPLUME code within GoldSim. ASHPLUME_DLL_LA V2.0 (BSC 2003 [DIRS 166571]) and GoldSim V 8.01 SP1 (Golder Associates 2003 [DIRS 166572]) were used to implement this calculation. Wind direction was held fixed (due south towards the RMEI) for each of the 1-km altitude bins in the wind data (Output DTN: MO0408SPADRWSD.002). The validity of each realization (combination of randomly chosen parameter values) was ensured by following the methodology outlined in Section 8.2, which requires that the values of the sampled parameters remain within established ranges. The 100 realizations of distributed input values are provided in Appendix E.

The value for the total fuel mass available for entrainment in this 100-run exercise was chosen based on the mass of fuel in commercial spent nuclear fuel waste, which is expected to comprise about 90 percent of the waste in the repository (CRWMS M\&O 2001 [DIRS 153938], p. 49). A total of 63,000 metric tonnes of heavy metals commercial spent nuclear fuel is expected to be emplaced in 7,860 waste packages (CRWMS M\&O 2001 [DIRS 153938]). The total mass of waste available for entrainment $\left(4.01 \times 10^{7} \mathrm{~g}\right)$ was calculated based on a median value of 
five waste packages calculated to be damaged if a hypothetical eruptive conduit were to intersect the repository (BSC 2004 [DIRS 170001]; DTN: SN0402T0503303.004 [DIRS 167515]).

The results of this Monte Carlo analysis are presented in Table 6-4, including the geometric mean of the concentration of the fuel form calculated for the RMEI at a location $18 \mathrm{~km}$ south of the repository (the location of the RMEI for these analyses). The areal ash concentrations reported in Table 6-4 can be interpreted as ash thicknesses based on a value for ash settled density of $1.0 \mathrm{~g} / \mathrm{cm}^{3}$ (BSC 2004 [DIRS 169980], Table 7-1; DTN: LA0407DK831811.001 [DIRS 170768]). This set of 100 realizations was rerun for this revision of this report due to the following changes:

- the version of GoldSim used for REV 00 runs had been superseded.

- $\sigma_{d}$ range changed from $-1.9,-1.3$ to +1.3 to +1.9

- Sequence numbers 8 and 9 in Table 8-2 have been reversed; that is, sequence number 8 is "ash particle density at maximum particle size" (1.04) and sequence number 9 is "ash particle density at minimum particle size" (2.08).

- The wind speed and direction data were revised.

The parameter values were changed as a result of errors found in the previous implementation. This set of parameters is consistent with those reported in Table 8-2 and those used in TSPA-LA.

Table 6-4. Calculated Concentration of Ash and Waste in the Midline of a Volcanic Plume at a Location $18 \mathrm{~km}$ South of the Repository

\begin{tabular}{|c|c|c|c|c|}
\hline $\begin{array}{c}\text { Realization } \\
\text { Number }\end{array}$ & $\begin{array}{c}\text { Ash } \\
\text { Concentration } \\
\left(\mathbf{g} / \mathbf{c m}^{2}\right)\end{array}$ & $\begin{array}{c}\text { Log Ash } \\
\text { Concentration } \\
\text { Log }\left(\mathbf{g} / \mathbf{c m}^{2}\right)\end{array}$ & $\begin{array}{c}\text { Waste } \\
\text { Concentration } \\
\left(\mathbf{g} / \mathbf{c m}^{2}\right)\end{array}$ & $\begin{array}{c}\text { Log Waste } \\
\text { Concentration } \\
\text { Log }\left(\mathbf{g} / \mathbf{c m}^{2}\right)\end{array}$ \\
\hline 1 & 0.8295 & -0.0812 & $4.58 \mathrm{E}-06$ & -5.3392 \\
\hline 2 & 14.1120 & 1.1496 & $2.15 \mathrm{E}-05$ & -4.6681 \\
\hline 3 & 15.5240 & 1.1910 & $2.09 \mathrm{E}-05$ & -4.6807 \\
\hline 4 & 3.9393 & 0.5954 & $1.89 \mathrm{E}-05$ & -4.7225 \\
\hline 5 & 1.9151 & 0.2822 & $4.10 \mathrm{E}-06$ & -5.3871 \\
\hline 6 & 0.2256 & -0.6466 & $2.47 \mathrm{E}-06$ & -5.6080 \\
\hline 7 & 1.6457 & 0.2164 & $8.09 \mathrm{E}-06$ & -5.0923 \\
\hline 8 & 0.2022 & -0.6942 & $1.34 \mathrm{E}-06$ & -5.8725 \\
\hline 9 & 0.6565 & -0.1828 & $2.27 \mathrm{E}-06$ & -5.6434 \\
\hline 10 & 1.2757 & 0.1057 & $1.87 \mathrm{E}-06$ & -5.7284 \\
\hline 11 & 3.4480 & 0.5376 & $1.58 \mathrm{E}-06$ & -5.8019 \\
\hline 12 & 13.0700 & 1.1163 & $1.10 \mathrm{E}-05$ & -4.9577 \\
\hline 13 & 4.8394 & 0.6848 & $4.45 \mathrm{E}-06$ & -5.3516 \\
\hline 14 & 0.4601 & -0.3372 & $5.20 \mathrm{E}-06$ & -5.2843 \\
\hline 15 & 0.2396 & -0.6205 & $4.27 \mathrm{E}-07$ & -6.3698 \\
\hline 16 & 3.1807 & 0.5025 & $1.46 \mathrm{E}-05$ & -4.8355 \\
\hline 17 & 19.2360 & 1.2841 & $1.62 \mathrm{E}-05$ & -4.7915 \\
\hline
\end{tabular}


Table 6-4. Calculated Concentration of Ash and Waste in the Midline of a Volcanic Plume at a Location $18 \mathrm{~km}$ South of the Repository (Continued)

\begin{tabular}{|c|c|c|c|c|}
\hline $\begin{array}{l}\text { Realization } \\
\text { Number }\end{array}$ & $\begin{array}{c}\text { Ash Concentration } \\
\left(\mathrm{g} / \mathrm{cm}^{2}\right)\end{array}$ & $\begin{array}{c}\text { Log Ash Concentration } \\
\log \left(\mathbf{g} / \mathrm{cm}^{2}\right)\end{array}$ & $\begin{array}{c}\text { Waste } \\
\text { Concentration }\left(\mathrm{g} / \mathrm{cm}^{2}\right) \\
\end{array}$ & $\begin{array}{c}\text { Log Waste } \\
\text { Concentration } \\
\text { Log }\left(\mathrm{g} / \mathrm{cm}^{2}\right)\end{array}$ \\
\hline 18 & 0.3520 & -0.4534 & 2.30E-06 & -5.6391 \\
\hline 19 & 3.6054 & 0.5570 & $2.08 \mathrm{E}-06$ & -5.6812 \\
\hline 20 & 10.0200 & 1.0009 & $2.15 \mathrm{E}-05$ & -4.6668 \\
\hline 21 & 4.6591 & 0.6683 & $7.98 \mathrm{E}-06$ & -5.0981 \\
\hline 22 & 1.8903 & 0.2765 & 8.76E-06 & -5.0575 \\
\hline 23 & 1.1967 & 0.0780 & $4.99 \mathrm{E}-06$ & -5.3021 \\
\hline 24 & 1.0053 & 0.0023 & $4.94 \mathrm{E}-06$ & -5.3059 \\
\hline 25 & 4.2214 & 0.6255 & 1.60E-05 & -4.7947 \\
\hline 26 & 1.4585 & 0.1639 & 1.80E-06 & -5.7450 \\
\hline 27 & 3.5631 & 0.5518 & 1.13E-05 & -4.9460 \\
\hline 28 & 1.9372 & 0.2872 & 5.74E-06 & -5.2407 \\
\hline 29 & 1.6432 & 0.2157 & 5.54E-06 & -5.2565 \\
\hline 30 & 0.3628 & -0.4404 & 2.61E-06 & -5.5840 \\
\hline 31 & 2.6091 & 0.4165 & $1.56 \mathrm{E}-05$ & -4.8065 \\
\hline 32 & 2.7975 & 0.4468 & 5.11E-06 & -5.2914 \\
\hline 33 & 54.7780 & 1.7386 & 3.78E-05 & -4.4222 \\
\hline 34 & 5.9887 & 0.7773 & $3.99 \mathrm{E}-06$ & -5.3989 \\
\hline 35 & 1.1886 & 0.0750 & $7.29 \mathrm{E}-06$ & -5.1371 \\
\hline 36 & 5.6287 & 0.7504 & 4.16E-06 & -5.3805 \\
\hline 37 & 1.1673 & 0.0672 & 7.07E-07 & -6.1505 \\
\hline 38 & 0.9830 & -0.0074 & $1.26 \mathrm{E}-05$ & -4.9004 \\
\hline 39 & 7.6290 & 0.8825 & $7.75 \mathrm{E}-06$ & -5.1105 \\
\hline 40 & 0.2549 & -0.5936 & 1.05E-06 & -5.9773 \\
\hline 41 & 1.6752 & 0.2241 & 1.86E-06 & -5.7298 \\
\hline 42 & 0.5012 & -0.3000 & $4.52 \mathrm{E}-06$ & -5.3445 \\
\hline 43 & 1.5501 & 0.1904 & $9.50 \mathrm{E}-06$ & -5.0221 \\
\hline .44 & 0.7844 & -0.1055 & 1.74E-06 & -5.7604 \\
\hline 45 & 1.0445 & 0.0189 & $2.15 \mathrm{E}-06$ & -5.6678 \\
\hline 46 & 17.6450 & 1.2466 & 1.15E-05 & -4.9378 \\
\hline 47 & 0.4742 & -0.3241 & 3.57E-07 & -6.4468 \\
\hline 48 & 0.5477 & -0.2615 & $4.98 \mathrm{E}-07$ & -6.3026 \\
\hline 49 & 0.6642 & -0.1777 & $2.55 \mathrm{E}-06$ & -5.5929 \\
\hline 50 & 6.8837 & 0.8378 & $1.03 \mathrm{E}-05$ & -4.9886 \\
\hline 51 & 5.3238 & 0.7262 & 3.25E-06 & -5.4885 \\
\hline 52 & 1.6343 & 0.2133 & $3.21 E-06$ & -5.4934 \\
\hline 53 & 0.9331 & -0.0301 & 7.34E-06 & -5.1345 \\
\hline 54 & 0.1181 & -0.9279 & 1.79E-07 & -6.7470 \\
\hline 55 & 0.2576 & -0.5890 & 4.23E-07 & -6.3734 \\
\hline 56 & 1.4787 & 0.1699 & $6.31 \mathrm{E}-06$ & -5.2002 \\
\hline 57 & 0.4137 & -0.3833 & 2.07E-06 & -5.6843 \\
\hline 58 & 0.3862 & -0.4132 & 1.84E-06 & -5.7341 \\
\hline 59 & 1.3546 & 0.1318 & 1.91E-06 & -5.7179 \\
\hline
\end{tabular}


Table 6-4. Calculated Concentration of Ash and Waste in the Midline of a Volcanic Plume at a Location $18 \mathrm{~km}$ South of the Repository (Continued)

\begin{tabular}{|c|c|c|c|c|}
\hline $\begin{array}{c}\text { Realization } \\
\text { Number }\end{array}$ & $\begin{array}{c}\text { Ash Concentration } \\
\left(\mathrm{g} / \mathrm{cm}^{2}\right)\end{array}$ & $\begin{array}{c}\text { Log Ash Concentration } \\
\log \left(\mathrm{g} / \mathrm{cm}^{2}\right)\end{array}$ & $\begin{array}{c}\text { Waste } \\
\text { Concentration }\left(\mathrm{g} / \mathrm{cm}^{2}\right)\end{array}$ & $\begin{array}{c}\text { Log Waste } \\
\text { Concentration } \\
\text { Log }\left(\mathrm{g} / \mathrm{cm}^{2}\right)\end{array}$ \\
\hline 60 & 1.2762 & 0.1059 & 2.63E-06 & -5.5808 \\
\hline 61 & 0.2162 & -0.6652 & 2.12E-06 & -5.6746 \\
\hline 62 & 6.3530 & 0.8030 & 1.24E-05 & -4.9065 \\
\hline 63 & 2.9069 & 0.4634 & 4.65E-06 & -5.3326 \\
\hline 64 & 0.5417 & -0.2663 & 1.12E-06 & -5.9519 \\
\hline 65 & 0.3347 & -0.4754 & $8.41 \mathrm{E}-07$ & -6.0751 \\
\hline 66 & 4.0544 & 0.6079 & $2.18 \mathrm{E}-05$ & -4.6619 \\
\hline 67 & 9.6663 & 0.9853 & 4.57E-06 & -5.3400 \\
\hline 68 & 14.2640 & 1.1542 & 1.54E-05 & -4.8113 \\
\hline 69 & 14.0560 & 1.1479 & 2.32E-05 & -4.6353 \\
\hline 70 & 0.6735 & -0.1716 & 2.64E-06 & -5.5780 \\
\hline 71 & 0.5081 & -0.2940 & $1.38 \mathrm{E}-06$ & -5.8606 \\
\hline 72 & 0.2639 & -0.5785 & $3.78 \mathrm{E}-07$ & -6.4227 \\
\hline 73 & 18.7750 & 1.2736 & $1.92 E-05$ & -4.7162 \\
\hline 74 & 18.5570 & 1.2685 & 1.44E-05 & -4.8425 \\
\hline 75 & 0.4519 & -0.3450 & 2.71E-06 & -5.5674 \\
\hline 76 & 0.6969 & -0.1569 & $5.46 \mathrm{E}-07$ & -6.2630 \\
\hline 77 & 1.9662 & 0.2936 & 1.86E-06 & -5.7302 \\
\hline 78 & 12.7860 & 1.1067 & 5.89E-06 & -5.2298 \\
\hline 79 & 21.8310 & 1.3391 & 2.23E-05 & -4.6513 \\
\hline 80 & 0.0719 & -1.1433 & $2.16 \mathrm{E}-07$ & -6.6664 \\
\hline 81 & 1.3540 & 0.1316 & 1.01E-05 & -4.9946 \\
\hline 82 & 7.8789 & 0.8965 & $6.00 \mathrm{E}-06$ & -5.2222 \\
\hline 83 & 16.9640 & 1.2295 & 1.77E-05 & -4.7532 \\
\hline 84 & 0.9268 & -0.0330 & 9.66E-06 & -5.0149 \\
\hline 85 & 18.3640 & 1.2640 & $3.08 \mathrm{E}-05$ & -4.5110 \\
\hline 86 & 1.2716 & 0.1044 & 1.44E-06 & -5.8402 \\
\hline 87 & 2.6627 & 0.4253 & 1.04E-05 & -4.9817 \\
\hline 88 & 1.6779 & 0.2248 & $5.76 \mathrm{E}-06$ & -5.2393 \\
\hline 89 & 4.0114 & 0.6033 & $2.05 \mathrm{E}-06$ & -5.6885 \\
\hline 90 & 5.2712 & 0.7219 & $1.38 \mathrm{E}-05$ & -4.8597 \\
\hline 91 & 2.2160 & 0.3456 & $1.54 \mathrm{E}-05$ & -4.8129 \\
\hline 92 & 2.3157 & 0.3647 & $2.26 \mathrm{E}-05$ & -4.6458 \\
\hline 93 & 4.9456 & 0.6942 & $3.64 \mathrm{E}-06$ & -5.4394 \\
\hline 94 & 5.2503 & 0.7202 & $1.04 E-05$ & -4.9825 \\
\hline 95 & 0.6850 & -0.1643 & 2.47E-07 & -6.6079 \\
\hline 96 & 0.7750 & -0.1107 & 4.03E-06 & -5.3942 \\
\hline
\end{tabular}


Table 6-4. Calculated Concentration of Ash and Waste in the Midline of a Volcanic Plume at a Location $18 \mathrm{~km}$ South of the Repository (Continued)

\begin{tabular}{|c|c|c|c|c|}
\hline $\begin{array}{c}\begin{array}{c}\text { Realization } \\
\text { Number }\end{array} \\
\end{array}$ & $\begin{array}{c}\text { Ash Concentration } \\
\left(\mathrm{g} / \mathrm{cm}^{2}\right)\end{array}$ & $\begin{array}{c}\text { Log Ash Concentration } \\
\log \left(\mathrm{g} / \mathrm{cm}^{2}\right)\end{array}$ & $\begin{array}{c}\text { Waste } \\
\text { Concentration }\left(\mathrm{g} / \mathrm{cm}^{2}\right)\end{array}$ & $\begin{array}{c}\text { Log Waste } \\
\text { Concentration } \\
\log \left(\mathrm{g} / \mathrm{cm}^{2}\right)\end{array}$ \\
\hline 97 & 0.7421 & -0.1295 & $7.25 E-06$ & -5.1394 \\
\hline 98 & 0.2479 & -0.6058 & $1.85 \mathrm{E}-06$ & -5.7334 \\
\hline 99 & 5.6625 & 0.7530 & 4.36E-06 & -5.3610 \\
\hline 100 & 0.5271 & -0.2781 & $1.07 \mathrm{E}-06$ & -5.9712 \\
\hline Mean of logs & & 0.2705 & & -5.3809 \\
\hline $\begin{array}{l}\text { Geometric Mean } \\
\text { Concentration }\end{array}$ & ASH: & .8641 & \multicolumn{2}{|c|}{ WASTE: (Mean Primary Waste Concentration) } \\
\hline $\begin{array}{l}\text { Standard } \\
\text { Deviation }\end{array}$ & & .3831 & \multicolumn{2}{|c|}{ 7.47E-06 } \\
\hline
\end{tabular}

Output DTN: LA0408GK831811.001.

\subsubsection{Ash Redistribution Model Abstraction}

\subsubsection{Model Description}

The ash redistribution model describes the range of conditions that allows for the transport of contaminated ash to the RMEI location by sedimentary processes. The model includes both alluvial and eolian transport processes as well as sediment transport mechanisms that could concentrate radionuclides at the RMEI location.

If a volcano were to intersect the repository, the eruption would most likely result in waste-contaminated tephra being dispersed in the northeasterly direction as determined by the prevailing wind during a future eruption (Section 5.2.1), but primary deposition of contaminated waste at the RMEI location could also occur (Figure 6-1). Tephra that originally did not fall at the RMEI location could be redistributed to the RMEI location by sedimentary processes.

\subsubsection{Formulation}

Field studies of tephra dilution in drainages around the Lathrop Wells cone and of surficial erosion/deposition rates based on ${ }^{137} \mathrm{Cs}$, along with general considerations of the sediment transport systems around Yucca Mountain, suggest a simple model for TSPA. This model and its output parameters for use in TSPA are summarized in Table 6-5 in terms of the two tephra fall/redistribution outcomes described in Section 6.6.1, as well as the two main geomorphic features at the RMEI location (interchannel divides and distributary channels). In Outcome 1, the primary tephra sheet is deposited at the location of the RMEI. In Outcome 2 the tephra sheet is deposited within the Fortymile Wash drainage basin (consistent with prevailing southwestern winds) at some distance upstream from the RMEI location. For the purposes of TSPA, the distinction between Outcomes 1 and 2 should be made on the basis of the presence of non-negligible thickness of ash at the RMEI location. Non-negligible ash thickness should be defined as greater than or equal to the smallest mean ash particle diameter of $0.001 \mathrm{~cm}$. This thickness, or greater, of ash constitutes ash fall at the RMEI location (Outcome 1); less than $0.001 \mathrm{~cm}$ constitutes Outcome 2. Model Outcomes 1 and 2 represent the maximum availability 
of waste-contaminated ash at the RMEI location. Other tephra-sheet orientations either eliminate ash from reaching the RMEI location, or reduce the available volume of ash to be redistributed to the RMEI location.

Table 6-5. Ash Redistribution Model Abstraction for the TSPA-LA Model

\begin{tabular}{|c|c|c|}
\hline & Interchannel Divide & Distributary Channels \\
\hline AREAL WEIGHT & 0.82 & 0.18 \\
\hline $\begin{array}{l}\text { Outcome } 1 \\
\text { Primary tephra (ash } \\
\text { fall) in the vicinity of } \\
\text { the RMEl location. }\end{array}$ & $\begin{array}{l}\text { Initial condition } \\
\text { Ash-layer (tephra) thickness } \\
\text { calculated by ASHPLUME in the } \\
\text { TSPA model. } \\
\text { Initial waste areal concentration } \\
\text { calculated in TSPA for the ash layer } \\
\text { at the location of the RMEI. } \\
\text { Ash removal } \\
\text { At a rate uniformly distributed } \\
\text { between } 0.02 \text { to } 0.04 \text { cm/yr. } \\
\text { Residual conditions } \\
9 \text {-cm contaminated soil layer } \\
\text { beneath initial ash. Volumetric } \\
\text { concentration of the waste (see } \\
\text { NOTES below) in this layer } \\
\text { decreases linearly from the initial } \\
\text { value calculated in the ash to } 1 / 100 \text { th } \\
\text { of that value at } 9 \text { cm. This layer is } \\
\text { removed at the same rate as the } \\
\text { initial ash layer, consistent with }{ }^{137} \mathrm{Cs} \\
\text { observations. The linear volumetric } \\
\text { concentration decrease is } \\
\text { conservative with respect to the } \\
\text { exponential decrease observed for } \\
137 \text { Cs. } \\
\text { Below the } 9 \text {-cm layer is an additional } \\
1 \text { to } 2 \text { cm (uniform distribution) layer } \\
\text { with } 1 / 100 \text { th of the initial volumetric } \\
\text { concentration. Assumed to remain } \\
\text { indefinitely. } \\
\text { Represents infiltration from initial ash } \\
\text { layer before removal. }\end{array}$ & $\begin{array}{l}\text { Initial condition } \\
\text { Initial ash-layer thickness: uniform distribution from } \\
1 \text { to } 15 \mathrm{~cm} \text {, or the initial ash layer thickness } \\
\text { calculated for the divide areas in the TSPA model, } \\
\text { whichever is greater. } \\
\text { Initial waste concentration: Mean Primary Waste } \\
\text { Concentration (see Table } 6-4 \text { and NOTES below) } \\
\text { except for realizations in which the ash thickness } \\
\text { calculated in the TSPA is greater than the } \\
\text { thickness sampled from the } 1 \text { to } 15 \text { cm uniform } \\
\text { distribution; in those cases, use the waste } \\
\text { volumetric concentration calculated in TSPA for the } \\
\text { ash layer at the location of the RMEl. } \\
\text { Ash removal } \\
\text { Volumetric concentration of waste in the ash layer } \\
\text { decreases linearly from its initial volumetric } \\
\text { concentration to } 1 / 100 \text { th of its initial volumetric } \\
\text { concentration within a time period uniformly } \\
\text { distributed between } 100 \text { and } 1,000 \text { years. This } \\
\text { decrease in volumetric concentration represents } \\
\text { dilution during removal and replacement of the } \\
\text { initial sediment. } \\
\text { Residual conditions } \\
\text { After removal of the initial volumetric concentration, } \\
\text { a layer with the same initial thickness but with } \\
1 / 100 \text { th of the initial volumetric concentration is } \\
\text { assumed to remain indefinitely. } \\
\text { This residual layer represents lower levels of } \\
\text { contamination that may be brought down the wash } \\
\text { or exposed from underlying soil. }\end{array}$ \\
\hline
\end{tabular}


Table 6-5. Ash Redistribution Model Abstraction for the TSPA-LA Model (Continued)

\begin{tabular}{|c|c|c|}
\hline & Interchannel Divide & Distributary Channels \\
\hline AREAL WEIGHT & 0.82 & 0.18 \\
\hline $\begin{array}{l}\text { Outcome } 2 \\
\text { No primary tephra fall } \\
\text { on or near the RMEl } \\
\text { location. Primary } \\
\text { tephra deposition in } \\
\text { upper Fortymile Wash } \\
\text { drainage basin. }\end{array}$ & $\begin{array}{l}\text { Possible contamination by eolian } \\
\text { processes or major flood events is } \\
\text { approximated by a } 1 \text { to } 2 \mathrm{~cm} \\
\text { (uniform distribution) layer. } 1 / 100 \text { th } \\
\text { of the initial Mean Primary Waste } \\
\text { Concentration (see Table } 6-4 \text { ) is } \\
\text { assumed to remain indefinitely. }\end{array}$ & $\begin{array}{l}\text { Initial condition } \\
\text { Initial ash-layer thickness: uniform distribution from } \\
1 \text { to } 15 \mathrm{~cm} \text {. } \\
\text { Initial waste concentration: Mean Primary Waste } \\
\text { Concentration (see Table } 6-4 \text { ). } \\
\text { Ash removal } \\
\text { Volumetric concentration of waste in the ash layer } \\
\text { decreases linearly from its initial volumetric } \\
\text { concentration to } 1 / 100 \text { th of its initial volumetric } \\
\text { concentration within a time period uniformly } \\
\text { distributed between } 100 \text { and } 1,000 \text { years. This } \\
\text { decrease in volumetric concentration represents } \\
\text { dilution during removal and replacement of the } \\
\text { initial sediment. } \\
\text { Residual conditions } \\
\text { After removal of the initial volumetric concentration, } \\
\text { a layer with the same initial thickness but with } \\
1 / 100 \text { th of the initial volumetric concentration is } \\
\text { assumed to remain indefinitely. } \\
\text { This residual layer represents lower levels of } \\
\text { contamination that may be brought down the wash } \\
\text { or exposed from underlying soil. }\end{array}$ \\
\hline
\end{tabular}

Output DTN: LA0408CH831811.001.

1. The uniform distribution of erosion rate of 0.02 to $0.04 \mathrm{~cm} / \mathrm{yr}$ is based on current climate conditions. Although there is considerable uncertainty associated with long-term $(10,000 \mathrm{yr})$ erosion rates, the range provided is considered reasonable for the regulatory time frame.

2. Areal weights are developed in Harrington (2004 [DIRS 171345], p. 77), MOL.20040817.0271.

3. Volumetric waste concentrations specified in this table should be derived from the Mean Primary Waste Concentration calculated at $18 \mathrm{~km}$, at the midpoint of the plume, as reported in Table 6-4, and from the mean ash layer thickness at the same location, which is also based on the results in Table 6-4. A value of $1.0 \mathrm{~g} / \mathrm{cm}^{3} \mathrm{should}$ be used for ash settled density (BSC 2004 [DIRS 169980], Table 7-1, DTN: LA0407DK831811.001 (BSC 2004 [DIRS 170768]). For example, ash areal concentration $\left(\mathrm{g} / \mathrm{cm}^{2}\right)$ divided by ash settled density $\left(\mathrm{g} / \mathrm{cm}^{3}\right)$ equals ash thickness $(\mathrm{cm})$; waste areal concentration $\left(\mathrm{g} / \mathrm{cm}^{2}\right)$ divided by ash (or deposit) thickness $(\mathrm{cm})$ equals waste volumetric concentration $\left(\mathrm{g} / \mathrm{cm}^{3}\right)$. The resulting volumetric concentration should then be applied to the layer thicknesses (e.g., 1 to $15 \mathrm{~cm}$ uniformly distributed or 1 to $2 \mathrm{~cm}$ uniformly distributed) in this table.

\subsubsection{Interchannel-Divide Areas}

The interchannel divides are the broad, nearly flat surfaces of the fan that separate active channels. Interchannel divides comprise 82 percent of the Fortymile Wash alluvial fan (Harrington 2004 [DIRS 171345], p. 77)).

Outcome 1 - For igneous eruptive events that produce an initial ash fall at the RMEI location (Table 6-5), the initial tephra thickness is provided by TSPA Ashplume results. An ash and soil removal factor ranging from $0.02 \mathrm{~cm} /$ year to $0.04 \mathrm{~cm} /$ year is applied so that removal of $10 \mathrm{~cm}$ tephra or soil by erosion would occur in 250 to 500 years.

The technical basis for the ash removal rate distribution is a ${ }^{137} \mathrm{Cs}$ study that demonstrates erosion of 1 to $2 \mathrm{~cm}$ of the upper soil horizon in interchannel divide areas over a 50 -year period. 
The uniform distribution of erosion rates of 0.02 to $0.04 \mathrm{~cm} /$ year is based on current climate conditions (Section 5.1.4).

The concentration of waste in ash is represented by a contaminated soil layer $9 \mathrm{~cm}$ thick (Figure 6-4), in which radionuclide concentration within the layer decreases linearly from the value initially in the ash to 1 percent of that value at $9 \mathrm{~cm}$ depth (Table 6-5). The linear concentration decrease is conservative with respect to the exponential decrease observed in ${ }^{137} \mathrm{Cs}$ studies (BSC 2004 [DIRS 169980], Section 6.3.4.2; DTN: LA0308CH831811.002 [DIRS 164853]; Anspaugh et al. 1975 [DIRS 151548]). An examination of the cesium concentrations in a reference soil profile demonstrates that cesium is concentrated in the upper $3 \mathrm{~cm}$, and ${ }^{137} \mathrm{Cs}$ concentration decreases exponentially with depth in the soil profile. The concentration of ${ }^{137} \mathrm{Cs}$ decreases an order of magnitude from the upper $3 \mathrm{~cm}$ to the next interval sampled at 3 to $6 \mathrm{~cm}$. At 6 to $9 \mathrm{~cm}$, concentration is reduced by two orders of magnitude relative to the concentration in the upper $3 \mathrm{~cm}$ (BSC 2004 [DIRS 169980], Section 6.3.4.2; DTN: LA0308CH831811.002 [DIRS 164853]). The 9-cm thick layer is removed at the same rate as the initial ash layer, consistent with ${ }^{137}$ Cs observations (BSC 2004 [DIRS 169980], Section 6.3.4.2; DTN: LA0308CH831811.002 [DIRS 164853]).

In the model abstraction, a persistent layer of subsurface contamination following removal of the $9 \mathrm{~cm}$ layer is represented by a layer 1 to $2 \mathrm{~cm}$ thick (uniform distribution) with 1 percent of the initial concentration (Table 6-5). This layer, which is assumed to remain indefinitely, accounts for the effects of infiltration of waste from the intial ash layer before removal as well as the potential low-level influx of waste-contaminated eolian dust over time. The field data indicate that the assumption of the presence of a persistent contaminated soil layer below the 9-cm soil layer is conservative. Field investigations show that carbonate layers are widespread at depths of about $9 \mathrm{~cm} .{ }^{137} \mathrm{Cs}$ has not been found in samples collected below this depth on the fan (Harrington 2003 [DIRS 164775], pp. 28 to 53). For thin surface layers, the model provides a reasonable approximation for the inhalation pathway to the RMEI. Inhalation pathways are dominated by exposure to contaminated materials from thin surface layers of several millimeters. However, this model abstraction may cause significant overestimation of dose from ingestion and external exposure pathways.

Outcome 2- Tephra falls upstream of the location of the RMEI in the Fortymile Wash drainage and is then available for redistribution by eolian or fluvial processes (Table 6-5). Contaminated ash may be present on interchannel divides, as a result of wind transport or infrequent flood events that fill channels and spill onto the interchannel divides

This process is represented by a layer 1 to $2 \mathrm{~cm}$ thick (uniform distribution) containing residual contamination at 1 percent of the initial waste concentration (Table 6-5). The TSPA model assumes the same constant residual contamination model as in Outcome 1. However, instead of using probabilistic Ashplume output from TSPA, the model conservatively uses the Mean Waste Concentration (Table 6-4) calculated at $18 \mathrm{~km}$ south of the repository with wind direction fixed southward (Section 6.7.1). The residual concentration remains indefinitely at 1 percent of the Mean Primary Waste Concentration. The resulting volumetric concentration is applied to the sampled layer thicknesses. 


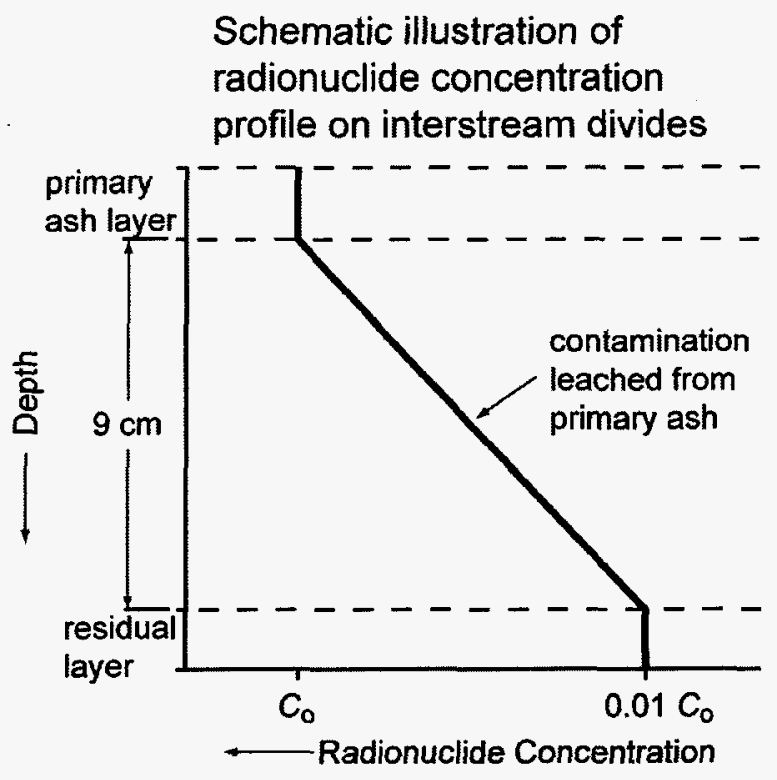

Source: BSC 2004 [DIRS 169980], Section 6.3.9.2.

NOTE: For illustration purposes only.

Figure 6-4. Schematic of Decrease in Radionuclide Concentration in Soil

\subsubsection{Distributary Channels}

Distributary channels are the parts of an alluvial fan that act as active drainages during runoff events. Distributary channels compose 18 percent of the Fortymile Wash alluvial fan (Harrington 2004 [DIRS 171345], p. 77).

Outcome 1-Processes are likely to be more complex in the distributary channels because tephra can be washed in from upstream areas during storm events. Redistributed sediment is in transient storage, and redistributed tephra thicknesses are variable with time within distributary channels. Although dilution is likely to occur, it is conservatively assumed that the initial washed-in tephra is not diluted but is deposited in channels at the RMEI location in layers ranging from 1-to $15-\mathrm{cm}$ thick. The upper value for this range was chosen on the basis of channel depths; sediment greater than $15-\mathrm{cm}$ thick would likely overtop the channel margins in this area of the alluvial fan.

The initial conditions in the distributary channels account for the rapid transport of contaminated ash in channels near the RMEI location in the first few years after the eruption. In addition the initial conditions account and for the possibility a hybrid model outcome in which significant ash is deposited at both the RMEI location and in the near portions of Fortymile Wash, and rapid transport within the wash results in enhanced thicknesses of ash in the distributary channels at the RMEI location. The initial thickness is determined as the greater of two values:

- A 1 to $15 \mathrm{~cm}$ thick layer sampled from a uniform distribution

- The initial ash layer thickness calculated for the interchannel divide areas. 
For these two possibilities, the concentration of waste in the ash is defined as, respectively:

- The geometric mean of the concentration calculated by ASHPLUME at $18 \mathrm{~km}$ (Table 6-4)

- The concentration calculated for ash fall on the interchannel divides.

The volumetric concentration of waste in the ash layer is assumed to decrease linearly from its initial concentration to 1 percent of its initial concentration within a time period uniformly distributed between 100 and 1,000 years. This decrease in volumetric concentration represents dilution during removal and replacement of the initial sediment by fluvial processes (Table 6-5). The ash redistribution model abstraction includes an implicit equivalence between waste volumetric concentration and areal concentration in this case, since waste dilution in channel sediments results from removal of waste from the RMEI area, rather than simple dilution by vertical migration. After removal of the initial concentration, a layer with the same initial thickness but with 1 percent of the initial concentration of waste is assumed to remain indefinitely (Section 6.7.2, Table 6-5).

Outcome 2-Initial conditions assume a 1 to $15 \mathrm{~cm}$ thick ash layer in the stream channels as a result of rapid erosion and transport from upstream slopes (but no primary ash fall at the RMEI location). The upper value for this range was chosen on the basis of channel depths; sediment greater than $15-\mathrm{cm}$ thick would likely overtop the channel margins in this area of the alluvial fan. The concentration of waste in the ash layer decreases linearly from its initial concentration (the Mean Primary Waste Concentration Table 6-4) to 1 percent of its initial concentration within a time period uniformly distributed between 100 and 1,000 years (Section 6.7.2). This decrease in concentration represents dilution during removal and replacement of the initial sediment by fluvial processes. The scenario assumes dilution occurs in a linear fashion until the tephra volume concentration reaches 1 percent of the initial concentration, after which there is no further decline in concentration. In other words, after dilution of the initial concentration, a layer with the same initial thickness, but with 1 percent of the initial waste concentration, is assumed to remain indefinitely. This residual layer represents lower levels of contamination that may be brought down the wash or exposed from underlying soil (Section 6.7.2, Table 6-5).

\subsubsection{Model Parameters}

Input parameters to TSPA for the ash redistribution model are based on geomorphological field studies in the Yucca Mountain region. The ${ }^{137} \mathrm{Cs}$ profiles are used as a proxy for all radionuclides because no other radionuclide data are available for the Fortymile Wash fan. For the purpose of the alternative ash redistribution model (Appendix I), datasets from the Nevada Test Site and the Chernobyl accident have been used for corroboration of the field ${ }^{137} \mathrm{Cs}$ data. 


\subsection{Areal weights for channels and interchannel divides}

Type: point values

Value: $0.18,0.82$

Units: N/A

The relative area factors (areal weights) for distributary channels and interchannel divides are used in TSPA-LA to combine the processes occurring on the two different landforms within the ash redistribution model (Table 6-5). The relative area covered by distributary channels on the upper portion of the Fortymile Wash alluvial fan is 0.18 , while the relative area covered by interchannel divides is 0.82 (Harrington 2004 [DIRS 171345], p. 77). These values were developed by the use of a planimeter (Figure 6-2).

\subsection{Ash erosion rate from interchannel divide areas}

Type: uniform distribution

Value: $0.02-0.04$

Units: $\mathrm{cm} / \mathrm{yr}$

The ash erosion rate is defined as the range $(0.02-0.04 \mathrm{~cm} / \mathrm{yr})$ for the removal of ash from interchannel divide areas in the Yucca Mountain region. The ash erosion rate is based on ${ }^{137} \mathrm{Cs}$ concentrations in samples collected from the YMR (BSC 2004 [DIRS 169980], Section 6.3.4). This rate is consistent with regional and statewide erosion for cultivated and non-cultivated farmland (BSC 2004 [DIRS 169980], Section 6.3.4.2.5).

\subsection{Residual concentration factor for waste in soil}

Type: point value

Value: 0.01

Units: N/A

The concentration of waste in the ash layer decreases linearly from its initial concentration to $1 \%$ of its initial concentration within a time period uniformly distributed between 100 and 1000 years. This decrease in concentration represents dilution during removal and replacement of the initial sediment. The assumed decrease in waste concentration in ash is consistent with the decrease in ${ }^{137} \mathrm{Cs}$ concentrations in soil from the surface to depths of about $9 \mathrm{~cm} .{ }^{137} \mathrm{Cs}$ concentrations decrease rapidly with depth and reach non-detectable levels at $9 \mathrm{~cm}$ or less. No ${ }^{137} \mathrm{Cs}$ has been detected below about $9 \mathrm{~cm}$ apparently because of the occurrence of a carbonate-rich layer that impedes infiltration of ${ }^{137} \mathrm{Cs}$. Based on the apparent analogy between waste concentration in ash-laden sediments and ${ }^{137} \mathrm{Cs}$ concentration in soil, the use of a residual waste concentration in ash is reasonable and perhaps conservative. 


\subsection{Time for ash dilution in channels}

Type: uniform distribution

Value: $100-1000$

Units: years

The concentration of waste in the ash layer decreases linearly from its initial concentration to $1 \%$ of its initial concentration within a time period uniformly distributed between 100 and 1000 years. This decrease in concentration represents dilution during removal and replacement of the initial sediment. The time period is consistent with the rate of sediment removal (and inferred transport) from the interchannel divides, approximately 1 to $2 \mathrm{~cm}$ per 50 years, or removal of $10 \mathrm{~cm}$ of sediment in $250-1000$ years. The range in this parameter is intended to provide order-of-magnitude bounds on uncertainty in the process of soil removal and sediment transport in the Fortymile Wash fan area.

\subsection{Thickness of residual contaminated soil layer}

Type: point value

Value: 9

Units: $\mathrm{cm}$

The concentration of waste in ash is represented by a contaminated soil layer $9 \mathrm{~cm}$ thick (Figure 6-4), based on the maximum depth of ${ }^{137} \mathrm{Cs}$ observed in alluvial soils in the Yucca Mountain region (BSC 2004 [DIRS 169980], Section 6.3.4.2; DTN: LA0308CH831811.002 [DIRS 164853]).

\subsection{Distribution of contamination within soil layer}

Type: linear decrease

Value: $1.0,0.01$

Units: N/A

The concentration of waste in ash in the $9 \mathrm{~cm}$-thick contaminated soil layer (Figure 6-4), decreases linearly from the value initially in the ash to 1 percent of that value at $9 \mathrm{~cm}$ (Table 6-5). The linear concentration decrease is conservative with respect to the exponential decrease observed in ${ }^{137} \mathrm{Cs}$ studies (BSC 2004 [DIRS 169980], Section 6.3.4.2; DTN: LA0308CH831811.002 [DIRS 164853]; Anspaugh et al. 1975 [DIRS 151548]). An examination of the cesium concentrations in a reference soil profile demonstrates that cesium is concentrated in the upper $3 \mathrm{~cm}$, and ${ }^{137} \mathrm{Cs}$ concentration decreases exponentially with depth in the soil profile. The concentration of ${ }^{137} \mathrm{Cs}$ decreases an order of magnitude from the upper $3 \mathrm{~cm}$ to the next interval sampled at 3 to $6 \mathrm{~cm}$. At 6 to $9 \mathrm{~cm}$, concentration is reduced by two orders of magnitude relative to the concentration in the upper $3 \mathrm{~cm}$ (BSC 2004 [DIRS 169980], Section 6.3.4.2; DTN: LA0308CH831811.002 [DIRS 164853]). 
INTENTIONALLY LEFT BLANK 


\section{MODEL VALIDATION}

Validation, or confidence building, is a means to ensure that the system behavior simulated by models is sufficiently consistent with observed behavior to give confidence in model outcomes. The Scientific Processes Guidelines Manual (BSC 2002 [DIRS 160313], Appendix B) describes three levels of model importance and corresponding validation guidelines commensurate with each level. These levels of model importance are based on the TSPA system sensitivity analyses and conclusions presented in Risk Information to Support Prioritization of Performance Assessment Models (BSC 2003 [DIRS 168796]), referred to herein as the Prioritization Report. The Scientific Processes Guidelines Manual (BSC 2002 [DIRS 160313], Appendix B, p. B-9) refers to a discussion about parameters related to an ash plume during a hypothetical eruption through a repository and TSPA sensitivity studies (see Sections 3.3.13 and 5.1.10 of the Prioritization Report). It states that the only parameters of this type evaluated in this report, that bear significantly on the estimate of the mean annual dose to the RMEI, are wind speed and direction. The Ashplume model parameters discussed in this model report correspond to this TSPA analysis. Accordingly, the Scientific Processes Guidelines Manual (BSC 2002 [DIRS 160313], Table B.1-1) states that adequate confidence in a model component would be obtained by considering the uncertainties and assumptions in the representation of these factors (e.g., wind speed and direction) and that confidence gained through Level II model validation should provide an adequate basis for the TSPA-LA. The Scientific Processes Guidelines Manual approach was adopted for model validation work associated with the Ashplume model and is described in this section. Appendix $\mathrm{C}$ of the Technical Work Plan: Igneous Activity Assessment for Disruptive Events, REV 04 (BSC 2003 [DIRS 166289]), describes the process used to validate these models.

The Ashplume model was validated in the previous version of this document (BSC 2004 [DIRS 167616]). This section is provided as historic documentation of the process used. The ash redistribution conceptual model was added to this model report after the Prioritization Report (BSC 2002 [DIRS 160780]) was completed. AP-SIII.10Q Rev 2 ICN 0, Models, does not require post-development model validation for a conceptual model; however, because the Ash Redistribution conceptual model and its representation in the TSPA may impact dose, the ash redistribution conceptual model is given the same level of importance as the Ashplume mathematical model. Appendix C of the Technical Work Plan: Igneous Activity Assessment for Disruptive Events, REV 04 (BSC 2003 [DIRS 166289]), describes the process used to validate this model.

\subsection{VALIDATION PROCEDURES}

The Scientific Processes Guidelines Manual (BSC 2002 [DIRS 160313], Appendix B) provided guidance for the approach to validate Level II models. A single post-development model validation method was required for both Level I and Level II importance models, as described in AP-SIII.10Q, Models (Rev 2 ICN 0, Section 5.3.3c). Although the Scientific Processes Guidelines Manual calls for Level II validation of the ash dispersal model, sufficient validation activity was performed for the Ashplume model to meet Level III standards. Specifically, two post-development model validation methods were completed for the Ashplume model. One method of post-development model validation (independent technical review) was completed for the ash redistribution conceptual model. Table 7-1 summarizes the validation activities carried 
out to satisfy the Level III validation criteria based on AP-SIII.10Q, Models (Rev 2 ICN 0 , Section 5.3.3) criteria, for the Ashplume model and specifies the location in this model report in which each activity is discussed.

Table 7-1. Confidence-Building and Post-Model Development Validation Activities

\begin{tabular}{|c|c|}
\hline $\begin{array}{l}\text { AP-SIII.10Q (Rev } 2 \text { ICN 0) } \\
\text { Validation Approaches }\end{array}$ & Location of Discussion in this Model Report \\
\hline \multicolumn{2}{|c|}{ Confidence-Building Activities Related to Model Development } \\
\hline \multirow[t]{3}{*}{$\begin{array}{l}\text { Selection of input parameters and/or data, } \\
\text { and a discussion of how the selection } \\
\text { process builds confidence in the model } \\
\text { (confidence building during model } \\
\text { development }(5.3 .3(b)(1)) \text { ). }\end{array}$} & $\begin{array}{l}\text { Input parameters were selected to represent conditions expected for a } \\
\text { volcanic eruption specific to the YMR and to include the range of } \\
\text { values representing uncertainty in future eruption parameters, } \\
\text { atmospheric conditions, and erosion/dilution rates. Model input } \\
\text { discussion is in Sections } 6.5 \text { and } 6.6 \text {. }\end{array}$ \\
\hline & Model assumptions and simplifications are discussed in Section 5. \\
\hline & $\begin{array}{l}\text { A special calculation has been completed to demonstrate that the } \\
\text { model is mass conservative (DOE } 2003 \text { [DIRS 166506]). }\end{array}$ \\
\hline $\begin{array}{l}\text { Description of calibration activities, and/or } \\
\text { initial/boundary condition runs, and/or run } \\
\text { convergences, and a discussion of how } \\
\text { the activity or activities build confidence in } \\
\text { the model. Include a discussion of } \\
\text { impacts of any run non-convergences } \\
\text { (confidence building during model } \\
\text { development }(5.3 .3(\mathrm{~b})(2) \text { ). }\end{array}$ & $\begin{array}{l}\text { A sensitivity analysis in which model simulations were carried out to } \\
\text { span the entire range of all parameters represented by distributions } \\
\text { and outputs checked for consistency. See Section } 7.2 \text {. }\end{array}$ \\
\hline $\begin{array}{l}\text { Discussion of the impacts of uncertainties } \\
\text { to model results (confidence building } \\
\text { during model development }(5.3 .3(b)(3)) \text { ). }\end{array}$ & $\begin{array}{l}\text { Parameter uncertainties, including wind speed and direction, are } \\
\text { discussed in Sections } 4,6.5 \text {, and } 6.6 \text {. } \\
\text { The representation of important model parameters with distributions of } \\
\text { values to be used in the TSPA-LA Monte Carlo approach ensures that } \\
\text { the range of possible outcomes is fully represented. Discussion of } \\
\text { selection of the parameter distributions is in Section } 6.5 \text {. }\end{array}$ \\
\hline \multicolumn{2}{|c|}{ Post-Development Model Validation Activities } \\
\hline $\begin{array}{l}\text { Corroboration of model results with data } \\
\text { acquired from the laboratory, field } \\
\text { experiments, analog studies or other } \\
\text { relevant observations, not previously used } \\
\text { to develop or calibrate the model (post- } \\
\text { development model corroboration } \\
(5.3 .3(\mathrm{c})(1))) \text {. }\end{array}$ & $\begin{array}{l}\text { Calculations were performed to compare Ashplume model results to } \\
\text { data collected for three volcanoes representative of volcanic ash } \\
\text { deposits in the YMR (Cerro Negro, Lathrop Wells, and Cinder Cone). } \\
\text { The comparisons are documented in Section 7.3. A corroborative ash } \\
\text { dilution study was completed on the Lathrop Wells cone for the ash } \\
\text { redistribution conceptual model. }\end{array}$ \\
\hline $\begin{array}{l}\text { Technical review, planned in the } \\
\text { applicable TWP, by reviewers } \\
\text { independent of the development, } \\
\text { checking, and interdisciplinary review of } \\
\text { the model documentation (post- } \\
\text { development model validation } \\
(5.3 .3(c)(5)) \text { ). }\end{array}$ & $\begin{array}{l}\text { An independent review was performed by Dr. Frank Spera of the } \\
\text { University of California to assess the applicability of the Ashplume } \\
\text { model. The independent technical review is documented in } \\
\text { Section } 7.4 \text { (see Appendix F for text of the technical review). }\end{array}$ \\
\hline $\begin{array}{l}\text { Technical review, planned in the } \\
\text { applicable TWP, by reviewers } \\
\text { independent of the development, } \\
\text { checking, and interdisciplinary review of } \\
\text { the model documentation (post- } \\
\text { development model validation } \\
(5.3 .3(c)(5))) \text {. }\end{array}$ & $\begin{array}{l}\text { An independent review was performed by Dr. David Buesch and Dr. } \\
\text { Dennis O'Leary, U.S. Geological Survey, to assess the applicability of } \\
\text { the ash redistribution conceptual model. The independent technical. } \\
\text { review is documented in Section } 7.4 \text { (see Appendix G for text of the } \\
\text { technical review). }\end{array}$ \\
\hline
\end{tabular}




\subsection{SENSITIVITY ANALYSIS}

A sensitivity analysis was performed to test the Ashplume model over the entire range of model input parameter values to be used in the TSPA analysis. This sensitivity analysis both ensured that the model operated as expected over the parameter ranges selected and identified limits to model validity due to any numerical constraints.

The sensitivity analysis was performed by varying the following input parameters: eruptive power, mean particle diameter, particle diameter standard deviation, column diffusion constant (beta), initial rise velocity, wind speed, wind direction, eruption duration, and waste incorporation ratio. These parameters were represented in the input set as distributions of parameters (Table C-10). During a TSPA-LA simulation, these parameters might take on any value within the distribution of values defined in Section 6.5. The input parameter values used in the sensitivity runs were selected from the tables shown in Appendix C. The model was run over the full range of values for each parameter shown in the tables.

The results of each ASHPLUME V2.0 (CRWMS-M\&O 2001 [DIRS 152844]) run for a given parameter were plotted and evaluated for sensitivity to change in value. The plots shown in Appendix C (Figure C-1 to Figure C-9) exhibit expected trends that are in accordance with increasing parameter values. No discontinuities in results were detected, which indicates numerical convergence in all simulations. The analysis indicates that the Ashplume model results are most sensitive to eruptive power, wind speed, wind direction, and eruption duration; the variations in these parameters over their respective ranges results in two or three order-of-magnitude changes in ash thickness. The model is much less sensitive to variations in beta, mean particle diameter, particle diameter standard deviation, initial rise velocity, and waste incorporation ratio; variations in these parameters over their respective ranges results in variations of ash thickness by less than a factor of three.

As described in the FY 01 Supplemental Science and Performance Analyses, Volume 1: Scientific Bases and Analyses (BSC 2001 [DIRS 155950], Section 14.3.3.4), the DOE completed analyses to evaluate the effects of uncertainties in waste-particle size on dose. This parameter is associated with the volcanic eruption scenario (BSC 2001 [DIRS 157876], Section 6.1 and Table 4). Waste-particle diameter was varied over a range of values (BSC 2001 [DIRS 155950], Section 14.3.3.4) sufficient to address uncertainties in the distribution. The sensitivity analysis showed that performance is relatively insensitive to uncertainty in waste-particle size within the range considered in the analysis (BSC 2001 [DIRS 154659], Section 3.3.1.2.2). The DOE considers that the sensitivity of performance to uncertainties in waste-particle size distribution is well understood and was sufficiently documented in the FY01 Supplemental Science and Performance Analyses, Volume 2: Performance Analyses (BSC 2001 [DIRS 154659], Section 3.3.1.2.2). The DOE considers the information in the volumes of the analysis above (BSC 2001 [DIRS 154659] as adequate to address this issue for TSPA-LA. 


\subsection{NATURAL ANALOG STUDIES FOR ASHPLUME AND THE ASH REDISTRIBUTION CONCEPTUAL MODEL}

\subsubsection{Ashplume}

\subsubsection{Cerro Negro}

The Cerro Negro volcano is one of a number of active basaltic volcanoes within an active volcanic chain in Nicaragua. Cerro Negro is located on the Caribbean tectonic plate, and the volcanic activity expressed within this long volcanic chain, which continues from southern Mexico to Costa Rica, is directly related to subduction of the Pacific tectonic plate under the Caribbean tectonic plate. Volcanism at Cerro Negro has a 150-year history with at least 22 documented eruptions. Its last eruption (1995) produced a tephra volume $\left(0.004 \mathrm{~km}^{3}\right)$ (Hill et al. 1998 [DIRS 151040]) similar to, but less than, that of the Lathrop Wells cone (>0.04 $\mathrm{km}^{3}$ ) (BSC 2004 [DIRS 169980], Section 6.3.3.4). The volume of the Cerro Negro cinder cone is over four times that of the Lathrop Wells cone (BSC 2004 [DIRS 169980]), but the 1995 Cerro Negro eruption may be somewhat analogous to the type of eruption that could occur in the YMR. However, Cerro Negro's long history, shape, and magma production rate suggest that it may represent a young composite volcano rather than a simple, long-lived cinder cone (McKnight and Williams 1997 [DIRS 162827]).

The measured eruption parameters published by Hill et al. (1998 [DIRS 151040]) were used to develop input parameters for the ASHPLUME code (versions 1.4 and 2.0). Because these field measurements were assumed to accurately represent the actual 1995 eruption of Cerro Negro (CRWMS M\&O 2000 [DIRS 152998]), these parameters were not varied in ASHPLUME to attempt to match the field data. Because of the uncertainties associated with the atmospheric and eruption conditions of the Cerro Negro event, comparison of ashfall thicknesses between the observed distribution and the Ashplume result is qualitative. However, this comparison provides confidence that the Ashplume model can give a reasonable facsimile of ash deposition for the type of a possible future eruption at Yucca Mountain.

As shown in Figure 7-1 the Ashplume calculations compare well with the observed data for distances from the volcanic vent greater than $10 \mathrm{~km}$. For distances less than $10 \mathrm{~km}$, the Ashplume results give ash thickness values greater than the observed data. The lobe on the northern side of the measured ash thickness data is interpreted to be a result of a variation in wind direction and/or speed that occurred during the eruption. This variation probably accounts for some of the discrepancy because Ashplume assumes a constant wind speed and direction for a given simulation. In addition, ASHPLUME V 1.4LV (BSC 2003 [DIRS 161296]) and ASHPLUME V 2.0 (CRWMS-M\&O 2001 [DIRS 152844]) are compared in Figure 7-1 to show the overall consistency between the two versions. 

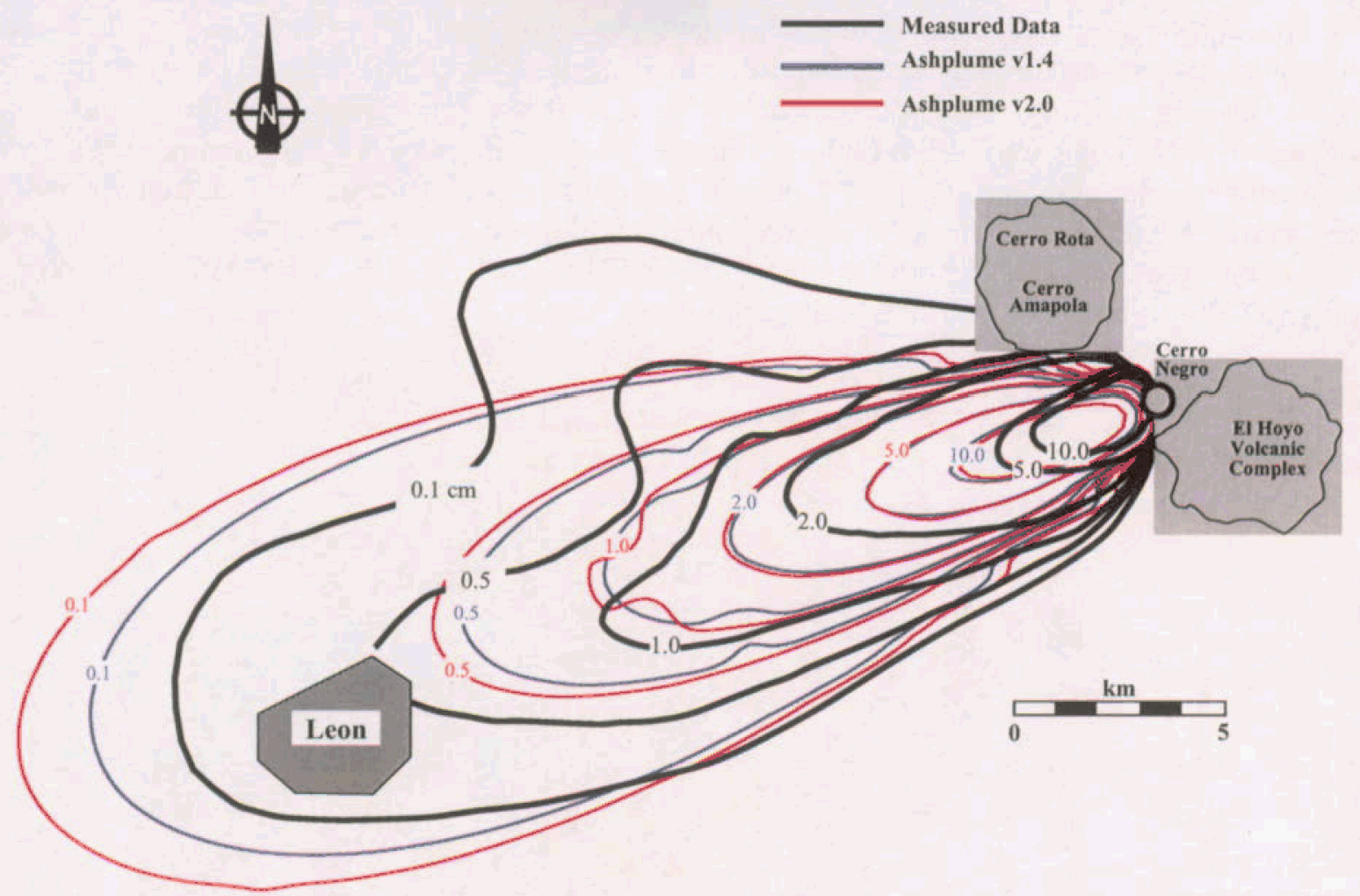

Source: CRWMS M\&O (2000 [DIRS 152998], Figure 6).

Figure 7-1 Comparison of Calculated and Measured Ash Deposition Thickness (cm) for 1995 Cerro Negro Eruption: Isopachs of Model Results from ASHPLUME V 1.4LV and V 2.0 Compared to Observed (Measured) Ash Thickness

\subsubsection{Lathrop Wells}

At 77,000-years old (Heizler et al. 1999 [DIRS 107255], p. 803), the Lathrop Wells Cone, Nevada, is the youngest basaltic volcano in the YMR. It is the southern-most surface expression of the Plio-Pleistocene Crater Flat Volcanic Zone (CFVZ) (Crowe and Perry 1990 [DIRS 100973], p. 328) and is located approximately $18 \mathrm{~km}$ south of Yucca Mountain. Characteristics of the volcanism comprising the CFVZ are documented in Perry et al. (1998 [DIRS 144335], Chapters 2 and 4). Eruptive history of the Lathrop Wells cone and volume estimates of the cone, lava flows, and eruptive tephra are provided in Characterize Eruptive Processes at Yucca Mountain, Nevada (BSC 2004 [DIRS 169980], Appendix C). The volume of tephra was estimated from field sample points, which located ashfall deposits that are now shallowly buried beneath younger colluvium and eolian deposits. Due to deeper burial or non-deposition of the tephra, data points to the south of the cone are largely absent, and this results in an apparent tephra fall pattern directed northward from the vent area. Additionally, there are no data for ash deposits less than 1-cm thick, which limits the identification of the northward extent of the ashfall. The tephra distribution presented in Characterize Eruptive Processes at Yucca Mountain, Nevada (BSC 2004 [DIRS 169980]) is, therefore, a minimum distribution. 
For the Lathrop Wells cone simulation, all parameters were set to base-case values, and several calculations were performed using the full range of wind speeds that will be used for the TSPA-LA. Specifically, wind speeds ranging between $0 \mathrm{~cm} / \mathrm{s}$ and $2,366 \mathrm{~cm} / \mathrm{s}$ were simulated, and results were compared to the Lathrop Wells cone data (Figure 7-2). The figure also shows the results of a simulation using wind speeds of $800 \mathrm{~cm} / \mathrm{s}$ (Model 4), which most closely matches the Lathrop Wells cone tephra data. The simulations showed that observed Lathrop Wells data fall within the range of results produced by ASHPLUME V 2.0 (CRWMS M\&O 2001 [DIRS 152844]) using the TSPA-LA range of wind speeds.

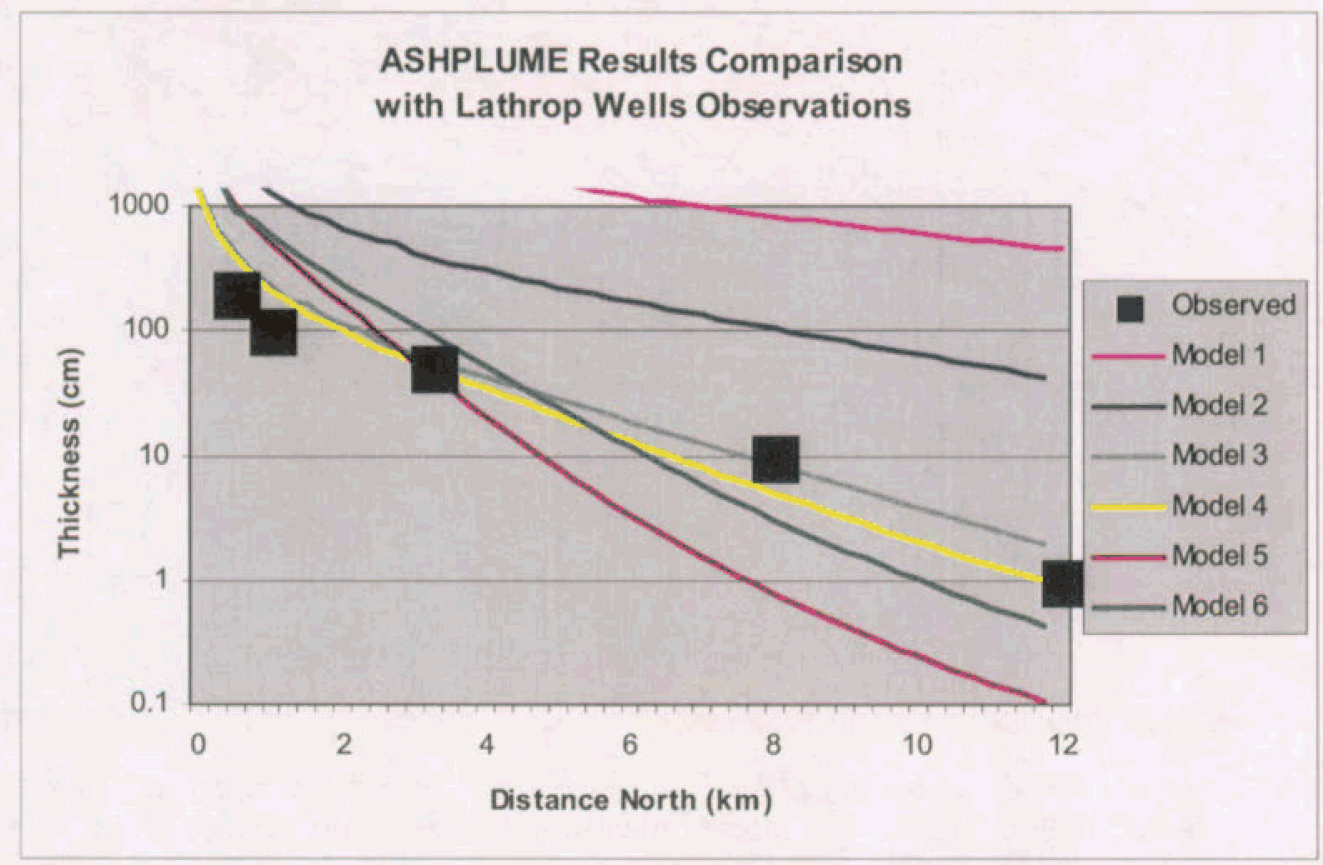

Source: Heiken et al. (2003 [DIRS 166290).

NOTE: Models 3 and 4 demonstrate a close match to observed data: within a factor of 3 proximally and within 5 percent distally. Observed data are from an isopach map in Krier and Harrington (2003 [DIRS 164023]. p. 153), measured north from the vent. Models are realizations for a wind blowing to the north. Parameters held constant for these comparisons are $\beta=0.3, \mathrm{~d}=0.0572 \mathrm{~cm}, \sigma_{\mathrm{d}}=0.2518, \rho_{\mathrm{c}}=0.3$, and $\mathrm{U}=0$. The following list shows the varied parameters in each model with $\mathrm{V}$ calculated from $\mathrm{P}$ and $\mathrm{T}_{d}$ by Equations 6-7a-6-7c for a conduit diameter of $10 \mathrm{~m}$ (Models 1 and 2) and $4.5 \mathrm{~m}$ (Models $3-6$ ).

Model 1: $P=5.0 \times 10^{12} W, V=0.08 \mathrm{~km}^{3}, T d=0.2 \mathrm{~d}, W_{0}=24.5 \mathrm{~m} / \mathrm{s}, \mathrm{u}=1000 \mathrm{~cm} / \mathrm{s}$ Model 2: $P=5.0 \times 10^{11} \mathrm{~W}, V=0.04 \mathrm{~km}^{3}, T d=1.0 \mathrm{~d}, W_{0}=12.1 \mathrm{~m} / \mathrm{s}, \mathrm{u}=1000 \mathrm{~cm} / \mathrm{s}$ Model 3: $P=5.0 \times 10^{10} \mathrm{~W}, V=0.004 \mathrm{~km}^{3}, T d=1.0 \mathrm{~d}, W_{0}=1.2 \mathrm{~m} / \mathrm{s}, \mathrm{u}=1000 \mathrm{~cm} / \mathrm{s}$ Model 4: $P=5.0 \times 10^{10} \mathrm{~W}, V=0.004 \mathrm{~km}^{3}, T d=1.0 \mathrm{~d}, W_{0}=1.2 \mathrm{~m} / \mathrm{s}, \mathrm{u}=800 \mathrm{~cm} / \mathrm{s}$ Model 5: $P=6.2 \times 10^{8} \mathrm{~W}, V=0.004 \mathrm{~km}^{3}, T d=75.0 \mathrm{~d}, W_{0}=0.01 \mathrm{~m} / \mathrm{s}, u=1000 \mathrm{~cm} / \mathrm{s}$ Model 6: $P=6.2 \times 10^{8} \mathrm{~W}, \mathrm{~V}=0.004 \mathrm{~km}^{3}, \mathrm{Td}=75.0 \mathrm{~d}, W_{0}=0.01 \mathrm{~m} / \mathrm{s}, \mathrm{u}=1400 \mathrm{~cm} / \mathrm{s}$.

Figure 7-2. Comparison of Ashplume Results to Lathrop Wells Ash Thickness Observations 


\subsubsection{Cinder Cone}

Basaltic ash thickness data from Cinder Cone, a 277-m-high Holocene cone in Lassen Volcanic National Park, California, is provided in Heiken (1978 [DIRS 162817]). Cone and tephra-sheet volume $\left(0.038 \mathrm{~km}^{3}\right.$ and $0.032 \mathrm{~km}^{3}$, respectively), composition, monogenetic behavior, and eruptive sequence make Cinder Cone a good analog for a future eruption in the YMR. Several ASHPLUME V 2.0 (CRWMS-M\&O 2001 [DIRS 152844]) simulations were carried out to compare ASHPLUME results (predictions) to observed ash-thickness data. For the Cinder Cone simulation (Figure 7-3), all parameters were set to base-case values except for particle size and sorting. These parameters were set based on information provided in Heiken (1978 [DIRS 162817]). Several calculations were performed using the full range of wind speeds used for the TSPA-LA. Similar to the Lathrop Wells analysis, wind speeds ranging between $0 \mathrm{~cm} / \mathrm{s}$ and $2,366 \mathrm{~cm} / \mathrm{s}$ were simulated, and results were compared to the Cinder Cone data. Figure 7-3 shows the results of the simulation. The $2,000-\mathrm{cm} / \mathrm{s}$ (Model 2) wind speed provides a good fit to the proximal and distal data. The simulations show that observed Cinder Cone data fall well within the range of results produced by Ashplume using the TSPA-LA range of wind speeds.

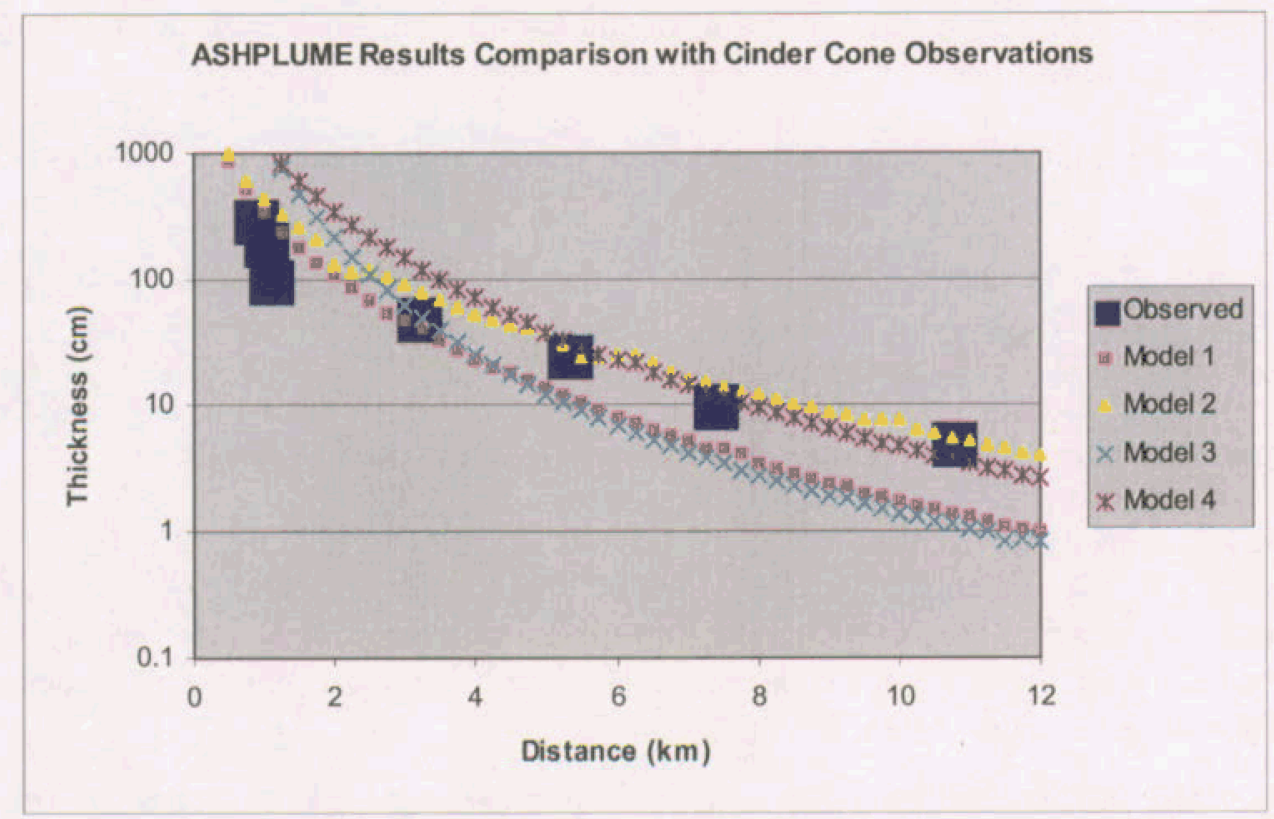

Source: Heiken et al. (2003 [DIRS 166290]).

NOTE: Model 2 demonstrates a close match to observed data: within a factor of 2 proximally and within 10 percent distally. Observed data are from Heiken (1978 [DIRS 162817]). Models are realizations for a wind blowing to the east. Parameters held constant for these comparisons are $\beta=0.3, d=0.193 \mathrm{~cm}$, $\sigma_{d}=-0.78, \rho_{c}=0.3$, and $U=0$. The following list shows the varied parameters in each model with $V$ calculated from $P$ and $T_{d}$ by Equations $6-7 \mathrm{a}-6-7 \mathrm{c}$ for a conduit diameter of $5.0 \mathrm{~m}$ (Models 1 and 2 ) and $8 \mathrm{~m}$ (Models 3 and 4).
Model 1: $P=5.0 \times 1010 \mathrm{~W}, V=0.004 \mathrm{~km} 3, T d=1.0 \mathrm{~d}, \mathrm{~W} 0=24.5 \mathrm{~m} / \mathrm{s}, \mathrm{u}=1000 \mathrm{~cm} / \mathrm{s}$
Model 2: $P=5.0 \times 1010 \mathrm{~W}, V=0.004 \mathrm{~km} 3, T d=1.0 \mathrm{~d}, W 0=1.2 \mathrm{~m} / \mathrm{s}, \mathrm{u}=2000 \mathrm{~cm} / \mathrm{s}$
Model 3: $P=7.5 \times 1010 \mathrm{~W}, V=0.065 \mathrm{~km} 3, T d=10.0 \mathrm{~d}, W 0=0.5 \mathrm{~m} / \mathrm{s}, \mathrm{u}=200 \mathrm{~cm} / \mathrm{s}$
Model 4: $P=6.8 \times 1010 \mathrm{~W}, \mathrm{~V}=0.018 \mathrm{~km} 3, \mathrm{Td}=3.0 \mathrm{~d}, \mathrm{~W} 0=0.5 \mathrm{~m} / \mathrm{s}, \mathrm{u}=800 \mathrm{~cm} / \mathrm{s}$

Figure 7-3. Comparison of Ashplume Results to Cinder Cone Ash Thickness Observations 
The Lathrop Wells and Cinder Cone simulations of tephra thicknesses provide additional confidence that the Ashplume model and model parameters selected for use in the TSPA-LA can produce ash thickness results that cover the range of values expected for volcanoes in the YMR.

\subsubsection{Ash Redistribution}

The sedimentary processes affecting the tephra sheet at the Lathrop Wells volcanic cone were studied (Harrington 2003 [DIRS 164775], pp. 14 to 16) to determine the extent of tephra sheet dilution and to validate the significance of the process. The observations demonstrate that dilution is an important feature of the ash redistribution conceptual model. The significance of the dilution is demonstrated by the estimate of ash dilution rates.

Redistribution of volcanic ash initiates in small channels developed on tephra sheets northwest of the Lathrop Wells cone. The tephra moves downslope as small debris flows with dimensions typically tens of centimeters wide and tens of meters long. Tephra moves through progressive generations of these small debris flows until it reaches a channel at the base of the slope. The channel may then merge with larger channels. Depending upon initial tephra thickness, each step in the process results in some dilution of the tephra with other material (Harrington 2003 [DIRS 164775], pp. 14 to 16 ).

There are two principal drainage systems that transport ash from the Lathrop Wells cone (Figure 7-4):

- The western drainage system transports material from the exposed tephra sheet on the northwest side of Lathrop Wells cone to the west and south into the Amargosa Valley.

- The eastern drainage system heads near the northern limit of the exposed tephra sheet and transports material around the eastern side of the Lathrop Wells cone.

The two drainage systems on the Lathrop Wells tephra sheet were sampled at depths of approximately $0.5 \mathrm{~m}$ to evaluate dilution rates by determining the ratio of tephra to non-tephra components. The stream sediment samples were split in the laboratory, analyzed by microscope, and separated by a magnet to obtain the percentages of basaltic ash components relative to their transport distance from the tephra sheet (Table 7-2).

Mixing occurs along the eastward drainage around the Lathrop Wells volcanic cone according to the trend evident in the table of basaltic ash content in the total sediment (Table 7-2). The data in Table 7-2 indicate that the concentration of basaltic ash is reduced by more than 50 percent, within 1-km distance from the head of the tephra-sheet drainage and shows substantial dilution in the first $700 \mathrm{~m}$. The channel on the west side has less than 40 percent basaltic ash after $1 \mathrm{~km}$ of transport. These data are illustrative of the effects of dilution during tephra redistribution in channels but also have uncertainties due to (1) the small number of samples, and (2) the fact that tephra redistribution processes around the Lathrop Wells cone have matured since the eruption approximately 77,000 years ago (Heizler et al. 1999 [DIRS 107255], p. 803). Dilution rates may have been substantially different shortly after the eruption. Also, differences in catchment area, bedrock types, vegetation, elevation, and precipitation may limit the direct analogy with a potential eruption at Yucca Mountain. 


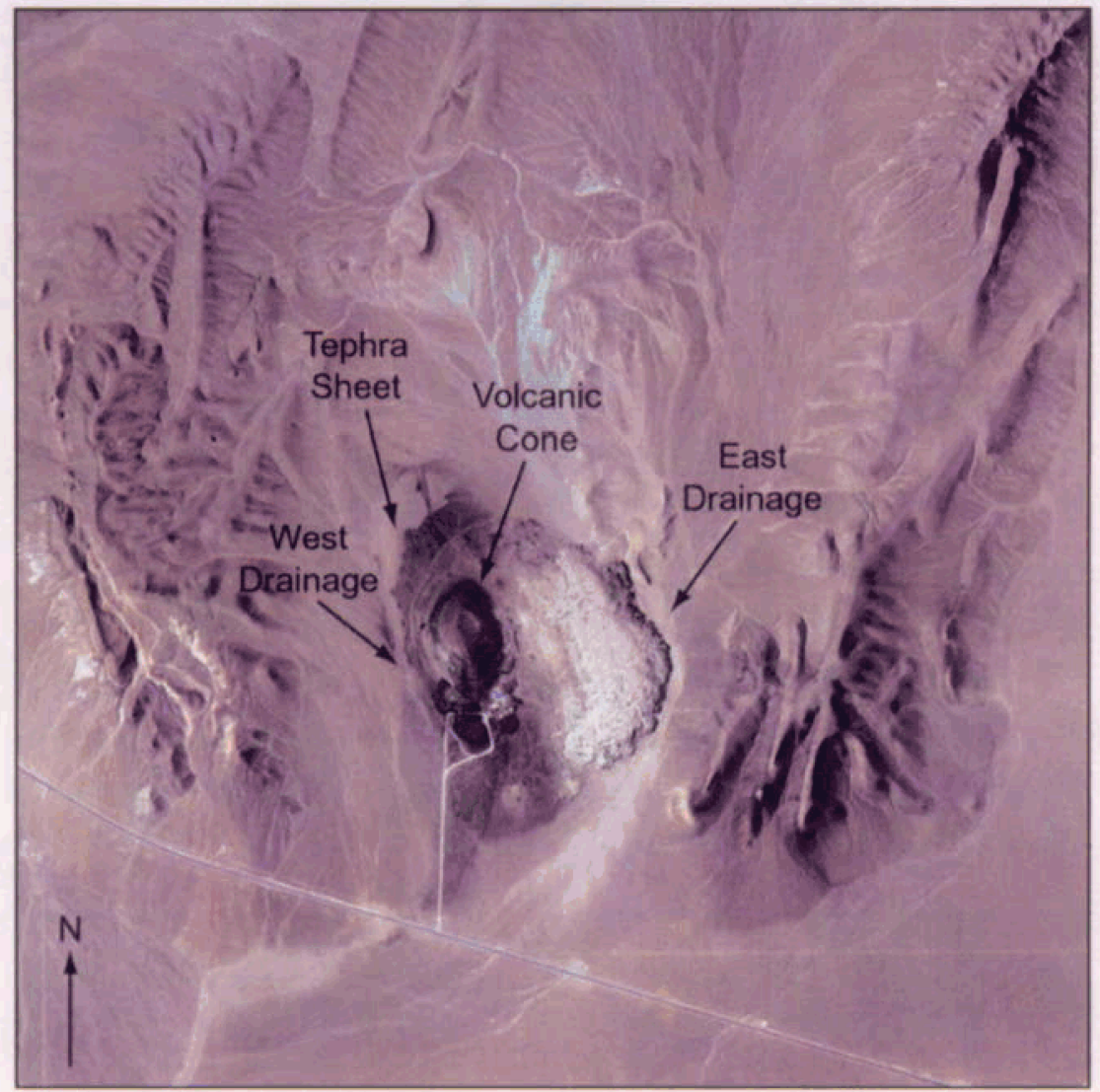

For illustration purposes only.

Photo source: EG\&G Mission, August 28, 1994, Photo frame 140, Elevation 32,000 ft.

NOTE: The Lathrop Wells basaltic cone is shown in the center of the photo with a tephra sheet draping the hill to the north. Two sets of samples were collected: one beyond the tephra sheet and in the east drainage system around the cone; the second set follows the drainage channel that lies west of the cone. The Amargosa Valley is south of the photo.

Figure 7-4. Aerial Photograph Showing Lathrop Wells Drainage System

Table 7-2. Ash Volume Percentages in Samples of Drainage Channels Near Lathrop Wells Cone

\begin{tabular}{|c|c|c|}
\hline $\begin{array}{c}\text { Sample } \\
\text { Number }\end{array}$ & $\begin{array}{c}\text { Basaltic Ash } \\
\text { (wt. } \%)\end{array}$ & $\begin{array}{c}\text { Distance from Head } \\
\text { of Channel }(\mathbf{m})\end{array}$ \\
\hline Lathrop Wells Cone, West Side & \multicolumn{2}{|c|}{} \\
\hline LWASH1-07/11/02-1 & 98.7 & 0 \\
\hline LWASH1-07/11/02-3 & 92.3 & $\sim 100$ \\
\hline LWASH1-07/11/02-5 & 35.0 & $\sim 200$ \\
\hline LWASH1-07/12/02-3 & 50.8 & $\sim 700$ \\
\hline LWASH1-07/12/02-5 & 39.6 & $\sim 1000$ \\
\hline
\end{tabular}


Table 7-2. Ash Volume Percentages in Samples of Drainage Channels Near Lathrop Wells Cone (Continued)

\begin{tabular}{|c|c|c|}
\hline $\begin{array}{c}\text { Sample } \\
\text { Number }\end{array}$ & $\begin{array}{c}\text { Basaltic Ash } \\
\text { (wt. \%) }\end{array}$ & $\begin{array}{c}\text { Distance from Head } \\
\text { of Channel (m) }\end{array}$ \\
\hline Lathrop Wells Cone, East Side & \multicolumn{2}{|c|}{} \\
\hline LWASH2-08/1/02-1 & 54.9 & 0 \\
\hline LWASH2-08/1/02-3 & 59.4 & $\sim 400$ \\
\hline LWASH2-08/1/02-6 & 10.1 & $\sim 1200$ \\
\hline LWASH2-08/1/02-8 & 0.8 & $\sim 2500$ \\
\hline
\end{tabular}

DTN: LA0405CH831811.001 [DIRS 169998].

NOTE: Sample locations are shown in BSC 2004 [DIRS 169980], Figure 6-10.

\subsection{INDEPENDENT TECHNICAL REVIEW}

Independent technical reviews were conducted for both the Ashplume model and the ash redistribution conceptual model as part of the validation activities. Summaries of these reviews are presented in Sections 7.4.1 and 7.4.2, respectively.

\subsubsection{Ashplume Mathematical Model}

Consistent with the guidance in AP-SIII.10Q, Models, for validation of mathematical models, an independent technical review was conducted to assess the application of Ashplume for representing potential future volcanic events at Yucca Mountain. The review was conducted by Dr. Frank Spera, Professor of Geology at the University of California, Santa Barbara, from March 24, 2003, to April 10, 2003. Revision 00, Draft B of this model report was made available to Dr. Spera for his review (see Appendix F) along with other requested material. Dr. Spera was also a member of the Peer Review Panel that addressed the approach used by the Yucca Mountain Project to evaluate igneous consequences from a potential igneous event intersecting a repository at Yucca Mountain, Nevada (February 2003) (Detournay et al. 2003 [DIRS 169660]). Dr. Spera was requested to consider if the mathematical model is appropriate for representing the conceptual model (i.e., is Ashplume appropriate for its intended use), which is to represent the atmospheric dispersal of waste-contaminated tephra from a potential volcanic eruption at Yucca Mountain.

Dr. Spera observed that the fundamental factors governing the fallout distribution of volcanic tephra include the height of the steady-state volcanic column, a function of eruptive mass flow rate, total eruptive volume, and the wind speeds and direction affecting the tephra being ejected into the atmosphere at different levels above the volcanic vent. He concluded that, if available, additional analogs should be considered. Since his review, work to characterize the Lathrop Wells tephra sheets has been completed and documented in the revision to the scientific analysis report, Characterize Eruptive Processes at Yucca Mountain, Nevada (BSC 2004 [DIRS 169980]). In addition, analog studies of physical volcanology have been completed and documented in Characterize Eruptive Processes at Yucca Mountain, Nevada (BSC 2004 [DIRS 169980]) for Cinder Cone. These studies were then used as an additional basis for validation of Ashplume in this model report. 
Dr. Spera also recommended that the Ashplume model be compared to other similar mathematical models. He specifically recommended ASHFALL for this purpose. This comparison has not been performed because the ASHFALL code is not made available by the developer and, therefore, qualified use for corroboration was not possible.

Finally, Dr. Spera recommended that greater mass discharge rates and corresponding higher plume heights be considered when Ashplume is implemented. In response to this recommendation, new wind information (NOAA 2004[DIRS 171035]) has been implemented in this model report to better represent eruption mechanics, including consideration of greater eruptive power and mass discharge rate, and consideration of the behavior of an ash plume at greater altitudes (up to $13 \mathrm{~km}$ ).

Based on information available and a full understanding of its limitations, Dr. Spera concluded that the outputs of Ashplume are a reasonable representation of what may be expected from a volcanic eruption at Yucca Mountain.

\subsubsection{Ash Redistribution Conceptual Model}

At the time of the model development, the TWP (BSC 2003 [DIRS 166289]) requested an independent technical review of the ash redistribution model to be completed as a post-development validation activity to build confidence in the model. The ash redistribution model is presently a conceptual model, and only simple mathematical abstractions were completed (see Table 6-5) for input to the TSPA model; nevertheless, this model has been assigned a "moderate" (Level II) level of importance based on guidance in the Scientific Processes Guidelines Manual (BSC 2002 [DIRS 160313], Appendix B) and the rationale described in the TWP (BSC 2003 [DIRS 166289]). The independent technical review was conducted to assess the ash redistribution conceptual model and its abstraction for representing the deposition of tephra in the vicinity of the RMEI following a potential future volcanic event at Yucca Mountain. Two technical reviewers with expertise in sedimentary processes and Quaternary geology, Dr. David Buesch and Dr. Dennis O'Leary of the U.S. Geological Survey, reviewed the ash redistribution conceptual model between October 31, 2003 and November 19, 2003. Drs. Buesch and O'Leary, both familiar with the Yucca Mountain Project, were requested to evaluate whether the conceptual model and its abstraction are appropriate for their intended use in the TSPA. In other words, do the model and its abstraction represent the sedimentary processes that would affect contaminated ash deposited in Fortymile Wash (the two model outcomes for the deposition of volcanic ash resulting in maximum potential exposure to the RMEI being upstream or at the location of the RMEI) from a hypothetical volcanic eruption at Yucca Mountain? Revision 00, Draft H of this model report, was made available to Drs. Buesch and O'Leary for their review (see Appendix G). While the whole document was made available, the two reviewers were requested to concentrate on Sections 1.0, 4.0, 5.0, 6.6, 6.7, 7.0, and 8.0 of this model report. The following criteria were considered for this review:

- Is the conceptual model reasonable and appropriate for its intended use?

- For given inputs, are the outputs of the model reasonable?

- Are limitations of field and analytical data addressed with respect to the conceptual model described? 
- Are there other approaches that may enhance the confidence in use of this model?

- Are there other alternative models that should be considered?

The reviewers concluded that the conceptual model is reasonably representative of the past sedimentary processes in the Fortymile Wash drainage basin and that the model also represents expected future sedimentary processes. They further conclude that the model abstractions (outputs) were logical and representative of the conceptual model. Both reviewers stated that the database is limited and the conceptual model is preliminary in its development. It can be inferred from the reviews that the conceptual model, as described, and its abstraction are sufficient to bound the range of uncertainty in the deposition of the tephra sheet and the post-ash-deposition sedimentary processes. Additional confirmatory studies are recommended that will provide better confidence in the sedimentary processes that are occurring in the Fortymile Wash drainage basin and the application of localized processes to the larger scale of Fortymile Wash.

The reviewers also concluded that the limitations of the model were addressed in the model discussions; however, the reviewers differed on the level at which they were addressed. Dr. Buesch believed that the discussions of data and model limitations should be strengthened, while Dr. O'Leary believed that the data and model limitations were adequately addressed. The authors of the text clearly recognize the limitations of both the data and model and have addressed these in the text, where appropriate.

Both reviewers recommended that the description of the conceptual model be improved to better describe the model. The authors have edited the text to better present the conceptual model. The reviewers recommended further development of the conceptual model and the consideration of other conceptual models. It is the belief of Dr. Buesch that a new conceptual model may ultimately surface from consideration of alternative models and further analyses of the Fortymile Wash drainage basin and analog dilution studies of recent ash deposits. The authors agree that, at a minimum, a more sophisticated model is a likely outcome of additional confirmatory activities because additional parameters will most likely be integrated into the model, but the authors contend that the basic conceptual model will remain the same.

The independent technical reviewers identified a number of issues (italics) that are addressed in the following paragraphs.

Is it appropriate to extrapolate the local-scale studies of surface erosion (based on cesium-137 profiles) and ash dilution (based on drainages immediately adjacent to the Lathrop Wells volcano) to the larger scale processes that would accompany redistribution of tephra in the Fortymile Wash drainage?

Surface erosion rates for interchannel divides are based on data obtained directly in the area of the RMEI and, therefore, should directly apply given current climate and tectonic conditions. A technical basis for how these erosion rates might differ after changes occur in climate and tectonic processes (e.g., subsidence of Amargosa Valley) is lacking. Ash dilution studies around the Lathrop Wells cone are an indicator of ash dilution but are limited in their application due to the size of the Lathrop Wells drainage compared to the Fortymile Wash drainage (scaling) and the age of the tephra sheet (approximately 77,000 years). The dilution factors measured there 
today might not accurately reflect those in the decades immediately following an eruption, which is key to the TSPA. Therefore, the model that is used for redistribution of tephra down the Fortymile Wash system by the TSPA assumes that the tephra is not diluted by other sedimentary material-rather, it is emplaced as a 1 - to $15-\mathrm{cm}$ package of pure tephra (contaminated by radioactive waste) at the RMEI location.

The model for infiltration of radioactive contamination into soils beneath a primary tephra deposit is based (both in absolute value and in its trend with depth) on measured concentrations of cesium-137. Is cesium-137 an appropriate analog for all significant radionuclides that might be present in tephra erupted through the repository?

This question relates both to the short half-life of ${ }^{137} \mathrm{Cs}$, compared to spent nuclear fuel radionuclides, as well as its mobility in the subsurface. Several published reports corroborate the ${ }^{137} \mathrm{Cs}$ data as representative of the infiltration of radionuclides into surficial soils (see Appendix I, Section I9.1).

An eruption through the Yucca Mountain repository is most likely to produce a fallout deposit that extends into Jackass Flats and possibly into the Calico Hills areas that drain into Topopah Wash (rather than Fortymile Wash). Could this be an additional source of material to the RMEI location?

The model proposed in this report is valid regardless of the fluvial pathway of redistributed tephra to the RMEI location. The two redistribution model outcomes encompass the conditions in which the maximum concentration of waste would be delivered to the RMEI location; all other conditions and pathways would deliver lower concentrations.

Data on surface wind speeds, which are available in other Project reports, might be useful in discussing eolian processes, as would more detailed information on the mobilization of tephra off slopes of different steepness and bedrock types.

It is agreed that such studies would be an approach to test the model parameters described in this report.

For Ashplume calculations, assumptions are made about the nature of incorporation of SNF into ash/tephra particles. Are these same assumptions made in the development of the ash redistribution model?

Yes, these same assumptions are made in the development of the ash redistribution conceptual model.

More information on how ash dilution data from the Lathrop Wells volcano can be extended into the Fortymile Wash transport system, based on data from analog sites such as Sunset Crater, need to be provided.

It is agreed that data from such analog sites would enhance confidence in the technical basis, but are not planned for the conceptual ash redistribution model. 
INTENTIONALLY LEFT BLANK 


\section{CONCLUSIONS}

The objectives of this model report are the following:

- Update documentation of the Ashplume conceptual and mathematical models, including parameterization and validation for the ASHPLUME V 2.0 code (CRWMS-M\&O 2001 [DIRS 152844]) and the ASHPLUME_DLL_LA V2.0 code (BSC 2003 [DIRS 166571]) as implemented in the TSPA-LA.

- Document a conceptual model for tephra redistribution after a hypothetical volcanic eruption through a repository at Yucca Mountain.

- Present results of a model of ash and waste form concentrations at a point $18 \mathrm{~km}$ downwind of a hypothetical volcanic vent, used to develop a Mean Primary Waste Concentration value for use in the tephra redistibution model.

- Provide representative wind speed and direction data for the YMR at altitudes up to $13 \mathrm{~km}$.

- Provide compliance with the criteria of Section 4.2 as shown in Appendix B.

\subsection{SUMMARY OF MODELING ACTIVITY}

The Ashplume conceptual model accounts for incorporation and entrainment of waste particles in an eruption plume and atmospheric transport of the contaminated tephra. The Ashplume mathematical model describes the conceptual model in mathematical terms to allow for prediction of radioactive waste/ash deposition on the ground surface in case the hypothetical eruptive event occurs. A key activity in the development of these models is the identification of realistic and representative values for the input parameters. The Ashplume mathematical model is implemented by the ASHPLUME_DLL_LA V2.0 (BSC 2003 [DIRS 166571]) computer code, which is a required component of the TSPA-LA model of the nuclear waste repository at Yucca Mountain. Within the TSPA, the model for atmospheric dispersal and deposition of tephra, implemented in the ASHPLUME code, is used to predict the ground-level concentration (areal density) of ash and waste after a violent Strombolian eruption that intersects the repository. The waste concentration is then combined with BDCFs in the TSPA-LA model to calculate an annual dose to the RMEI. Other uses of Ashplume have not been evaluated in this report.

The conceptual model for tephra redistribution from a basaltic cone addresses the sedimentary processes that occur after eruption and deposition of the tephra sheet. In this case, the volcanic eruption occurs through a repository at Yucca Mountain. The erosional processes that occur within Fortymile Wash are representative of what might be expected from the redistribution of ash from a tephra sheet upgradient from the RMEI location. The conceptual model describes the erosional and depositional processes that are expected to occur on two landforms (interchannel divides and distributary channels) that may be locally covered by the tephra sheet. Supported by the results of site-specific and natural-analog ash dilution and ${ }^{137} \mathrm{Cs}$ studies, the ash redistribution model develops parameters that will be implemented in the TSPA-LA. The TSPA redistribution model considers tephra thicknesses, tephra/soil removal rates, and long-term residual 
contamination after erosion of the tephra sheet within the context of these two geomorphic landforms (Section 6.7.2).

\subsection{MODEL REPORT OUTPUTS}

The output from this model report consists of four components, which are summarized in Table 8-1. First, a set of input parameter values (points and ranges of values) for ASHPLUME_DLL_LA V2.0 (BSC 2003 [DIRS 166571]) are summarized in Table 8-2 for use in the TSPA modeling. Second, a set of summary data characterizing wind speed and direction in the YMR for heights above the surface of Yucca Mountain up to $13 \mathrm{~km}$ are presented in Tables 8-3 and 8-4, respectively. (The full set of wind speed and wind direction data are given in Appendix D.) Third, output from the Ashplume model providing the Mean Primary Waste Concentration, a mean concentration of waste $18 \mathrm{~km}$ downwind of a hypothetical eruption through the repository, is presented in Table 6-4. Fourth, the ash redistribution model abstraction is presented in Table 6-5. These outputs are described in detail in the following paragraphs.

Table 8-1. Output Data

\begin{tabular}{|l|l|l|}
\hline \multicolumn{1}{|c|}{ Data Description } & Data Tracking Number & \multicolumn{1}{|c|}{$\begin{array}{c}\text { Location of Output DTNs in } \\
\text { this Report }\end{array}$} \\
\hline $\begin{array}{l}\text { Parameter values to be used as input for the } \\
\text { ASHPLUME_DLL_LA V2.0 model for TSPA }\end{array}$ & LA0408GK831811.002 & Table 8-2 \\
\hline $\begin{array}{l}\text { Desert Rock wind speed and wind direction data } \\
\text { analyses for years 1978 - 1995 }\end{array}$ & MO0408SPADRWSD.002 & $\begin{array}{l}\text { Section 6.7.1; Tables 8-3 and } \\
8-4 ; \text { Figure 8-1; Table D-1; } \\
\text { Tables D-10 through D-45; } \\
\text { Figures D-3 through D-15. }\end{array}$ \\
\hline $\begin{array}{l}\text { Mean Primary Waste Concentration (calculation } \\
\text { of waste-form concentrations in ash from an ash } \\
\text { plume at 18 km from a vent) }\end{array}$ & LA0408GK831811.001 & Table 6-4 \\
\hline $\begin{array}{l}\text { Ash redistribution model abstraction for the } \\
\text { TSPA-LA model }\end{array}$ & LA0408CH831811.001 & Table 6-5 \\
\hline
\end{tabular}

Table 8-2 lists the parameterization and other code inputs required to run the ASHPLUME_DLL_LA V2.0 code (BSC 2003 [DIRS 166571]) within the TSPA-LA model, which is implemented within the GoldSim modeling system. GoldSim requires a vector of Ashplume inputs for each realization of the model. Some of the Ashplume parameters required in GoldSim are represented as point values and do not change from one realization to the next. Some input parameters are represented by distributions that are sampled by GoldSim. The sampled values are then passed to Ashplume for each realization. Following are instructions for sampling the distributed parameter values and building an input file for each realization:

1. Sample distributions for the parameters $\beta, d, \sigma_{d}, W_{0}$, and $P$. 
2. Calculate limits for the total eruption duration ( $T_{d_{-} \min }, T_{d_{-} \max }$, in seconds) using Equations $6-7 \mathrm{~b}$ and $6-7 \mathrm{c}$ such that the range of allowable total eruption volume $\left(0.004-0.08 \mathrm{~km}^{3}\right)$ is respected (using $P$ in watts):

$$
\begin{aligned}
& T_{d_{-} \min }=\frac{V_{\min } s}{\dot{Q}}=\frac{V_{\min } s}{P /\left(C_{p} \Delta T\right)}=\frac{\left(0.004 \mathrm{~km}^{3}\right)\left(10^{18} \frac{\mathrm{W} \cdot \mathrm{s}}{\mathrm{km}^{3}}\right)}{P(\mathrm{~W})} \\
& T_{d_{-} \max }=\frac{V_{\max } s}{\dot{Q}}=\frac{V_{\max s}}{P /\left(C_{p} \Delta T\right)}=\frac{\left(0.08 \mathrm{~km}^{3}\right)\left(10^{18} \frac{\mathrm{W} \cdot \mathrm{s}}{\mathrm{km}^{3}}\right)}{P(\mathrm{~W})}
\end{aligned}
$$

3. Sample $T_{d}$ from the range (log-uniform) bounded by $T_{d_{-} \min }, T_{d_{-} \max }$.

4. Calculate eruption column height by Equation $6-7 \mathrm{a}: \mathrm{H}=0.0082\left(\mathrm{P}^{0.25}\right)$, with $H$ in $\mathrm{km}$ and $P$ in watts.

5. Use eruption column height to sample the appropriate altitude bin in the cumulative distribution functions for wind direction (udir) and wind speed $(u)$; if the column height is exactly equal to an altitude bin boundary (e.g., $8.00 \mathrm{~km}$ ), sample the next higher bin (e.g., 8 to $9 \mathrm{~km}$ ).

Note that the upper bound on eruption duration calculated in Eq. 8-1b (up to 3 years) may fall outside the range established for eruption duration in Section 6.5.2.2. Given the relative insensitivity of waste concentration to eruption duration (Appendix C), this variation is expected to have negligible effect on the TSPA model results.

Two outputs are contained in the output vector from Ashplume after a single realization within the GoldSim model: (1) $x_{a s h}$, the ash deposition in $\mathrm{g} / \mathrm{cm}^{2}$, and (2) $x_{\text {fuel }}$, the fuel deposition in $\mathrm{g} / \mathrm{cm}^{2}$.

All output feeds from this model report to the TSPA-LA model are identified in Tables 6-2 and 8-2 and in Appendix D, Tables D-10 through D-35. Table 8-2 indicates the relative position within the input vector required by Ashplume (i.e., the sequence number), the variable name used within GoldSim, a brief description of the parameter, the units of the parameter, the value(s) for the parameter, and the distribution type. Two parameters-wind speed and wind direction-are identified in Table 8-2 as having distribution type "empirical." For the empirical-distribution type, the TSPA-LA model requires a tabular listing of the CDF or PDF of the parameter.

In this report, wind speed and wind direction data tables were formulated (Output DTN: MO0408SPADRWSD.002) to be used as input to the TSPA-LA model. These data have also been modified further to fit the specific form and function of the model. The tabular listings for the wind speed CDFs at incremental distances above Yucca Mountain are given in Tables D-10 through D-22. Table 8-3 (also included as Table D-9) gives a summary of wind speed in relation to height above Yucca Mountain. The tabular listings for wind direction PDF for incremental distances above Yucca Mountain are given in Tables D-23 through D-35, and corresponding wind rose diagrams are given in Figures D-3 through D-15. Tables 8-3 and 
8-4 and Figure 8-1 below are representative samples of the more complete listings found in Appendix D.

Section 6.7.2 (Table 6-5) summarizes the ash redistribution conceptual model to be implemented in the TSPA-LA. The general results of an ash dilution study are assessed in conjunction with results of a ${ }^{137} \mathrm{Cs}$ study to establish a technical basis for erosion rates. The ${ }^{137} \mathrm{Cs}$ studies are also directly used in the redistribution model to define parameters related to erosion and removal rates of the tephra sheet and to abstract predicted concentrations of diluted, redeposited sediments. A separate set of ASHPLUME_DLL_LA V2.0 (BSC 2003 [DIRS 166571]) calculations are developed to define the Mean Primary Waste Concentration (Table 6-4) for those realizations in which there is no ash fall realized at the RMEI location during a particular TSPA realization.

The Mean Primary Waste Concentration analyses were calculated using ASHPLUME_DLL_LA V2.0 (BSC 2003 [DIRS 166571]) (Table 6-4, Appendix E). The uncertainty in parameter values was incorporated by using a Monte Carlo method involving 100 realizations of distributed input parameters (beta, particle size, standard deviation of particle size, initial eruption velocity, power, duration of eruption event, and wind speed). Individual realizations were screened for validity by following the methodology given in Steps 1 through 5 , in this section, to ensure that the values of the sampled parameters were within established ranges. Based on this modeling, the mean concentration of waste form at a point $18 \mathrm{~km}$ directly downwind from a volcanic vent is $4.16 \times 10^{-6} \mathrm{~g} / \mathrm{cm}^{2}$ with a standard deviation of $7.47 \times 10^{-6} \mathrm{~g} / \mathrm{cm}^{2}$.

Table 8-2. Input Parameter Values for the ASHPLUME_DLL_LA V2.0 Model for TSPA

\begin{tabular}{|c|c|c|c|c|c|}
\hline $\begin{array}{l}\text { Seq. } \\
\text { No.* }\end{array}$ & $\begin{array}{l}\text { ASHPLUME } \\
\text { Parameter }\end{array}$ & Description & Units & Value & $\begin{array}{c}\text { Distribution } \\
\text { Type }\end{array}$ \\
\hline 1 & iscrn & Run type ( $0=$ no screen output) & none & 0 & point value \\
\hline 2 & $X_{\min }$ & Minimum $X$ grid location & $\mathrm{km}$ & 0 & point value \\
\hline 3 & $X_{\max }$ & Maximum $X$ grid location & $\mathrm{km}$ & 0 & point value \\
\hline 4 & $Y_{\min }$ & Minimum $\mathrm{Y}$ grid location & $\mathrm{km}$ & 0 & point value \\
\hline 5 & $Y_{\max }$ & Maximum $Y$ grid location & $\mathrm{km}$ & -18 & point value \\
\hline 6 & $N_{x}$ & Number of $X$ grid locations & none & 1 & point value \\
\hline 7 & $N_{y}$ & Number of $Y$ grid locations & none & 2 & point value \\
\hline 8 & $\Psi_{p}^{\text {low }}$ & $\begin{array}{l}\text { Ash particle density at maximum } \\
\text { particle size }\end{array}$ & $\mathrm{g} / \mathrm{cm}^{3}$ & 1.04 & point value \\
\hline 9 & $\Psi_{p}^{\text {high }}$ & $\begin{array}{l}\text { Ash particle density at minimum } \\
\text { particle size }\end{array}$ & $\mathrm{g} / \mathrm{cm}^{3}$ & 2.08 & point value \\
\hline 10 & $\rho_{a}^{\text {low }}$ & $\begin{array}{l}\text { Log ash particle size at maximum } \\
\text { ash density }\end{array}$ & $\log (\mathrm{cm})$ & -3 & point value \\
\hline 11 & $\rho_{a}^{\text {high }}$ & $\begin{array}{l}\text { Log ash particle size at minimum } \\
\text { ash density }\end{array}$ & $\log (\mathrm{cm})$ & 0 & point value \\
\hline 12 & $F$ & Ash particle shape factor & none & 0.5 & point value \\
\hline 13 & $\Psi_{\mathrm{a}}$ & Air density & $\mathrm{g} / \mathrm{cm}^{3}$ & 0.001117 & point value \\
\hline 14 & $\eta_{\mathrm{a}}$ & Air viscosity & $\mathrm{g} / \mathrm{cm} / \mathrm{s}$ & 0.0001758 & point value \\
\hline 15 & $C$ & Eddy diffusivity constant & $\mathrm{cm}^{2} / \mathrm{s}^{5 / 2}$ & 400.0 & point value \\
\hline 16 & $d_{\max }$ & $\begin{array}{l}\text { Maximum particle diameter for } \\
\text { transport }\end{array}$ & $\mathrm{cm}$ & 10 & point value \\
\hline
\end{tabular}


Table 8-2. Input Parameter Values for the ASHPLUME_DLL_LA V2.0 Model for TSPA (Continued)

\begin{tabular}{|c|c|c|c|c|c|}
\hline $\begin{array}{l}\text { Seq. } \\
\text { No.* }\end{array}$ & $\begin{array}{l}\text { ASHPLUME } \\
\text { Parameter }\end{array}$ & Description & Units & Value & $\begin{array}{c}\text { Distribution } \\
\text { Type }\end{array}$ \\
\hline 17 & $e_{\min }^{f}$ & Minimum waste particle size & $\mathrm{cm}$ & 0.0001 & point value \\
\hline 18 & $\rho_{\text {mode }}^{\prime}$ & Mode waste particle size & $\mathrm{cm}$ & 0.0016 & point value \\
\hline 19 & $\rho_{\max }^{f}$ & Maximum waste particle size & $\mathrm{cm}$ & 0.05 & point value \\
\hline 20 & $H_{\min }$ & Minimum height of eruption column & $\mathrm{km}$ & 0.001 & point value \\
\hline 21 & Ash Cutoff & $\begin{array}{l}\text { Threshold limit on ash } \\
\text { accumulation }\end{array}$ & $\mathrm{g} / \mathrm{cm}^{2}$ & $1 \times 10^{-10}$ & point value \\
\hline 22 & $\beta$ & Column diffusion constant (Beta) & none & $0.01-0.5$ & uniform \\
\hline 23 & $d$ & Mean ash particle diameter & $\mathrm{cm}$ & $\begin{array}{l}0.001-0.01- \\
0.1\end{array}$ & log triangular \\
\hline 24 & $\sigma_{d}$ & $\begin{array}{l}\text { Ash particle diameter standard } \\
\text { deviation }\end{array}$ & $\log (\mathrm{cm})$ & $(1.3)-(1.9)$ & uniform \\
\hline 25 & $\rho_{c}$ & Waste incorporation ratio & none & 0.3 & point value \\
\hline 26 & $U$ & Mass of waste to incorporate & g & $\begin{array}{l}\text { Calculated within } \\
\text { the TSPA model }\end{array}$ & N/A \\
\hline 27 & Wind Direction & Wind Direction & degrees & $\begin{array}{l}\text { DTN: } \\
\text { MO0408SPADR } \\
\text { WSD.002 }\end{array}$ & empirical \\
\hline 28 & U & Wind Speed & $\mathrm{cm} / \mathrm{s}$ & $\begin{array}{l}\text { DTN: } \\
\text { MO0 } 408 \text { SPADR } \\
\text { WSD.002 }\end{array}$ & empirical \\
\hline 29 & $W_{0}$ & Initial rise velocity & $\mathrm{cm} / \mathrm{s}$ & $\begin{array}{l}1.0 \times 10^{0}-1.2 \times \\
10^{4}\end{array}$ & log-uniform \\
\hline 30 & $P$ & Eruptive power & $w$ & $\begin{array}{l}6.17 \times 10^{8}- \\
5 \times 10^{12}\end{array}$ & log-uniform \\
\hline 31 & $T_{d}$ & Eruption duration & $s$ & $\begin{array}{l}\text { See Equations } \\
8-1 \mathrm{a} \text { and } 8-1 \mathrm{~b}\end{array}$ & log-uniform \\
\hline
\end{tabular}

Output DTN: LA0408GK831811.002.

NOTE: *Seq. No. = GoldSim sequence number.

Table 8-3. Wind Speed in Relation to Height Above Yucca Mountain

\begin{tabular}{|c|c|c|c|}
\hline $\begin{array}{c}\text { Height above YM } \\
\text { (km) }\end{array}$ & $\begin{array}{c}\text { Minimum Wind Speed } \\
\text { (cm/s) }\end{array}$ & $\begin{array}{c}\text { Maximum Wind Speed } \\
\text { (cm/s) }\end{array}$ & $\begin{array}{c}\text { Average Wind Speed } \\
\text { (cm/s) }\end{array}$ \\
\hline 0 to 1 & 0 & 4670 & 668 \\
\hline 1 to 2 & 0 & 4480 & 817 \\
\hline 2 to 3 & 0 & 5000 & 1007 \\
\hline 3 to 4 & 0 & 6400 & 1215 \\
\hline 4 to 5 & 0 & 10500 & 1486 \\
\hline 5 to 6 & 0 & 14100 & 1695 \\
\hline 6 to 7 & 0 & 10300 & 1949 \\
\hline 7 to 8 & 0 & 11000 & 2160 \\
\hline 8 to 9 & 0 & 8700 & 2294 \\
\hline
\end{tabular}


Table 8-3. Wind Speed in Relation to Height above Yucca Mountain (Continued)

\begin{tabular}{|c|c|c|c|}
\hline $\begin{array}{c}\text { Height above YM } \\
\text { (km) }\end{array}$ & $\begin{array}{c}\text { Minimum Wind Speed } \\
(\mathbf{c m} / \mathbf{s})\end{array}$ & $\begin{array}{c}\text { Maximum Wind Speed } \\
\text { (cm/s) }\end{array}$ & $\begin{array}{c}\text { Average Wind Speed } \\
\text { (cm/s) }\end{array}$ \\
\hline 9 to 10 & 0 & 8640 & 2416 \\
\hline 10 to 11 & 0 & 8900 & 2437 \\
\hline 11 to 12 & 0 & 9900 & 2311 \\
\hline 12 to 13 & 0 & 7300 & 2064 \\
\hline
\end{tabular}

Source: NOAA 2004 [DIRS 171035]. Output DTN: MO0408SPADRWSD.002.

NOTE: This table is also given as Table D-9 in Appendix $D$ of this report. The data listed in this table are representative of the wind-speed data listed in the attachment.

Table 8-4. Wind Direction PDF at 3 to $4 \mathrm{~km}$ Above Yucca Mountain

\begin{tabular}{|c|c|c|c|}
\hline Compass Degrees & Ashplume Degrees & Count & PDF \\
\hline 165 to 195 & 90 (North) & 5788 & 0.818 \\
\hline 195 to 225 & 60 & 9821 & 0.1388 \\
\hline 225 to 255 & 30 & 12019 & 0.1699 \\
\hline 255 to 285 & 0 (East) & 11030 & 0.1559 \\
\hline 285 to 315 & -30 & 10186 & 0.1440 \\
\hline 315 to 345 & -60 & 7486 & 0.1058 \\
\hline 345 to 15 & -90 (South) & 4402 & 0.0622 \\
\hline 15 to 45 & -120 & 2497 & 0.0353 \\
\hline 45 to 75 & -150 & 1639 & 0.0232 \\
\hline 75 to 105 & 180 (West) & 1407 & 0.0199 \\
\hline 105 to 135 & 150 & 1743 & 0.0246 \\
\hline 135 to 165 & 120 & 2730 & 0.0386 \\
\hline Total & & 33,093 & 1.0000 \\
\hline
\end{tabular}

Source: NOAA 2004 [DIRS 171035]. Output DTN: MO0408SPADRWSD.002.

NOTE: This table is also given as Table D-26 in Appendix D. The data listed in this table are representative of the wind-direction data listed in the attachment to this report. 


\section{Wind Rose Frequency of Occurrences (wind toward designation) at 3 to $4 \mathrm{~km}$ above $\mathrm{YM}$}

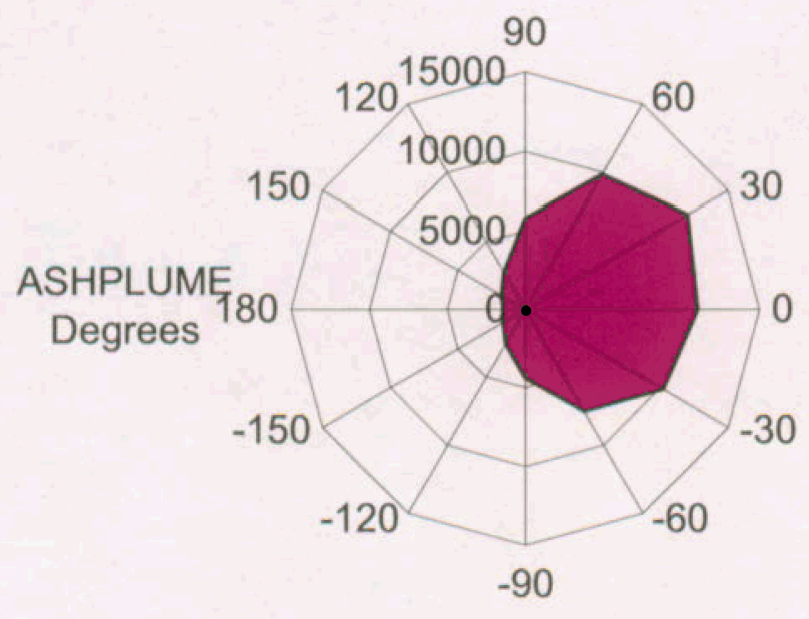

Count

Source: NOAA 2004 [DIRS 171035]. Output DTN: MO0408SPADRWSD.002.

NOTE: This figure is also given as Figure D-6 in Appendix D. The wind rose frequency of occurrences shown in this figure is a representation of the wind-direction data listed in Table 8-4 above (see also Table D-26 in Appendix D).

Figure 8-1. Wind-Rose Frequency of Occurrences at 3 to $4 \mathrm{~km}$ Above Yucca Mountain

\subsection{OUTPUT UNCERTAINTY}

The TSPA-LA model uses Monte Carlo simulation as a method for mapping uncertainty in model parameters and future system states, expressed as probability distributions, into predictions of model output (BSC 2003 [DIRS 166296]). Epistemic uncertainties exist in Ashplume model input parameters due to the uncertainty in underlying data or imperfect knowledge of other required inputs (model for volcanic eruption). Ashplume model parameters that contain uncertainty and that may significantly affect the outcome of TSPA-LA calculations are expressed as probability distributions to be compatible with the Monte Carlo method used in the TSPA-LA model. Table 8-2 shows all ASHPLUME input parameters and indicates those that are represented by probability distributions and those that use fixed values.

The ash redistribution conceptual model abstraction (Table 6-5) for the TSPA-LA has considerable uncertainty due to the limited database and use of ${ }^{137} \mathrm{Cs}$ as a proxy for representing long-lived radionuclides; however, the mathematical implementation of the conceptual model and the output parameter values are considered to be sufficiently conservative to bound any uncertainty. A key factor in the conceptual model for contaminated ash redistribution is dilution. It was observed (Section 7.3) that mixing with non-ash material is significant and that any contaminated ash reaching the location of the RMEI will be significantly diluted by mixing with pre-existing, uncontaminated rock material. Although dilution is a significant factor, there are 
insufficient data available to include it in the output parameter values provided as input for the TSPA-LA.

These parameter uncertainties, represented by the parameter distributions developed and documented in this model report, are propagated throughout the TSPA-LA model and reflected in the average dose calculated by the TSPA-LA model to the RMEI. 


\section{INPUTS AND REFERENCES}

\subsection{DOCUMENTS CITED}

The following is a list of the references cited in this document. Column 2 represents the unique six-digit numerical identifier (the Document Input Reference System [DIRS] number), which is placed in the text following the reference callout (e.g., BSC 2002 [DIRS 160780]). The purpose of these numbers is to assist the reader in locating a specific reference in the DIRS database.

Altman, W.D.; Donnelly, J.P.; and Kennedy, J.E. 1988. Peer Review for High-Level 103597 Nuclear Waste Repositories: Generic Technical Position. NUREG-1297.

Washington, D.C.: U.S. Nuclear Regulatory Commission. TIC: 200651.

Altman, W.D.; Donnelly, J.P.; and Kennedy, J.E. 1988. Qualification of Existing 103750 Data for High-Level Nuclear Waste Repositories: Generic Technical Position. NUREG-1298. Washington, D.C.: U.S. Nuclear Regulatory Commission.

TIC: 200652.

Anspaugh, L.R.; Shinn, J.H.; Phelps, P.L.; and Kennedy, N.C. 1975. "Resuspension 151548 and Redistribution of Plutonium in Soils." Health Physics, 29, (4), 571-582. New York, New York: Pergamon Press. TIC: 248619.

Anspaugh, L.R.; Simon, S.L.; Gordeev, K.I.; Likhtarev, I.A.; Maxwell, R.M.; and Shinkarev, S.M. 2002. "Movement of Radionuclides in Terrestrial Ecosystems by Physical Processes." Health Physics, 82, (5), 669-679. [Baltimore, Maryland: Lippincott Williams \& Wilkins]. TIC: 256136.

Arkley, R.J. 1963. "Calculation of Carbonate and Water Movement in Soil from 171102 Climatic Data." Soil Science, 96, 239-248. Baltimore, Maryland: Williams \& Wilkins Company. TIC: 223544.

Bacon, C.R. 1977. "High Temperature Heat Content and Heat Capacity of Silicate 165512 Glasses: Experimental Determination and a Model for Calculation." American Journal of Science, 277, 109-135. [New Haven, Connecticut: Yale University, Kline Geology Laboratory]. TIC: 255125.

Best, M.G. 1982. Igneous and Metamorphic Petrology. New York, New York: W.H. Freeman and Company. TIC: 247662.

BSC (Bechtel SAIC Company) 2001. FY 01 Supplemental Science and Performance Analyses, Volume 1: Scientific Bases and Analyses. TDR-MGR-MD-000007 REV 00 ICN 01. Las Vegas, Nevada: Bechtel SAIC Company. ACC: MOL.20010801.0404; MOL.20010712.0062; MOL.20010815.0001. 
BSC 2001. FY01 Supplemental Science and Performance Analyses, Volume 2:

Performance Analyses. TDR-MGR-PA-000001 REV 00. Las Vegas,

Nevada: Bechtel SAIC Company. ACC: MOL.20010724.0110.

BSC 2001. Igneous Consequence Modeling for the TSPA-SR.

ANL-WIS-MD-000017 REV 00 ICN 02. Las Vegas, Nevada: Bechtel SAIC

157876

Company. ACC: MOL.20011107.0005.

BSC 2002. Risk Information to Support Prioritization of Performance Assessment 160780 Models. TDR-WIS-PA-000009 REV 01 ICN 01. Las Vegas, Nevada: Bechtel SAIC Company. ACC: MOL.20021017.0045.

BSC 2002. Scientific Processes Guidelines Manual. MIS-WIS-MD-000001 REV 01. Las Vegas, Nevada: Bechtel SAIC Company.

ACC: MOL.20020923.0176.

BSC 2003. Risk Information to Support Prioritization of Performance Assessment Models. TDR-WIS-PA-000009 REV 01 ICN 01 [Errata 001]. Las Vegas, Nevada: Bechtel SAIC Company. ACC: MOL.20021017.0045; DOC.20031014.0003.

BSC 2003. Technical Work Plan: Igneous Activity Assessment for Disruptive 166289 Events. TWP-WIS-MD-000007 REV 04. Las Vegas, Nevada: Bechtel SAIC Company. ACC: DOC.20031125.0006.

BSC 2003. Total System Performance Assessment-License Application Methods and 166296 Approach. TDR-WIS-PA-000006 REV 00 ICN 01. Las Vegas, Nevada: Bechtel SAIC Company. ACC: DOC.20031215.0001.

BSC 2004. Agricultural and Environmental Input Parameters for the Biosphere 169673 Model. ANL-MGR-MD-000006 REV 02. Las Vegas, Nevada: Bechtel SAIC Company. ACC: DOC.20040915.0007.

BSC 2004. Atmospheric Dispersal and Deposition of Tephra from a Potential 167616 Volcanic Eruption at Yucca Mountain, Nevada. MDL-MGR-GS-000002 REV 00. Las Vegas, Nevada: Bechtel SAIC Company. ACC: DOC.20040218.0003.

BSC 2004. Biosphere Model Report. MDL-MGR-MD-000001, Rev. 01. 169460 Las Vegas, Nevada: Bechtel SAIC Company.

BSC 2004. Characteristics of the Receptor for the Biosphere Model. ANL-MGR-MD-000005 REV 03. Las Vegas, Nevada: Bechtel SAIC Company. ACC: DOC.20040913.0004. 
BSC 2004. Characterize Eruptive Processes at Yucca Mountain, Nevada.

169980

ANL-MGR-GS-000002 REV 02. Las Vegas, Nevada: Bechtel SAIC Company.

ACC: DOC.20041004.0006.

BSC 2004. Characterize Framework for Igneous Activity at Yucca Mountain,

169989

Nevada. ANL-MGR-GS-000001, Rev. 02. Las Vegas, Nevada: Bechtel SAIC

Company.

BSC 2004. Dike/Drift Interactions. MDL-MGR-GS-000005, Rev. 01. Las Vegas,

170028

Nevada: Bechtel SAIC Company.

BSC 2004. Features, Events, and Processes: Disruptive Events.

ANL-WIS-MD-000005, Rev. 02. Las Vegas, Nevada: Bechtel SAIC Company.

BSC 2004. Future Climate Analysis. ANL-NBS-GS-000008 REV 01. Las Vegas,

Nevada: Bechtel SAIC Company. ACC: DOC.20040908.0005.

BSC 2004. Number of Waste Packages Hit by Igneous Intrusion.

170001

ANL-MGR-GS-000003, Rev. 01. Las Vegas, Nevada: Bechtel SAIC Company.

BSC 2004. Q-List. 000-30R-MGR0-00500-000-000 REV 00. Las Vegas, Nevada:

168361

Bechtel SAIC Company. ACC: ENG.20040721.0007.

BSC 2004. Technical Work Plan for Igneous Activity Assessment for Disruptive

Events. TWP-WIS-MD-000007 REV 06. Las Vegas, Nevada: Bechtel SAIC

Company. ACC: DOC.20040820.0001.

Bull, W.B. 1991. Geomorphic Responses to Climate Change. New York, 102040 New York: Oxford University Press. TIC: 223847.

Canori, G.F. and Leitner, M.M. 2003. Project Requirements Document. 166275 TER-MGR-MD-000001 REV 02. Las Vegas, Nevada: Bechtel SAIC Company. ACC: DOC.20031222.0006.

Carslaw, H.S. and Jaeger, J.C. 1959. Conduction of Heat in Solids. 2nd Edition. 100968 Oxford, Great Britain: Oxford University Press. TIC: 206085.

Codell, R. 2003. "Alternative Igneous Source Term Model for the Yucca Mountain 165503 Repository." Proceedings of the 10th International High-Level Radioactive Waste Management Conference (IHLRWM), March 30-April 2, 2003, Las Vegas, Nevada. Pages 405-412. La Grange Park, Illinois: American Nuclear Society. TIC: 254559. 
Coe, J.A.; Glancy, P.A.; and Whitney, J.W. 1997. "Volumetric Analysis and 104691 Hydrologic Characterization of a Modern Debris Flow Near Yucca Mountain, Nevada." Geomorphology, 20, (1-2), 11-28. Amsterdam, The Netherlands: Elsevier. TIC: 241945.

Crowe, B.M. and Perry, F.V. 1990. "Volcanic Probability Calculations for the Yucca Mountain Site: Estimation of Volcanic Rates." Proceedings of the Topical Meeting on Nuclear Waste Isolation in the Unsaturated Zone, FOCUS '89, September 17-21, 1989, Las Vegas, Nevada. Pages 326-334. La Grange Park, Illinois: American Nuclear Society. TIC: 212738.

CRWMS M\&O 1996. Probabilistic Volcanic Hazard Analysis for Yucca Mountain, Nevada. BA0000000-01717-2200-00082 REV 0. Las Vegas, Nevada: CRWMS M\&O. ACC: MOL.19971201.0221.

CRWMS M\&O 2000. Comparison of ASHPLUME Model Results to Representative Tephra Fall Deposits. CAL-WIS-MD-000011 REV 00. Las Vegas, Nevada: CRWMS M\&O. ACC: MOL.20001204.0032.

CRWMS M\&O 2000. Total System Performance Assessment for the Site 153246 Recommendation. TDR-WIS-PA-000001 REV 00 ICN 01. Las Vegas, Nevada: CRWMS M\&O. ACC: MOL.20001220.0045.

CRWMS M\&O 2000. Yucca Mountain Site Description. TDR-CRW-GS-000001 151945 REV 01 ICN 01. Las Vegas, Nevada: CRWMS M\&O.

ACC: MOL.20001003.0111.

CRWMS M\&O 2001. Miscellaneous Waste-Form FEPs. ANL-WIS-MD-000009 153938 REV 00 ICN 01. Las Vegas, Nevada: CRWMS M\&O. ACC: MOL.20010216.0006.

Dagan, G. 1989. Flow and Transport in Porous Formations. New York, New York: 147409 Springer-Verlag. TIC: 234219.

Dehaudt, P. 2001. "Physical and Chemical State of the Nuclear Spent Fuel After 164019 Irradiation." Section 5.2 of Synthesis on the Long Term Behavior of the Spent Nuclear Fuel. Poinssot, C., ed. CEA-R-5958(E). Volume I. Paris, France: Commissariat à l'Énergie Atomique. TIC: 253976.

Detournay, E.; Mastin, L.G.; Pearson, J.R.A.; Rubin, A.M.; and Spera, F.J. 2003. 169660 Final Report of the Igneous Consequences Peer Review Panel, with Appendices. Las Vegas, Nevada: Bechtel SAIC Company. ACC: MOL.20031014.0097; MOL.20030730.0163. 
DOE (U.S. Department of Energy) 2003. Review of Oxidation Rates of DOE Spent 166027 Nuclear Fuel Part 2. Nonmetallic Fuel. DOE/SNF/REP-068, Rev. 0. Idaho Falls, Idaho: U.S. Department of Energy, Idaho Operations Office.

ACC: DOC.20030905.0009.

DOE (U.S. Department of Energy) 2003. Validation Test Report for:

ASHPLUME_DLL_LA Version 2.0. 11117-VTR-2.0-00. Las Vegas, Nevada: U.S. Department of Energy, Office of Repository Development.

ACC: MOL.20031212.0443.

Drury, M.J. 1987. “Thermal Diffusivity of Some Crystalline Rocks." Geothermics, 16, (2), 105-115. New York, New York: Pergamon Press. TIC: 251764.

Evans, M.; Hastings, N.; and Peacock, B. 1993. Statistical Distributions. $2^{\text {nd }}$ Edition. New York, New York: John Wiley \& Sons. TIC: 246114.

Folk, R.L. 1980. Petrology of Sedimentary Rocks. Austin, Texas: Hemphill 164773 Publishing Company. TIC: 254754.

Gale, H.J.; Humphreys, D.L.O.; and Fisher, E.M.R. 1964. "Weathering of 169807

Caesium-137 in Soil." Nature, 201, (491), 257-261. London, England: Macmillan Magazines. TIC: 256310.

Gilbert, R.O. and Eberhardt, L.L. 1976. "Statistical Analysis of 'A Site' Data and Interlaboratory Comparisons for the Nevada Applied Ecology Group." Studies of Environmental Plutonium and Other Transuranics in Desert Ecosystems, Nevada Applied Ecology Group Progress Report (Workshop Session - May, 1975). White, M.G. and Dunaway, P.B., eds. NVO-159. Pages 117-154. Las Vegas, Nevada: U.S. Energy Research and Development Administration, Nevada Operations Office.

TIC: 201475.

Harrington, C. 2003. Ash and Soil Redistribution Studies. Scientific Notebook SN-LANL-SCI-285-V1. ACC: MOL.20030411.0312.

Harrington, C. 2004. Ash and Soil Redistribution Studies. Partial Submittal for Scientific Notebook SN-LANL-SCI-285-V1. Pages 71-79. ACC: MOL.20040116.0145; MOL.20040817.0271.

Harrington, C. 2004. Ash and Soil Redistribution Studies. Scientific Notebook SN-LANL-SCI-285-V1 [partial submittal]. Pages 82-94 ACC: MOL.20040817.0271; MOL.20040929.0089. 
Heiken, G. 1978. "Characteristics of Tephra from Cinder Cone, Lassen Volcanic 162817

National Park, California." Bulletin of Volcanology, 41-2, 119-130. New York,

New York: Springer-Verlag. TIC: 235508.

Heiken, G.; Harrington, C.; and Keating, G. 2003. Magnetic Separation of Surficial Materials for Disruptive Events Field Investigations. Scientific Notebook

166290

SN-LANL-SCI-292-V1. ACC: MOL.20031201.0013.

Heizler, M.T.; Perry, F.V.; Crowe, B.M.; Peters, L.; and Appelt, R. 1999. "The Age of Lathrop Wells Volcanic Center: $\mathrm{An}{ }^{40} \mathrm{Ar} /{ }^{39} \mathrm{Ar}$ Dating Investigation." Journal of Geophysical Research, 104, (B1), 767-804. Washington, D.C.: American Geophysical Union. TIC: 243399.

Hill, B.E.; Connor, C.B.; Jarzemba, M.S.; La Femina, P.C.; Navarro, M.; and Strauch, W. 1998. "1995 Eruptions of Cerro Negro Volcano, Nicaragua, and Risk

Assessment for Future Eruptions." Geological Society of America Bulletin, 110, (10), 1231-1241. Boulder, Colorado: Geological Society of America. TIC: 245102.

Jarzemba, M.S. 1997. "Stochastic Radionuclide Distributions After a Basaltic Eruption for Performance Assessments of Yucca Mountain." Nuclear Technology, 118, 132-141. . Hinsdale, Illinois: American Nuclear Society. TIC: 237944.

Jarzemba, M.S.; LaPlante, P.A.; and Poor, K.J. 1997. ASHPLUME Version 1.0-A Code for Contaminated Ash Dispersal and Deposition, Technical Description and User's Guide. CNWRA 97-004, Rev. 1. San Antonio, Texas: Center for Nuclear Waste Regulatory Analyses. ACC: MOL.20010727.0162.

Kotra, J.P.; Lee, M.P.; Eisenberg, N.A.; and DeWispelare, A.R. 1996. Branch Technical Position on the Use of Expert Elicitation in the High-Level Radioactive Waste Program. NUREG-1563. Washington, D.C.: U.S. Nuclear Regulatory Commission. TIC: 226832.

Krier, D. and Harrington, C.D. 2003. Ash Redistribution, Lava Morphology, and 164023 Igneous Processes Studies. Scientific Notebook SN-LANL-SCI-286-V1. ACC: MOL.20030701.0109.

Kutzbach, J.E.; Guetter, P.J.; Behling, P.J.; and Selin, R. 1993. "Simulated Climatic 119269 Changes: Results of the COHMAP Climate-Model Experiments." Chapter 4 of Global Climates Since the Last Glacial Maximum. Wright, H., Jr.; Kutzbach, J.; Webb, T., III; Ruddiman, W.; Street-Perrott, F., Bartlein, P., eds. Minneapolis, Minnesota: University of Minnesota Press. TIC: 234248. 
Lide, D.R., ed. 1994. CRC Handbook of Chemistry and Physics, A Ready-Reference 147834 Book of Chemical and Physical Data. 75th Edition. Boca Raton, Florida: CRC

Press. TIC: 102972.

Likhtarev, I.A.; Kovgan, L.N.; Jacob, P.; and Anspaugh, L.R. 2002. "Chernobyl 169810 Accident: Retrospective and Prospective Estimates of External Dose of the Population of Ukraine." Health Physics, 82, (3), 290-303. Baltimore, Maryland: Lippincott Williams \& Wilkins]. TIC: 256138.

Machette, M.N. 1985. "Calcic Soils of the Southwestern United States." Soils and Quaternary Geology of the Southwestern United States. Weide, D.L. and Faber, M.L., eds. Special Paper 203. Pages 1-21. Boulder, Colorado: Geological Society of America. TIC: 239387.

Marcus, W.A.; Meyer, G.A.; and Nimmo, D.R. 2001. "Geomorphic Control of 171177 Persistent Mine Impacts in a Yellowstone Park Stream and Implications for the Recovery of Fluvial Systems." Geology, 29, (4), 355-358. Boulder, Colorado: Geological Society of America. TIC: 256307.

McKnight, S.B. and Williams, S.W. 1997. "Old Cinder Cone or Young Composite Volcano?: The Nature of Cerro Negro, Nicaragua." Geology, 25, (4), 339-342. Boulder, Colorado: Geological Society of America. TIC: 254104.

Mück, K.; Pröhl, G.; Likhtarev, I.; Kovgan, L.; Golikov, V.; and Zeger, J. 2002. "Reconstruction of the Inhalation Dose in the 30-km Zone After the Chernobyl Accident." Health Physics, 82, (2), 157-172. Philadelphia, Pennsylvania: Lippincott Williams \& Wilkins. TIC: 256234.

NOAA (National Oceanic and Atmospheric Administration) 2004. Upper Air Data for Desert Rock, Nevada Years 1978-2003. NCDC (National Climatic Data Center) Digital Upper Air Files TD 6201 and 6301 (Includes Compact Disk and Special Instruction Sheet with Listing of Files). Asheville, North Carolina: National Oceanic and Atmospheric Administration. ACC: MOL.20040817.0103.

NRC (U.S. Nuclear Regulatory Commission) 1998. Issue Resolution Status Report Key Technical Issue: Igneous Activity. Rev. 0. Washington, D.C.: U.S. Nuclear Regulatory Commission. ACC: MOL.19980514.0576.

NRC (U.S. Nuclear Regulatory Commission) 2002. Integrated Issue Resolution Status Report. NUREG-1762. Washington, D.C.: U.S. Nuclear Regulatory Commission, Office of Nuclear Material Safety and Safeguards. TIC: 253064. 
NRC (U.S. Nuclear Regulatory Commission) 2003. Yucca Mountain Review Plan, 163274 Final Report. NUREG-1804, Rev. 2. Washington, D.C.: U.S. Nuclear Regulatory Commission, Office of Nuclear Material Safety and Safeguards. TIC: 254568.

Pareschi, M.T.; Santacroce, R.; Sulpizio, R.; and Zanchetta, G. 2002. 171394

"Volcaniclastic Debris Flows in the Clanio Valley (Campania, Italy): Insights for the Assessment of Hazard Potential." Geomorphology, 43, 219-231. New York, New York: Elsevier. TIC: 256431.

Perry, F.V.; Crowe, B.M.; Valentine, G.A.; and Bowker, L.M., eds. 1998. Volcanism Studies: Final Report for the Yucca Mountain Project. LA-13478. Los Alamos, New Mexico: Los Alamos National Laboratory. TIC: 247225.

Quiring, R.F. 1968. Climatological Data Nevada Test Site and Nuclear Rocket Development Station. ESSA Research Laboratories Technical Memorandum - ARL 7. Las Vegas, Nevada: U.S. Department of Commerce, Environmental Science Services Administration Research Laboratories. ACC: NNA.19870406.0047.

Reamer, C.W. 1999. "Issue Resolution Status Report (Key Technical Issue: Igneous Activity, Revision 2)." Letter from C.W. Reamer (NRC) to Dr. S. Brocoum (DOE/YMSCO), July 16, 1999, with enclosure. ACC: MOL.19990810.0639.

Reheis, M.C.; Goodmacher, J.; Harden, J.; McFadden, L.D.; Rockwell, T.K.; Shroba, R.R.; Sowers, J.M.; and Taylor, E.M. 1995. "Quaternary Soils and Dust Deposition in Southern Nevada and California." Geological Society of America Bulletin, 107, (9), 1003-1022. Boulder, Colorado: Geological Society of America. TIC: 234884.

Romney, E.M.; Mork, H.M.; and Larson, K.H. 1970. "Persistence of Plutonium in Soil, Plants, and Small Mammals." Health Physics, 19, (4), 487-491. New York, New York: Pergamon Press. TIC: 256308.

Sagar, B., ed. 1997. NRC High-Level Radioactive Waste Program Annual Progress Report: Fiscal Year 1996. NUREG/CR-6513, No. 1. Washington, D.C.: U.S. Nuclear Regulatory Commission. ACC: MOL.19970715.0066.

Sandoval, R.P.; Weber, J.P.; Levine, H.S.; Romig, A.D.; Johnson, J.D.; Luna, R.E.; 156313 Newton, G.J.; Wong, B.A.; Marshall, R.W., Jr.; Alvarez, J.L.; and Gelbard, F. 1983. An Assessment of the Safety of Spent Fuel Transportation in Urban Environs. SAND82-2365. Albuquerque, New Mexico: Sandia National Laboratories. ACC: NNA.19870406.0489. 
Schlueter, J.R. 2003. "Igneous Activity Agreement 2.09, Additional Information 165740

Needed." Letter from J.R. Schlueter (NRC) to J.D. Ziegler (DOE/ORD), March 25, 2003, 0331036684, with enclosure. ACC: MOL.20031009.0249.

Searcy, C.; Dean, K.; and Stringer, W. 1998. "PUFF: A High-Resolution Volcanic 101015 Ash Tracking Model." Journal of Volcanology and Geothermal Research, 80, 1-16. Amsterdam, The Netherlands: Elsevier. TIC: 238696.

Self, S. and Walker, G.P.L. 1994. "Ash Clouds: Characteristics of Eruption 162831 Columns." Volcanic Ash and Aviation Safety: Proceedings of the First International Symposium on Volcanic Ash and Aviation Safety held in Seattle, Washington in July 1991. Casadevall, T.J., ed. U.S. Geological Survey Bulletin 2047. Pages 65-74. Washington, D.C.: U.S. Government Printing Office. TIC: 254494.

Suzuki, T. 1983. "A Theoretical Model for Dispersion of Tephra." Arc Volcanism: 100489 Physics and Tectonics, Proceedings of a 1981 IAVCEI Symposium, August-September, 1981, Tokyo and Hakone. Shimozuru, D. and Yokoyama, I., eds. Pages 95-113. Tokyo, Japan: Terra Scientific Publishing Company. TIC: 238307.

Taylor, E.M. 1986. Impact of Time and Climate on Quaternary Soils in the Yucca 102864 Mountain Area of the Nevada Test Site. Master's thesis. Boulder, Colorado: University of Colorado. TIC: 218287.

Van Kampen, N.G. 1997. Stochastic Processes in Physics and Chemistry. Revised 151889 and Enlarged Edition. New York, New York: Elsevier. TIC: 248764.

Wells, S.G.; McFadden, L.D.; Poths, J.; and Olinger, C.T. 1995. "Cosmogenic ${ }^{3}$ He 171051 Surface-Exposure Dating of Stone Pavements: Implications for Landscape Evolution in Deserts." Geology, 23, (7), 613-616. Boulder, Colorado: Geological Society of America. TIC: 256306.

Wescott, R.G.; Lee, M.P.; Eisenberg, N.A.; McCartin, T.J.; and Baca, R.G., eds. 100476 1995. NRC Iterative Performance Assessment Phase 2, Development of Capabilities for Review of a Performance Assessment for a High-Level Waste Repository. NUREG-1464. Washington, D.C.: U.S. Nuclear Regulatory Commission. ACC: MOL.19960710.0075.

Whicker, J.J.; Breshears, D.D.; Wasiolek, P.T.; Kirchner, T.B.; Tavani, R.A.; Schoep, 171050 D.A.; and Rodgers, J.C. 2002. "Temporal and Spatial Variation of Episodic Wind Erosion in Unburned and Burned Semiarid Shrubland." Journal of Environmental Quality, 31, (2), 599-612. Madison, Wisconsin: American Society of Agronomy. TIC: 256309. 
Wilson, L. and Head, J.W., III 1981. "Ascent and Eruption of Basaltic Magma on the 101034 Earth and Moon." Journal of Geophysical Research, 86, (B4), 2971-3001.

Washington, D.C.: American Geophysical Union. TIC: 225185.

Wilson, L.; Sparks, R.S.J.; Huang, T.C.; and Watkins, N.D. 1978. "The Control of 162859 Volcanic Column Heights by Eruption Energetics and Dynamics." Journal of Geophysical Research, 83, (B4), 1829-1836. Washington, D.C.: American Geophysical Union. TIC: 254493.

YMP (Yucca Mountain Site Characterization Project) 1993. Evaluation of the 100520 Potentially Adverse Condition "Evidence of Extreme Erosion During the Quaternary Period" at Yucca Mountain, Nevada. Topical Report YMP/92-41-TPR. Las Vegas, Nevada: Yucca Mountain Site Characterization Office. ACC: NNA.19930316.0208.

\subsection{CODES, STANDARDS, REGULATIONS, AND PROCEDURES}

10 CFR 63. Energy: Disposal of High-Level Radioactive Wastes in a Geologic Repository at Yucca Mountain, Nevada. Readily available.

40 CFR 197. Protection of Environment: Public Health and Environmental 165519 Radiation Protection Standards for Yucca Mountain, Nevada. Readily available.

AP-2.22Q, Classification Analyses and Maintenance of the Q-List, Rev 1 ICN 1.

LP-SI.11Q-BSC, Software Management, Rev 0 ICN 1.

AP-SIII.10Q, Models, Rev 2 ICN 7.

\subsection{SOFTWARE}

CRWMS M\&O 2001. Software Code: ASHPLUME. V2.0. PC. 10022-2.0-00

152844

BSC (Bechtel SAIC Company) 2002. Software Code: ASHPLUME. 1.4LV. PC, Windows 2000/NT/98. 10022-1.4LV-02.

BSC (Bechtel SAIC Company) 2003. Software Code: ASHPLUME_DLL_LA. V2.0. PC, Windows 2000. 11117-2.0-00.

Golder Associates. 2003. Software Code: GoldSim. V8.01 Service Pack 1. PC, Windows 2000. 10344-8.01 SP1-00.

\subsection{SOURCE DATA, LISTED BY DATA TRACKING NUMBER}

LA0308CH831811.002. Interpretation of 137-Cesium Profile Values for Samples from the Fortymile Wash alluvial fan. Submittal date: 08/20/2003. 
LA0405CH831811.001. Basaltic Ash Weight Percentages of Drainage Channel 169998

Samples Near Lathrop Wells Cone. Submittal date: 10/08/2003.

LA0407DK831811.001. Physical Parameters of Basaltic Magma and Eruption 170768

Phenomena. Submittal date: 11/03/2003.

MO0103COV01031.000. Coverage: BORES3Q. Submittal date: 03/22/2001.

MO0407SEPFEPLA.000. LA FEP List. Submittal date: 07/20/2004. Imaging in

Process

SN0402T0503303.004. Updated Number of Waste Packages Hit by Igneous Intrusion. Submittal date: 11/06/2003.

\subsection{OUTPUT DATA, LISTED BY DATA TRACKING NUMBER}

LA0408GK831811.001. Calculation of Waste-Form Concentrations in Ash from an Ash Plume at $18 \mathrm{~km}$ from a Vent. Submittal date: 08/19/2004.

LA0408GK831811.002. Input Parameter Values for the ASHPLUME V 2.0DLL Model for TSPA-LA. Submittal date: 08/19/2004.

LA0408CH831811.001. Ash Redistribution Model Abstraction for TSPA-LA. Submittal date: 08/19/2004.

MO0408SPADRWSD.002. Desert Rock Wind Speed and Wind Direction Analyses for Years 1978-1995. Submittal date: 08/17/04. 
INTENTIONALLY LEFT BLANK 


\section{APPENDICES CONTENTS}

Page

APPENDIX A - QUALIFICATION OF EXTERNAL SOURCES .................................... A-1

A1. Jarzemba, M.S.; LaPlante, P.A.; and Poor, K.J. 1997 .................................................. A-1

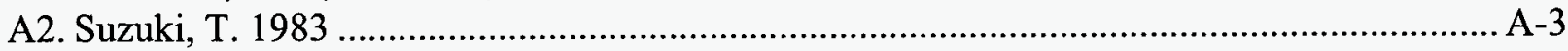

A3. Bacon, C.R. 1977; Drury, M.J. 1987; Best, M.G. 1982 .............................................. A-3

APPENDIX B - KEY TECHNICAL ISSUES, DOE-NRC AGREEMENTS, AND YUCCA MOUNTAIN REVIEW PLAN ACCEPTANCE CRITERIA .......................

B1. Background

B-1

B2. Igneous Activity Key Technical Issue ................................................................... B-1

B3. Yucca Mountain Review Plan Acceptance Criteria ...................................................... B-2

B3.1 INTEGRATED SUBISSUE: AIRBORNE TRANSPORT OF RADIONUCLIDES …............................................................................

B3.2 INTEGRATED SUBISSUE: REDISTRIBUTION OF RADIONUCLIDES

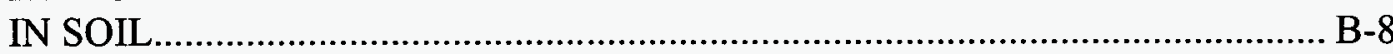

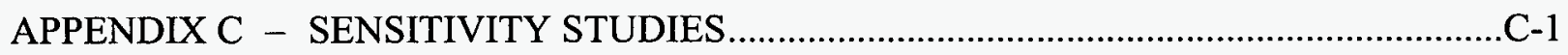

APPENDIX D - DESERT ROCK WIND DATA ANALYSES ....................................... D-1

APPENDIX E - INPUT VALUES FOR WASTE FORM CONCENTRATION AT THE RMEI LOCATION

APPENDIX F - INDEPENDENT TECHNICAL REVIEW OF MDL-MGR-GS 000002

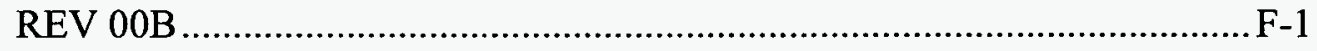

APPENDIX G - INDEPENDENT TECHNICAL REVIEW OF MDL-MGR-GS 000002, REV 00H, ASH REDISTRIBUTION CONCEPTUAL MODEL

APPENDIX H - AN ESTIMATE OF FUEL-PARTICLE SIZES FOR PHYSICALLY DEGRADED SPENT FUEL FOLLOWING A DISRUPTIVE VOLCANIC EVENT THROUGH THE REPOSITORY.

APPENDIX I - ALTERNATIVE MODEL FOR ASH REDISTRIBUTION..........................I-1

I1. PURPOSE ......................................................................................................

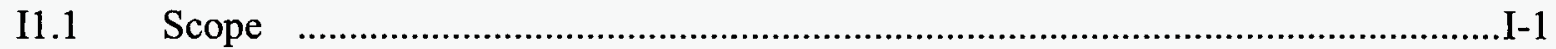

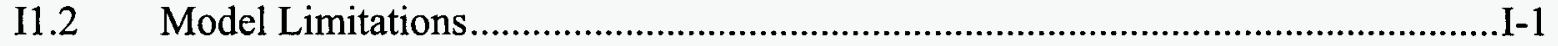

I2. QUALITY ASSURANCE .............................................................................

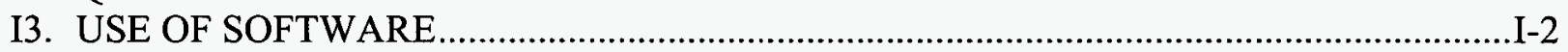

I3.1 Software Tracked by Configuration Management............................................. I-2

I3.2 Exempt Software .....................................................................................

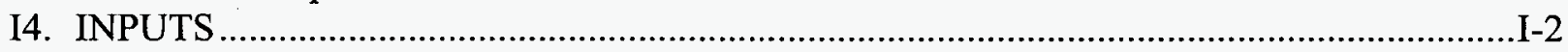

I4.1 Data, Parameters And Other Model Inputs ................................................ I-2 


\section{APPENDICES CONTENTS (Continued)}

I4.1.1 Value for $f$, the Fraction Of Waste Deposited in Fortymile Wash Drainage Basin Redistributed to the RMEI Location

I4.2 CRITERIA

15. ASSUMPTIONS

I5.1.1 Tephra Sheet Distribution for Ash Redistribution Model

I5.1.2 Future Climate

I5.1.3 Stability of Distributary Channels and Neglect of Fluvial Erosion and Deposition on Interchannel Divides in the RMEI Location

I5.1.4 Neglect of Eolian Redistribution to the RMEI Location

PARAMETER ASSUMPTIONS.

I5.2.1 Initial Conditions

I5 22 Depth to the Impermeable Carbonate Horizon (L

I5.2.3 Rates of Eolian Erosion (E Values): .......................................................

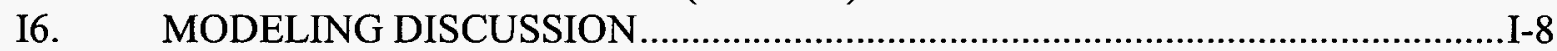

I6.1 MODELING OBJECTIVES .......................................................................

I6.2 BASIS OF ALTERNATIVE REDISTRIBUTION MODEL ................................ I-9

I6.3 CONSIDERATION OF OTHER ALTERNATIVE REDISTRIBUTION

MODELS

I6.4 DESCRIPTION OF THE ALTERNATIVE REDISTRIBUTION

MODEL

I6.4.1 Primary Redistribution to RMEI Location Following an Eruption ............I-10

I6.4.1.1 Distinction Between Channels and Interchannel Divides in the RMEI Area ............................................................... I-10

I6.4.1.2 Redistribution in the Soil Column........................................ I-10

I6.4.1.3 Redistribution by Eolian Transport ....................................... I-11

I6.4.1.4 Redistribution by Fluvial Transport ..................................... I-11

I6.4.2 Mathematical Description of the Alternative Ash Redistribution

Model

I6.4.2.1 Definition of Model Variables

I6.4.2.2 Initial Conditions.

16.4.2.3 Redistribution in the Soil Column.

$\mathrm{I}-14$

I6.4.2.4 Redistribution by Eolian Erosion and Deposition ....................I-14

I6.5 MODEL RESULTS AND ABSTRACTIONS ............................................. I-20

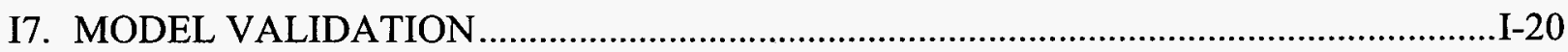

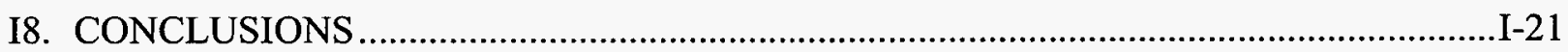

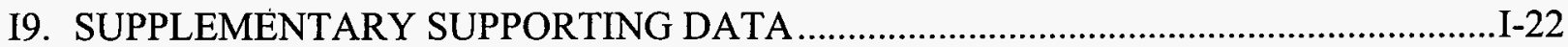

I9.1 DESCRIPTION OF REDISTRIBUTION OF RADIONUCLIDES IN

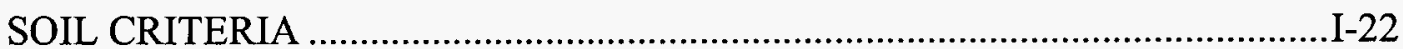

I9.2 DEPTH OF IMPERMEABLE SOIL HORIZON. .............................................

I9.2.1 $L_{0}$ VALUES FOR INTERCHANNEL DIVIDES ............................... I-26

I9.2.2 $L_{0}$ VALUES FOR CHANNELS ......................................................... 


\section{APPENDICES FIGURES}

C-1. Sensitivity of Calculated Ash and Fuel Concentration to Eruptive Power C-2

C-2. Sensitivity of Calculated Ash and Fuel Concentration to Mean Ash Particle Diameter

C-3. Sensitivity of Calculated Ash and Fuel Concentration to Ash Particle Diameter Standard Deviation C-4

C-4. Sensitivity of Calculated Ash and Fuel Concentration to Column Diffusion Constant (Beta)

C-5. Sensitivity of Calculated Ash and Fuel Concentration to Initial Rise Velocity ............... 6

C-6. Sensitivity of Calculated Ash and Fuel Concentration to Wind Speed........................... -7

C-7. Sensitivity of Calculated Ash and Fuel Concentration to Wind Direction.....................C-8

C-8. Sensitivity of Calculated Ash and Fuel Concentration to Eruption Duration .................C-9

C-9. Sensitivity of Calculated Ash and Fuel Concentration to Waste Incorporation Ratio

D-1. Compass (inside numbers) and Ashplume (outside numbers) Degree Comparison ...... D-4

D-2. Wind Rose Diagram for 0 to $1 \mathrm{~km}$ above Yucca Mountain ....................................... D-6

D-3. Wind Frequency of Occurrences at 0 to $1 \mathrm{~km}$ above Yucca Mountain...................... D-38

D-4. Wind Rose Frequency of Occurrences at 1 to $2 \mathrm{~km}$ above Yucca Mountain.............. D-39

D-5. Wind Rose Frequency of Occurrences at 2 to $3 \mathrm{~km}$ above Yucca Mountain.............. D-40

D-6. Wind Rose Frequency of Occurrences at 3 to $4 \mathrm{~km}$ above Yucca Mountain.............. D-41

D-7. Wind Rose Frequency of Occurrences at 4 to $5 \mathrm{~km}$ above Yucca Mountain.............. D-42

D-8. Wind Rose Frequency of Occurrences at 5 to $6 \mathrm{~km}$ above Yucca Mountain.............. D-43

D-9. Wind Rose Frequency of Occurrences at 6 to $7 \mathrm{~km}$ above Yucca Mountain.............. D-44

D-10. Wind Rose Frequency of Occurrences at 7 to $8 \mathrm{~km}$ above Yucca Mountain.............. D-45

D-11. Wind Rose Frequency of Occurrences at 8 to $9 \mathrm{~km}$ above Yucca Mountain.............. D-46

D-12. Wind Rose Frequency of Occurrences at 9 to $10 \mathrm{~km}$ above Yucca Mountain........... D-47

D-13. Wind Rose Frequency of Occurrences at 10 to $11 \mathrm{~km}$ above Yucca Mountain.......... D-48

D-14. Wind Rose Frequency of Occurrences at 11 to $12 \mathrm{~km}$ above Yucca Mountain.......... D-49

D-15. Wind Rose Frequency of Occurrences at 12 to $13 \mathrm{~km}$ above Yucca Mountain.......... D-50

I-1. Illustration of Drainage Basin Slope Mapping Derived from DEM Dataset ..................I-3

I-2. Illustrated Hazard Assessment Use of Drainage Basin Slope Mapping Derived from DEM Dataset ............................................................................................... I-4

I-3. Plots of Concentration (Normalized to Initial Concentration) vs. Depth for a Range of Values of Time $\left(t_{1}\right)$.

I-4. Illustration of the Brownian Motion Model for Erosion and Deposition ....................... I-18

I-5. Schematic Illustration of the Dilution Effect During Eolian Erosion ...........................I-19

I-6. Schematic Illustration of the Dilution Effect of Silt Deposition 


\section{INTENTIONALLY LEFT BLANK}




\section{APPENDICES TABLES}

Page

C-1. Sensitivity of Calculated Ash and Fuel Concentration to Eruptive Power

C-2. Sensitivity of Calculated Ash and Fuel Concentration to Mean Ash Particle Diameter .

C-3. Sensitivity of Calculated Ash and Fuel Concentration to Ash Particle Diameter Standard Deviation

C-4. Sensitivity of Calculated Ash and Fuel Concentration to Column Diffusion Constant (Beta).

C-5. Sensitivity of Calculated Ash and Fuel Concentration to Initial Rise Velocity ..............C-6

C-6. Sensitivity of Calculated Ash and Fuel Concentration to Wind Speed...........................

C-7. Sensitivity of Calculated Ash and Fuel Concentration to Wind Direction....................... -8

C-8. Sensitivity of Calculated Ash and Fuel Concentration to Eruption Duration .................C-9

C-9. Sensitivity of Calculated Ash and Fuel Concentration to Waste Incorporation Ratio

C-10. Input Parameter Values for ASHPLUME Sensitivity Studies C-11

D-1. Height Grouping Query Results

D-2. Example of Table Exported from Access to Excel.............................................. D-2

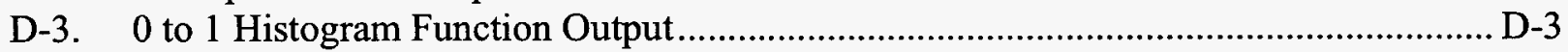

D-4. Bins Converted to Compass Degree Intervals...................................................... D-3

D-5. Compass Degrees from Direction Converted to Ashplume Degrees toward Direction

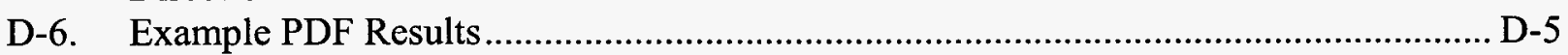

D-7. Format of Tables Used to Calculate Wind Speed CDFs ........................................ D-7

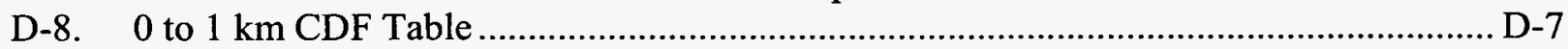

D-9. Wind Speed Minimum, Maximum, and Average................................................... D-12

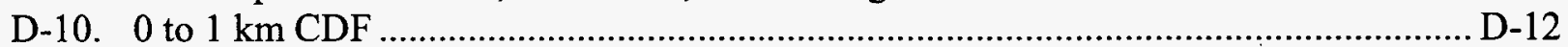

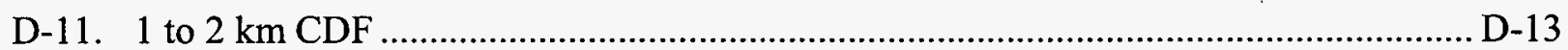

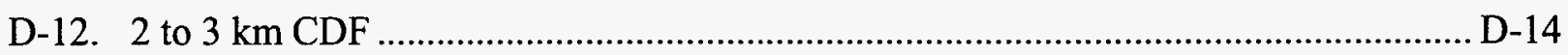

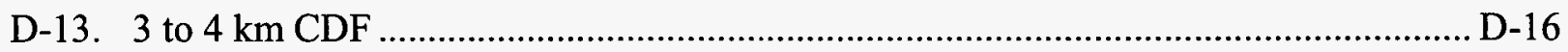

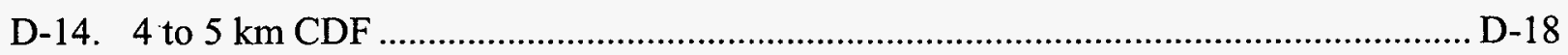

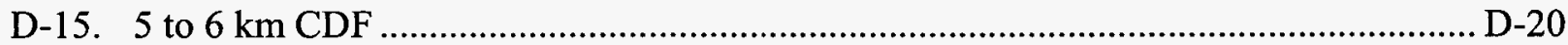

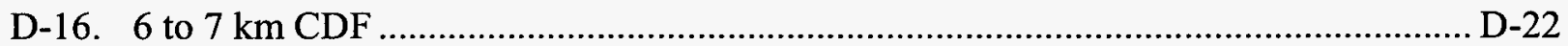

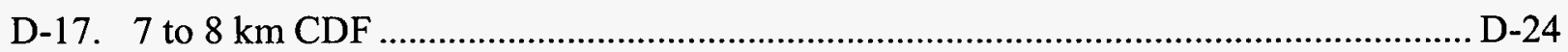

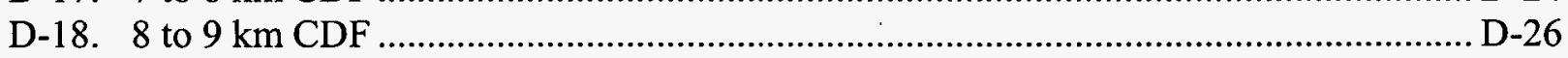

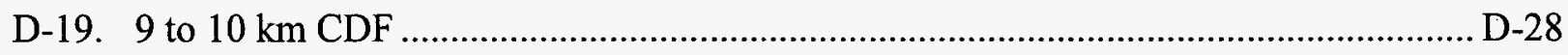

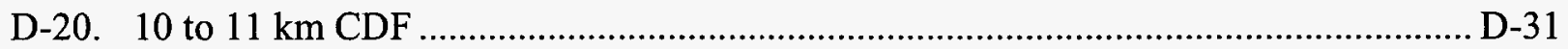

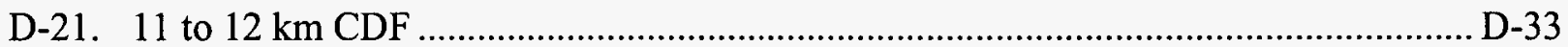

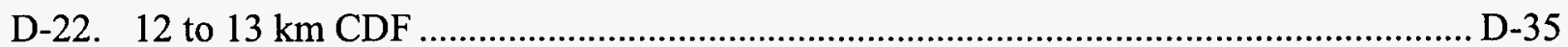

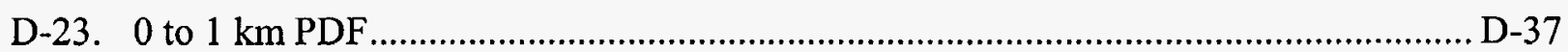

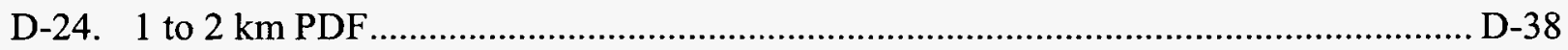

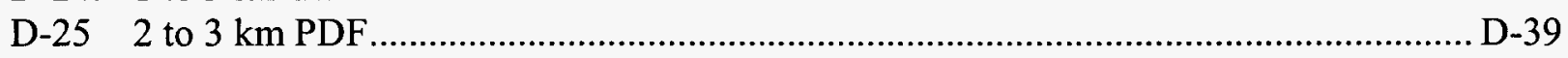

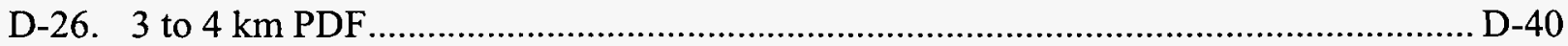




\section{APPENDICES TABLES (Continued)}

Page

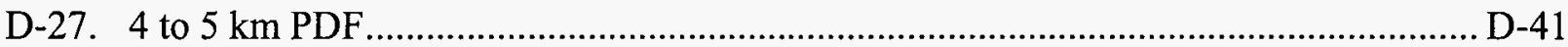

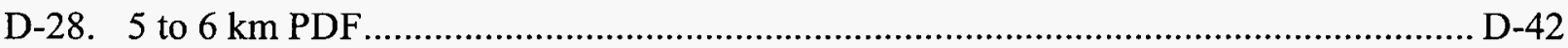

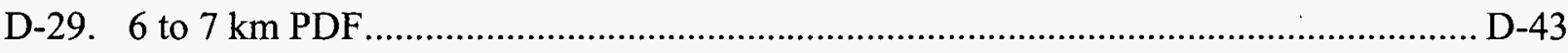

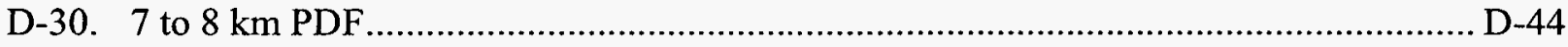

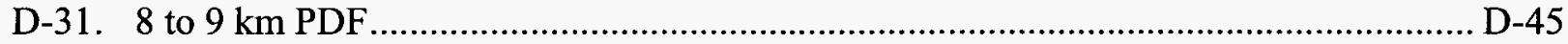

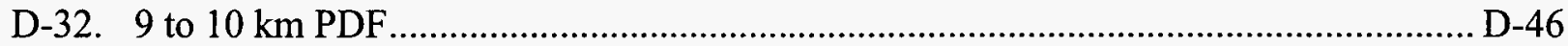

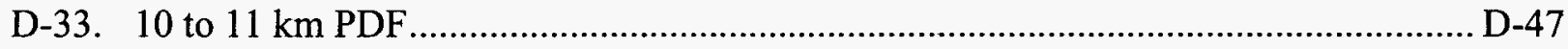

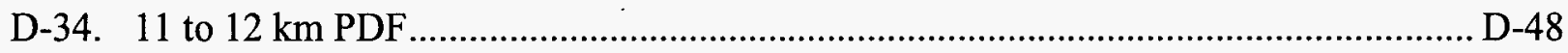

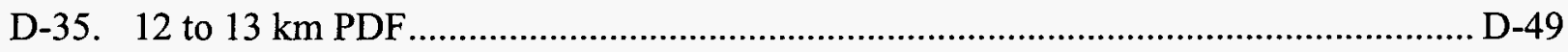

E-1. Fixed Input Values for ASHPLUME ....................................................................

E-2. Realizations for Distributed Parameter Values ......................................................E-2

I-1. Exempt Software ........................................................................................

I-2. Initial Conditions for the Alternative Redistribution Model .................................. I-13

I-3. Abstraction of Ash Redistribution Model for TSPA ............................................. I-21

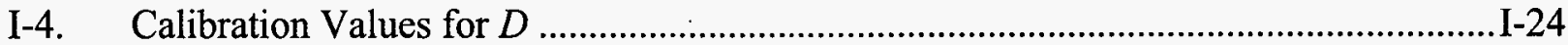

I-5. Inferred $D$ Values from Romney et al. (1970).............................................. I-25

I-6. Inferred $D$ Values from Anspaugh et al. (1975) ..................................................

I-7. Inferred $D$ Values from Gilbert and Eberhardt (1976) ..................................... I-25 


\section{APPENDIX A QUALIFICATION OF EXTERNAL SOURCES}

External sources have provided unqualified data that have been used as direct input to this document. The inputs from these sources are qualified for intended use within the document using the criteria found in AP-SIII.10Q, Models. These criteria represent a subset of the methods and attributes required for qualification of data per AP-SIII.2Q, Qualification of Unqualified Data. The following information is provided for each source: The full reference citation, a description of the data that were used from the source, and the extent to which the data demonstrate the properties of interest. In addition one or more of the following criteria is also addressed:

- Reliability of data source

- Qualifications of personnel or organizations generating the data

- Prior uses of the data

- Availability of corroborating data.

The criteria described above meet the requirements of AP-SIII.10 Q and are provided as justification that the data that have been used from these sources are considered to be qualified for intended use.

\section{A1. JARZEMBA, M.S.; LAPLANTE, P.A.; AND POOR, K.J. 1997}

Reference-Jarzemba, M.S.; LaPlante, P.A.; and Poor, K.J. 1997. ASHPLUME Version 1.0-A Code for Contaminated Ash Dispersal and Deposition, Technical Description and User's Guide. CNWRA 97-004, Rev. 1. San Antonio, Texas: Center for Nuclear Waste Regulatory Analyses. ACC: MOL.20010727.0162. [DIRS 100987]

Description of Use-Jarzemba et al. (1997 [DIRS 100987]) are the source of two parameters required by the ASHPLUME computer code. The two parameters and their reference location in Jarzemba are as follows:

- Column Diffusion Constant, $\beta$ (p. 4-6, Table 5-1)

- Waste Incorporation Ratio, $\rho_{c}$ (Section 2.2, Eq. 2-7)

The specific range of values for the column diffusion constant is discussed as in Section 6.5.2.3. The column diffusion constant $(\beta)$ is set at a uniform distribution with a minimum value of 0.01 and a maximum value of 0.5 . The column diffusion constant was discussed earlier by Suzuki (1983 [DIRS 100489], pp. 104 to 107). This parameter affects the distribution of particles vertically in the ash column and helps determine where particles exit the column. Jarzemba et al. (1997 [DIRS 100987], p. 4-1) uses a log-uniform distribution for beta that has a minimum value of 0.01 and a maximum value of 0.5 . This range of values spans more than an order of magnitude and encompasses the range that is valid for the ASHPLUME model. However, to simulate the anvil cloud associated with a violent Strombolian eruption properly, samples from the range in beta should be focused toward the upper end of the range; therefore, a uniform (rather than log-uniform) distribution is recommended. 
The specific value for the mass incorporation ratio $\left(\rho_{c}=0.3\right)$ is discussed as in Section 6.5.2.6. The incorporation ratio describes the ratio of ash/waste particle sizes that can be combined for transport. An incorporation ratio of 0.3 corresponds to a maximum incorporated waste particle size equal to half the diameter of the ash particle (i.e., any waste particles larger than half the ash particle diameter cannot be incorporated into the ash).

Extent to which the Data Demonstrate the Properties of Interest-Studies have been underway by the Yucca Mountain Project, as well as by the Center for Nuclear Waste Regulatory Analysis at the Southwest Research Institute, which provides technical support for the Yucca Mountain Project. The computer code, ASHPLUME, was developed by Jarzemba at Southwest Research Institute, under contract to the NRC. The code is used to model volcanic ash and waste dispersal during a hypothetical future volcanic eruption through the repository. The two parameters are provided in the documentation for the ASHPLUME code, ASHPLUME Version 1.0-A Code for Contaminated Ash Dispersal and Deposition, Technical Description and User's Guide, Jarzemba et al. (1997 [DIRS 100987]).

Qualifications of Personnel or Organizations Generating the Data and Prior Use of the Data-The source document (Jarzemba et al. 1997 [DIRS 100987]) is the technical description and user's guide for ASHPLUME, version 1.0. ASHPLUME Version 1.0, a code for contaminated ash dispersal and deposition, was prepared for the NRC under contract to the Center for Nuclear Waste Regulatory Analyses, San Antonio, Texas. The Center for Nuclear Waste Regulatory Analyses at Southwest Research Institute is a federally funded research and development center created to support the NRC. The principal author of the code was Dr. Mark S. Jarzemba.

\section{Qualifications of M.S. Jarzemba:}

Education:

B.S. 19.88, Engineering Physics, Ohio State University

M.S. 1991, Nuclear Engineering, Ohio State University

Ph.D. 1993, Nuclear Engineering, Ohio State University

Dr. Jarzemba has over 15 years of research and professional experience. His background includes nuclear instrumentation and shielding, radon gas-phase transport modeling, environmental/dose pathway analyses and criticality analyses. At the time of publication, Dr. Jarzemba was a research scientist with Southwest Research Institute. Dr. Jarzemba is the author and co-author of numerous books and publications.

Based on the foregoing discussion, the data cited from Jarzemba [DIRS 100987], can be accepted as qualified for use in this report. 


\section{A2. SUZUKI, T. 1983}

Reference-Suzuki, T. 1983. "A Theoretical Model for Dispersion of Tephra." Arc Volcanism: Physics and Tectonics, Proceedings of a 1981 IAVCEI Symposium, August-September, 1981, Tokyo and Hakone. Shimozuru, D. and Yokoyama, I., eds. Pages 95-113. Tokyo, Japan: Terra Scientific Publishing Company. TIC: 238307. [DIRS 100489]

Description of Use-Suzuki (1983 [DIRS100489], p. 99) is the source for eddy diffusivity $\left(400 \mathrm{~cm}^{2} / \mathrm{s}^{5 / 2}\right.$ ) discussed in Section 6.5 .1 and the value is listed in Table $6-3$ of this model report. Suzuki developed the mathematical model that underlies the ASHPLUME code, which is used in development of this model report. The underlying 2-D partial differential equation relates the change in concentration, $\xi$, at a point $\mathrm{x}-\mathrm{y}$ (with $\mathrm{x}$ downwind) to wind velocity, $u$, and an eddy diffusivity constant, $C$.

Extent to which the Data Demonstrate the Properties of Interest-The Ashplume model for Yucca Mountain is based on a mathematical model of Suzuki (1983 [DIRS 100489]) that Jarzemba et al. (1997 [DIRS 100987]) refined to represent violent Strombolian-type eruptions. The code is used to model volcanic ash and waste dispersal during a hypothetical future volcanic eruption through the repository. The eddy diffusivity constant was developed as part of that mathematical model.

Prior Use of the Data-The above-listed reference document provides the basis for ASHPLUME, Version 1.0, a code for contaminated ash dispersal and deposition, prepared by the Center for Nuclear Waste Regulatory Analyses at Southwest Research Institute, San Antonia Texas, under contract to the NRC. The code was developed for use in evaluation of potential igneous events at Yucca Mountain. The specific value for eddy diffusivity, $400 \mathrm{~cm}^{2} / \mathrm{s}^{5 / 2}$, was used as an input value to the code as documented in Tables 5-1 and 5-2 of Jarzemba et al. (1997 [DIRS 100987]). The resultant graph, Figure 5-1b, is identical to the results recorded by Suzuki, Figure 6c.

Based on the foregoing discussion, the data cited from Suzuki [DIRS 100489], can be accepted as qualified for use in this AMR.

\section{A3. BACON, C.R. 1977; DRURY, M.J. 1987; BEST, M.G. 1982}

References-Bacon, C.R. 1977. "High Temperature Heat Content and Heat Capacity of Silicate Glasses: Experimental Determination and a Model for Calculation." American Journal of Science, 277, 109-135. [New Haven, Connecticut: Yale University, Kline Geology Laboratory]. TIC: 255125. [DIRS 165512]

Drury, M.J. 1987. “Thermal Diffusivity of Some Crystalline Rocks." Geothermics, 16, (2), 105-115. New York, New York: Pergamon Press. TIC: 251764. [DIRS 156447]

Best, M.G. 1982. Igneous and Metamorphic Petrology. New York, New York: W.H. Freeman and Company. TIC: 247662. [DIRS 147740]

Description of Use-Bacon, C.R., 1977 and Drury, 1987, are used as the basis for the value $(1000 \mathrm{~J} /(\mathrm{kg}-\mathrm{K}))$ selected for the heat capacity of magma. The value is rounded from data 
presented in Figures 1 and 2 in the Bacon article, and from Table 2 in the Drury reference. Heat capacity is one of the variables in the calculation of eruptive power, which is a direct feed to TSPA-LA.

Extent to which the Data Demonstrate the Properties of Interest-The Bacon (1977 [DIRS 165512]), reference documents the results of experimental work to determine the thermodynamic properties of silicate melts. The property of interest, heat capacity, is plotted for different compositions of silicate glasses at different temperatures. Bacon's compositions one through three bracket the magma compositions (discussed in Characterize Eruptive Processes at Yucca Mountain, Nevada (BSC 2004 [DIRS 169980])) assumed for this model report. Drury (1987 [DIRS 156447]) also reports thermodynamic data from experimental work on igneous materials of different compositions, including the heat capacity for basalt.

Corroborative Data and Prior Use-The values and ranges for heat capacity for melts of basaltic compositions from these two articles are corroborative. For compositions close to those proposed for this model report, the Bacon reference shows experimental heat capacities ranging from 800 to $1100 \mathrm{~J} /(\mathrm{kg}-\mathrm{K})$. In Drury (1987 [DIRS 156447]), a value of $1010 \mathrm{~J} /(\mathrm{kg}-\mathrm{K})$ is listed for the basaltic composition. A value of $1000 \mathrm{~J} /(\mathrm{kg}-\mathrm{K})$ for specific heat is also reported in Characterize Eruptive Processes at Yucca Mountain, Nevada, (BSC 2004 [DIRS 169980], Table 6-5), where the property is also used to calculate mass discharge rate. The source that is used as a basis for the latter value is Best (1982 [DIRS 147740]; page 301). This reference book presents a range of specific heat of 800 to $1300 \mathrm{~J} / \mathrm{kg}$. The similarity of reported values in the three references, combined with the prior use of the specific values in other igneous studies for Yucca Mountain provide the necessary justification that this value is qualified for the intended use. 


\section{APPENDIX B}

KEY TECHNICAL ISSUES, DOE-NRC AGREEMENTS, AND YUCCA MOUNTAIN REVIEW PLAN ACCEPTANCE CRITERIA 


\section{APPENDIX B \\ KEY TECHNICAL ISSUES, DOE-NRC AGREEMENTS, AND YUCCA MOUNTAIN REVIEW PLAN ACCEPTANCE CRITERIA}

\section{B1. BACKGROUND}

Early in 1995, the NRC recognized the need to refocus its prelicensing repository program on resolving issues most significant to repository performance. In 1996, the NRC identified 10 key technical issues (Sagar 1997 [DIRS 145235]) intended to reflect the topics that the NRC considered most important to repository performance. Nine of the issues were technical, and the tenth concerned the development of the dose standard for a repository at Yucca Mountain (see 40 CFR Part 197 [DIRS 165519]). The technical issues included igneous activity, and the status of resolution of each issue and associated open items were described by the NRC in a series of Issue Resolution Status Reports (e.g., Reamer 1999 [DIRS 119693]). In 2002, the NRC consolidated the subissues into a series of integrated subissues and replaced the series of nine issue resolution status reports with an Integrated Issue Resolution Status Report (NRC 2002 [DIRS 159538]). The Integrated Issue Resolution Status Report was based on the realization that the issue resolution process was "mature enough to develop a single Integrated Issue Resolution Status Report that would clearly and consistently reflect the interrelationships among the various key technical issue subissues and the overall resolution status" (NRC 2002 [DIRS 159538], pp. xviii and xix). The Integrated Issue Resolution Status Report and periodic letters from the NRC (e.g., Schlueter 2003 [DIRS 165740]) provide information about the resolution status of the integrated subissues that are described in the Yucca Mountain Review Plan, NUREG-1804 (NRC 2003 [DIRS 163274]).

\section{B2. IGNEOUS ACTIVITY KEY TECHNICAL ISSUE}

The key technical issue for igneous activity was defined by the NRC staff as "predicting the consequence and probability of igneous activity affecting the repository in relationship to the overall system performance objective" (NRC 1998 [DIRS 100297], p. 3). Hence, the NRC defined two subissues for the igneous activity key technical issue: probability and consequences (NRC 1998 [DIRS 100297], p. 3). The probability subissue addresses the likelihood that future igneous activity would disrupt a repository at Yucca Mountain. The DOE estimated the probability of future disruption of a repository at Yucca Mountain in the Probabilistic Volcanic Hazard Analysis for Yucca Mountain, Nevada (CRWMS M\&O 1996 [DIRS 100116]). For the TSPA-LA, an analysis based on the Probabilistic Volcanic Hazard Analysis for Yucca Mountain, Nevada results and consideration of the repository LA design were both updated and documented in the scientific analysis report, Characterize Framework for Igneous Activity at Yucca Mountain, Nevada (BSC 2004 [DIRS 169989]).

The consequences subissue examined the effects of igneous activity on various engineered and natural components of the repository system. The consequences subissue comprises four integrated subissues: mechanical disruption of engineered barriers (NRC 2003 [163274] Section 2.3.1.3.2 and NRC 2002 [159538] Section 3.3.10.1, paragraph 1); volcanic disruption of waste packages ((NRC 2003 [163274] Section 2.3.1.3.10); airborne transport of radionuclides (NRC 2003 [163274] Section 2.3.1.3.11); and redistribution of radionuclides in soil (NRC 2003 [163274] Section 2.3.1.3.13). This model report addresses the integrated subissues of airborme 
transport of radionuclides and redistribution of radionuclides in soil (NRC 2003 [163274] Section 2.3.1.3.11). Mechanical disruption of engineered barriers and volcanic disruption of waste packages are addressed in Dike/Drift Interactions (BSC 2004 [DIRS 170028]), and Number of Waste Packages Hit by Igneous Intrusion (BSC 2004 [DIRS 170001]).

For the TSPA-SR, the DOE defined two igneous scenarios to evaluate the effects of igneous activity on the repository and its contents (BSC 2001 [DIRS 157876]):

- A direct-release scenario featuring penetration of the repository by an ascending basaltic dike followed by eruption of contaminated ash at the surface

- An indirect release or igneous-intrusion, groundwater-release scenario featuring penetration of the repository by an ascending basaltic dike and no surface eruption.

In the latter scenario, release of radionuclides would be through the groundwater pathway. Both igneous scenarios are being carried forward for TSPA-LA.

For the TSPA-LA, the direct-release model has been described, and documentation is provided in this model report. For the indirect-release scenario, the potential effects of the repository on the propagation of a basaltic dike, the environmental conditions accompanying intersection of the repository by an ascending dike, and analyses of effects of intrusive igneous activity on repository structures and components are documented in the model report Dike/Drift Interactions (BSC 2004 [DIRS 170028]).

In addition, this model report describes the ash redistribution conceptual model and documents the development and validation of this model (Sections 6.6.2 and 7). This conceptual model is potentially important to the TSPA-LA because reworking of contaminated tephra deposits could increase the concentration of radioactive waste material at the RMEI location and, thereby, potentially increase the dose risk to the RMEI.

\section{B3. YUCCA MOUNTAIN REVIEW PLAN ACCEPTANCE CRITERIA}

The Yucca Mountain Review Plan (NUREG-1804, NRC 2003 [DIRS 163274]) associates the integrated subissue of airborne transport of radionuclides with the requirements listed in 10 CFR 63.114 (10 CFR 63(a)-(c) and (e)-(g) [DIRS 156605]). NUREG-1804 (NRC 2003 [DIRS 163274], Sections 2.2.1.3.11 and 2.2.1.3.13) describes the acceptance criteria that the NRC will use to evaluate the adequacy of information addressing the airborne transport of radionuclides in the license application. The application acceptance criteria may also be addressed in other analysis model reports. The acceptance criteria will be considered fully addressed when this report is considered in conjunction with those reports. The following discussion provides a summary of how the information in this model report addresses those criteria that are associated with the development and use of the ASHPLUME model. This model report also addresses the integrated subissue redistribution of radionuclides in the soil NRC 2003 [DIRS 163274], Section 2.2.1.3.13). 


\section{B3.1 Integrated Subissue: Airborne Transport of Radionuclides}

\section{Acceptance Criterion 1: System Description and Model Integration Are Adequate}

1. Total system performance assessment adequately incorporates important design features, physical phenomena, and couplings, and uses consistent and appropriate assumptions throughout the airborne transport of radionuclides abstraction process.

This model report documents the use of the ASHPLUME code to model the airborne transport of radionuclides. This report provides information about the development of the ASHPLUME conceptual model by Suzuki (1983 [DIRS 100489]) (Section 6.3) and describes the consistency of the conceptual model with physical phenomena associated with violent Strombolian eruptions and the development and propagation of an ash cloud downwind of the eruption site followed by deposition of tephra deposits on the ground surface (Section 6.3). This report also documents the consistency between the conceptual model and the ASHPLUME mathematical model used in the TSPA (Section 6.5). A mathematical description of the base case conceptual model is described in Section 6.5.1. The inputs to the model are described in Section 6.5.2. Model assumptions needed to use the ASHPLUME model are described in Section 5.1, and parameter assumptions are described in Section 5.2. The TSPA code, GoldSim, includes the ASHPLUME code (ASHPLUME V 2.0 dll) as a dynamic link library. Inclusion of ASHPLUME as a DLL ensures that physical phenomena and couplings important to the analysis of airborne transport of radionuclides are consistently and appropriately treated in performance assessment.

2. Models used to assess airborne transport of radionuclides are consistent with physical processes generally interpreted from igneous features in the Yucca Mountain region and/or observed at active igneous systems.

This model report provides information about the basis for the ASHPLUME conceptual model (Suzuki 1983 [DIRS 100489]) in Section 6.3.1. Section 6.3.1 also describes the consistency of the conceptual model with physical phenomena associated with violent Strombolian eruptions and the development and propagation of an ash cloud downwind of the eruption site followed by deposition of tephra deposits on the ground surface. Base-case model inputs and uncertainties and their consistency with igneous features either observed in the Yucca Mountain region or with features observed at analog igneous systems are described in Section 6.5.2. The bases for the selection of an appropriate distribution for each uncertain parameter are described in this report (Section 6.5.2). Model inputs that are developed and documented in other analyses or models are appropriately identified, described, and cross-referenced.

Alternative models considered are described in Section 6.4.1.

3. Models account for changes in igneous processes that may occur from interactions with engineered repository systems.

The ASHPLUME model does not account for changes in igneous processes that might result from interactions between processes and components of the engineered barrier 
system. Such interactions are described in other analyses or model reports, as appropriate (e.g., Dike/Drift Interactions (BSC 2004 [DIRS 170028]) and Number of Waste Packages Hit by Igneous Intrusion (BSC 2004 [DIRS 170001).

4. Guidance in NUREG-1297 and NUREG-1298 (Altman et al. 1988 [DIRS 103597]; Altman et al. 1988 [DIRS 103750]), or in other acceptable approaches for peer review and data qualification is followed.

Quality assurance considerations for modeling activities associated with development of the ASHPLUME V 2.0 software (CRWMS M\&O 2001 [DIRS 152844]) are described in Section 2. Data, parameters, and other model inputs are described in Section 4.1 .

NUREG-1297 describes the generic technical position with respect to the use of peer reviews on high-level waste repository programs. The independent peer review of the ASHPLUME model is described in Section 7.4.1. Additional documentation is provided in Appendix F. The review was done in accordance with the Project procedure, Peer Review (AP-2.12Q). NUREG-1298 describes the generic technical position with respect to qualification of existing data. External sources have provided unqualified data that have been used as direct input to this document. The inputs from these sources are qualified for intended use within the document using the criteria found in AP-SIII.9Q, Scientific Analyses. These criteria represent a subset of the methods and attributes required for qualification of data per AP-SIII.2Q, Qualification of Unqualified Data. These methods and attributes are based on those that are presented in NUREG 1298, which are meant to provide "the level of confidence in the data ... commensurate with their intended use.

\section{Acceptance Criterion 2: Data Are Sufficient for Model Justification}

1. Parameter values used in the license application to evaluate airborne transport of radionuclides are sufficient and adequately justified. Adequate descriptions of how the data were used, interpreted, and appropriately synthesized into the parameters are provided.

Uses of the parameter values are generally described as part of the mathematical description of the base-case model in Section 6.5.1. The development of all model inputs used for the atmospheric dispersal model is discussed in Section 6.5.2. Subsections describe the individual model input parameters and provide detailed technical bases supporting the use of the numerical value or range for each parameter. Model report outputs for the TSPA-LA are described in Section 8.2.

2. Data used to model processes affecting airborne transport of radionuclides are derived from appropriate techniques. These techniques may include site-specific field measurements, natural analog investigations, and laboratory experiments.

The parameter values used as inputs for ASHPLUME V 2.0 dll are described in the model report in Section 4.1, and model outputs are described in Section 8.2. Modeling objectives, the characteristics of the base-case model, consideration of alternative conceptual models, and the basis for the selection of ASHPLUME for modeling 
airborne transport of radionuclides are discussed in Sections 6.1, 6.3, and 6.4, respectively. The formulation of the mathematical model is described in Section 6.5.1, and the base-case model inputs and their appropriateness are described in Section 6.5.2.

This model report describes the conceptual model, formulation of the mathematical model, identification of parameters, selection of appropriate parameter values or distributions, and discusses the consideration of alternative models. All of these considerations are included in the basis for selection of the ASHPLUME model as appropriate for analyzing the airborne transport of radionuclides for the license application. The alternative models considered are described in Section 6.4.1, and a summary of alternative conceptual models is provided in Section 6.4.3. Section 7.3 of the report discusses validation of the model and shows how the validation exercises have shown the efficacy of the ASHPLUME model to represent observed variations in tephra deposit thicknesses at analog sites. The validation work also shows that the model is internally consistent and produces numerical convergence in simulations. These lines of evidence demonstrate that the ASHPLUME model is appropriate to analyze the airborne transport of radionuclides.

3. Sufficient data are available to integrate features, events, and processes, relevant to airborne transport of radionuclides into process-level models, including site-specific determination of appropriate interrelationships and parameter correlations.

FEPs related to the development and use of the ASHPLUME model are discussed in Section 6.2. Table 6-1 includes descriptions of the specific data elements associated with the FEPs associated with the ASHPLUME model and summarizes how objectives for the integration of FEPs are addressed by the development of the model.

4. Where sufficient data do not exist, the definition of parameter values and associated conceptual models is based on appropriate use of expert elicitation conducted, in accordance with NUREG-1563 (Kotra et al. 1996 [DIRS 100909]). If other approaches are used, the U.S. Department of Energy adequately justifies their use.

Sufficient data exist to define the parameter values and associated conceptual models needed to model the atmospheric dispersal and deposition of tephra (Section 6.5.2). Expert elicitation was not used in the definition of parameter values and associated conceptual models.

\section{Acceptance Criterion 3: Data Uncertainty is Characterized and Propagated Through the Model Abstraction}

1. Models use parameter values, assumed ranges, probability distributions, and bounding assumptions that are technically defensible, reasonably account for uncertainties and variabilities, and do not result in an under-representation of the risk estimate.

The development of the individual mathematical formulations for the model is described in the model report (Section 6.5.1) as are the inputs to the model and assumptions needed to use the ASHPLUME model for analysis (Section 6.5.2). Uncertainties associated with changes in igneous processes are included in 
ASHPLUME analyses through the use of parameter distributions (Section 6.5.2). The bases for the selection of an appropriate distribution for each uncertain parameter are described in the report (Section 6.5.2). The reasonableness of values and distributions for parameters and their suitability for use are described in Section 6.5.2. Assumptions associated with the appropriateness of the ASHPLUME model are described in Section 5.1, and assumptions associated with specific model parameters are described in Section 5.2. The appropriateness of the base-case model is described in Section 6.3.1, and the consideration of alternative models is documented in Section 6.4.1. The screening of an alternative basis for the selection of ASHPLUME is also documented in Section 6.4.1 (see Table 6-2). Input parameter uncertainty is addressed in Section 4.1.2.

2. Parameter uncertainty accounts quantitatively for the uncertainty in parameter values derived from site data and the available literature (i.e., data precision) and the uncertainty introduced by model abstraction (i.e., data accuracy).

Data precision is addressed in the mathematical description of the base case conceptual model (Section 6.5.1) and in the development of the input parameters (Section 6.5.2 and subsections). Data accuracy is addressed by evaluating uncertainties introduced by model abstraction. These uncertainties are explicitly addressed by the results of the model validation exercise (Sections 7.1, 7.2, and 7.3), which shows how well the ASHPLUME model outputs conform to evaluation criteria, including sensitivity of outputs to variations in input parameters (Section 7.2), comparison of model ash thicknesses with observed thicknesses at analog sites (Section 7.3), and conservation of mass (DOE 2003 [DIRS 166506]) (Section 7.3).

Uncertainties associated with changes in igneous processes are included in ASHPLUME analyses through the use of parameter distributions (Section 6.5.2). The bases for the selection of an appropriate distribution for each uncertain parameter are described in the report (Section 6.5.2). Parameter uncertainty is addressed in Section 4.1.2.

3. Where sufficient data do not exist, the definition of parameter values and associated uncertainty is based on appropriate use of expert elicitation conducted in accordance with NUREG-1563 (Kotra et al. 1996 [DIRS 100909]). If other approaches are used, the U.S. Department of Energy adequately justifies their use.

Sufficient data exist to define the parameter values and associated conceptual models needed to model the atmospheric dispersal and deposition of tephra (Section 6.5.2). Expert elicitation has not been used in the definition of parameter values and associated conceptual models.

\section{Acceptance Criterion 4: Model Uncertainty is Characterized and Propagated Through the Model Abstraction}

1. Alternative modeling approaches to airborne transport of radionuclides are considered and are consistent with the available data and current scientific understandings, and the results and limitations are appropriately considered in the abstraction. 
The alternative models that were considered for modeling airborne transport of radionuclides are described in Section 6.4.1, including the screening of an alternative basis for the selection of ASHPLUME (see Table 6-2). The consistency of the ASHPLUME model with data and current scientific understanding is described in Sections 6.3.1 and 6.5.1. Sections 7.1 - 7.3 discuss validation of the model and show how the validation exercises have demonstrated the efficacy of the ASHPLUME model to represent observed variations in tephra deposit thicknesses at analog sites. The validation work shows that the model is internally consistent and produces numerical convergence in simulations. Limitations of the ASHPLUME model are discussed in Section 1.3.

2. Uncertainties in abstracted models are adequately defined and documented, and effects of these uncertainties are assessed in the total system performance assessment.

Uncertainties associated with ASHPLUME model outputs are described in Section 8.3, and input parameters and parameter uncertainties are described in Section 4.1.2. Section 7.2 describes the sensitivity analyses that were done to evaluate the response of the ASHPLUME model over the entire range of model input parameter values. The results show that the model is sensitive to variations in eruptive power, wind speed, wind direction, and eruption duration. TSPA sensitivity to parameter variations is beyond the scope of this report.

3. Consideration of conceptual model uncertainty is consistent with available site characterization data, laboratory experiments, field measurements, natural analog information, and process-level modeling studies; and the treatment of conceptual model uncertainty does not result in an under representation of the risk estimate.

The basis of the ASHPLUME conceptual model is described in Section 6.3.1, and the mathematical description of the base-case conceptual model is provided in Section 6.5.1. Uncertainties in the model outputs are described in Section 8.3, and conservatisms included to assure that model outputs to the TSPA do not result in an under representation of risk are described as part of the conceptual model (Section 6.5.2 and subsections).

The alternative models that were considered for modeling airborne transport of radionuclides are described in Section 6.4.1 and are summarized in Section 6.4.3. The screening of an alternative basis for the selection of ASHPLUME is also documented in Section 6.4.1 (see Table 6-2). The consistency of the ASHPLUME model with data and current scientific understanding is described in Sections 6.3.1 and 6.5.1. Sections $7.1-7.3$ discuss validation of the model and show how the validation exercises have demonstrated the efficacy of the ASHPLUME model to represent observed variations in tephra deposit thicknesses at analog sites. The validation work shows that the model is internally consistent and produces numerical convergence in simulations. Limitations of the ASHPLUME model are discussed in Section 1.3. 


\section{Acceptance Criterion 5: Model Abstraction Output is Supported by Objective Comparisons}

1. Models implemented in the airborne transport of radionuclides abstraction provide results consistent with output from detailed process-level models and/or empirical observations (laboratory and field testings and/or natural analogs).

Section 6.2 lists the specific FEPs that are included in the ASHPLUME model. Section 6.3.1 provides a detailed description of the basis for the ASHPLUME conceptual model and the appropriateness of that model for the analysis of airborne transport of radionuclides. Section 6.5.1 provides a detailed description of the mathematical formulation of the base-case conceptual model and the consistency of that formulation with natural processes. Sections $7.1-7.3$ of the model report discuss validation of the model and show how the validation exercises have shown the efficacy of the ASHPLUME model to represent observed variations in tephra deposit thicknesses at analog sites. The validation work also shows that the model is internally consistent and produces numerical convergence in simulations.

2. Inconsistencies between abstracted models and comparative data are documented, explained, and quantified. The resulting uncertainty is accounted for in the model results.

The model outputs are described in Section 8.2 and model output uncertainties are described in Section 8.3. Sections 7.1 - 7.3 discuss validation of the model and show how the validation exercises have shown the efficacy of the ASHPLUME model to represent observed variations in tephra deposit thicknesses at analog sites (Section 7.3). The validation work also shows that the model is internally consistent and produces numerical convergence in simulations.

\section{B3.2 Integrated Subissue: Redistribution of Radionuclides in Soil}

The Yucca Mountain Review Plan (NUREG-1804, NRC 2003 [DIRS 163274]) associates the integrated subissue of redistribution of radionuclides in soil with the requirements listed in 10 CFR 63.114(1)(a)-(c), (e)-(g), and 63.305 [DIRS 156605] as they relate to the redistribution of radionuclides in soil abstraction. NUREG-1804 (NRC 2003 [DIRS 163274], Section 2.2.1.3.13.3) describes the acceptance criteria that the NRC will use to evaluate the adequacy of information addressing the redistribution of radionuclides in soil in the license application. The following discussion provides a summary of how the information in this model report addresses those criteria that are associated with the development and use of the ash redistribution conceptual model.

\section{Acceptance Criterion 1: System Description and Model Integration Are Adequate}

1. Total system performance assessment adequately incorporates important features, physical phenomena and couplings between different models, and uses consistent and appropriate assumptions throughout the abstraction of redistribution of radionuclides in the soil abstraction process.

Information in this model report describes the conceptual model for ash redistribution, the validity of the model, and providing model outputs for use in the TSPA-LA. 
Features, events, and processes included in the model are described in Section 6.2 and discussed in more detail in Table 6-1. The basis of the ash redistribution model is described in Section 6.3.2. The ash redistribution conceptual model is described in Section 6.6, and the two outcomes used to bound ash redistribution in the Yucca Mountain area are described in Sections 6.6.6 and 6.6.7. A general description of the tephra dilution process is provided in Section 6.6.3, and rates of surficial processes are described in Section 6.6.4. Assumptions associated with the use of the model are described in Sections 5.1.3 - 5.1.9, and results of the ash redistribution model are described in Section 6.7.2 and Table 6-5. Model report outputs are described in Section 8.2. Output uncertainties associated with the ash redistribution model are described in Section 8.3.

It is beyond the scope of this report to document the use of model outputs and abstractions in the TSPA-LA.

2. The total system performance assessment model abstraction identified and describes aspects of redistribution of radionuclides in soil that are important to repository performance, including the technical bases for these descriptions. For example, the abstraction should include modeling of the deposition of contaminated material in the soil and the determination of the depth distribution of the deposited radionuclides.

Output from the ASHPLUME model provides estimates of the primary amount of contaminated ash in the tephra blanket in terms of concentration of waste per unit area $\left(\mathrm{g} / \mathrm{cm}^{2}\right)$ (Table 6-4). The ash redistribution model abstraction is described in Section 6.7.2, and assumptions used in the model are documented in Sections 5.1.3 - 5.1.9.

3. Relevant site features, events, and processes have been appropriately modeled in the abstraction of redistribution of radionuclides, from surface processes, and sufficient technical bases are provided.

Site FEPs included in the model are described in Section 6.2. The technical bases for the included FEPs are described in detail in Table 6-1.

4. Guidance in NUREG-1297 and NUREG-1298 (Altman et al. 1988 [DIRS 103597]; Altman et al. 1988 [DIRS 103750]), or other acceptable approaches for peer reviews is followed.

NUREG-1297 describes the generic technical position with respect to the use of peer reviews on high-level waste repository programs. The use of independent peer reviews of the ash redistribution conceptual model is described in Section 7.4.2. These reviews were done in accordance with the Project procedure, Peer Review (AP-2.12Q), and are found in Appendix G. NUREG-1298 describes the generic technical position with respect to qualification of existing data. External sources have provided unqualified data that have been used as direct input to this document. The inputs from these sources are qualified for intended use within the document using the criteria found in AP-SIII.9Q, Scientific Analyses. These criteria represent a subset of the methods and attributes required for qualification of data per AP-SIII.2Q, 
Qualification of Unqualified Data. These methods and attributes are based on those that are presented in NUREG 1298, which are meant to provide "the level of confidence in the data ... commensurate with their intended use."

\section{Acceptance Criterion 2: Data Are Sufficient for Model Justification}

1. Behavioral, hydrological, and geochemical values used in the license application are adequately justified (e.g., irrigation and precipitation rates, erosion rates, radionuclide solubility values, etc.). Adequate descriptions of how the data were used, interpreted, and appropriately synthesized into the parameters are provided.

Data sources that provided inputs for the development of parameters used in the ash redistribution conceptual model are identified in Section 4.1.1. The appropriateness of the data is also discussed. A general description of tephra redistribution processes is provided in Sections 6.3.2 and 6.6.3. Rates of surficial processes that are needed to support model development and use are documented in Section 6.6.4, and the Cs-137 data, used to identify a time stratigraphic marker in the surficial deposits and provide a proxy for determining the soil depths that fine particles and associated radionuclides from waste could penetrate, are described in Section 6.6.4. Analog studies to support the ash redistribution conceptual model are described in Section 7.3, and the results of an independent review of the ash redistribution model are described in Section 7.4.2 (see Appendix $\mathrm{G}$ for the reviews). Model output uncertainties associated with the ash redistribution conceptual model are described in Section 8.3. Outputs from the ash redistribution conceptual model are described in Section 6.7.2, and 8.2, and listed in Table 6-5. Guidelines for using the outputs in the TSPA model are also provided in Section 6.7.2.

2. Sufficient data (e.g., field laboratory, and natural analog data) are available to adequately define relevant parameters and conceptual models necessary for developing the abstraction of redistribution of radionuclides in soil in the total system performance assessment.

Data sources that provide inputs for the development of parameters used in the ash redistribution conceptual model are identified in Section 4.1.1. The appropriateness of the data is also discussed. Rates of surficial processes that are needed to support model development and use are documented in Section 6.6.4, and the Cs-137 data that form a time stratigraphic marker in the surficial deposits and provide a proxy for determining the soil depths that fine particles and associated radionuclides from waste could penetrate are described in Section 6.6.4. Table 6-5 lists the TSPA factors that are provided by the ash redistribution conceptual model. Guidelines for using the outputs in the TSPA model are provided in Section 6.7.2.

\section{Acceptance Criterion 3: Data Uncertainty Is Characterized and Propagated Through the Model Abstraction}

1. Models use parameter values, assumed ranges, probability distributions, and bounding assumptions that are technically defensible, reasonably account for uncertainties and variabilities, do not result in an under-representation of the risk estimate, and are 
consistent with the characteristics of the reasonably maximally exposed individual in 10 CFR Part 63 [DIRS 156605].

Inputs for the ash redistribution conceptual model and the appropriateness of the inputs for use in the model are described in Section 4.1.1. Assumptions are described in Sections 5.1.3 - 5.1.9. Analog studies undertaken to ensure the model appropriately considers sedimentary processes that affect tephra sheets are described in Section 7.3. Uncertainties in the model outputs are described in Section 8.3, and conservatisms included to assure that model outputs to the TSPA do not result in an under representation of risk are described as part of the conceptual model in Sections 6.3.2 and 6.6.2. The method to incorporate conservatism is development of two model outcomes that bound the mechanisms of ash redistribution in the Yucca Mountain area. These outcomes are described in Sections 6.6.6 and 6.6.7, respectively.

The development and use of the ash redistribution conceptual model is not dependent on consideration of the characteristics of the reasonably maximally exposed individual. Characteristics of the RMEI are provided in Characteristics of the Receptor for the Biosphere Model (BSC 2004 [DIRS 169671]), which defines values for biosphere model parameters that are related to the dietary, lifestyle, and dosimetric characteristics of the receptor. Agricultural and environmental input parameters for the biosphere model are described in the report, Agricultural and Environmental Input Parameters for the Biosphere Model (BSC 2004 [DIRS 169673], Section 6).

2. The technical bases for the parameter values and ranges in the TSPA abstraction are consistent with data from the Yucca Mountain region (e.g., Amargosa Valley survey, Cannon Center for Survey Research, 1997), studies of surface processes in the Fortymile Wash drainage basin, applicable laboratory testings, or other valid sources of data. For example, soil types, crop types, plow depths, and irrigation rates should be consistent with current farming practices, and data on the airborne particulate concentration should be based on the resuspension of appropriate material in a climate and level of disturbance similar to that which is expected to be found at the location of the reasonably maximally exposed individual during the compliance time period.

The ash redistribution conceptual model is based on erosion-rate data, soil-profile data, and surficial-processes information collected in the Yucca Mountain area, including sample locations in Fortymile Wash and surrounding the Lathrop Wells cone. Figure 6-3 is an illustration of the conceptual model based on information from Fortymile Wash that shows redistribution of tephra toward a RMEI. Sample locations and study areas are shown in Figures 6-1 and 7-3. Figure 6-4 is an example of a Cs-137 profile in Fortymile Wash that illustrates the effects of erosion. Rates of surficial processes in Fortymile Wash are described in Section 6.6.4, and the cesium study on the Fortymile Wash alluvial fan is described in Section 6.6.4.

The development and use of the ash redistribution conceptual model is not dependent on consideration of the characteristics of the RMEI. Characteristics of the RMEI are provided in Characteristics of the Receptor for the Biosphere Model (BSC 2004 [DIRS 169671], which defines values for biosphere model parameters that are related to the dietary, lifestyle, and dosimetric characteristics of the receptor. Agricultural and 
environmental input parameters for the biosphere model are described in the report, Agricultural and Environmental Input Parameters for the Biosphere Model (BSC 2004 [DIRS 169673]).

3. Uncertainty is adequately represented in parameters for conceptual models, process models, and alternative conceptual models considered in developing the total system performance assessment abstraction of redistribution of radionuclides in soil, either through sensitivity analyses, conservative limits, or bounding values supported by data, as necessary. Correlations between input values are appropriately established in the total system performance assessment.

Model outputs that provide inputs (factors) for the TSPA are described in Table 6-5. As can be seen from Table 6-5, uncertainties in soil redistribution factors are provided as distributions for use in the TSPA. The ash redistribution conceptual model is described in Sections 6.3.1 and 6.6.3. Uncertainties in the model outputs are described in Section 8.3, and conservatisms included to assure that model outputs to the TSPA do not result in an under representation of risk are described as part of the conceptual model in Section Sections 6.3.2 and 6.6.2. The method to incorporate conservatism is development of two model outcomes that bound the mechanisms of ash redistribution in the Yucca Mountain area. These outcomes are described in Sections 6.6.6 and 6.6.7, respectively. A general description of tephra redistribution processes is provided in Section 6.6.3, and effects of processes such as erosion and eolian inflation on Cs-137 values are described in Section 6.6.4.

Section 1.3 discusses the limitations of the ash redistribution conceptual model.

4. Parameters or models that most influence repository performance based on the performance measure and time period of compliance, specified in 10 CFR Part 63, are identified.

Section 8.2 notes that five factors related to the ash redistribution conceptual model are important to repository performance. These factors are described in Section 6.7.2 and are listed in Table 6-5. Guidance is also provided in Section 6.7.2 for using the factors in the TSPA model to best represent the factors given in this report.

5. Where sufficient data do not exist, the definition of parameter values and conceptual models on appropriate uses of other sources, such as expert elicitation, are conducted in accordance with appropriate guidance, such as NUREG-1563 (Kotra et al. 1996 [DIRS 100909]).

The ash redistribution conceptual model is based on observations and laboratory data from field work in Fortymile Wash, on the Fortymile Wash alluvial fan, and from drainages near the Lathrop Wells cone. Specifically, the ash redistribution conceptual model is based on erosion-rate data, soil-profile data, and surficial-processes information collected in the Yucca Mountain area, including sample locations in Fortymile Wash and surrounding the Lathrop Wells cone. Figure 6-3 is an illustration of the conceptual model based on information from Fortymile Wash and shows redistribution of tephra toward a RMEI. Sample locations and study areas are shown 
in Figures 6-1 and 7-3. Rates of surficial processes in Fortymile Wash are described in Section 6.6.4, and the cesium study on the Fortymile Wash alluvial fan is also described in Section 6.6.3. Model limitations are described in Section 1.3.

Development of the conceptual model is based on analog data from sites at and near Yucca Mountain (Sections 6.3.2, 6.6.4, and 6.6.5). Model development did not rely on other sources, such as expert elicitation.

\section{Acceptance Criterion 4: Model Uncertainty is Characterized and Propagated Through the Model Abstraction}

1. Alternative modeling approaches of features, events, and processes are considered and are consistent with available data, and current scientific understanding, and the results and limitations are appropriately considered in the abstraction.

Consideration of an alternative conceptual model for ash redistribution is described in Section 6.4.2. Features, events, and processes included in the ash redistribution conceptual model are described in Section 6.2, and Table 6-1 provides details about the disposition of FEP 1.2.04.07.0C, Ash Redistribution Via Soil and Sediment Transport. A general description of tephra redistribution processes is provided in Section 6.6.3. Rates of surficial processes that are needed to support model development and use are documented in Section 6.6.4, and the Cs-137 data used to identify a time stratigraphic marker in the surficial deposits and provide a proxy for determining the soil depths that fine particles and associated radionuclides from waste could penetrate, are described in Section 6.6.4. Descriptions of how the data are used are provided in Section 6.7.2. Analog studies to support the ash redistribution conceptual model are described in Section 7.3, and the results of an independent review of this model are described in Section 7.4.2. Uncertainties associated with the ash redistribution conceptual model outputs are described in Section 8.3. Model limitations are described in Section 1.3.

2. Sufficient evidence is provided that alternative conceptual models of features, events, and processes have been considered; that the preferred models (if any) are consistent with available data (e.g., field, laboratory, and natural analog) and current scientific understanding; and that the effect on total system performance assessment of uncertainties from these alternative conceptual models has been evaluated.

The ash redistribution conceptual model is new, but consideration of alternative conceptual models for ash redistribution is discussed in Section 6.4.2. Development of the ash redistribution conceptual model is based on analog data from sites at and near Yucca Mountain (Sections 6.3.2, 6.6.4, and 6.6.5). Features, events, and processes included in the ash redistribution conceptual model are described in Section 6.2, and Table 6-1 provides details about the disposition of FEP 1.2.04.07.0C, Ash Redistribution Via Soil and Sediment Transport. A general description of tephra redistribution processes is provided in Section 6.6.3.

Rates of surficial processes that are needed to support model development and use are documented in Section 6.6.4, and the Cs-137 data used to identify a time stratigraphic 
marker in the surficial deposits and provide a proxy for determining the soil depths that fine particles and associated radionuclides from waste could penetrate are described in Section 6.6.4. Descriptions of how the data are used are provided in Section 6.7.2. Analog studies to support the ash redistribution conceptual model are described in Section 7.3. Uncertainties associated with the ash redistribution conceptual model outputs are described in Section 8.3. Model limitations are described in Section 1.3.

3. Consideration of conceptual model uncertainty is consistent with available site characterization data, laboratory experiments, field measurements, natural analog information and process-level modeling studies; and the treatment of conceptual model uncertainty does not result in an under-representation of the risk estimate.

Inputs for the ash redistribution conceptual model and the appropriateness of the inputs for use in the model are described in Section 4.1.1. Assumptions are described in Sections 5.1.3 - 5.1.9. Analog studies undertaken in the Yucca Mountain area to ensure the model appropriately considers sedimentary processes that affect tephra sheets are described in Section 7.3. Uncertainties in the model outputs are described in Section 8.3, and conservatisms included to assure that model outputs to the TSPA do not result in an under representation of risk are described as part of the conceptual model in Section Sections 6.3.2 and 6.6.2.

\section{Acceptance Criterion 5: Model Abstraction Output Is Supported by Objective Comparisons}

1. Models implemented in the abstraction provide results consistent with output from detailed process-level models and/or empirical observations (e.g., laboratory testing, field measurements, and/or natural analogs).

Inputs for the ash redistribution conceptual model and the appropriateness of the inputs for use in the model are described in Section 4.1.1. Assumptions are described in Sections 5.1.3 - 5.1.9. Analog studies undertaken in the Yucca Mountain area to ensure the model appropriately considers sedimentary processes that affect tephra sheets are described in Section 7.3.Model outputs are described in Section 8.2, and uncertainties associated with the model outputs are described in Section 8.3. 
APPENDIX C

SENSITIVITY STUDIES 


\section{APPENDIX C SENSITIVITY STUDIES}

Sensitivity analyses were performed both to ensure that the ASHPLUME model operated over the parameter ranges selected and to demonstrate that there were not limitations in model validity due to numerical constraints (Heiken et al. 2003 [DIRS 166290], pp. 96 to 107). The sensitivity analyses were performed by varying the value of the following input parameters: eruptive power, mean ash particle diameter, ash particle diameter standard deviation, column diffusion constant (beta), initial rise velocity, wind speed, wind direction, eruption duration, and waste incorporation ratio. The range for each of these parameters is provided in Table 8-2. Values were chosen for the sensitivity analyses based on scientific judgment to evaluate the entire range of each parameter, and values for non-varying parameters were set at base-case values (Table C-10). Sensitivity analyses results are presented in this attachment in the form of tables and graphs that display the varying parameter values and calculated values for ash and fuel deposition $\left(\mathrm{g} / \mathrm{cm}^{2}\right)$ at the RMEI location. These analyses are discussed in greater detail in Heiken et al. (2003 [DIRS 166290], pp. 96 to 107.)

Figure C-1 shows the sensitivity of ash and fuel concentration to eruptive power. As power increases, the ash deposition $18 \mathrm{~km}$ downwind increases linearly as would be expected because of increased mass flux according to Equation 6-7b. The fuel concentration also increases because the increased eruptive column height resulting from the increased power of eruption encounters higher wind speeds to transport the ash/fuel mixture farther downwind toward the $18 \mathrm{~km}$ receptor location.

Figure $\mathrm{C}-2$ shows the sensitivity of ash and fuel concentration to mean ash particle diameter and Figure C-3 shows sensitivity to mean ash particle diameter standard deviation. Those two figures show little sensitivity of ash concentration to these two parameters. However, fuel concentration increases by more than a factor of two over the parameter ranges. The cause of the dip in the fuel curve in Figure C-3 is undetermined; however, it does not occur in the fuel concentration, which is what affects dose.

Figure C-4 shows the sensitivity of ash and fuel concentration to the column diffusion constant (Beta). Both ash and fuel concentration monotonically decrease as Beta increases, however the change is less than 10 percent. The Beta parameter, in effect, is related to the buoyancy of particles in the eruptive column and determines how high most particles will travel before exiting the column (see Section 6.5.3.2).

Figure C-5 shows the sensitivity of ash and fuel concentration to the initial rise velocity. The figure shows that ash and fuel concentration are not very sensitive to this parameter below values of about $1000 \mathrm{~cm} / \mathrm{s}$. Above that value, ash and fuel concentrations at $18 \mathrm{~km}$ increase significantly.

Figure C-6 shows the sensitivity of ash and fuel concentration to wind speed. In general, as wind speed increases, the concentration at $18 \mathrm{~km}$ downwind would be expected to increase. Figure C-6 shows the expected response. Figure C-7 shows the sensitivity to wind direction of ash and fuel concentration at $18 \mathrm{~km}$ due south. This figure shows the expected response of 
maximum concentration when the wind is blowing directly towards the receptor and minimum concentration when wind is blowing directly away from the receptor.

Figure C-8 shows the sensitivity of ash and fuel concentration to the eruption duration. Ash concentration increases linearly with eruption duration because of the linear relationship between eruption volume and duration (Equation 6-7c). The fuel concentration in terms of $\mathrm{g} / \mathrm{cm}^{2}$ deposited on the surface remains constant because the mass of fuel available for transport was held constant.

Figure C-9 shows the sensitivity of ash and fuel concentration to waste incorporation ratio, Ash concentration is unaffected because this parameter only affects the amount of fuel carried with the ash and not the calculation of ash itself. Fuel concentrations vary by a factor of 3 across the range analyzed, following the decreasing capacity for fuel/ash particle attachment with increasing values of waste incorporation ratio (Section 6.5.1).

Table C-1. Sensitivity of Calculated Ash and Fuel Concentration to Eruptive Power

\begin{tabular}{|c|c|c|}
\hline $\begin{array}{c}\text { Power } \\
(\mathbf{W})\end{array}$ & $\begin{array}{c}\text { Calculated Ash Deposition } \\
\left(\mathbf{g} / \mathrm{cm}^{2}\right)\end{array}$ & $\begin{array}{c}\text { Calculated Fuel Deposition } \\
\left(\mathrm{g} / \mathrm{cm}^{2}\right)\end{array}$ \\
\hline $6.17 \mathrm{E}+08$ & $3.33 \mathrm{E}-02$ & $4.57 \mathrm{E}-06$ \\
\hline $1.52 \mathrm{E}+09$ & $8.59 \mathrm{E}-02$ & $6.74 \mathrm{E}-06$ \\
\hline $3.73 \mathrm{E}+09$ & $2.22 \mathrm{E}-01$ & $7.26 \mathrm{E}-06$ \\
\hline $9.18 \mathrm{E}+09$ & $5.75 \mathrm{E}-01$ & $7.81 \mathrm{E}-06$ \\
\hline $2.26 \mathrm{E}+10$ & $1.49 \mathrm{E}+00$ & $8.41 \mathrm{E}-06$ \\
\hline $5.55 \mathrm{E}+10$ & $3.89 \mathrm{E}+00$ & $9.11 \mathrm{E}-06$ \\
\hline $1.37 \mathrm{E}+11$ & $1.02 \mathrm{E}+01$ & $9.89 \mathrm{E}-06$ \\
\hline $3.36 \mathrm{E}+11$ & $2.68 \mathrm{E}+01$ & $1.08 \mathrm{E}-05$ \\
\hline $8.26 \mathrm{E}+11$ & $7.14 \mathrm{E}+01$ & $1.19 \mathrm{E}-05$ \\
\hline $2.03 \mathrm{E}+12$ & $1.89 \mathrm{E}+02$ & $1.31 \mathrm{E}-05$ \\
\hline $5.00 \mathrm{E}+12$ & $5.07 \mathrm{E}+02$ & $1.44 \mathrm{E}-05$ \\
\hline
\end{tabular}

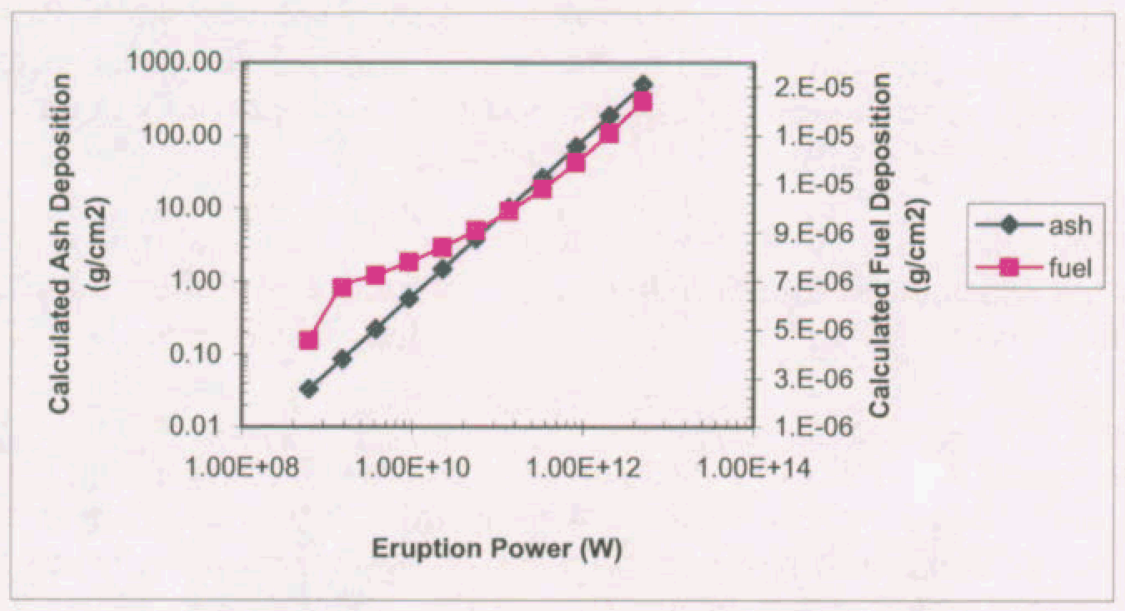

Figure C-1. Sensitivity of Calculated Ash and Fuel Concentration to Eruptive Power 
Table C-2. Sensitivity of Calculated Ash and Fuel Concentration to Mean Ash Particle Diameter

\begin{tabular}{|c|c|c|}
\hline $\begin{array}{c}\text { Mean Ash Particle Diameter } \\
(\mathbf{c m})\end{array}$ & $\begin{array}{c}\text { Calculated Ash Deposition } \\
\left(\mathbf{g} / \mathbf{c m}^{2}\right)\end{array}$ & $\begin{array}{c}\text { Calculated Fuel Deposition } \\
\left(\mathbf{g} / \mathbf{c m}^{2}\right)\end{array}$ \\
\hline 0.00100 & $3.32 \mathrm{E}+00$ & $2.58 \mathrm{E}-06$ \\
\hline 0.00158 & $3.54 \mathrm{E}+00$ & $3.03 \mathrm{E}-06$ \\
\hline 0.00251 & $3.72 \mathrm{E}+00$ & $3.53 \mathrm{E}-06$ \\
\hline 0.00398 & $3.88 \mathrm{E}+00$ & $4.11 \mathrm{E}-06$ \\
\hline 0.00631 & $3.95 \mathrm{E}+00$ & $4.74 \mathrm{E}-06$ \\
\hline 0.01000 & $3.97 \mathrm{E}+00$ & $5.47 \mathrm{E}-06$ \\
\hline 0.01585 & $3.93 \mathrm{E}+00$ & $6.27 \mathrm{E}-06$ \\
\hline 0.02512 & $3.83 \mathrm{E}+00$ & $7.16 \mathrm{E}-06$ \\
\hline 0.03981 & $3.68 \mathrm{E}+00$ & $8.18 \mathrm{E}-06$ \\
\hline 0.06310 & $3.47 \mathrm{E}+00$ & $9.27 \mathrm{E}-06$ \\
\hline 0.10000 & $3.24 \mathrm{E}+00$ & $1.05 \mathrm{E}-05$ \\
\hline
\end{tabular}

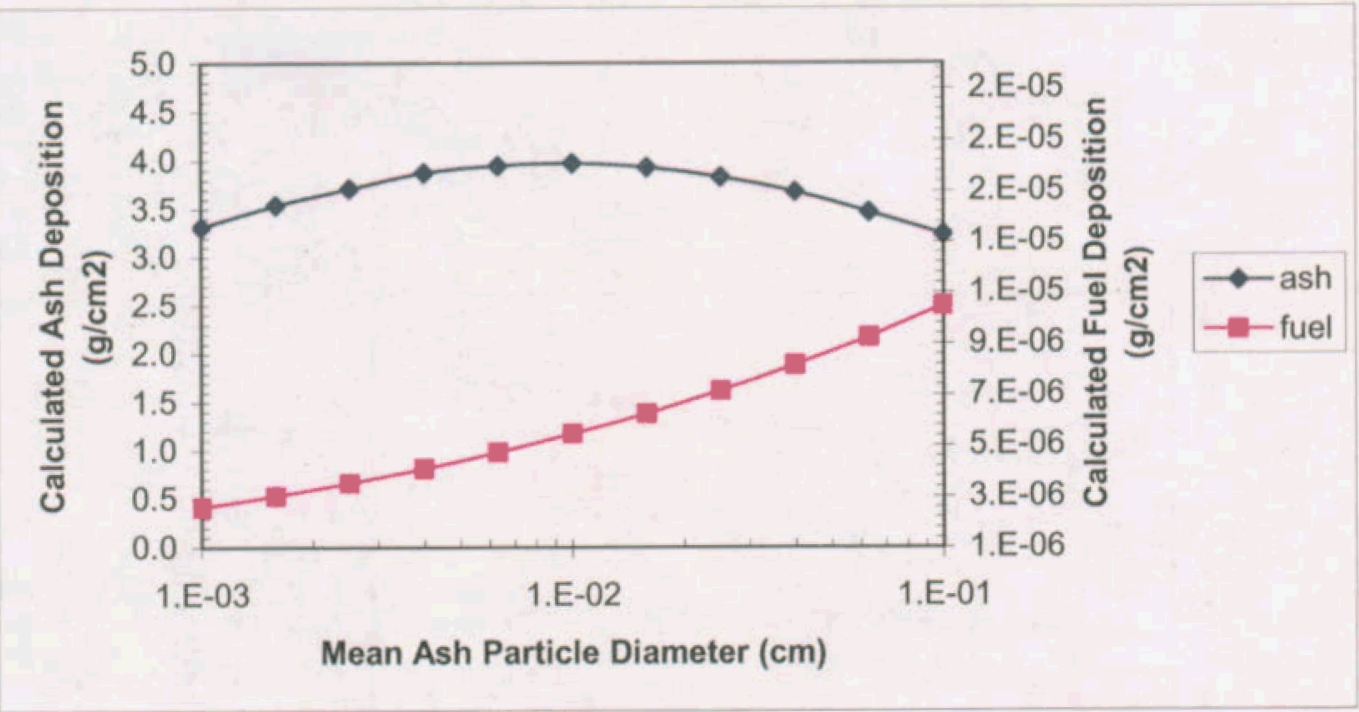

Figure C-2. Sensitivity of Calculated Ash and Fuel Concentration to Mean Ash Particle Diameter 
Table C-3. Sensitivity of Calculated Ash and Fuel Concentration to Ash Particle Diameter Standard Deviation

\begin{tabular}{|c|c|c|}
\hline $\begin{array}{c}\text { Ash Particle Diameter } \\
\text { Standard Deviation } \\
(\log (\mathbf{c m}))\end{array}$ & $\begin{array}{c}\text { Calculated Ash Deposition } \\
\left(\mathbf{g} / \mathbf{c m}^{2}\right)\end{array}$ & $\begin{array}{c}\text { Calculated Fuel Deposition } \\
\left(\mathbf{g} / \mathbf{c m}^{2}\right)\end{array}$ \\
\hline-1.9 & $3.08 \mathrm{E}+00$ & $6.31 \mathrm{E}-06$ \\
\hline-1.84 & $3.15 \mathrm{E}+00$ & $6.70 \mathrm{E}-06$ \\
\hline-1.78 & $3.24 \mathrm{E}+00$ & $7.18 \mathrm{E}-06$ \\
\hline-1.72 & $3.01 \mathrm{E}+00$ & $7.71 \mathrm{E}-06$ \\
\hline-1.66 & $3.43 \mathrm{E}+00$ & $8.33 \mathrm{E}-06$ \\
\hline-1.6 & $3.52 \mathrm{E}+00$ & $9.03 \mathrm{E}-06$ \\
\hline-1.54 & $3.62 \mathrm{E}+00$ & $9.85 \mathrm{E}-06$ \\
\hline-1.48 & $3.73 \mathrm{E}+00$ & $1.09 \mathrm{E}-05$ \\
\hline-1.42 & $3.83 \mathrm{E}+00$ & $1.20 \mathrm{E}-05$ \\
\hline-1.36 & $3.96 \mathrm{E}+00$ & $1.35 \mathrm{E}-05$ \\
\hline-1.3 & $4.06 \mathrm{E}+00$ & $1.52 \mathrm{E}-05$ \\
\hline & & \\
\hline
\end{tabular}

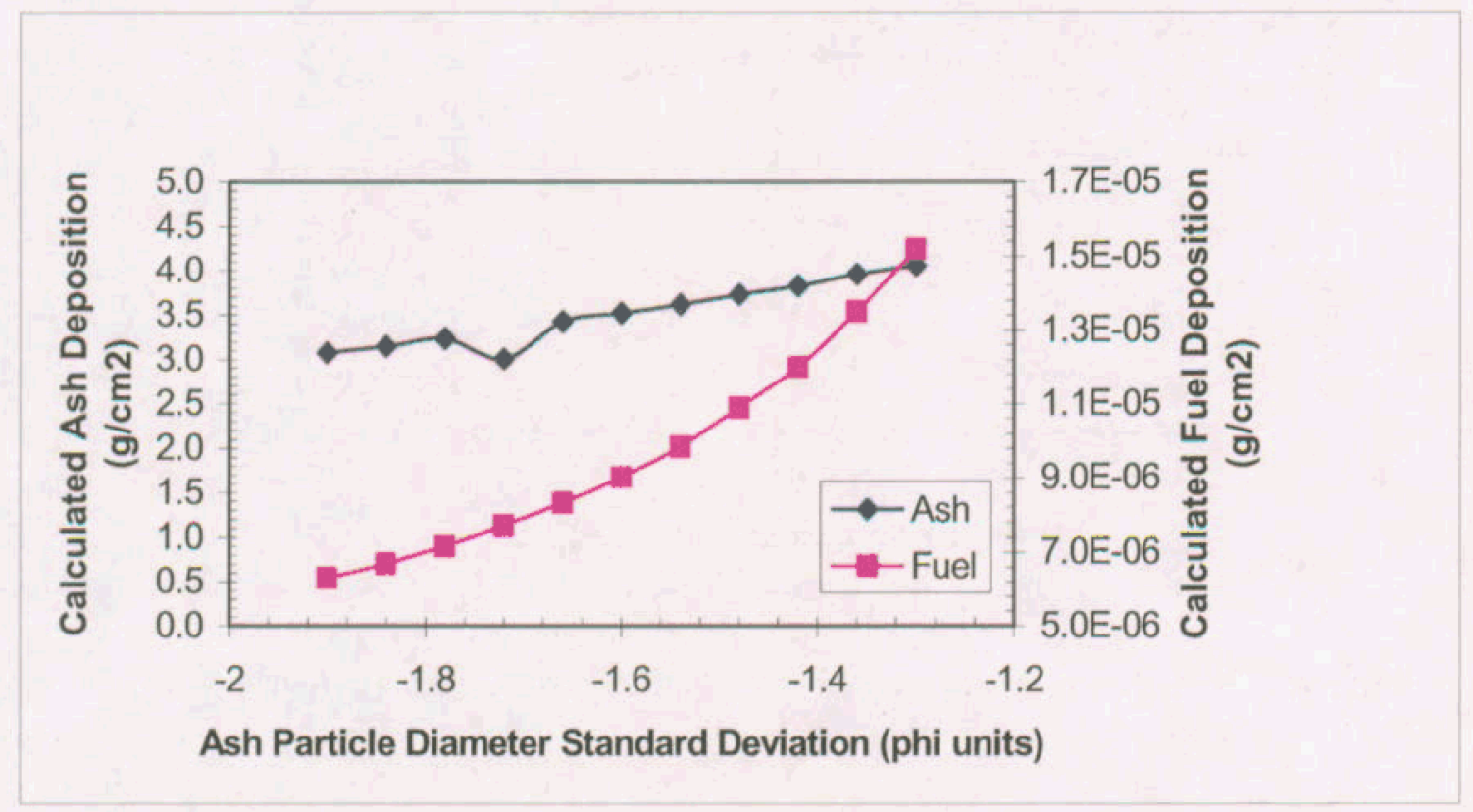

Figure C-3. Sensitivity of Calculated Ash and Fuel Concentration to Ash Particle Diameter Standard Deviation 
Table C-4. Sensitivity of Calculated Ash and Fuel Concentration to Column Diffusion Constant (Beta)

\begin{tabular}{|c|c|c|}
\hline $\begin{array}{c}\text { Column Diffusion Constant } \\
(\text { Beta) }\end{array}$ & $\begin{array}{c}\text { Calculated Ash Deposition } \\
\left(\mathbf{g} / \mathbf{c m}^{2}\right)\end{array}$ & $\begin{array}{c}\text { Calculated Fuel Deposition } \\
\left(\mathbf{g} / \mathbf{c m}^{2}\right)\end{array}$ \\
\hline 0.0100 & $3.90 \mathrm{E}+00$ & $9.69 \mathrm{E}-06$ \\
\hline 0.0148 & $3.89 \mathrm{E}+00$ & $9.67 \mathrm{E}-06$ \\
\hline 0.0219 & $3.87 \mathrm{E}+00$ & $9.64 \mathrm{E}-06$ \\
\hline 0.0323 & $3.84 \mathrm{E}+00$ & $9.60 \mathrm{E}-06$ \\
\hline 0.0478 & $3.81 \mathrm{E}+00$ & $9.56 \mathrm{E}-06$ \\
\hline 0.0707 & $3.77 \mathrm{E}+00$ & $9.49 \mathrm{E}-06$ \\
\hline 0.1046 & $3.72 \mathrm{E}+00$ & $9.40 \mathrm{E}-06$ \\
\hline 0.1546 & $3.66 \mathrm{E}+00$ & $9.29 \mathrm{E}-06$ \\
\hline 0.2287 & $3.58 \mathrm{E}+00$ & $9.15 \mathrm{E}-06$ \\
\hline 0.3381 & $3.49 \mathrm{E}+00$ & $8.98 \mathrm{E}-06$ \\
\hline 0.5000 & $3.39 \mathrm{E}+00$ & $8.79 \mathrm{E}-06$ \\
\hline
\end{tabular}

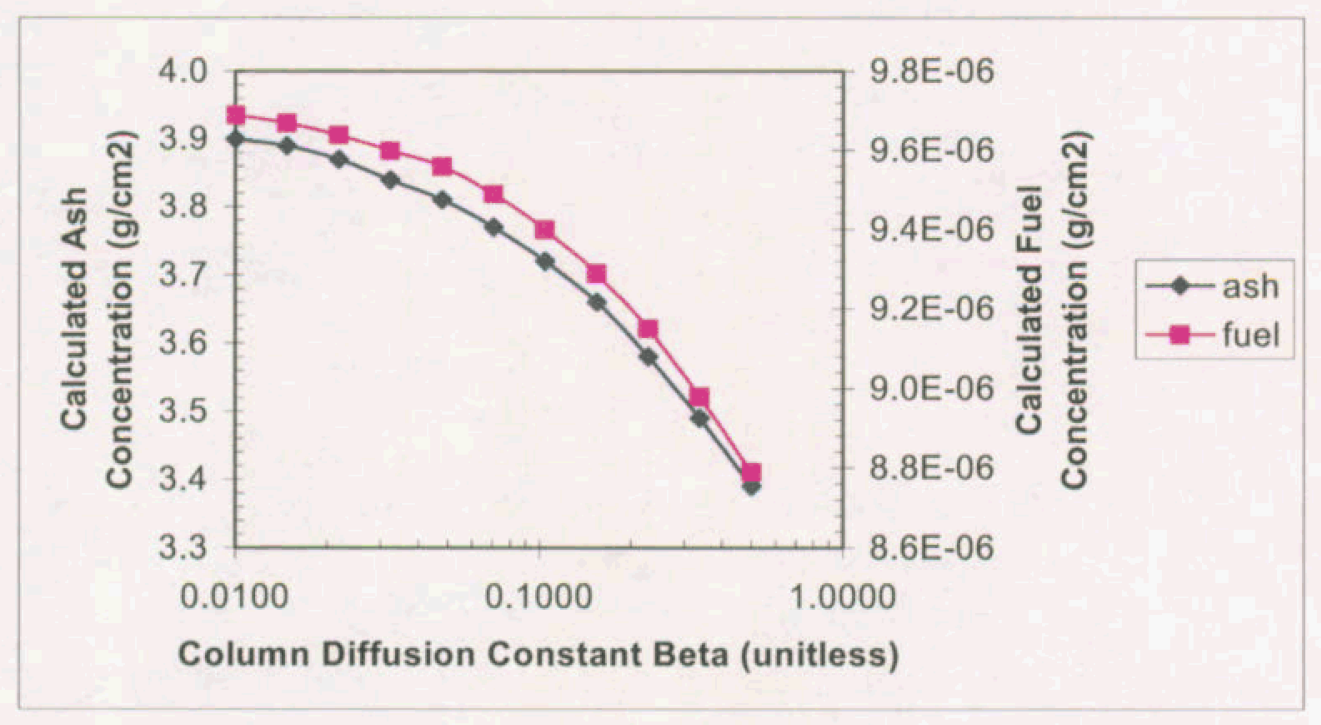

Figure C-4. Sensitivity of Calculated Ash and Fuel Concentration to Column Diffusion Constant (Beta) 
Table C-5. Sensitivity of Calculated Ash and Fuel Concentration to Initial Rise Velocity

\begin{tabular}{|c|c|c|}
\hline $\begin{array}{c}\text { Initial Rise Velocity } \\
(\mathbf{c m} / \mathbf{s})\end{array}$ & $\begin{array}{c}\text { Calculated Ash Deposition } \\
\left(\mathbf{g} / \mathbf{c m}^{2}\right)\end{array}$ & $\begin{array}{c}\text { Calculated Fuel Deposition } \\
\left(\mathbf{g} / \mathbf{c m}^{2}\right)\end{array}$ \\
\hline 1 & $3.90 \mathrm{E}+00$ & $9.69 \mathrm{E}-06$ \\
\hline 3 & $3.85 \mathrm{E}+00$ & $9.62 \mathrm{E}-06$ \\
\hline 7 & $3.78 \mathrm{E}+00$ & $9.51 \mathrm{E}-06$ \\
\hline 17 & $3.66 \mathrm{E}+00$ & $9.29 \mathrm{E}-06$ \\
\hline 43 & $3.46 \mathrm{E}+00$ & $8.91 \mathrm{E}-06$ \\
\hline 110 & $3.22 \mathrm{E}+00$ & $8.44 \mathrm{E}-06$ \\
\hline 280 & $3.07 \mathrm{E}+00$ & $8.22 \mathrm{E}-06$ \\
\hline 717 & $3.28 \mathrm{E}+00$ & $8.95 \mathrm{E}-06$ \\
\hline 1834 & $3.98 \mathrm{E}+00$ & $1.10 \mathrm{E}-05$ \\
\hline 4691 & $4.68 \mathrm{E}+00$ & $1.31 \mathrm{E}-05$ \\
\hline 12000 & $5.07 \mathrm{E}+00$ & $1.43 \mathrm{E}-05$ \\
\hline
\end{tabular}

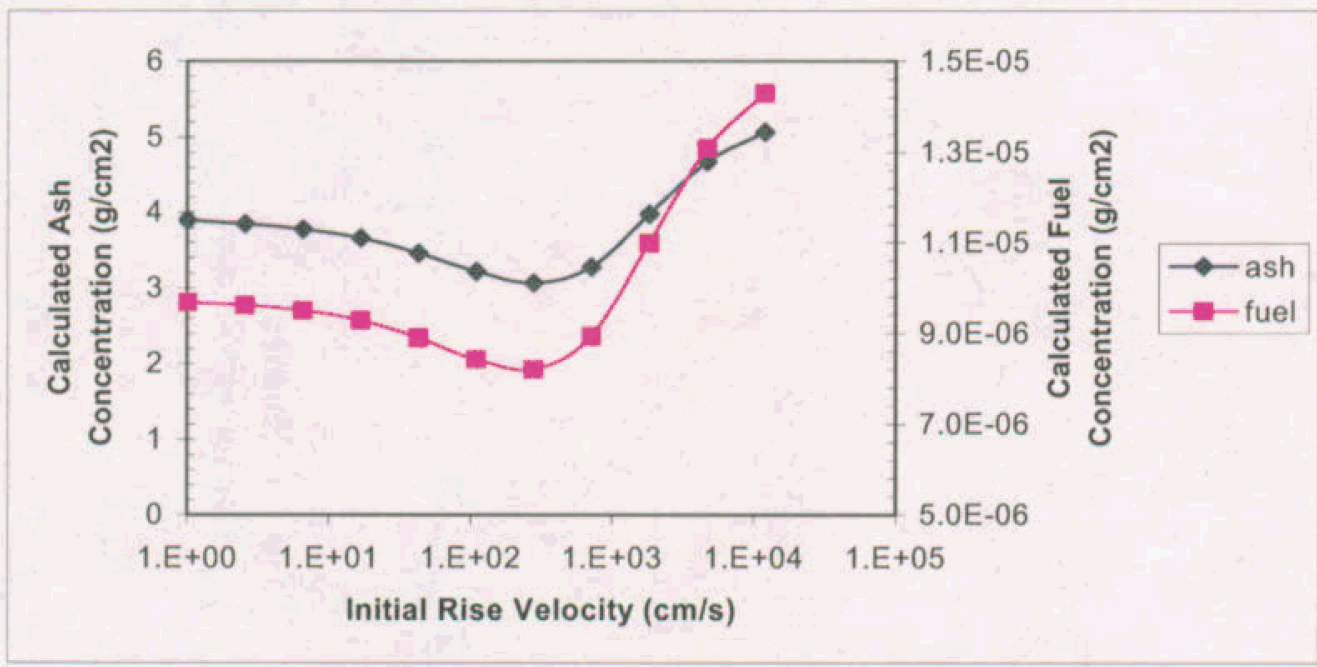

Figure C-5. Sensitivity of Calculated Ash and Fuel Concentration to Initial Rise Velocity 
Table C-6. Sensitivity of Calculated Ash and Fuel Concentration to Wind Speed

\begin{tabular}{|c|c|c|}
\hline $\begin{array}{c}\text { Wind Speed } \\
(\mathbf{c m} / \mathbf{s})\end{array}$ & $\begin{array}{c}\text { Calculated Ash Deposition } \\
\left(\mathbf{g} / \mathrm{cm}^{2}\right)\end{array}$ & $\begin{array}{c}\text { Calculated Fuel Deposition } \\
\left(\mathbf{g} / \mathbf{c m}^{2}\right)\end{array}$ \\
\hline 0 & $2.67 \mathrm{E}-01$ & $6.20 \mathrm{E}-07$ \\
\hline 566 & $4.26 \mathrm{E}+00$ & $1.10 \mathrm{E}-05$ \\
\hline 1132 & $1.28 \mathrm{E}+01$ & $3.51 \mathrm{E}-05$ \\
\hline 1698 & $2.43 \mathrm{E}+01$ & $6.92 \mathrm{E}-05$ \\
\hline 2264 & $3.20 \mathrm{E}+01$ & $9.47 \mathrm{E}-05$ \\
\hline 2830 & $5.32 \mathrm{E}+01$ & $1.56 \mathrm{E}-04$ \\
\hline 3396 & $7.83 \mathrm{E}+01$ & $2.27 \mathrm{E}-04$ \\
\hline 3962 & $8.56 \mathrm{E}+01$ & $2.54 \mathrm{E}-04$ \\
\hline 4528 & $1.00 \mathrm{E}+02$ & $2.99 \mathrm{E}-04$ \\
\hline 5094 & $1.16 \mathrm{E}+02$ & $3.45 \mathrm{E}-04$ \\
\hline 5660 & $1.34 \mathrm{E}+02$ & $4.08 \mathrm{E}-04$ \\
\hline & & \\
\hline
\end{tabular}

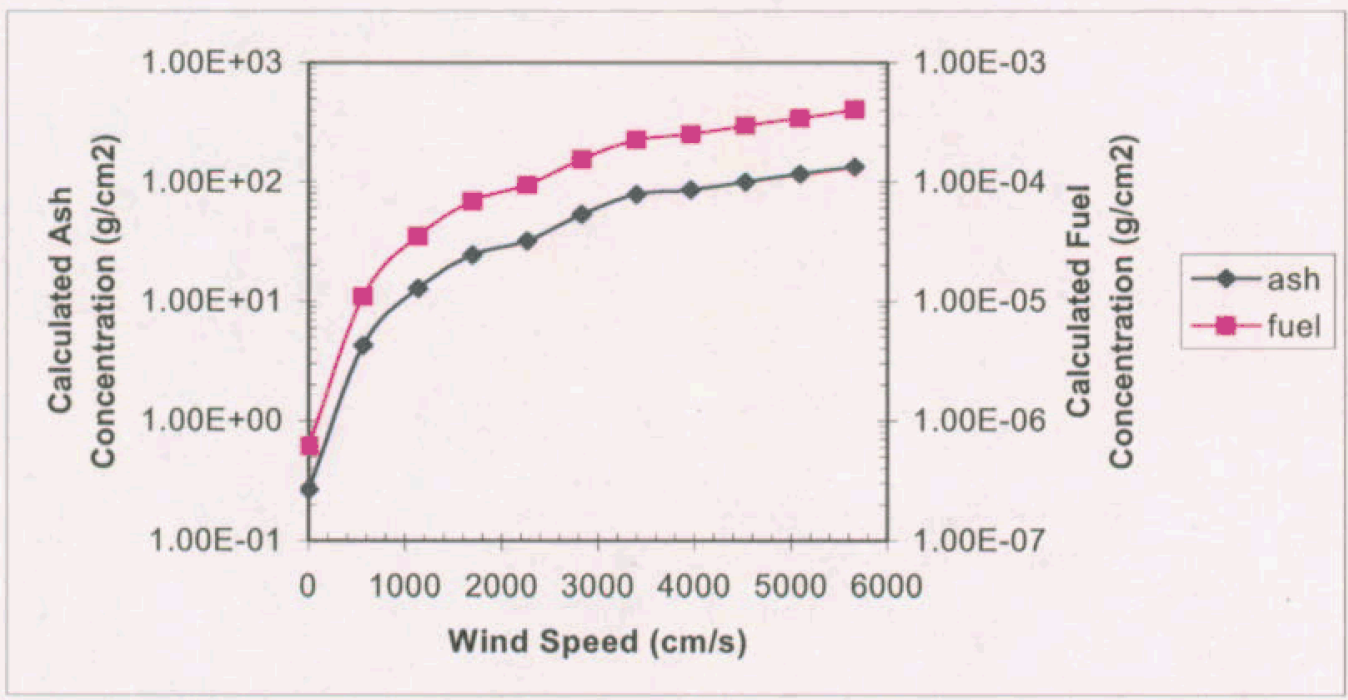

Figure C-6. Sensitivity of Calculated Ash and Fuel Concentration to Wind Speed 
Table C-7. Sensitivity of Calculated Ash and Fuel Concentration to Wind Direction

\begin{tabular}{|c|c|c|}
\hline $\begin{array}{c}\text { Wind Direction } \\
\text { (degrees) }\end{array}$ & $\begin{array}{c}\text { Calculated Ash Deposition } \\
\left(\mathbf{g} / \mathbf{c m}^{2}\right)\end{array}$ & $\begin{array}{c}\text { Calculated Fuel Deposition } \\
\left(\mathbf{g} / \mathbf{c m}^{2}\right)\end{array}$ \\
\hline-150 & $4.41 \mathrm{E}-02$ & $1.06 \mathrm{E}-07$ \\
\hline-117 & $9.75 \mathrm{E}-01$ & $2.48 \mathrm{E}-06$ \\
\hline-84 & $3.29 \mathrm{E}+00$ & $8.42 \mathrm{E}-06$ \\
\hline-51 & $3.16 \mathrm{E}-01$ & $7.93 \mathrm{E}-07$ \\
\hline-18 & $1.85 \mathrm{E}-02$ & $4.26 \mathrm{E}-08$ \\
\hline 15 & $4.49 \mathrm{E}-03$ & $9.43 \mathrm{E}-09$ \\
\hline 48 & $2.40 \mathrm{E}-03$ & $4.78 \mathrm{E}-09$ \\
\hline 81 & $1.90 \mathrm{E}-03$ & $3.72 \mathrm{E}-09$ \\
\hline 114 & $2.03 \mathrm{E}-03$ & $4.00 \mathrm{E}-09$ \\
\hline 147 & $3.00 \mathrm{E}-03$ & $6.08 \mathrm{E}-09$ \\
\hline 180 & $7.41 \mathrm{E}-03$ & $1.61 \mathrm{E}-08$ \\
\hline
\end{tabular}

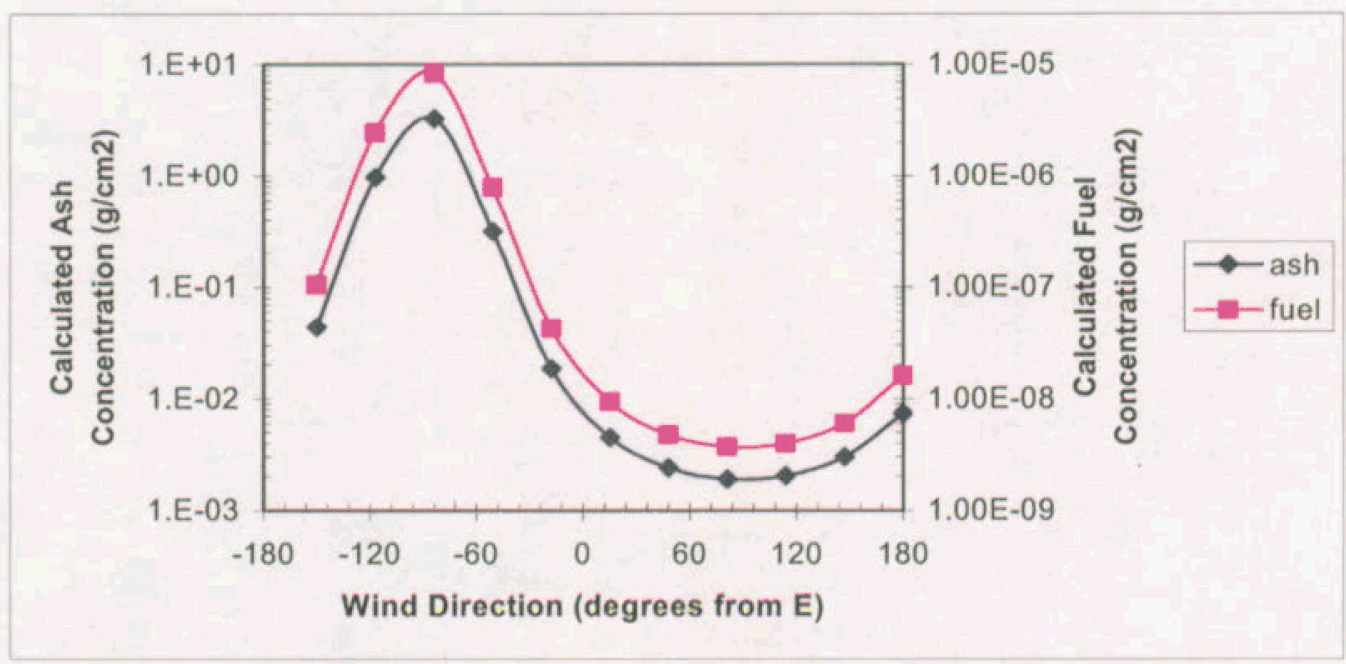

Figure C-7. Sensitivity of Calculated Ash and Fuel Concentration to Wind Direction 
Table C-8. Sensitivity of Calculated Ash and Fuel Concentration to Eruption Duration

\begin{tabular}{|c|c|c|}
\hline $\begin{array}{c}\text { Eruption Duration } \\
(\mathbf{s})\end{array}$ & $\begin{array}{c}\text { Calculated Ash Deposition } \\
\left(\mathbf{g} / \mathbf{c m}^{2}\right)\end{array}$ & $\begin{array}{c}\text { Calculated Fuel Deposition } \\
\left(\mathbf{g} / \mathbf{c m}^{2}\right)\end{array}$ \\
\hline $8.64 \mathrm{E}+04$ & $1.18 \mathrm{E}-01$ & $9.03 \mathrm{E}-06$ \\
\hline $1.33 \mathrm{E}+05$ & $1.81 \mathrm{E}-01$ & $9.03 \mathrm{E}-06$ \\
\hline $2.05 \mathrm{E}+05$ & $2.79 \mathrm{E}-01$ & $9.03 \mathrm{E}-06$ \\
\hline $3.16 \mathrm{E}+05$ & $4.30 \mathrm{E}-01$ & $9.03 \mathrm{E}-06$ \\
\hline $4.86 \mathrm{E}+05$ & $6.61 \mathrm{E}-01$ & $9.03 \mathrm{E}-06$ \\
\hline $7.48 \mathrm{E}+05$ & $1.02 \mathrm{E}+00$ & $9.03 \mathrm{E}-06$ \\
\hline $1.15 \mathrm{E}+06$ & $1.56 \mathrm{E}+00$ & $9.03 \mathrm{E}-06$ \\
\hline $1.77 \mathrm{E}+06$ & $2.41 \mathrm{E}+00$ & $9.03 \mathrm{E}-06$ \\
\hline $2.73 \mathrm{E}+06$ & $3.71 \mathrm{E}+00$ & $9.03 \mathrm{E}-06$ \\
\hline $4.21 \mathrm{E}+06$ & $5.73 \mathrm{E}+00$ & $9.03 \mathrm{E}-06$ \\
\hline $6.48 \mathrm{E}+06$ & $8.81 \mathrm{E}+00$ & $9.03 \mathrm{E}-06$ \\
\hline
\end{tabular}

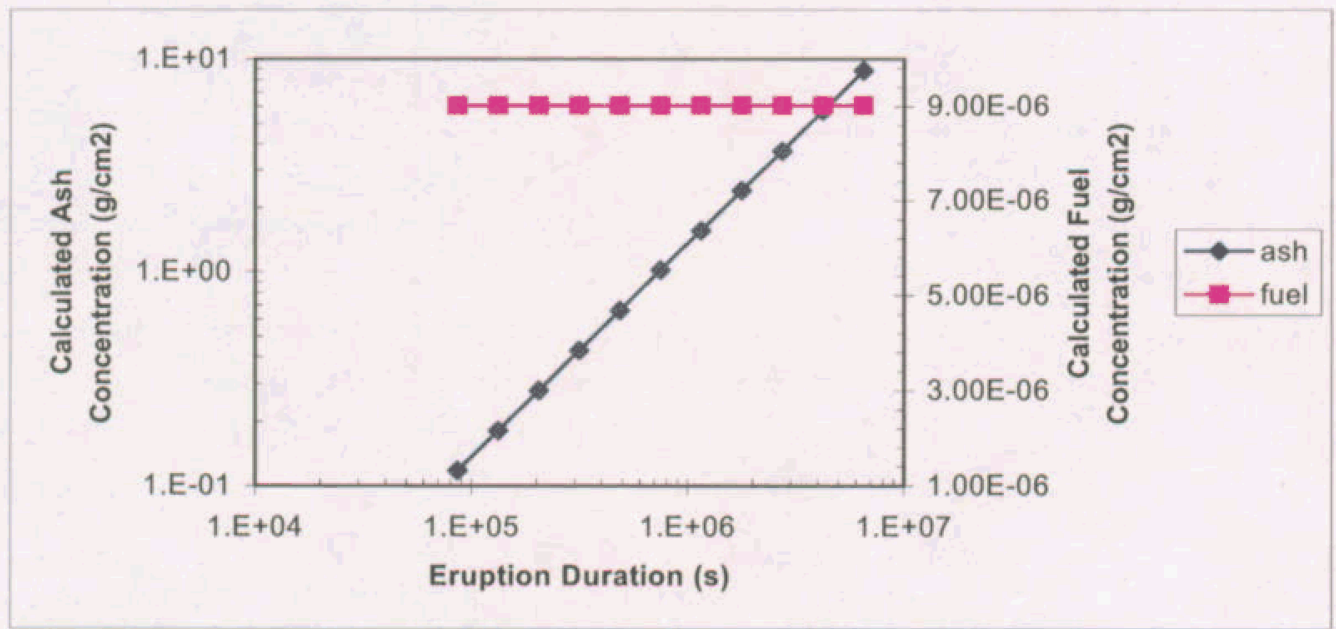

Figure C-8. Sensitivity of Calculated Ash and Fuel Concentration to Eruption Duration 
Table C-9. Sensitivity of Calculated Ash and Fuel Concentration to Waste Incorporation Ratio

\begin{tabular}{|c|c|c|}
\hline $\begin{array}{c}\text { Waste Incorporation } \\
\text { Ratio }\end{array}$ & $\begin{array}{c}\text { Calculated Ash Deposition } \\
\left(\mathbf{g} / \mathbf{c m}^{2}\right)\end{array}$ & $\begin{array}{c}\text { Calculated Fuel Deposition } \\
\left(\mathbf{g} / \mathbf{c m}^{2}\right)\end{array}$ \\
\hline 0.1 & $3.52 \mathrm{E}+00$ & $2.23 \mathrm{E}-06$ \\
\hline 0.2 & $3.52 \mathrm{E}+00$ & $2.13 \mathrm{E}-06$ \\
\hline 0.3 & $3.52 \mathrm{E}+00$ & $2.01 \mathrm{E}-06$ \\
\hline 0.4 & $3.52 \mathrm{E}+00$ & $1.87 \mathrm{E}-06$ \\
\hline 0.5 & $3.52 \mathrm{E}+00$ & $1.72 \mathrm{E}-06$ \\
\hline 0.6 & $3.52 \mathrm{E}+00$ & $1.55 \mathrm{E}-06$ \\
\hline 0.7 & $3.52 \mathrm{E}+00$ & $1.37 \mathrm{E}-06$ \\
\hline 0.8 & $3.52 \mathrm{E}+00$ & $1.19 \mathrm{E}-06$ \\
\hline 0.9 & $3.52 \mathrm{E}+00$ & $1.01 \mathrm{E}-06$ \\
\hline 1.0 & $3.52 \mathrm{E}+00$ & $8.41 \mathrm{E}-07$ \\
\hline
\end{tabular}

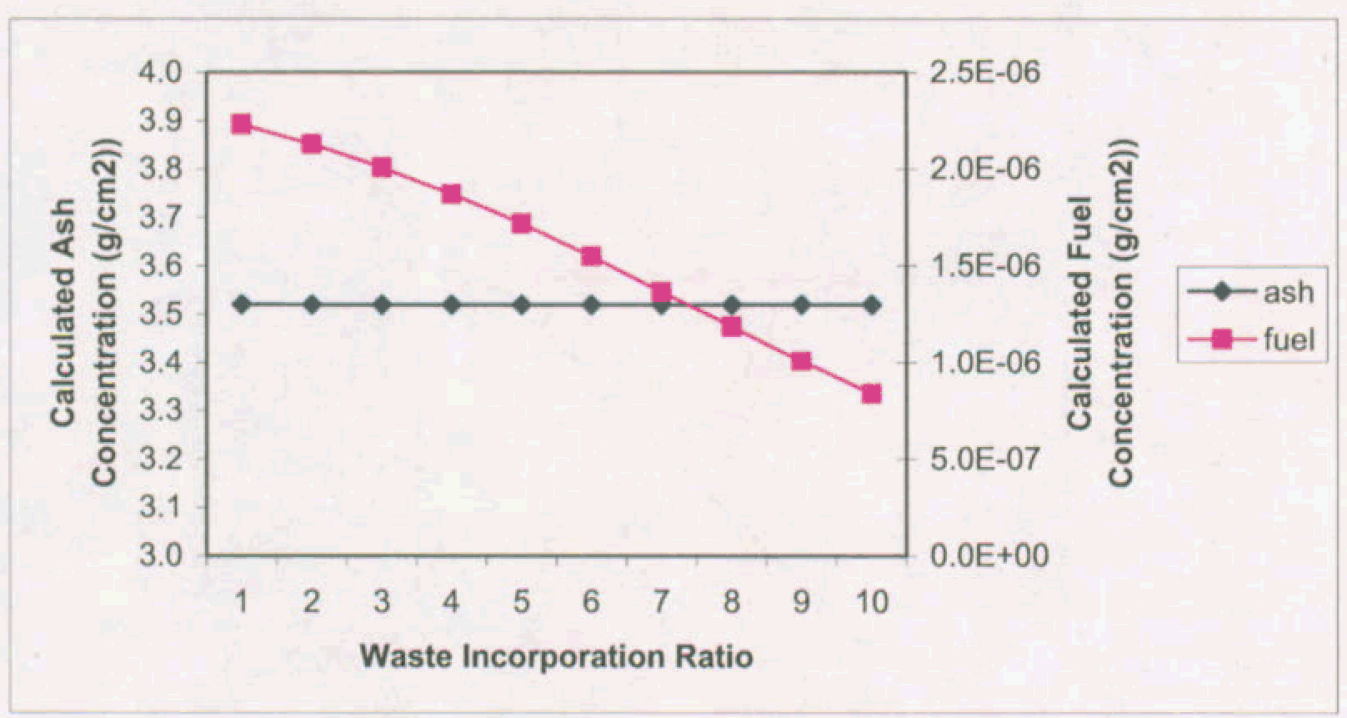

Figure C-9. Sensitivity of Calculated Ash and Fuel Concentration to Waste Incorporation Ratio 


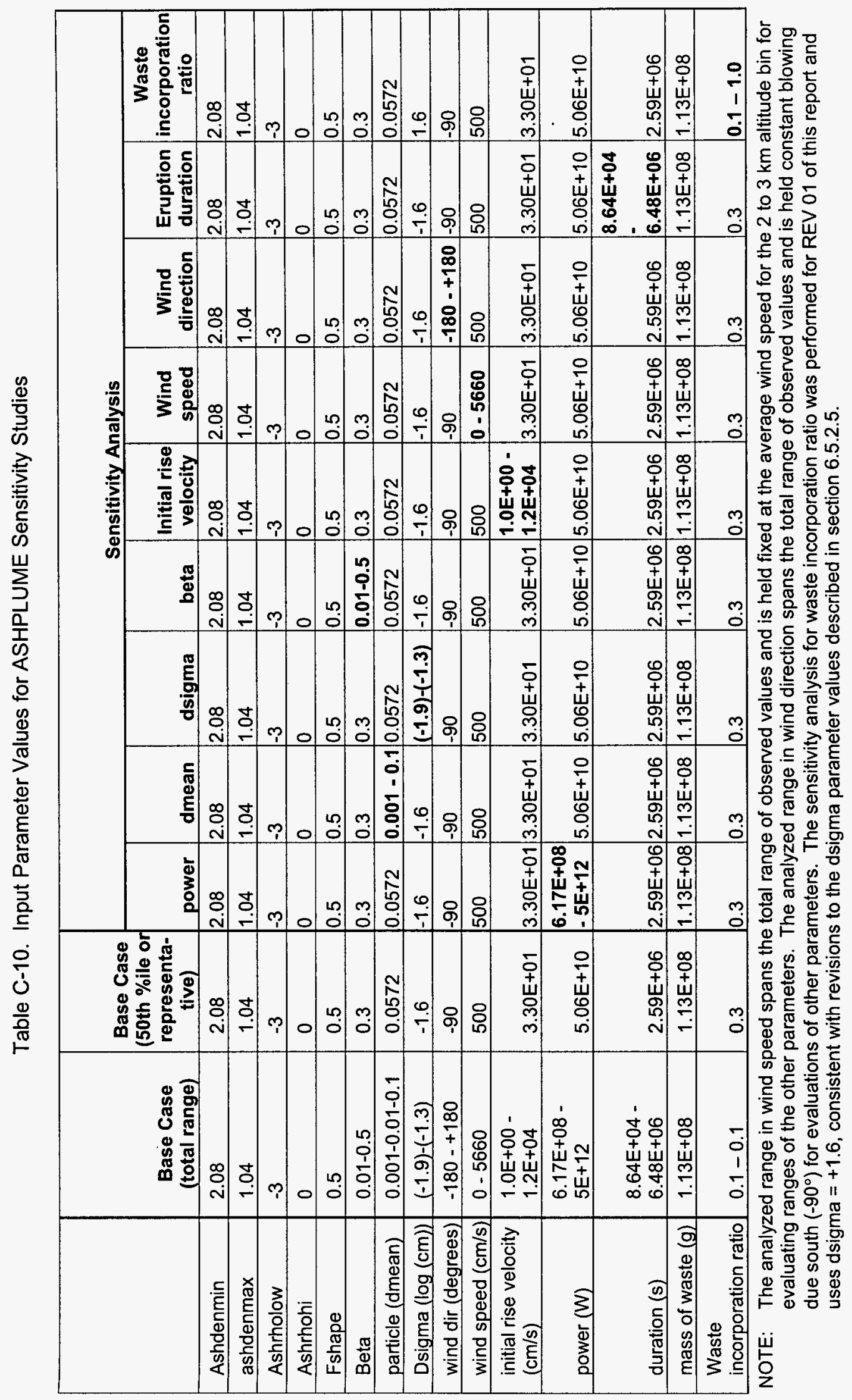


INTENTIONALLY LEFT BLANK 


\section{APPENDIX D}

\section{DESERT ROCK WIND DATA ANALYSES}




\section{APPENDIX D \\ DESERT ROCK WIND DATA ANALYSES}

A need exists to develop parameter distributions for atmospheric data inputs to the TSPA model according to AP-SV.1Q, Control of the Electronic Management of Information. Statistical analyses, including CDFs and probability distribution functions (PDFs) were performed on a qualified data set to develop these parameter distributions. The parameter distributions developed from these data account for uncertainty in the observed data. The parameters under consideration are wind speed and wind direction. Both the data and the methods used to develop these parameter distributions are also contained in the associated output DTN: O0408SPADRWSD.002.

The wind data presented in this Appendix have been revised due to errors detected in the data reported in an earlier version of this Model Report, MDL-MGR-GS-000002 REV00, Attachment III. These errors resulted from an incomplete download of the wind dataset from NOAA. The revised analysis presented in this Appendix is based on a complete data download from NOAA and increases wind speeds by approximately a factor of two compared to the earlier, erroneous analysis.

The first step in analyzing Desert Rock wind data involved importing a usable data file into Microsoft Access, desertrock.zip (NOAA 2004 [171035]) provided through an FTP site (ftp.ncdc.noaa.gov) by Scott Stephens of the National Climatic Data Center in Asheville, North Carolina, on August 3, 2004. A total of 1,619,404 data lines were imported.

Column headers followed by blank lines were present within the data file received. As such, deletion of 48,321 header and blank rows was completed. Following, one wind speed column data value with a " 0 " in the cell that had an associated direction reading was deleted. Then, three data lines having a wind speed reading without an associated direction were deleted. Next, a search for "999.9" and "999" (i.e., the designators for blank data fields) was completed for the wind speed and direction columns, respectively. In all, there were 124,253 lines of data deleted as a result of the blank field data search, for a total of 1,446,826 data lines left for analysis.

\section{Height Groupings}

At the repository site, the crest of Yucca Mountain is approximately $4,905 \mathrm{ft}(1,495 \mathrm{~m})$ above sea level (CRWMS M\&O 2000 [153246], Figure 3.2-10; DTN: MO0103COV01031.000 [155271], boring SD-6). As such, heights in meters above mean sea level in the data file were sorted by height in meters above Yucca Mountain. This was accomplished by setting the query field under the height column to the text shown in Table D-1. This process was repeated for each height interval, from 0 to $13 \mathrm{~km}$, resulting in thirteen tables used for further data analyses as described later in this appendix.

The resulting datasets were saved as tables containing four columns including: height in meters (HEIGHT MTR), wind speed in meters per second (WNDSP MS), direction in degrees (DIR), and the id number (ID) assigned to each line by Access. These tables were then exported from Microsoft Access to Microsoft Excel for further analyses of wind direction and speed. Prior to 
being imported into Excel, all fields were changed from text to number format in the table design view. Table D-2 provides the format of the data tables used for the CDF and PDF analyses.

For the 1 to 2,2 to 3 , and 3 to 4 data groupings, the number of data lines exceeded the number able to be stored $(65,536)$ per worksheet in Excel. As such, lines up to 65,536 were exported automatically by Access while the remaining lines were copied and pasted manually into an additional worksheet. Therefore, the CDFs and PDFs for these groupings were done separately for each worksheet then combined at the end.

Table D-1. Height Grouping Query Results

\begin{tabular}{|c|c|}
\hline Query Name (number of data lines resulting) & Query Field Contents Under Height Column \\
\hline 0 to $1(64,002)$ & $>=" 1495 "$ And <" 2495" \\
\hline 1 to $2(72,498)$ & $>="$ 2495" And <" 3495" \\
\hline 2 to $3(82,192)$ & $>=" 3495^{\prime \prime}$ And <" $4495^{\prime \prime}$ \\
\hline 3 to $4(70,748)$ & $>=“ 4495 "$ And <" 5495" \\
\hline 4 to $5(65,494)$ & $>=" 5495^{\prime \prime}$ And <" 6495" \\
\hline 5 to $6(62,169)$ & $>=“ 6495 "$ And < $7495^{\prime \prime}$ \\
\hline 6 to $7(57,505)$ & $>=“ 7495 "$ And <“ 8495" \\
\hline 7 to $8(51,434)$ & $>=“ 8495^{\prime \prime}$ And <“ 9495" \\
\hline 8 to $9(47,373)$ & $>="$ 9495" And <“ 10495" \\
\hline 9 to $10(49,869)$ & $>==^{\prime \prime} 10495 "$ And <“ 11495" \\
\hline 10 to $11(53,635)$ & $>={ }^{\prime} 11495 "$ And <“ 12495" \\
\hline 11 to $12(56,917)$ & $>==^{\prime \prime} 12495^{\prime \prime}$ And < 13495" \\
\hline 12 to $13(51,774)$ & $>=“ 13495^{\prime \prime}$ And < $14495^{\prime \prime}$ \\
\hline
\end{tabular}

Table D-2. Example of Table Exported from Access to Excel

\begin{tabular}{|c|c|c|c|}
\hline \multicolumn{4}{|c|}{ O to 1 Table } \\
\hline HEIGHT MTR & WINDSP MS & DIR & ID \\
\hline 1927 & 16 & 192 & 8 \\
\hline
\end{tabular}

HEIGHT MTR $=$ height in meters

WINDSP MD $=$ wind speed in meters per second

DIR = direction in degrees

$I D=I D$ number

\section{Wind Direction}

The wind directions given in the raw data were in compass degrees from the indicated direction and needed to be converted to Ashplume degrees toward the indicated direction. For each of the heights indicated above, data were initially grouped into bins using the histogram function under the data analysis selection under the tools menu in Excel. Degree bins were entered manually into column $\mathrm{E}$ of the spreadsheet. After choosing tools, data analyses, and then histograms, a popup menu appeared and requested choices regarding input and output options. For the input, the wind direction data were entered (column $C$ in the spreadsheet) in the input range cell like the following for the 0- to 1-km data table, "\$C\$2:\$C\$64003." Column E (bin degrees) was then 
chosen as the input for the bin range and typed in as: "\$E\$2:\$E $\$ 15$ " under the Histogram function. This process was repeated for each of the remaining height groupings.

Table D-3 provides the histogram function analysis output.

Bins 0,14 , and 360 were combined to represent the 345 - to 15 -degree interval on the compass. The remaining bins represent the degree intervals as indicated in Table D-4.

Table D-3. 0 to 1 Histogram Function Output

\begin{tabular}{|c|c|}
\hline Bin (in compass degrees) & Frequency \\
\hline 0 & 125 \\
\hline 14 & 1931 \\
\hline 44 & 5411 \\
\hline 74 & 5225 \\
\hline 104 & 3596 \\
\hline 134 & 2411 \\
\hline 164 & 2363 \\
\hline 194 & 8336 \\
\hline 224 & 18290 \\
\hline 254 & 6633 \\
\hline 284 & 2910 \\
\hline 314 & 2407 \\
\hline 344 & 2670 \\
\hline 360 & 1694 \\
\hline
\end{tabular}

Output DTN: MO0408SPADRWSD.002.

Table D-4. Bins Converted to Compass Degree Intervals

\begin{tabular}{|c|c|}
\hline Compass Degree Intervals & Representative Bins \\
\hline 345 to 15 & 0,14, and 360 \\
\hline 15 to 45 & 44 \\
\hline 45 to 75 & 74 \\
\hline 75 to 105 & 104 \\
\hline 105 to 135 & 134 \\
\hline 135 to 165 & 164 \\
\hline 165 to 195 & 194 \\
\hline 195 to 225 & 224 \\
\hline 225 to 255 & 254 \\
\hline 255 to 285 & 284 \\
\hline 285 to 315 & 314 \\
\hline 15 to 345 & 344 \\
\hline
\end{tabular}

NOTE: This table summarizes the histogram bins used to represent compass degree intervals. 
Converting compass degrees to Ashplume degrees is depicted by Figure D-1. Ashplume degrees (Figure D-1, Ashplume degrees are around the perimeter, compass degrees are inside) toward the indicated direction were determined by selecting the Ashplume direction exactly opposite of the indicated compass-degree interval and recording the midpoint of the degree interval (Table D-5).

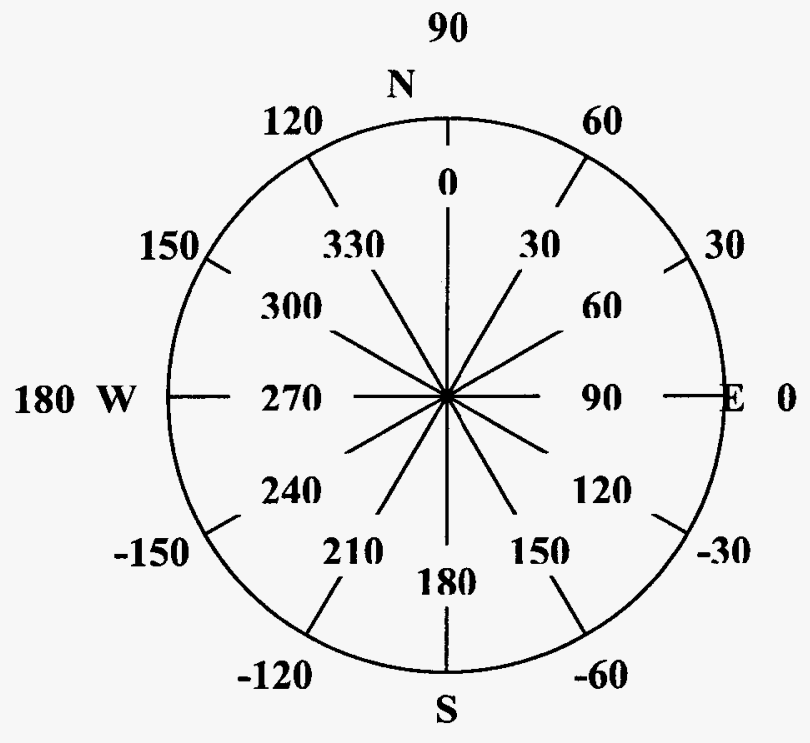

$-90$

Figure D-1. Compass (inside numbers) and Ashplume (outside numbers) Degree Comparison

Table D-5. Compass Degrees from Direction Converted to Ashplume Degrees toward Direction

\begin{tabular}{|c|c|}
\hline Compass Degrees & Ashplume Degrees \\
\hline 165 to 195 & 90 (North) \\
\hline 195 to 225 & 60 \\
\hline 225 to 255 & 30 \\
\hline 255 to 285 & 0 (East) \\
\hline 285 to 315 & -30 \\
\hline 315 to 345 & -60 \\
\hline 345 to 15 & -90 (South) \\
\hline 15 to 45 & -120 \\
\hline 45 to 75 & -150 \\
\hline 75 to 105 & 180 (West) \\
\hline 105 to 135 & 150 \\
\hline 135 to 165 & 120 \\
\hline
\end{tabular}

NOTE: This table summarizes the conversion of compass direction to Ashplume direction using the relationship depicted in Figure D-1. 
Table D-6. Example PDF Results

\begin{tabular}{|c|c|c|c|c|c|}
\hline & A & B & C & $\mathrm{D}^{*}$ & D \\
\hline 1 & Compass Degrees & $\begin{array}{c}\text { ASHPLUME } \\
\text { degrees }\end{array}$ & $\begin{array}{c}\text { Count/ } \\
\text { Frequency }\end{array}$ & PDF & PDF \\
\hline 2 & 165 to 195 & 90 (North) & 8336 & $=\mathrm{C} 2 /($ sumC2:C13) & 0.1303 \\
\hline 3 & 195 to 225 & 60 & 18290 & $=\mathrm{C} 3 /($ sumC2:C13) & 0.2858 \\
\hline 4 & 225 to 255 & 30 & 6633 & $=\mathrm{C} 4 /($ sumC2:C13) & 0.1036 \\
\hline 5 & 255 to 285 & 0 (East) & 2910 & $=\mathrm{C} 5 /($ sumC $2: \mathrm{C} 13)$ & 0.0455 \\
\hline 6 & 285 to 315 & -30 & 2407 & $=\mathrm{C} 6 /($ sumC2:C13) & 0.0376 \\
\hline 7 & 315 to 345 & -60 & 2670 & $=\mathrm{C} 7 /($ sumC2:C13) & 0.0417 \\
\hline 8 & 345 to 15 & -90 (South) & 3750 & $=\mathrm{C} 8 /($ sumC $2: \mathrm{C} 13)$ & 0.0586 \\
\hline 9 & 15 to 45 & -120 & 5411 & $=\mathrm{C} 9 /($ sumC $2: \mathrm{C} 13)$ & 0.0845 \\
\hline 10 & 45 to 75 & -150 & 5225 & $=\mathrm{C} 10 /($ sumC2:C13) & 0.0816 \\
\hline 11 & 75 to 105 & 180 (West) & 3596 & $=C 11 /($ sumC2:C13) & 0.0562 \\
\hline 12 & 105 to 135 & 150 & 2411 & $=\mathrm{C} 12 /($ sumC $2: C 13)$ & 0.0377 \\
\hline 13 & 135 to 165 & 120 & 2363 & $=\mathrm{C} 13 /(\mathrm{sumC} 2: \mathrm{C} 13)$ & 0.0369 \\
\hline
\end{tabular}

* $=$ visible cell calculation

NOTE: This spreadsheet excerpt illustrates the method used to create wind direction PDFs for the 0 to $1 \mathrm{~km}$ interval.

Next, a PDF was completed using Microsoft Excel for each data grouping. This was performed by taking the sample count for each interval and dividing by the total number of samples for that particular height interval. The ASHPLUME degrees and count were then plotted against one another using the radar-type graph under the chart function to produce a "wind rose" diagram like Figure D-2.

Specifically, Table D-6 was constructed for the 0 to $1 \mathrm{~km}$ interval in Excel. For final insertion into the TSPA model, four decimal places were used for the PDF values, and adjustments $(+/-0.0001)$ were made to ensure the sum of the distribution equaled exactly 1 . ASHPLUME Degrees were arranged sequentially, and the "Frequency" and "Compass Degrees" columns were deleted as shown in output DTN: MO0408SPADRWSD.002.

Under the insert pull-down menu, chart was selected, radar was selected, and then the last example of radar graphs was chosen. Following, Columns B and C were plotted against each other to form the Figure D-2 for the 0- to 1-km interval. Tables for all 13 intervals are displayed later in this appendix (Tables D-23 through D-35). For TSPA, these tables were formatted to contain only the PDF value and ASHPLUME degrees columns organized in ascending order (output DTN: MO0408SPADRWSD.002). 


\section{Wind Rose Frequency of Occurrences (wind toward designation) at 0 to $1 \mathrm{~km}$ above $\mathrm{YM}$}

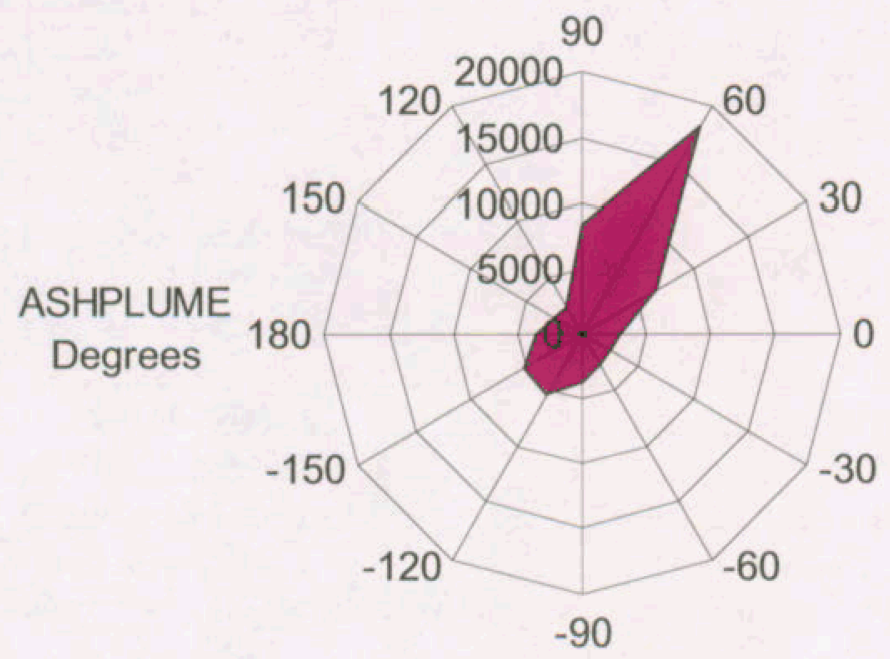

Count

Output DTN: MO0408SPADRWSD.002.

NOTE: This figure illustrates the method used in presenting information graphically using a radar-type graph. This figure is the same as Figure D-3, which lists the source of information (NOAA 2004 [171035]) and the data output.

Figure D-2. Wind Rose Diagram for 0 to $1 \mathrm{~km}$ above Yucca Mountain

\section{Wind Speed}

A CDF was calculated for each height grouping also using the Histogram function under the data analysis menu in Microsoft Excel. The wind speed column from table "0 to_1_Table" was copied and pasted into column $\mathrm{A}$ of a new worksheet, named " 0 to 1 windspeed." Following, the wind speeds in meters per second were converted to centimeters per second in column B by multiplying each cell by 100 . Table D-7 below shows the conversion. After choosing tools, data analysis, and then histogram, a popup menu appeared and asked for input and output options. For the input, the wind-speed data were entered in the input range cell, "\$B\$2:\$B\$64003," for the 0 - to 1-km example. Wind-speed bin intervals consisting of $100 \mathrm{~cm} / \mathrm{s}$ each, up to the highest wind speed recorded $(14,100 \mathrm{~cm} / \mathrm{s})$ for all applicable heights $(0$ to $13 \mathrm{~km})$, were then pasted to each Excel table in Column C (Table D-7). This column was then chosen as the input for the bin range cell and typed in as: "\$C\$2:\$C\$143" under the Histogram function. 
Table D-7. Format of Tables Used to Calculate Wind Speed CDFs

\begin{tabular}{|l|l|l|l|}
\hline A & \multicolumn{1}{|c|}{ B $^{*}$} & B & \multicolumn{1}{c|}{ C } \\
\hline WNDSP MS & WNDSP CONV & WNDSP CMS & BINS CMS \\
\hline 16 & $=\mathrm{A} 2 \times 100$ & 1600 & 0 \\
\hline 15 & $=\mathrm{A} 3 \times 100$ & 1500 & 100 \\
\hline 9 & $=\mathrm{A} 4 \times 100$ & 900 & 200 \\
\hline 7 & $=\mathrm{A} 5 \times 100$ & 700 & 300 \\
\hline 8 & $=\mathrm{A} 6 \times 100$ & 800 & 400 \\
\hline 7 & $=\mathrm{A} 7 \times 100$ & 700 & 500 \\
\hline 8 & $=\mathrm{A} 8 \times 100$ & 800 & 600 \\
\hline 7 & $=\mathrm{A} 9 \times 100$ & 700 & 700 \\
\hline 6 & $=\mathrm{A} 10 \times 100$ & 600 & 800 \\
\hline 6 & $=\mathrm{A} 11 \times 100$ & 600 & 900 \\
\hline 1 & $=\mathrm{A} 12 \times 100$ & 100 & 1000 \\
\hline 3 & $=\mathrm{A} 13 \times 100$ & 300 & 1100 \\
\hline 2 & $=\mathrm{A} 14 \times 100$ & 200 & 1200 \\
\hline 3 & $=\mathrm{A} 15 \times 100$ & 300 & 1300 \\
\hline 2 & $=\mathrm{A} 16 \times 100$ & 200 & 1400 \\
\hline 1 & $=\mathrm{A} 17 \times 100$ & 100 & 1500 \\
\hline 2 & $=\mathrm{A} 18 \times 100$ & 200 & 1600 \\
\hline 4 & $=\mathrm{A} 19 \times 100$ & 400 & 1700 \\
\hline 4 & $=\mathrm{A} 20 \times 100$ & 400 & 1800 \\
\hline 3 & $=\mathrm{A} 21 \times 100$ & 300 & 1900 \\
\hline 3 & $=\mathrm{A} 22 \times 100$ & 300 & 2000 \\
\hline 9 & $=\mathrm{A} 23 \times 100$ & 900 & 2100 \\
\hline 13 & $=\mathrm{A} 24 \times 100$ & 1300 & 2200 \\
\hline
\end{tabular}

* $=$ visible cell calculation

NOTE: This spreadsheet excerpt illustrates the method used to bin the wind speed data.

Additionally, the cumulative percentage (converted to decimal in example Table D-8 below by simply formatting the cell) and chart output boxes in the output menu were selected, which resulted in a table similar to Table D-8.

Table D-8. 0 to $1 \mathrm{~km} \mathrm{CDF} \mathrm{Table}$

\begin{tabular}{|c|c|c|}
\hline $\operatorname{Bin}(\mathbf{c m} / \mathbf{s})$ & Frequency & CDF \\
\hline 0 & 125 & 0.00195 \\
\hline 100 & 2624 & 0.04295 \\
\hline 200 & 3326 & 0.09492 \\
\hline 300 & 6156 & 0.19110 \\
\hline 400 & 8571 & 0.32502 \\
\hline 500 & 6873 & 0.43241 \\
\hline
\end{tabular}


Table D-8. 0 to $1 \mathrm{~km}$ CDF Table (Continued)

\begin{tabular}{|c|c|c|}
\hline $\operatorname{Bin}(\mathrm{cm} / \mathrm{s})$ & Frequency & CDF \\
\hline 600 & 4840 & 0.50803 \\
\hline 700 & 6045 & 0.60248 \\
\hline 800 & 5301 & 0.68531 \\
\hline 900 & 4661 & 0.75813 \\
\hline 1000 & 3916 & 0.81932 \\
\hline 1100 & 2907 & 0.86474 \\
\hline 1200 & 2252 & 0.89993 \\
\hline 1300 & 1743 & 0.92716 \\
\hline 1400 & 1271 & 0.94702 \\
\hline 1500 & 908 & 0.96120 \\
\hline 1600 & 695 & 0.97206 \\
\hline 1700 & 480 & 0.97956 \\
\hline 1800 & 382 & 0.98553 \\
\hline 1900 & 259 & 0.98958 \\
\hline 2000 & 135 & 0.99169 \\
\hline 2100 & 193 & 0.99470 \\
\hline 2200 & 121 & 0.99659 \\
\hline 2300 & 71 & 0.99770 \\
\hline 2400 & 48 & 0.99845 \\
\hline 2500 & 32 & 0.99895 \\
\hline 2600 & 22 & 0.99930 \\
\hline 2700 & 16 & 0.99955 \\
\hline 2800 & 12 & 0.99973 \\
\hline 2900 & 8 & 0.99986 \\
\hline 3000 & 5 & 0.99994 \\
\hline 3100 & 0 & 0.99994 \\
\hline 3200 & 1 & 0.99995 \\
\hline 3300 & 0 & 0.99995 \\
\hline 3400 & 0 & 0.99995 \\
\hline 3500 & 0 & 0.99995 \\
\hline 3600 & 0 & 0.99995 \\
\hline 3700 & 0 & 0.99995 \\
\hline 3800 & 1 & 0.99997 \\
\hline 3900 & 0 & 0.99997 \\
\hline 4000 & 0 & 0.99997 \\
\hline 4100 & 0 & 0.99997 \\
\hline 4200 & 0 & 0.99997 \\
\hline 4300 & 0 & 0.99997 \\
\hline 4400 & 0 & 0.99997 \\
\hline 4500 & 1 & 0.99998 \\
\hline
\end{tabular}


Table D-8. 0 to $1 \mathrm{~km}$ CDF Table (Continued)

\begin{tabular}{|c|c|c|}
\hline $\operatorname{Bin}(\mathrm{cm} / \mathrm{s})$ & Frequency & CDF \\
\hline 4600 & 0 & 0.99998 \\
\hline 4700 & 1 & 1.00000 \\
\hline 4800 & 0 & 1.00000 \\
\hline 4900 & 0 & 1.00000 \\
\hline 5000 & 0 & 1.00000 \\
\hline 5100 & 0 & 1.00000 \\
\hline 5200 & 0 & 1.00000 \\
\hline 5300 & 0 & 1.00000 \\
\hline 5400 & 0 & 1.00000 \\
\hline 5500 & 0 & 1.00000 \\
\hline 5600 & 0 & 1.00000 \\
\hline 5700 & 0 & 1.00000 \\
\hline 5800 & 0 & 1.00000 \\
\hline 5900 & 0 & 1.00000 \\
\hline 6000 & 0 & 1.00000 \\
\hline 6100 & 0 & 1.00000 \\
\hline 6200 & 0 & 1.00000 \\
\hline 6300 & 0 & 1.00000 \\
\hline 6400 & 0 & 1.00000 \\
\hline 6500 & 0 & 1.00000 \\
\hline 6600 & 0 & 1.00000 \\
\hline 6700 & 0 & 1.00000 \\
\hline 6800 & 0 & 1.00000 \\
\hline 6900 & 0 & 1.00000 \\
\hline 7000 & 0 & 1.00000 \\
\hline 7100 & 0 & 1.00000 \\
\hline 7200 & 0 & 1.00000 \\
\hline 7300 & 0 & 1.00000 \\
\hline 7400 & 0 & 1.00000 \\
\hline 7500 & 0 & 1.00000 \\
\hline 7600 & 0 & 1.00000 \\
\hline 7700 & 0 & 1.00000 \\
\hline 7800 & 0 & 1.00000 \\
\hline 7900 & 0 & 1.00000 \\
\hline 8000 & 0 & 1.00000 \\
\hline 8100 & 0 & 1.00000 \\
\hline 8200 & 0 & 1.00000 \\
\hline 8300 & 0 & 1.00000 \\
\hline 8400 & 0 & 1.00000 \\
\hline 8500 & 0 & 1.00000 \\
\hline
\end{tabular}


Table D-8. 0 to $1 \mathrm{~km}$ CDF Table (Continued)

\begin{tabular}{|c|c|c|}
\hline $\operatorname{Bin}(\mathrm{cm} / \mathrm{s})$ & Frequency & CDF \\
\hline 8600 & 0 & 1.00000 \\
\hline 8700 & 0 & 1.00000 \\
\hline 8800 & 0 & 1.00000 \\
\hline 8900 & 0 & 1.00000 \\
\hline 9000 & 0 & 1.00000 \\
\hline 9100 & 0 & 1.00000 \\
\hline 9200 & 0 & 1.00000 \\
\hline 9300 & 0 & 1.00000 \\
\hline 9400 & 0 & 1.00000 \\
\hline 9500 & 0 & 1.00000 \\
\hline 9600 & 0 & 1.00000 \\
\hline 9700 & 0 & 1.00000 \\
\hline 9800 & 0 & 1.00000 \\
\hline 9900 & 0 & 1.00000 \\
\hline 10000 & 0 & 1.00000 \\
\hline 10100 & 0 & 1.00000 \\
\hline 10200 & 0 & 1.00000 \\
\hline 10300 & 0 & 1.00000 \\
\hline 10400 & 0 & 1.00000 \\
\hline 10500 & 0 & 1.00000 \\
\hline 10600 & 0 & 1.00000 \\
\hline 10800 & 0 & 1.00000 \\
\hline 10900 & 0 & 1.00000 \\
\hline 11000 & 0 & 1.00000 \\
\hline 11100 & 0 & 1.00000 \\
\hline 11200 & 0 & 1.00000 \\
\hline 11300 & 0 & 1.00000 \\
\hline 11400 & 0 & 1.00000 \\
\hline 11500 & 0 & 1.00000 \\
\hline 11600 & 0 & 1.00000 \\
\hline 11700 & 0 & 1.00000 \\
\hline 11800 & 0 & 1.00000 \\
\hline 11900 & 0 & 1.00000 \\
\hline 12000 & 0 & 1.00000 \\
\hline 12100 & 0 & 1.00000 \\
\hline 12200 & 0 & 1.00000 \\
\hline 12300 & 0 & 1.00000 \\
\hline 12400 & 0 & 1.00000 \\
\hline 12500 & 0 & 1.00000 \\
\hline 12600 & 0 & 1.00000 \\
\hline
\end{tabular}


Table D-8. 0 to $1 \mathrm{~km}$ CDF Table (Continued)

\begin{tabular}{|c|c|c|}
\hline Bin (cm/s) & Frequency & CDF \\
\hline 12700 & 0 & 1.00000 \\
\hline 12800 & 0 & 1.00000 \\
\hline 12900 & 0 & 1.00000 \\
\hline 13000 & 0 & 1.00000 \\
\hline 13100 & 0 & 1.00000 \\
\hline 13200 & 0 & 1.00000 \\
\hline 13300 & 0 & 1.00000 \\
\hline 13400 & 0 & 1.00000 \\
\hline 13500 & 0 & 1.00000 \\
\hline 13600 & 0 & 1.00000 \\
\hline 13700 & 0 & 1.00000 \\
\hline 13800 & 0 & 1.00000 \\
\hline 13900 & 0 & 1.00000 \\
\hline 14000 & 0 & 1.00000 \\
\hline 14100 & 0 & 1.00000 \\
\hline
\end{tabular}

Output DTN: MO0408SPADRWSD.002.

This same procedure was followed for the remaining 12 tables ( 1 to $2 \mathrm{~km}, 2$ to $3 \mathrm{~km}, 3$ to $4 \mathrm{~km}, 4$ to $5 \mathrm{~km}, 5$ to $6 \mathrm{~km}, 6$ to $7 \mathrm{~km}, 7$ to $8 \mathrm{~km}, 8$ to $9 \mathrm{~km}, 9$ to $10 \mathrm{~km}, 10$ to $11 \mathrm{~km}, 11$ to $12 \mathrm{~km}$, and 12 to $13 \mathrm{~km}$ ).

For correct insertion into the TSPA model, the formatting of these tables was modified further. Specifically, all bins without samples (Frequency $=0$ ) were deleted from the tables, the "Frequency" column was deleted, and only 5 decimal places were used for the CDF values. Additionally, the TSPA model requires the first bin CDF value to equal zero. As such, the zero wind speed bin was replaced with $1 \mathrm{E}-30$ to account for data having a wind speed of zero, and the first bin was added which equaled zero. The wind speed CDF tables formatted for TSPA are inserted below (Tables D-10 through D-22). Table D-9 is the result of the minimum, maximum, and average wind speeds (in $\mathrm{cm} / \mathrm{s}$ ) calculated for each height interval in Access and then imported into one table in Excel. Tables D-23 through D-35 are the wind direction PDF tables. 
Table D-9. Wind Speed Minimum, Maximum, and Average

\begin{tabular}{|c|c|c|c|}
\hline $\begin{array}{c}\text { Height } \\
\text { (km) }\end{array}$ & $\begin{array}{c}\text { Minimum } \\
\text { (cm/s) }\end{array}$ & $\begin{array}{c}\text { Maximum } \\
\text { (cm/s) }\end{array}$ & $\begin{array}{c}\text { Average } \\
\text { (cm/s) }\end{array}$ \\
\hline 0 to 1 & 0 & 4670 & 668 \\
\hline 1 to 2 & 0 & 4480 & 817 \\
\hline 2 to 3 & 0 & 5000 & 1007 \\
\hline 3 to 4 & 0 & 6400 & 1215 \\
\hline 4 to 5 & 0 & 10500 & 1486 \\
\hline 5 to 6 & 0 & 14100 & 1695 \\
\hline 6 to 7 & 0 & 10300 & 1949 \\
\hline 7 to 8 & 0 & 11000 & 2160 \\
\hline 8 to 9 & 0 & 8700 & 2294 \\
\hline 9 to 10 & 0 & 8640 & 2416 \\
\hline 10 to 11 & 0 & 8900 & 2437 \\
\hline 11 to 12 & 0 & 9900 & 2311 \\
\hline 12 to 13 & 0 & 7300 & 2064 \\
\hline
\end{tabular}

Output DTN: MO0408SPADRWSD.002.

Table D-10. 0 to $1 \mathrm{~km} \mathrm{CDF}$

\begin{tabular}{|c|c|}
\hline CDF & Bin (cm/s) \\
\hline 0.00000 & 0 \\
\hline 0.00195 & $1.00 \mathrm{E}-30$ \\
\hline 0.04295 & 100 \\
\hline 0.09492 & 200 \\
\hline 0.19110 & 300 \\
\hline 0.32502 & 400 \\
\hline 0.43241 & 500 \\
\hline 0.50803 & 600 \\
\hline 0.60248 & 700 \\
\hline 0.68531 & 800 \\
\hline 0.75813 & 900 \\
\hline 0.81932 & 1000 \\
\hline 0.86474 & 1100 \\
\hline 0.89993 & 1200 \\
\hline 0.92716 & 1300 \\
\hline 0.94702 & 1400 \\
\hline 0.96120 & 1500 \\
\hline 0.97206 & 1600 \\
\hline 0.97956 & 1700 \\
\hline 0.98553 & 1800 \\
\hline 0.98958 & 1900 \\
\hline 0.99169 & 2000 \\
\hline & \\
\hline & \\
\hline
\end{tabular}


Table D-10. 0 to $1 \mathrm{~km}$ CDF (Continued)

\begin{tabular}{|c|c|}
\hline CDF & Bin $(\mathbf{c m} / \mathbf{s})$ \\
\hline 0.99470 & 2100 \\
\hline 0.99659 & 2200 \\
\hline 0.99770 & 2300 \\
\hline 0.99845 & 2400 \\
\hline 0.99895 & 2500 \\
\hline 0.99930 & 2600 \\
\hline 0.99955 & 2700 \\
\hline 0.99973 & 2800 \\
\hline 0.99986 & 2900 \\
\hline 0.99994 & 3000 \\
\hline 0.99995 & 3200 \\
\hline 0.99997 & 3800 \\
\hline 0.99998 & 4500 \\
\hline 1.00000 & 4700 \\
\hline
\end{tabular}

Output DTN: MO0408SPADRWSD.002.

Table D-11. 1 to $2 \mathrm{~km}$ CDF

\begin{tabular}{|c|c|}
\hline CDF & Bin (cm/s) \\
\hline 0.00000 & 0 \\
\hline 0.00110 & $1.00 E-30$ \\
\hline 0.02928 & 100 \\
\hline 0.06453 & 200 \\
\hline 0.13111 & 300 \\
\hline 0.23150 & 400 \\
\hline 0.32544 & 500 \\
\hline 0.39702 & 600 \\
\hline 0.48348 & 700 \\
\hline 0.56574 & 800 \\
\hline 0.63869 & 900 \\
\hline 0.70420 & 1000 \\
\hline 0.76024 & 1100 \\
\hline 0.80820 & 1200 \\
\hline 0.84620 & 1300 \\
\hline 0.88023 & 1400 \\
\hline 0.90612 & 1500 \\
\hline 0.92720 & 1600 \\
\hline 0.94547 & 1700 \\
\hline 0.95992 & 1800 \\
\hline 0.96983 & 1900 \\
\hline & \\
\hline & \\
\hline
\end{tabular}


Table D-11. 1 to $2 \mathrm{~km} \mathrm{CDF} \mathrm{(Continued)}$

\begin{tabular}{|c|c|}
\hline CDF & Bin $(\mathrm{cm} / \mathbf{s})$ \\
\hline 0.97528 & 2000 \\
\hline 0.98196 & 2100 \\
\hline 0.98708 & 2200 \\
\hline 0.99105 & 2300 \\
\hline 0.99379 & 2400 \\
\hline 0.99546 & 2500 \\
\hline 0.99669 & 2600 \\
\hline 0.99757 & 2700 \\
\hline 0.99832 & 2800 \\
\hline 0.99899 & 2900 \\
\hline 0.99937 & 3000 \\
\hline 0.99970 & 3100 \\
\hline 0.99982 & 3200 \\
\hline 0.99989 & 3300 \\
\hline 0.99996 & 3400 \\
\hline 0.99997 & 3500 \\
\hline 0.99999 & 3700 \\
\hline 1.00000 & 4500 \\
\hline
\end{tabular}

Output DTN: MO0408SPADRWSD.002.

Table D-12. 2 to $3 \mathrm{~km}$ CDF

\begin{tabular}{|c|c|}
\hline CDF & Bin $(\mathrm{cm} / \mathbf{s})$ \\
\hline 0.00000 & 0 \\
\hline 0.00072 & $1.00 \mathrm{E}-30$ \\
\hline 0.01802 & 100 \\
\hline 0.04272 & 200 \\
\hline 0.08866 & 300 \\
\hline 0.15890 & 400 \\
\hline 0.22871 & 500 \\
\hline 0.29000 & 600 \\
\hline 0.36961 & 700 \\
\hline 0.44771 & 800 \\
\hline 0.52039 & 900 \\
\hline 0.58798 & 1000 \\
\hline 0.64808 & 1100 \\
\hline 0.70021 & 1200 \\
\hline 0.74401 & 1300 \\
\hline 0.78398 & 1400 \\
\hline 0.81856 & 1500 \\
\hline
\end{tabular}


Table D-12. 2 to $3 \mathrm{~km}$ CDF (Continued)

\begin{tabular}{|c|c|}
\hline CDF & $\operatorname{Bin}(\mathrm{cm} / \mathrm{s})$ \\
\hline 0.84619 & 1600 \\
\hline 0.87071 & 1700 \\
\hline 0.89252 & 1800 \\
\hline 0.91219 & 1900 \\
\hline 0.92311 & 2000 \\
\hline 0.93829 & 2100 \\
\hline 0.95045 & 2200 \\
\hline 0.96087 & 2300 \\
\hline 0.96923 & 2400 \\
\hline 0.97591 & 2500 \\
\hline 0.98103 & 2600 \\
\hline 0.98463 & 2700 \\
\hline 0.98813 & 2800 \\
\hline 0.99088 & 2900 \\
\hline 0.99308 & 3000 \\
\hline 0.99517 & 3100 \\
\hline 0.99647 & 3200 \\
\hline 0.99759 & 3300 \\
\hline 0.99838 & 3400 \\
\hline 0.99883 & 3500 \\
\hline 0.99923 & 3600 \\
\hline 0.99951 & 3700 \\
\hline 0.99960 & 3800 \\
\hline 0.99968 & 3900 \\
\hline 0.99981 & 4000 \\
\hline 0.99987 & 4100 \\
\hline 0.99990 & 4300 \\
\hline 0.99995 & 4400 \\
\hline 0.99996 & 4700 \\
\hline 0.99999 & 4800 \\
\hline 1.00000 & 5000 \\
\hline
\end{tabular}

Output DTN: MO0408SPADRWSD.002. 
Table D-13. 3 to $4 \mathrm{~km} \mathrm{CDF}$

\begin{tabular}{|c|c|}
\hline CDF & $\operatorname{Bin}(\mathrm{cm} / \mathrm{s})$ \\
\hline 0.00000 & $\underline{0}$ \\
\hline 0.00031 & $1.00 \mathrm{E}-30$ \\
\hline 0.01214 & 100 \\
\hline 0.02960 & 200 \\
\hline 0.06417 & 300 \\
\hline 0.12112 & 400 \\
\hline 0.17309 & 500 \\
\hline 0.21907 & 600 \\
\hline 0.28050 & 700 \\
\hline 0.34572 & 800 \\
\hline 0.41196 & 900 \\
\hline 0.47477 & 1000 \\
\hline 0.53414 & 1100 \\
\hline 0.58985 & 1200 \\
\hline 0.63913 & 1300 \\
\hline 0.68183 & 1400 \\
\hline 0.71943 & 1500 \\
\hline 0.75362 & 1600 \\
\hline 0.78268 & 1700 \\
\hline 0.81033 & 1800 \\
\hline 0.83488 & 1900 \\
\hline 0.84985 & 2000 \\
\hline 0.87099 & 2100 \\
\hline 0.88892 & 2200 \\
\hline 0.90439 & 2300 \\
\hline 0.91888 & 2400 \\
\hline 0.93221 & 2500 \\
\hline 0.94343 & 2600 \\
\hline 0.95215 & 2700 \\
\hline 0.95943 & 2800 \\
\hline 0.96643 & 2900 \\
\hline 0.97232 & 3000 \\
\hline 0.97686 & 3100 \\
\hline 0.98103 & 3200 \\
\hline 0.98476 & 3300 \\
\hline 0.98759 & 3400 \\
\hline 0.98991 & 3500 \\
\hline 0.99208 & 3600 \\
\hline 0.99363 & 3700 \\
\hline
\end{tabular}


Table D-13. 3 to $4 \mathrm{~km}$ CDF (Continued)

\begin{tabular}{|c|c|}
\hline CDF & $\operatorname{Bin}(\mathrm{cm} / \mathrm{s})$ \\
\hline 0.99430 & 3800 \\
\hline 0.99542 & 3900 \\
\hline 0.99644 & 4000 \\
\hline 0.99734 & 4100 \\
\hline 0.99799 & 4200 \\
\hline 0.99842 & 4300 \\
\hline 0.99869 & 4400 \\
\hline 0.99888 & 4500 \\
\hline 0.99911 & 4600 \\
\hline 0.99935 & 4700 \\
\hline 0.99946 & 4800 \\
\hline 0.99960 & 4900 \\
\hline 0.99969 & 5000 \\
\hline 0.99979 & 5100 \\
\hline 0.99983 & 5200 \\
\hline 0.99987 & 5300 \\
\hline 0.99989 & 5400 \\
\hline 0.99990 & 5500 \\
\hline 0.99992 & 5600 \\
\hline 0.99993 & 5700 \\
\hline 0.99997 & 6300 \\
\hline 1.00000 & 6400 \\
\hline
\end{tabular}

Output DTN: MO0408SPADRWSD.002. 
Table D-14. 4 to $5 \mathrm{~km}$ CDF

\begin{tabular}{|c|c|}
\hline CDF & $\operatorname{Bin}(\mathrm{cm} / \mathrm{s})$ \\
\hline 0.00000 & 0 \\
\hline 0.00026 & $1.00 \mathrm{E}-30$ \\
\hline 0.00864 & 100 \\
\hline 0.02063 & 200 \\
\hline 0.04692 & 300 \\
\hline 0.08757 & 400 \\
\hline 0.13023 & 500 \\
\hline 0.16377 & 600 \\
\hline 0.21110 & 700 \\
\hline 0.26015 & 800 \\
\hline 0.31218 & 900 \\
\hline 0.36145 & 1000 \\
\hline 0.41169 & 1100 \\
\hline 0.46132 & 1200 \\
\hline 0.50883 & 1300 \\
\hline 0.55370 & 1400 \\
\hline 0.59263 & 1500 \\
\hline 0.62879 & 1600 \\
\hline 0.66191 & 1700 \\
\hline 0.69538 & 1800 \\
\hline 0.72596 & 1900 \\
\hline 0.74547 & 2000 \\
\hline 0.77370 & 2100 \\
\hline 0.79871 & 2200 \\
\hline 0.82075 & 2300 \\
\hline 0.84081 & 2400 \\
\hline 0.85904 & 2500 \\
\hline 0.87581 & 2600 \\
\hline 0.89146 & 2700 \\
\hline 0.90697 & 2800 \\
\hline 0.92016 & 2900 \\
\hline 0.93152 & 3000 \\
\hline 0.94102 & 3100 \\
\hline 0.94928 & 3200 \\
\hline 0.95607 & 3300 \\
\hline 0.96224 & 3400 \\
\hline 0.96797 & 3500 \\
\hline 0.97326 & 3600 \\
\hline 0.97696 & 3700 \\
\hline
\end{tabular}


Table D-14. 4 to $5 \mathrm{~km}$ CDF (Continued)

\begin{tabular}{|c|c|}
\hline CDF & $\operatorname{Bin}(\mathrm{cm} / \mathrm{s})$ \\
\hline 0.97923 & 3800 \\
\hline 0.98232 & 3900 \\
\hline 0.98499 & 4000 \\
\hline 0.98719 & 4100 \\
\hline 0.98913 & 4200 \\
\hline 0.99113 & 4300 \\
\hline 0.99282 & 4400 \\
\hline 0.99400 & 4500 \\
\hline 0.99519 & 4600 \\
\hline 0.99592 & 4700 \\
\hline 0.99670 & 4800 \\
\hline 0.99740 & 4900 \\
\hline 0.99776 & 5000 \\
\hline 0.99809 & 5100 \\
\hline 0.99832 & 5200 \\
\hline 0.99852 & 5300 \\
\hline 0.99882 & 5400 \\
\hline 0.99905 & 5500 \\
\hline 0.99918 & 5600 \\
\hline 0.99931 & 5700 \\
\hline 0.99942 & 5800 \\
\hline 0.99947 & 5900 \\
\hline 0.99951 & 6000 \\
\hline 0.99959 & 6100 \\
\hline 0.99969 & 6200 \\
\hline 0.99973 & 6300 \\
\hline 0.99974 & 6400 \\
\hline 0.99977 & 6500 \\
\hline 0.99979 & 6600 \\
\hline 0.99980 & 6700 \\
\hline 0.99982 & 7000 \\
\hline 0.99986 & 7100 \\
\hline 0.99992 & 7200 \\
\hline 0.99994 & 7400 \\
\hline 0.99995 & 7500 \\
\hline 0.99997 & 7700 \\
\hline 0.99998 & 8500 \\
\hline 1.00000 & 10500 \\
\hline
\end{tabular}

Output DTN: MO0408SPADRWSD.002. 
Table D-15. 5 to $6 \mathrm{~km}$ CDF

\begin{tabular}{|c|c|}
\hline CDF & $\operatorname{Bin}(\mathrm{cm} / \mathrm{s})$ \\
\hline 0.00000 & 0 \\
\hline 0.00032 & $1.00 \mathrm{E}-30$ \\
\hline 0.00668 & 100 \\
\hline 0.01592 & 200 \\
\hline 0.03474 & 300 \\
\hline 0.06735 & 400 \\
\hline 0.10101 & 500 \\
\hline 0.13029 & 600 \\
\hline 0.17049 & 700 \\
\hline 0.20962 & 800 \\
\hline 0.25323 & 900 \\
\hline 0.29679 & 1000 \\
\hline 0.34035 & 1100 \\
\hline 0.38173 & 1200 \\
\hline 0.42336 & 1300 \\
\hline 0.46592 & 1400 \\
\hline 0.50623 & 1500 \\
\hline 0.54363 & 1600 \\
\hline 0.57879 & 1700 \\
\hline 0.61318 & 1800 \\
\hline 0.64714 & 1900 \\
\hline 0.66844 & 2000 \\
\hline 0.69956 & 2100 \\
\hline 0.72755 & 2200 \\
\hline 0.75391 & 2300 \\
\hline 0.77801 & 2400 \\
\hline 0.80003 & 2500 \\
\hline 0.82009 & 2600 \\
\hline 0.83867 & 2700 \\
\hline 0.85654 & 2800 \\
\hline 0.87201 & 2900 \\
\hline 0.88641 & 3000 \\
\hline 0.89852 & 3100 \\
\hline 0.91127 & 3200 \\
\hline 0.92163 & 3300 \\
\hline 0.93079 & 3400 \\
\hline 0.93920 & 3500 \\
\hline 0.94713 & 3600 \\
\hline 0.95488 & 3700 \\
\hline
\end{tabular}


Table D-15. 5 to $6 \mathrm{~km}$ CDF (Continued)

\begin{tabular}{|c|c|}
\hline CDF & $\operatorname{Bin}(\mathrm{cm} / \mathrm{s})$ \\
\hline 0.95877 & 3800 \\
\hline 0.96400 & 3900 \\
\hline 0.96894 & 4000 \\
\hline 0.97322 & 4100 \\
\hline 0.97706 & 4200 \\
\hline 0.98073 & 4300 \\
\hline 0.98343 & 4400 \\
\hline 0.98599 & 4500 \\
\hline 0.98827 & 4600 \\
\hline 0.99004 & 4700 \\
\hline 0.99164 & 4800 \\
\hline 0.99295 & 4900 \\
\hline 0.99416 & 5000 \\
\hline 0.99530 & 5100 \\
\hline 0.99616 & 5200 \\
\hline 0.99680 & 5300 \\
\hline 0.99725 & 5400 \\
\hline 0.99781 & 5500 \\
\hline 0.99791 & 5600 \\
\hline 0.99833 & 5700 \\
\hline 0.99878 & 5800 \\
\hline 0.99912 & 5900 \\
\hline 0.99936 & 6000 \\
\hline 0.99952 & 6100 \\
\hline 0.99958 & 6200 \\
\hline 0.99965 & 6300 \\
\hline 0.99969 & 6400 \\
\hline 0.99971 & 6500 \\
\hline 0.99973 & 6800 \\
\hline 0.99977 & 6900 \\
\hline 0.99982 & 7100 \\
\hline 0.99984 & 7300 \\
\hline 0.99987 & 7400 \\
\hline 0.99989 & 7500 \\
\hline 0.99992 & 7800 \\
\hline 0.99994 & 8000 \\
\hline
\end{tabular}


Table D-15. 5 to $6 \mathrm{~km}$ CDF (Continued)

\begin{tabular}{|r|r|}
\hline CDF & Bin (cm/s) \\
\hline 0.99995 & 8200 \\
\hline 0.99997 & 8400 \\
\hline 0.99998 & 10700 \\
\hline 1.00000 & 14100 \\
\hline
\end{tabular}

Output DTN: MO0408SPADRWSD.002.

Table D-16. 6 to $7 \mathrm{~km} \mathrm{CDF}$

\begin{tabular}{|c|c|}
\hline CDF & $\operatorname{Bin}(\mathrm{cm} / \mathrm{s})$ \\
\hline 0.00000 & $\underline{0}$ \\
\hline 0.00023 & $1.00 \mathrm{E}-30$ \\
\hline 0.00478 & 100 \\
\hline 0.01097 & 200 \\
\hline 0.02393 & 300 \\
\hline 0.04697 & 400 \\
\hline 0.07062 & 500 \\
\hline 0.09192 & 600 \\
\hline 0.12373 & 700 \\
\hline 0.15653 & 800 \\
\hline 0.19172 & 900 \\
\hline 0.22840 & 1000 \\
\hline 0.26559 & 1100 \\
\hline 0.30387 & 1200 \\
\hline 0.34115 & 1300 \\
\hline 0.38007 & 1400 \\
\hline 0.41815 & 1500 \\
\hline 0.45419 & 1600 \\
\hline 0.48723 & 1700 \\
\hline 0.52293 & 1800 \\
\hline 0.55764 & 1900 \\
\hline 0.57847 & 2000 \\
\hline 0.61010 & 2100 \\
\hline 0.64097 & 2200 \\
\hline 0.66989 & 2300 \\
\hline 0.69584 & 2400 \\
\hline 0.72037 & 2500 \\
\hline 0.74352 & 2600 \\
\hline 0.76503 & 2700 \\
\hline 0.78781 & 2800 \\
\hline
\end{tabular}


Table D-16. 6 to $7 \mathrm{~km}$ CDF (Continued)

\begin{tabular}{|c|c|}
\hline CDF & $\operatorname{Bin}(\mathrm{cm} / \mathrm{s})$ \\
\hline 0.80750 & 2900 \\
\hline 0.82567 & 3000 \\
\hline 0.84194 & 3100 \\
\hline 0.85747 & 3200 \\
\hline 0.87147 & 3300 \\
\hline 0.88413 & 3400 \\
\hline 0.89676 & 3500 \\
\hline 0.90849 & 3600 \\
\hline 0.91903 & 3700 \\
\hline 0.92526 & 3800 \\
\hline 0.93453 & 3900 \\
\hline 0.94244 & 4000 \\
\hline 0.94980 & 4100 \\
\hline 0.95663 & 4200 \\
\hline 0.96292 & 4300 \\
\hline 0.96844 & 4400 \\
\hline 0.97339 & 4500 \\
\hline 0.97652 & 4600 \\
\hline 0.97990 & 4700 \\
\hline 0.98256 & 4800 \\
\hline 0.98484 & 4900 \\
\hline 0.98744 & 5000 \\
\hline 0.98943 & 5100 \\
\hline 0.99134 & 5200 \\
\hline 0.99264 & 5300 \\
\hline 0.99383 & 5400 \\
\hline 0.99464 & 5500 \\
\hline 0.99544 & 5600 \\
\hline 0.99631 & 5700 \\
\hline 0.99711 & 5800 \\
\hline 0.99774 & 5900 \\
\hline 0.99824 & 6000 \\
\hline 0.99866 & 6100 \\
\hline 0.99894 & 6200 \\
\hline 0.99906 & 6300 \\
\hline 0.99939 & 6400 \\
\hline 0.99957 & 6500 \\
\hline 0.99970 & 6600 \\
\hline 0.99974 & 6700 \\
\hline 0.99977 & 6800 \\
\hline
\end{tabular}


Table D-16. 6 to $7 \mathrm{~km}$ CDF (Continued)

\begin{tabular}{|c|c|}
\hline CDF & Bin $(\mathbf{c m} / \mathbf{s})$ \\
\hline 0.99979 & 6900 \\
\hline 0.99983 & 7000 \\
\hline 0.99984 & 7300 \\
\hline 0.99988 & 7500 \\
\hline 0.99990 & 7700 \\
\hline 0.99991 & 7900 \\
\hline 0.99993 & 8200 \\
\hline 0.99995 & 8400 \\
\hline 0.99997 & 8600 \\
\hline 0.99998 & 9000 \\
\hline 1.00000 & 10300 \\
\hline
\end{tabular}

Output DTN: MO0408SPADRWSD.002.

Table D-17. 7 to $8 \mathrm{~km}$ CDF

\begin{tabular}{|c|c|}
\hline $\mathrm{CDF}$ & $\operatorname{Bin}(\mathrm{cm} / \mathrm{s})$ \\
\hline 0.00000 & 0 \\
\hline 0.00019 & $1.00 \mathrm{E}-30$ \\
\hline 0.00325 & 100 \\
\hline 0.00764 & 200 \\
\hline 0.01684 & 300 \\
\hline 0.03393 & 400 \\
\hline 0.05211 & 500 \\
\hline 0.06801 & 600 \\
\hline 0.09231 & 700 \\
\hline 0.11870 & 800 \\
\hline 0.14712 & 900 \\
\hline 0.17990 & 1000 \\
\hline 0.21268 & 1100 \\
\hline 0.24845 & 1200 \\
\hline 0.28145 & 1300 \\
\hline 0.31668 & 1400 \\
\hline 0.35111 & 1500 \\
\hline 0.38383 & 1600 \\
\hline 0.41778 & 1700 \\
\hline 0.45221 & 1800 \\
\hline 0.48596 & 1900 \\
\hline 0.50636 & 2000 \\
\hline 0.53783 & 2100 \\
\hline 0.56735 & 2200 \\
\hline
\end{tabular}


Table D-17. 7 to $8 \mathrm{~km} \mathrm{CDF} \mathrm{(Continued)}$

\begin{tabular}{|c|c|}
\hline CDF & $\operatorname{Bin}(\mathrm{cm} / \mathrm{s})$ \\
\hline 0.59727 & 2300 \\
\hline 0.62570 & 2400 \\
\hline 0.65299 & 2500 \\
\hline 0.67893 & 2600 \\
\hline 0.70453 & 2700 \\
\hline 0.72711 & 2800 \\
\hline 0.74863 & 2900 \\
\hline 0.76994 & 3000 \\
\hline 0.79026 & 3100 \\
\hline 0.80849 & 3200 \\
\hline 0.82504 & 3300 \\
\hline 0.84083 & 3400 \\
\hline 0.85523 & 3500 \\
\hline 0.86972 & 3600 \\
\hline 0.88471 & 3700 \\
\hline 0.89188 & 3800 \\
\hline 0.90386 & 3900 \\
\hline 0.91568 & 4000 \\
\hline 0.92694 & 4100 \\
\hline 0.93658 & 4200 \\
\hline 0.94513 & 4300 \\
\hline 0.95260 & 4400 \\
\hline 0.95884 & 4500 \\
\hline 0.96388 & 4600 \\
\hline 0.96874 & 4700 \\
\hline 0.97327 & 4800 \\
\hline 0.97694 & 4900 \\
\hline 0.97994 & 5000 \\
\hline 0.98270 & 5100 \\
\hline 0.98538 & 5200 \\
\hline 0.98765 & 5300 \\
\hline 0.98979 & 5400 \\
\hline 0.99178 & 5500 \\
\hline 0.99273 & 5600 \\
\hline 0.99403 & 5700 \\
\hline 0.99483 & 5800 \\
\hline 0.99551 & 5900 \\
\hline 0.99625 & 6000 \\
\hline 0.99704 & 6100 \\
\hline 0.99745 & 6200 \\
\hline
\end{tabular}


Table D-17. 7 to $8 \mathrm{~km}$ CDF (Continued)

\begin{tabular}{|c|c|}
\hline CDF & $\operatorname{Bin}(\mathrm{cm} / \mathrm{s})$ \\
\hline 0.99804 & 6300 \\
\hline 0.99850 & 6400 \\
\hline 0.99887 & 6500 \\
\hline 0.99907 & 6600 \\
\hline 0.99926 & 6700 \\
\hline 0.99938 & 6800 \\
\hline 0.99951 & 6900 \\
\hline 0.99967 & 7000 \\
\hline 0.99973 & 7100 \\
\hline 0.99975 & 7200 \\
\hline 0.99981 & 7500 \\
\hline 0.99983 & 7600 \\
\hline 0.99984 & 7700 \\
\hline 0.99986 & 8200 \\
\hline 0.99988 & 8500 \\
\hline 0.99990 & 8700 \\
\hline 0.99992 & 9100 \\
\hline 0.99994 & 9600 \\
\hline 0.99996 & 10000 \\
\hline 0.99998 & 10700 \\
\hline 1.00000 & 11000 \\
\hline
\end{tabular}

Output DTN: MO0408SPADRWSD.002.

Table D-18. 8 to $9 \mathrm{~km} \mathrm{CDF}$

\begin{tabular}{|c|c|}
\hline CDF & Bin (cm/s) \\
\hline 0.00000 & 0 \\
\hline 0.00006 & $1.00 \mathrm{E}-30$ \\
\hline 0.00264 & 100 \\
\hline 0.00538 & 200 \\
\hline 0.01250 & 300 \\
\hline 0.02531 & 400 \\
\hline 0.03943 & 500 \\
\hline 0.05271 & 600 \\
\hline 0.07314 & 700 \\
\hline 0.09434 & 800 \\
\hline 0.12032 & 900 \\
\hline 0.14648 & 1000 \\
\hline 0.17371 & 1100 \\
\hline
\end{tabular}


Table D-18. 8 to $9 \mathrm{~km}$ CDF (Continued)

\begin{tabular}{|c|c|}
\hline CDF & $\operatorname{Bin}(\mathrm{cm} / \mathrm{s})$ \\
\hline 0.20415 & 1200 \\
\hline 0.23410 & 1300 \\
\hline 0.26547 & 1400 \\
\hline 0.29842 & 1500 \\
\hline 0.33141 & 1600 \\
\hline 0.36487 & 1700 \\
\hline 0.39987 & 1800 \\
\hline 0.43679 & 1900 \\
\hline 0.45726 & 2000 \\
\hline 0.48747 & 2100 \\
\hline 0.51827 & 2200 \\
\hline 0.54909 & 2300 \\
\hline 0.57856 & 2400 \\
\hline 0.60765 & 2500 \\
\hline 0.63551 & 2600 \\
\hline 0.66306 & 2700 \\
\hline 0.68917 & 2800 \\
\hline 0.71591 & 2900 \\
\hline 0.73886 & 3000 \\
\hline 0.76280 & 3100 \\
\hline 0.78384 & 3200 \\
\hline 0.80388 & 3300 \\
\hline 0.82222 & 3400 \\
\hline 0.83928 & 3500 \\
\hline 0.85602 & 3600 \\
\hline 0.87073 & 3700 \\
\hline 0.87788 & 3800 \\
\hline 0.89055 & 3900 \\
\hline 0.90210 & 4000 \\
\hline 0.91385 & 4100 \\
\hline 0.92432 & 4200 \\
\hline 0.93365 & 4300 \\
\hline 0.94246 & 4400 \\
\hline 0.94970 & 4500 \\
\hline 0.95652 & 4600 \\
\hline 0.96194 & 4700 \\
\hline 0.96692 & 4800 \\
\hline 0.97121 & 4900 \\
\hline 0.97537 & 5000 \\
\hline
\end{tabular}


Table D-18. 8 to $9 \mathrm{~km}$ CDF (Continued)

\begin{tabular}{|c|c|}
\hline CDF & $\operatorname{Bin}(\mathrm{cm} / \mathrm{s})$ \\
\hline 0.97936 & 5100 \\
\hline 0.98250 & 5200 \\
\hline 0.98571 & 5300 \\
\hline 0.98820 & 5400 \\
\hline 0.99029 & 5500 \\
\hline 0.99105 & 5600 \\
\hline 0.99227 & 5700 \\
\hline 0.99350 & 5800 \\
\hline 0.99449 & 5900 \\
\hline 0.99521 & 6000 \\
\hline 0.99599 & 6100 \\
\hline 0.99658 & 6200 \\
\hline 0.99704 & 6300 \\
\hline 0.99755 & 6400 \\
\hline 0.99804 & 6500 \\
\hline 0.99856 & 6600 \\
\hline 0.99884 & 6700 \\
\hline 0.99916 & 6800 \\
\hline 0.99941 & 6900 \\
\hline 0.99956 & 7000 \\
\hline 0.99960 & 7100 \\
\hline 0.99966 & 7200 \\
\hline 0.99977 & 7300 \\
\hline 0.99979 & 7400 \\
\hline 0.99983 & 7600 \\
\hline 0.99987 & 7700 \\
\hline 0.99989 & 7900 \\
\hline 0.99992 & 8100 \\
\hline 0.99996 & 8300 \\
\hline 0.99998 & 8500 \\
\hline 1.00000 & 8700 \\
\hline
\end{tabular}

Output DTN: MO0408SPADRWSD.002.

Table D-19. 9 to $10 \mathrm{~km} \mathrm{CDF}$

\begin{tabular}{|c|r|}
\hline CDF & Bin (cm/s) \\
\hline 0.00000 & 0 \\
\hline 0.00004 & $1.00 \mathrm{E}-30$ \\
\hline 0.00180 & 100 \\
\hline 0.00445 & 200 \\
\hline
\end{tabular}


Table D-19. 9 to $10 \mathrm{~km}$ CDF (Continued)

\begin{tabular}{|c|c|}
\hline CDF & $\operatorname{Bin}(\mathrm{cm} / \mathrm{s})$ \\
\hline 0.00952 & 300 \\
\hline 0.01927 & 400 \\
\hline 0.02956 & 500 \\
\hline 0.03962 & 600 \\
\hline 0.05446 & 700 \\
\hline 0.07231 & 800 \\
\hline 0.09328 & 900 \\
\hline 0.11484 & 1000 \\
\hline 0.13732 & 1100 \\
\hline 0.16225 & 1200 \\
\hline 0.18801 & 1300 \\
\hline 0.21603 & 1400 \\
\hline 0.24538 & 1500 \\
\hline 0.27693 & 1600 \\
\hline 0.30875 & 1700 \\
\hline 0.34212 & 1800 \\
\hline 0.37424 & 1900 \\
\hline 0.39463 & 2000 \\
\hline 0.42945 & 2100 \\
\hline 0.46195 & 2200 \\
\hline 0.49434 & 2300 \\
\hline 0.52716 & 2400 \\
\hline 0.55842 & 2500 \\
\hline 0.58968 & 2600 \\
\hline 0.62069 & 2700 \\
\hline 0.65137 & 2800 \\
\hline 0.68058 & 2900 \\
\hline 0.70856 & 3000 \\
\hline 0.73597 & 3100 \\
\hline 0.76105 & 3200 \\
\hline 0.78450 & 3300 \\
\hline 0.80645 & 3400 \\
\hline 0.82616 & 3500 \\
\hline 0.84511 & 3600 \\
\hline 0.86324 & 3700 \\
\hline 0.87307 & 3800 \\
\hline 0.88726 & 3900 \\
\hline 0.90138 & 4000 \\
\hline 0.91452 & 4100 \\
\hline
\end{tabular}


Table D-19. 9 to $10 \mathrm{~km} \mathrm{CDF} \mathrm{(Continued)}$

\begin{tabular}{|c|c|}
\hline CDF & $\operatorname{Bin}(\mathrm{cm} / \mathrm{s})$ \\
\hline 0.92675 & 4200 \\
\hline 0.93730 & 4300 \\
\hline 0.94586 & 4400 \\
\hline 0.95348 & 4500 \\
\hline 0.95996 & 4600 \\
\hline 0.96557 & 4700 \\
\hline 0.97102 & 4800 \\
\hline 0.97524 & 4900 \\
\hline 0.97830 & 5000 \\
\hline 0.98135 & 5100 \\
\hline 0.98370 & 5200 \\
\hline 0.98606 & 5300 \\
\hline 0.98817 & 5400 \\
\hline 0.99005 & 5500 \\
\hline 0.99092 & 5600 \\
\hline 0.99234 & 5700 \\
\hline 0.99358 & 5800 \\
\hline 0.99445 & 5900 \\
\hline 0.99521 & 6000 \\
\hline 0.99593 & 6100 \\
\hline 0.99643 & 6200 \\
\hline 0.99683 & 6300 \\
\hline 0.99713 & 6400 \\
\hline 0.99737 & 6500 \\
\hline 0.99765 & 6600 \\
\hline 0.99785 & 6700 \\
\hline 0.99803 & 6800 \\
\hline 0.99834 & 6900 \\
\hline 0.99858 & 7000 \\
\hline 0.99892 & 7100 \\
\hline 0.99926 & 7200 \\
\hline 0.99938 & 7300 \\
\hline 0.99952 & 7400 \\
\hline 0.99962 & 7500 \\
\hline 0.99970 & 7600 \\
\hline 0.99972 & 7700 \\
\hline 0.99974 & 7800 \\
\hline 0.99976 & 8000 \\
\hline 0.99984 & 8100 \\
\hline
\end{tabular}


Table D-19. 9 to $10 \mathrm{~km} \mathrm{CDF} \mathrm{(Continued)}$

\begin{tabular}{|c|c|}
\hline CDF & Bin $(\mathbf{c m} / \mathbf{s})$ \\
\hline 0.99988 & 8200 \\
\hline 0.99992 & 8300 \\
\hline 0.99996 & 8500 \\
\hline 0.99998 & 8600 \\
\hline 1.00000 & 8700 \\
\hline
\end{tabular}

Output DTN: MO0408SPADRWSD.002.

Table D-20. 10 to $11 \mathrm{~km} \mathrm{CDF}$

\begin{tabular}{|c|c|}
\hline CDF & $\operatorname{Bin}(\mathrm{cm} / \mathrm{s})$ \\
\hline 0.00000 & 0 \\
\hline 0.00002 & $1.00 \mathrm{E}-30$ \\
\hline 0.00119 & 100 \\
\hline 0.00289 & 200 \\
\hline 0.00736 & 300 \\
\hline 0.01644 & 400 \\
\hline 0.02470 & 500 \\
\hline 0.03280 & 600 \\
\hline 0.04581 & 700 \\
\hline 0.06011 & 800 \\
\hline 0.07581 & 900 \\
\hline 0.09393 & 1000 \\
\hline 0.11502 & 1100 \\
\hline 0.13769 & 1200 \\
\hline 0.16032 & 1300 \\
\hline 0.18656 & 1400 \\
\hline 0.21464 & 1500 \\
\hline 0.24477 & 1600 \\
\hline 0.27641 & 1700 \\
\hline 0.30862 & 1800 \\
\hline 0.34336 & 1900 \\
\hline 0.36461 & 2000 \\
\hline 0.40188 & 2100 \\
\hline 0.43969 & 2200 \\
\hline 0.47603 & 2300 \\
\hline 0.51243 & 2400 \\
\hline 0.54951 & 2500 \\
\hline 0.58542 & 2600 \\
\hline 0.61831 & 2700 \\
\hline 0.65159 & 2800 \\
\hline
\end{tabular}


Table D-20. 10 to $11 \mathrm{~km}$ CDF (Continued)

\begin{tabular}{|c|c|}
\hline CDF & $\operatorname{Bin}(\mathrm{cm} / \mathrm{s})$ \\
\hline 0.68205 & 2900 \\
\hline 0.71259 & 3000 \\
\hline 0.74149 & 3100 \\
\hline 0.76924 & 3200 \\
\hline 0.79491 & 3300 \\
\hline 0.81779 & 3400 \\
\hline 0.84016 & 3500 \\
\hline 0.86050 & 3600 \\
\hline 0.87959 & 3700 \\
\hline 0.88931 & 3800 \\
\hline 0.90407 & 3900 \\
\hline 0.91783 & 4000 \\
\hline 0.92919 & 4100 \\
\hline 0.93995 & 4200 \\
\hline 0.94925 & 4300 \\
\hline 0.95702 & 4400 \\
\hline 0.96374 & 4500 \\
\hline 0.96881 & 4600 \\
\hline 0.97382 & 4700 \\
\hline 0.97779 & 4800 \\
\hline 0.98154 & 4900 \\
\hline 0.98369 & 5000 \\
\hline 0.98605 & 5100 \\
\hline 0.98818 & 5200 \\
\hline 0.98984 & 5300 \\
\hline 0.99105 & 5400 \\
\hline 0.99228 & 5500 \\
\hline 0.99297 & 5600 \\
\hline 0.99394 & 5700 \\
\hline 0.99467 & 5800 \\
\hline 0.99556 & 5900 \\
\hline 0.99646 & 6000 \\
\hline 0.99702 & 6100 \\
\hline 0.99746 & 6200 \\
\hline 0.99767 & 6300 \\
\hline 0.99802 & 6400 \\
\hline 0.99821 & 6500 \\
\hline 0.99843 & 6600 \\
\hline 0.99866 & 6700 \\
\hline
\end{tabular}


Table D-20. 10 to $11 \mathrm{~km}$ CDF (Continued)

\begin{tabular}{|c|c|}
\hline CDF & Bin (cm/s) \\
\hline 0.99886 & 6800 \\
\hline 0.99897 & 6900 \\
\hline 0.99914 & 7000 \\
\hline 0.99924 & 7100 \\
\hline 0.99937 & 7200 \\
\hline 0.99944 & 7300 \\
\hline 0.99957 & 7400 \\
\hline 0.99968 & 7500 \\
\hline 0.99974 & 7600 \\
\hline 0.99979 & 7800 \\
\hline 0.99987 & 7900 \\
\hline 0.99991 & 8000 \\
\hline 0.99996 & 8100 \\
\hline 0.99998 & 8600 \\
\hline 1.00000 & 8900 \\
\hline
\end{tabular}

Output DTN: MO0408SPADRWSD.002.

Table D-21. 11 to $12 \mathrm{~km} \mathrm{CDF}$

\begin{tabular}{|r|r|}
\hline CDF & Bin (cm/s) \\
\hline 0.00000 & 0 \\
\hline 0.00009 & $1.00 E-30$ \\
\hline 0.00095 & 100 \\
\hline 0.00281 & 200 \\
\hline 0.00706 & 300 \\
\hline 0.01478 & 400 \\
\hline 0.02393 & 500 \\
\hline 0.03340 & 600 \\
\hline 0.04535 & 700 \\
\hline 0.06093 & 800 \\
\hline 0.07847 & 900 \\
\hline 0.09690 & 1000 \\
\hline 0.11842 & 1100 \\
\hline 0.14433 & 1200 \\
\hline 0.17128 & 1300 \\
\hline 0.19922 & 1400 \\
\hline 0.22953 & 1500 \\
\hline 0.26001 & 1600 \\
\hline 0.29236 & 1700 \\
\hline & \\
\hline
\end{tabular}


Table D-21. 11 to $12 \mathrm{~km} \mathrm{CDF} \mathrm{(Continued)}$

\begin{tabular}{|c|c|}
\hline CDF & $\operatorname{Bin}(\mathrm{cm} / \mathrm{s})$ \\
\hline 0.32732 & 1800 \\
\hline 0.36624 & 1900 \\
\hline 0.39180 & 2000 \\
\hline 0.43337 & 2100 \\
\hline 0.47364 & 2200 \\
\hline 0.51610 & 2300 \\
\hline 0.55620 & 2400 \\
\hline 0.59444 & 2500 \\
\hline 0.63324 & 2600 \\
\hline 0.67006 & 2700 \\
\hline 0.70482 & 2800 \\
\hline 0.74001 & 2900 \\
\hline 0.77084 & 3000 \\
\hline 0.79857 & 3100 \\
\hline 0.82478 & 3200 \\
\hline 0.84739 & 3300 \\
\hline 0.86718 & 3400 \\
\hline 0.88578 & 3500 \\
\hline 0.90194 & 3600 \\
\hline 0.91709 & 3700 \\
\hline 0.92559 & 3800 \\
\hline 0.93747 & 3900 \\
\hline 0.94698 & 4000 \\
\hline 0.95613 & 4100 \\
\hline 0.96381 & 4200 \\
\hline 0.96997 & 4300 \\
\hline 0.97526 & 4400 \\
\hline 0.97948 & 4500 \\
\hline 0.98352 & 4600 \\
\hline 0.98647 & 4700 \\
\hline 0.98865 & 4800 \\
\hline 0.99055 & 4900 \\
\hline 0.99208 & 5000 \\
\hline 0.99329 & 5100 \\
\hline 0.99452 & 5200 \\
\hline 0.99533 & 5300 \\
\hline 0.99584 & 5400 \\
\hline 0.99638 & 5500 \\
\hline 0.99684 & 5600 \\
\hline
\end{tabular}


Table D-21. 11 to $12 \mathrm{~km}$ CDF (Continued)

\begin{tabular}{|c|c|}
\hline CDF & $\operatorname{Bin}(\mathrm{cm} / \mathrm{s})$ \\
\hline 0.99728 & 5700 \\
\hline 0.99766 & 5800 \\
\hline 0.99814 & 5900 \\
\hline 0.99838 & 6000 \\
\hline 0.99859 & 6100 \\
\hline 0.99882 & 6200 \\
\hline 0.99909 & 6300 \\
\hline 0.99916 & 6400 \\
\hline 0.99924 & 6500 \\
\hline 0.99944 & 6600 \\
\hline 0.99954 & 6700 \\
\hline 0.99960 & 6800 \\
\hline 0.99965 & 6900 \\
\hline 0.99972 & 7000 \\
\hline 0.99975 & 7200 \\
\hline 0.99977 & 7300 \\
\hline 0.99979 & 7400 \\
\hline 0.99988 & 7600 \\
\hline 0.99989 & 7900 \\
\hline 0.99991 & 8000 \\
\hline 0.99993 & 8100 \\
\hline 0.99996 & 8200 \\
\hline 0.99998 & 8800 \\
\hline 1.00000 & 9900 \\
\hline
\end{tabular}

Output DTN: MO0408SPADRWSD.002.

Table D-22. 12 to $13 \mathrm{~km} \mathrm{CDF}$

\begin{tabular}{|c|r|}
\hline CDF & Bin (cm/s) \\
\hline 0.00000 & 0 \\
\hline 0.00002 & $1.00 \mathrm{E}-30$ \\
\hline 0.00160 & 100 \\
\hline 0.00338 & 200 \\
\hline 0.00805 & 300 \\
\hline 0.01771 & 400 \\
\hline 0.02870 & 500 \\
\hline 0.03909 & 600 \\
\hline 0.05427 & 700 \\
\hline 0.07280 & 800 \\
\hline 0.09468 & 900 \\
\hline
\end{tabular}


Table D-22. 12 to $13 \mathrm{~km}$ CDF (Continued)

\begin{tabular}{|c|c|}
\hline CDF & $\operatorname{Bin}(\mathrm{cm} / \mathrm{s})$ \\
\hline 0.12039 & 1000 \\
\hline 0.14801 & 1100 \\
\hline 0.17996 & 1200 \\
\hline 0.21327 & 1300 \\
\hline 0.24941 & 1400 \\
\hline 0.28655 & 1500 \\
\hline 0.32655 & 1600 \\
\hline 0.36599 & 1700 \\
\hline 0.41104 & 1800 \\
\hline 0.45807 & 1900 \\
\hline 0.48590 & 2000 \\
\hline 0.53199 & 2100 \\
\hline 0.57681 & 2200 \\
\hline 0.62132 & 2300 \\
\hline 0.66192 & 2400 \\
\hline 0.70207 & 2500 \\
\hline 0.73888 & 2600 \\
\hline 0.77352 & 2700 \\
\hline 0.80529 & 2800 \\
\hline 0.83277 & 2900 \\
\hline 0.85825 & 3000 \\
\hline 0.88089 & 3100 \\
\hline 0.90169 & 3200 \\
\hline 0.91942 & 3300 \\
\hline 0.93304 & 3400 \\
\hline 0.94464 & 3500 \\
\hline 0.95461 & 3600 \\
\hline 0.96357 & 3700 \\
\hline 0.96784 & 3800 \\
\hline 0.97412 & 3900 \\
\hline 0.97935 & 4000 \\
\hline 0.98337 & 4100 \\
\hline 0.98650 & 4200 \\
\hline 0.98920 & 4300 \\
\hline 0.99142 & 4400 \\
\hline 0.99307 & 4500 \\
\hline 0.99446 & 4600 \\
\hline 0.99556 & 4700 \\
\hline 0.99662 & 4800 \\
\hline
\end{tabular}


Table D-22. 12 to $13 \mathrm{~km}$ CDF (Continued)

\begin{tabular}{|c|c|}
\hline CDF & $\operatorname{Bin}(\mathrm{cm} / \mathrm{s})$ \\
\hline 0.99728 & 4900 \\
\hline 0.99791 & 5000 \\
\hline 0.99830 & 5100 \\
\hline 0.99867 & 5200 \\
\hline 0.99890 & 5300 \\
\hline 0.99909 & 5400 \\
\hline 0.99932 & 5500 \\
\hline 0.99934 & 5600 \\
\hline 0.99948 & 5700 \\
\hline 0.99959 & 5800 \\
\hline 0.99969 & 5900 \\
\hline 0.99971 & 6000 \\
\hline 0.99979 & 6100 \\
\hline 0.99986 & 6200 \\
\hline 0.99990 & 6400 \\
\hline 0.99992 & 6500 \\
\hline 0.99996 & 6800 \\
\hline 0.99998 & 6900 \\
\hline 1.00000 & 7300 \\
\hline
\end{tabular}

Output DTN: MO0408SPADRWSD.002.

Table D-23. 0 to $1 \mathrm{~km}$ PDF

\begin{tabular}{|c|c|c|c|}
\hline Compass Degrees & ASHPLUME Degrees & Count & PDF \\
\hline 165 to 195 & 90 & 8336 & 0.1303 \\
\hline 195 to 225 & 60 & 18290 & 0.2858 \\
\hline 225 to 255 & 30 & 6633 & 0.1036 \\
\hline 255 to 285 & 0 & 2910 & 0.0455 \\
\hline 285 to 315 & -30 & 2407 & 0.0376 \\
\hline 315 to 345 & -60 & 2670 & 0.0417 \\
\hline 345 to 15 & -90 & 3750 & 0.0586 \\
\hline 15 to 45 & -120 & 5411 & 0.0845 \\
\hline 45 to 75 & -150 & 5225 & 0.0816 \\
\hline 75 to 105 & 180 & 3596 & 0.0562 \\
\hline 105 to 135 & 150 & 2411 & 0.0377 \\
\hline 135 to 165 & 120 & 2363 & 0.0369 \\
\hline & Totals & 64002 & 1.0000 \\
\hline
\end{tabular}




\section{Wind Rose Frequency of Occurrences (wind toward designation) at 0 to $1 \mathrm{~km}$ above $\mathrm{YM}$}

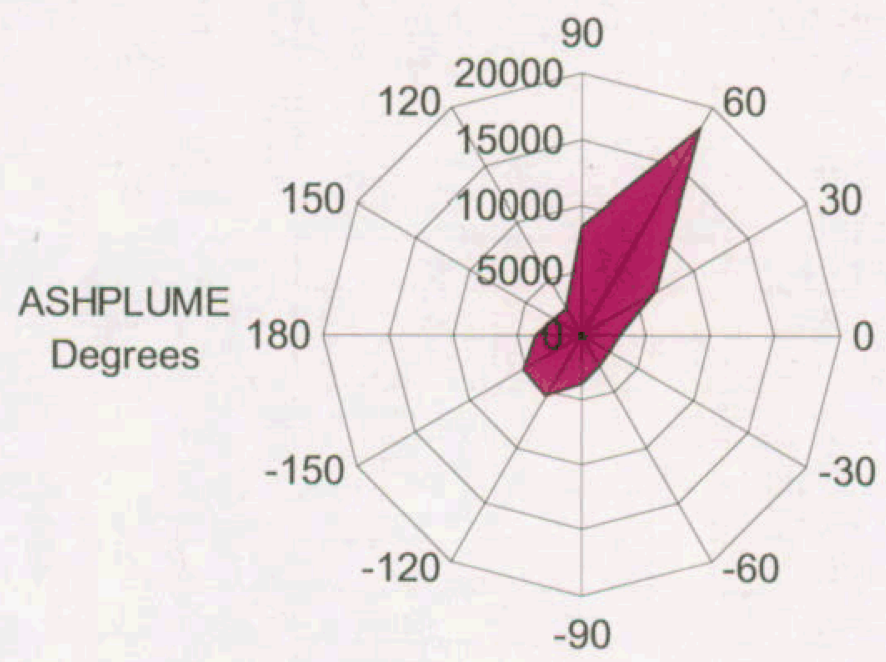

Count

Output DTN: MO0408SPADRWSD.002.

Figure D-3. Wind Frequency of Occurrences at 0 to $1 \mathrm{~km}$ above Yucca Mountain

Table D-24. 1 to $2 \mathrm{~km}$ PDF

\begin{tabular}{|c|c|c|c|}
\hline Compass Degrees & ASHPLUME Degrees & Count & PDF \\
\hline 165 to 195 & 90 & 9213 & 0.1271 \\
\hline 195 to 225 & 60 & 16871 & 0.2327 \\
\hline 225 to 255 & 30 & 9220 & 0.1272 \\
\hline 255 to 285 & 0 & 4836 & 0.0667 \\
\hline 285 to 315 & -30 & 4869 & 0.0671 \\
\hline 315 to 345 & -60 & 6337 & 0.0874 \\
\hline 345 to 15 & -90 & 6299 & 0.0869 \\
\hline 15 to 45 & -120 & 5038 & 0.0695 \\
\hline 45 to 75 & -150 & 2871 & 0.0396 \\
\hline 75 to 105 & 180 & 1839 & 0.0254 \\
\hline 105 to 135 & 150 & 1908 & 0.0263 \\
\hline 135 to 165 & 120 & 3197 & 0.0441 \\
\hline & Totals & 72498 & 1.0000 \\
\hline
\end{tabular}




\section{Wind Rose Frequency of Occurrences (wind toward designation) at 1 to $2 \mathrm{~km}$ above $\mathrm{YM}$}

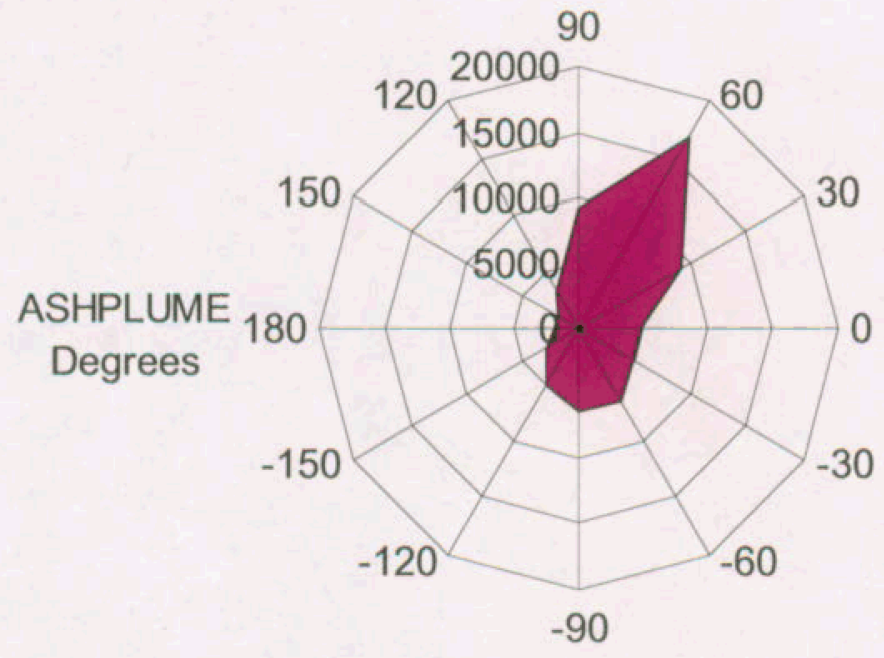

Count

Output DTN: MO0408SPADRWSD.002.

Figure D-4. Wind Rose Frequency of Occurrences at 1 to $2 \mathrm{~km}$ above Yucca Mountain Table D-25. 2 to $3 \mathrm{~km}$ PDF

\begin{tabular}{|c|c|c|c|}
\hline Compass Degrees & ASHPLUME Degrees & Count & PDF \\
\hline 165 to 195 & 90 & 8013 & 0.0975 \\
\hline 195 to 225 & 60 & 12663 & 0.1541 \\
\hline 225 to 255 & 30 & 12793 & 0.1557 \\
\hline 255 to 285 & 0 & 9373 & 0.1140 \\
\hline 285 to 315 & -30 & 9428 & 0.1147 \\
\hline 315 to 345 & -60 & 9049 & 0.1101 \\
\hline 345 to 15 & -90 & 6332 & 0.0770 \\
\hline 15 to 45 & -120 & 3696 & 0.0450 \\
\hline 45 to 75 & -150 & 2148 & 0.0261 \\
\hline 75 to 105 & 180 & 1811 & 0.0220 \\
\hline 105 to 135 & 150 & 2456 & 0.0299 \\
\hline 135 to 165 & 120 & 4430 & 0.0539 \\
\hline & Totals & 82192 & 1.0000 \\
\hline
\end{tabular}




\section{Wind Rose Frequency of Occurrences (wind toward designation) at 2 to $3 \mathrm{~km}$ above $\mathrm{YM}$}

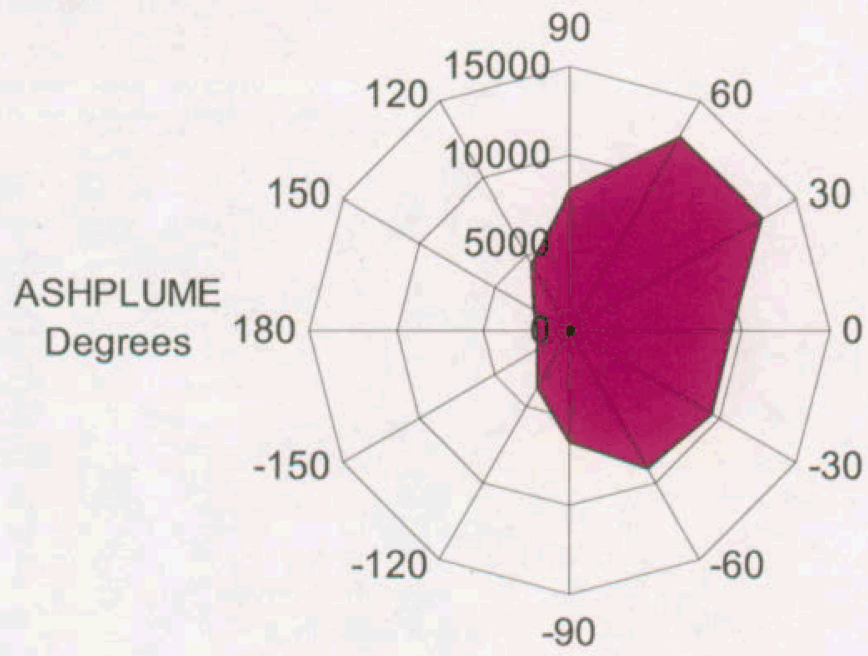

Count

Output DTN: MO0408SPADRWSD.002.

Figure D-5. Wind Rose Frequency of Occurrences at 2 to $3 \mathrm{~km}$ above Yucca Mountain Table D-26. 3 to $4 \mathrm{~km}$ PDF

\begin{tabular}{|c|c|c|c|}
\hline Compass Degrees & ASHPLUME Degrees & Count & PDF \\
\hline 165 to 195 & 90 & 5788 & 0.0818 \\
\hline 195 to 225 & 60 & 9821 & 0.1388 \\
\hline 225 to 255 & 30 & 12019 & 0.1699 \\
\hline 255 to 285 & 0 & 11030 & 0.1559 \\
\hline 285 to 315 & -30 & 10186 & 0.1440 \\
\hline 315 to 345 & -60 & 7486 & 0.1058 \\
\hline 345 to 15 & -90 & 4402 & 0.0622 \\
\hline 15 to 45 & -120 & 2497 & 0.0353 \\
\hline 45 to 75 & -150 & 1639 & 0.0232 \\
\hline 75 to 105 & 180 & 1407 & 0.0199 \\
\hline 105 to 135 & 150 & 1743 & 0.0246 \\
\hline 135 to 165 & 120 & 2730 & 0.0386 \\
\hline & Totals & 70748 & 1.0000 \\
\hline
\end{tabular}




\section{Wind Rose Frequency of Occurrences (wind toward designation) at 3 to $4 \mathrm{~km}$ above YM}

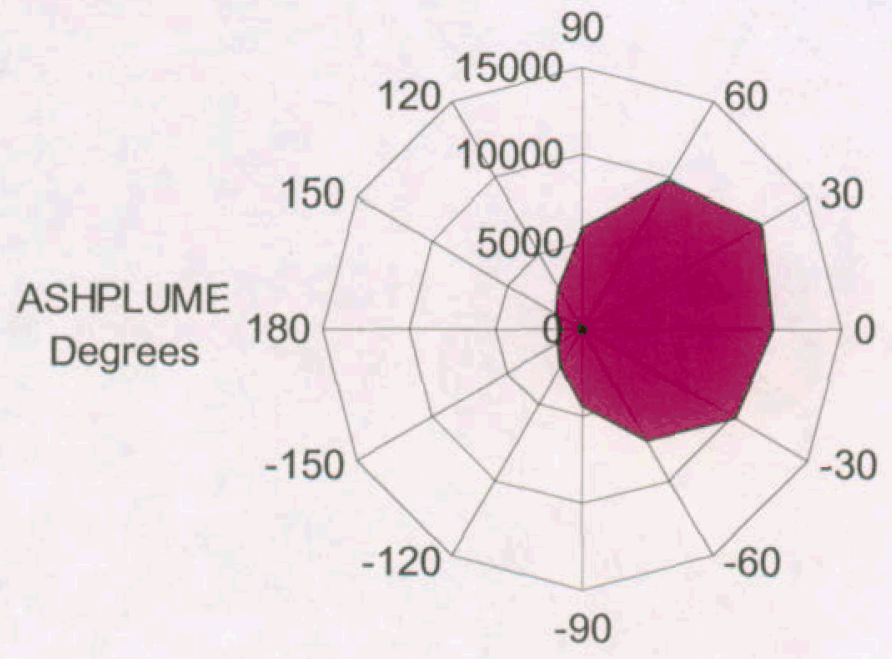

Count

Output DTN: MO0408SPADRWSD.002.

Figure D-6. Wind Rose Frequency of Occurrences at 3 to $4 \mathrm{~km}$ above Yucca Mountain

Table D-27. 4 to $5 \mathrm{~km}$ PDF

\begin{tabular}{|c|c|c|c|}
\hline Compass Degrees & ASHPLUME Degrees & Count & PDF \\
\hline 165 to 195 & 90 & 4010 & 0.0612 \\
\hline 195 to 225 & 60 & 8761 & 0.1338 \\
\hline 225 to 255 & 30 & 12613 & 0.1926 \\
\hline 255 to 285 & 0 & 12291 & 0.1877 \\
\hline 285 to 315 & -30 & 10219 & 0.1560 \\
\hline 315 to 345 & -60 & 6696 & 0.1022 \\
\hline 345 to 15 & -90 & 3630 & 0.0554 \\
\hline 15 to 45 & -120 & 2051 & 0.0313 \\
\hline 45 to 75 & -150 & 1380 & 0.0211 \\
\hline 75 to 105 & 180 & 1014 & 0.0155 \\
\hline 105 to 135 & 150 & 1095 & 0.0167 \\
\hline 135 to 165 & 120 & 1734 & 0.0265 \\
\hline & Totals & 65494 & 1.0000 \\
\hline
\end{tabular}




\section{Wind Rose Frequency of Occurrences (wind toward designation) at 4 to $5 \mathrm{~km}$ above YM}

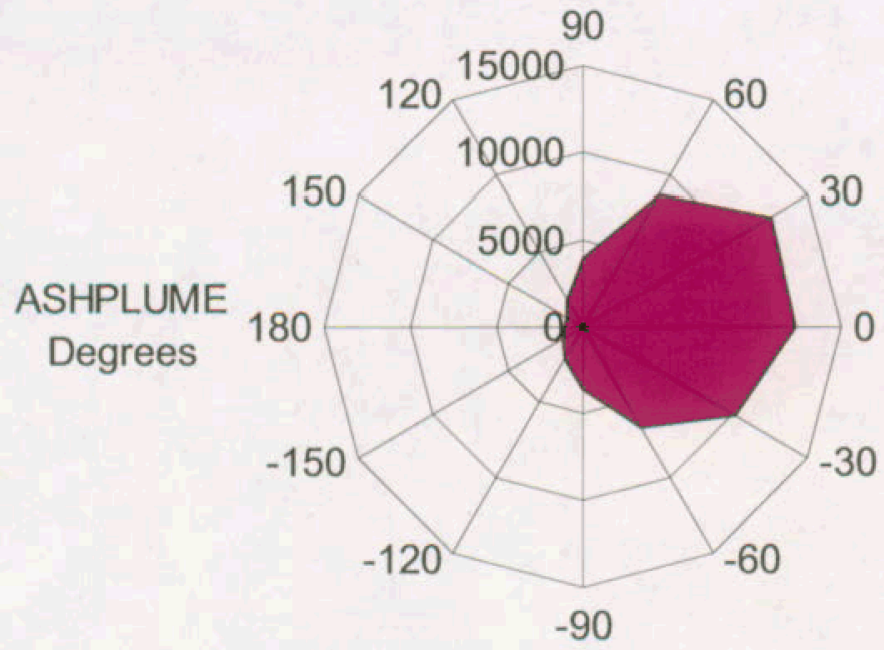

Count

Output DTN: MO0408SPADRWSD.002.

Figure D-7. Wind Rose Frequency of Occurrences at 4 to $5 \mathrm{~km}$ above Yucca Mountain Table D-28. 5 to $6 \mathrm{~km}$ PDF

\begin{tabular}{|c|c|c|c|}
\hline Compass Degrees & ASHPLUME Degrees & Count & PDF \\
\hline 165 to 195 & 90 & 3169 & 0.0509 \\
\hline 195 to 225 & 60 & 8423 & 0.1355 \\
\hline 225 to 255 & 30 & 12947 & 0.2083 \\
\hline 255 to 285 & 0 & 12401 & 0.1994 \\
\hline 285 to 315 & -30 & 9854 & 0.1585 \\
\hline 315 to 345 & -60 & 6098 & 0.0981 \\
\hline 345 to 15 & -90 & 3177 & 0.0511 \\
\hline 15 to 45 & -120 & 1807 & 0.0291 \\
\hline 45 to 75 & -150 & 1183 & 0.0190 \\
\hline 75 to 105 & 180 & 838 & 0.0135 \\
\hline 105 to 135 & 150 & 917 & 0.0148 \\
\hline 135 to 165 & 120 & 1355 & 0.0218 \\
\hline & Totals & 62169 & 1.0000 \\
\hline
\end{tabular}




\section{Wind Rose Frequency of Occurrences (wind toward designation) at 5 to $6 \mathrm{~km}$ above $\mathrm{YM}$}

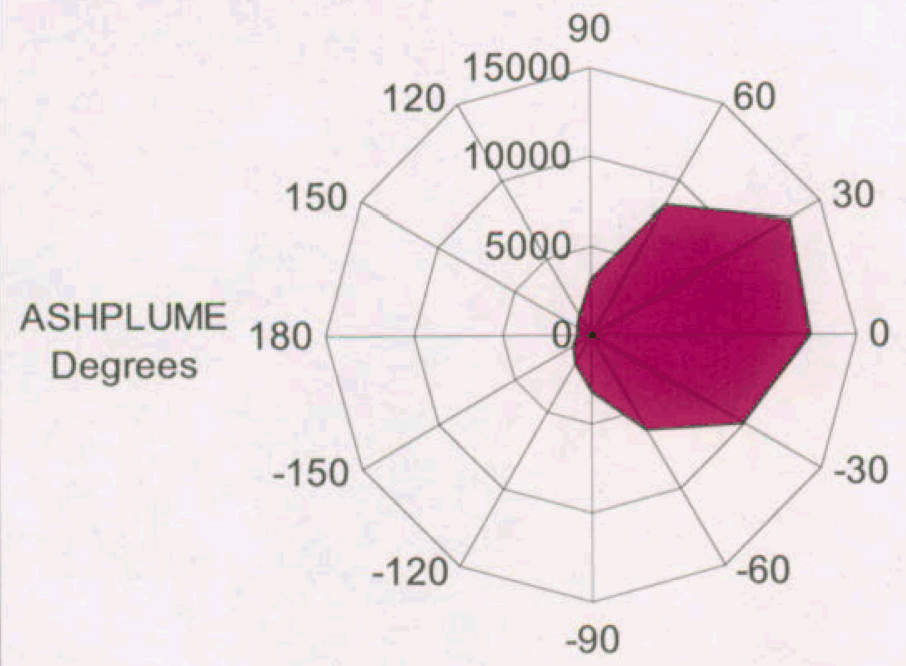

Count

Output DTN: MO0408SPADRWSD.002.

Figure D-8. Wind Rose Frequency of Occurrences at 5 to $6 \mathrm{~km}$ above Yucca Mountain Table D-29. 6 to $7 \mathrm{~km}$ PDF

\begin{tabular}{|c|c|c|c|}
\hline Compass Degrees & ASHPLUME Degrees & Count & PDF \\
\hline 165 to 195 & 90 & 2718 & 0.0473 \\
\hline 195 to 225 & 60 & 7349 & 0.1278 \\
\hline 225 to 255 & 30 & 12617 & 0.2194 \\
\hline 255 to 285 & 0 & 11934 & 0.2075 \\
\hline 285 to 315 & -30 & 8959 & 0.1558 \\
\hline 315 to 345 & -60 & 5696 & 0.0990 \\
\hline 345 to 15 & -90 & 3067 & 0.0533 \\
\hline 15 to 45 & -120 & 1750 & 0.0304 \\
\hline 45 to 75 & -150 & 952 & 0.0166 \\
\hline 75 to 105 & 180 & 703 & 0.0122 \\
\hline 105 to 135 & 150 & 670 & 0.0117 \\
\hline 135 to 165 & 120 & 1090 & 0.0190 \\
\hline & Totals & 57505 & 1.0000 \\
\hline
\end{tabular}




\section{Wind Rose Frequency of Occurrences (wind toward designation) at 6 to $7 \mathrm{~km}$ above YM}

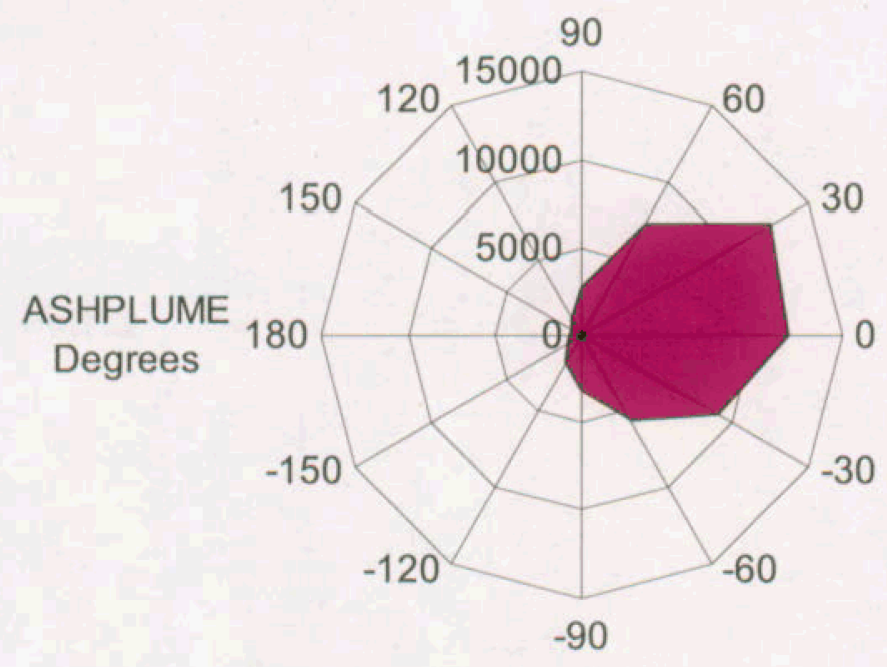

Count

Output DTN: MO0408SPADRWSD.002.

Figure D-9. Wind Rose Frequency of Occurrences at 6 to $7 \mathrm{~km}$ above Yucca Mountain Table D-30. 7 to $8 \mathrm{~km}$ PDF

\begin{tabular}{|c|c|c|c|}
\hline Compass Degrees & ASHPLUME Degrees & Count & PDF \\
\hline 165 to 195 & 90 & 2302 & 0.0448 \\
\hline 195 to 225 & 60 & 6333 & 0.1231 \\
\hline 225 to 255 & 30 & 11358 & 0.2208 \\
\hline 255 to 285 & 0 & 11152 & 0.2168 \\
\hline 285 to 315 & -30 & 8158 & 0.1586 \\
\hline 315 to 345 & -60 & 5123 & 0.0996 \\
\hline 345 to 15 & -90 & 2690 & 0.0523 \\
\hline 15 to 45 & -120 & 1523 & 0.0296 \\
\hline 45 to 75 & -150 & 775 & 0.0151 \\
\hline 75 to 105 & 180 & 518 & 0.0101 \\
\hline 105 to 135 & 150 & 565 & 0.0110 \\
\hline 135 to 165 & 120 & 937 & 0.0182 \\
\hline & Totals & 51434 & 1.0000 \\
\hline
\end{tabular}




\section{Wind Rose Frequency of Occurrences (wind toward designation) at 7 to $8 \mathrm{~km}$ above $\mathrm{YM}$}

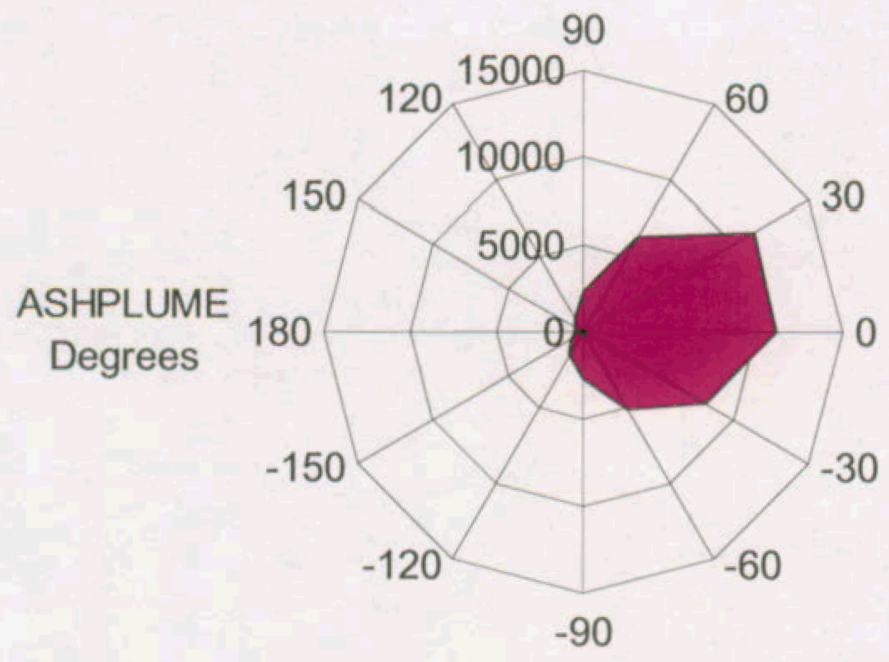

Count

Output DTN: MO0408SPADRWSD.002.

Figure D-10. Wind Rose Frequency of Occurrences at 7 to $8 \mathrm{~km}$ above Yucca Mountain Table D-31. 8 to $9 \mathrm{~km}$ PDF

\begin{tabular}{|c|c|c|c|}
\hline Compass Degrees & ASHPLUME Degrees & Count & PDF \\
\hline 165 to 195 & 90 & 1976 & 0.0417 \\
\hline 195 to 225 & 60 & 5646 & 0.1192 \\
\hline 225 to 255 & 30 & 11114 & 0.2346 \\
\hline 255 to 285 & 0 & 10783 & 0.2276 \\
\hline 285 to 315 & -30 & 7419 & 0.1566 \\
\hline 315 to 345 & -60 & 4503 & 0.0951 \\
\hline 345 to 15 & -90 & 2462 & 0.0520 \\
\hline 15 to 45 & -120 & 1254 & 0.0265 \\
\hline 45 to 75 & -150 & 651 & 0.0137 \\
\hline 75 to 105 & 180 & 428 & 0.0090 \\
\hline 105 to 135 & 150 & 397 & 0.0084 \\
\hline 135 to 165 & 120 & 740 & 0.0156 \\
\hline & Totals & 47373 & 1.0000 \\
\hline
\end{tabular}




\section{Wind Rose Frequency of Occurrences (wind toward designation) at 8 to $9 \mathrm{~km}$ above $\mathrm{YM}$}

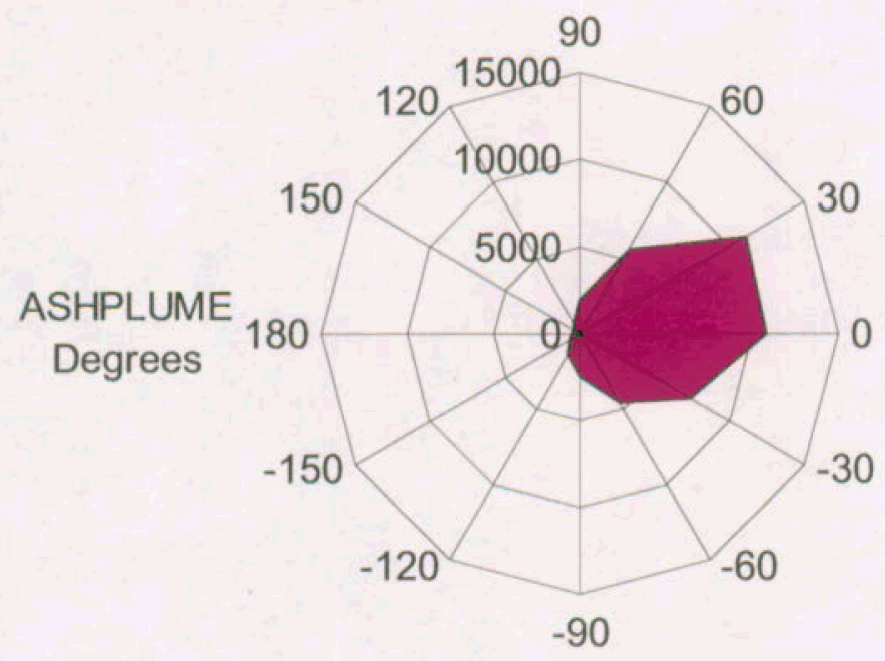

Count

Output DTN: MO0408SPADRWSD.002.

Figure D-11. Wind Rose Frequency of Occurrences at 8 to $9 \mathrm{~km}$ above Yucca Mountain

Table D-32. 9 to $10 \mathrm{~km}$ PDF

\begin{tabular}{|c|c|c|c|}
\hline Compass Degrees & ASHPLUME Degrees & Count & PDF \\
\hline 165 to 195 & 90 & 1571 & 0.0315 \\
\hline 195 to 225 & 60 & 5534 & 0.1110 \\
\hline 225 to 255 & 30 & 12081 & 0.2423 \\
\hline 255 to 285 & 0 & 12068 & 0.2420 \\
\hline 285 to 315 & -30 & 8405 & 0.1685 \\
\hline 315 to 345 & -60 & 4816 & 0.0966 \\
\hline 345 to 15 & -90 & 2356 & 0.0472 \\
\hline 15 to 45 & -120 & 1209 & 0.0242 \\
\hline 45 to 75 & -150 & 566 & 0.0114 \\
\hline 75 to 105 & 180 & 361 & 0.0072 \\
\hline 105 to 135 & 150 & 349 & 0.0070 \\
\hline 135 to 165 & 120 & 553 & 0.0111 \\
\hline & Totals & 49869 & 1.0000 \\
\hline
\end{tabular}




\section{Wind Rose Frequency of Occurrences (wind toward designation) at 9 to $10 \mathrm{~km}$ above $\mathrm{YM}$}

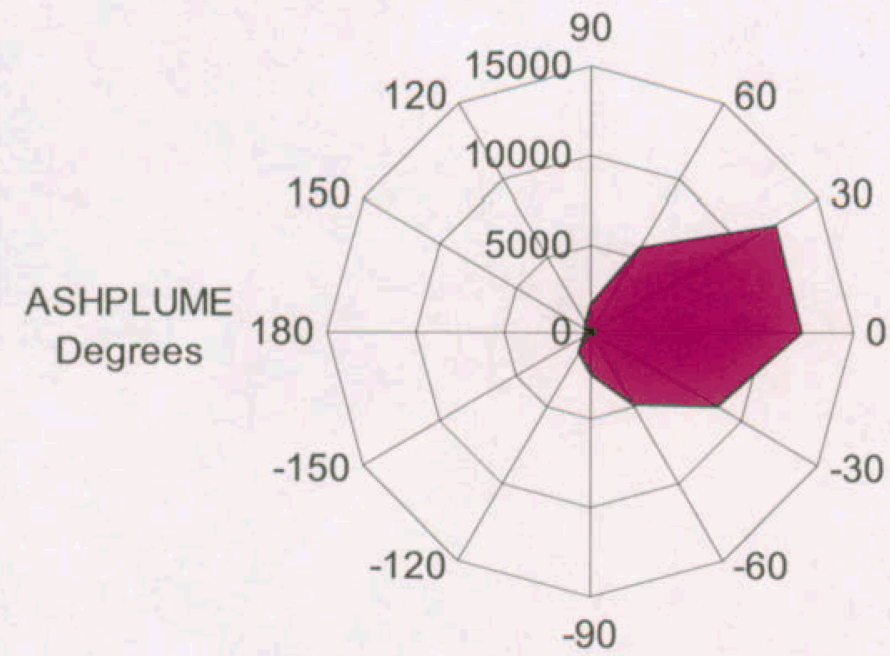

Count

Output DTN: MO0408SPADRWSD.002.

Figure D-12. Wind Rose Frequency of Occurrences at 9 to $10 \mathrm{~km}$ above Yucca Mountain

Table D-33. 10 to $11 \mathrm{~km}$ PDF

\begin{tabular}{|c|c|c|c|}
\hline Compass Degrees & ASHPLUME Degrees & Count & PDF \\
\hline 165 to 195 & 90 & 1334 & 0.0249 \\
\hline 195 to 225 & 60 & 5272 & 0.0983 \\
\hline 225 to 255 & 30 & 12850 & 0.2396 \\
\hline 255 to 285 & 0 & 14714 & 0.2743 \\
\hline 285 to 315 & -30 & 10223 & 0.1906 \\
\hline 315 to 345 & -60 & 4782 & 0.0892 \\
\hline 345 to 15 & -90 & 2119 & 0.0395 \\
\hline 15 to 45 & -120 & 943 & 0.0176 \\
\hline 45 to 75 & -150 & 444 & 0.0083 \\
\hline 75 to 105 & 180 & 238 & 0.0044 \\
\hline 105 to 135 & 150 & 308 & 0.0057 \\
\hline 135 to 165 & 120 & 408 & 0.0076 \\
\hline & Totals & 53635 & 1.0000 \\
\hline
\end{tabular}




\section{Wind Rose Frequency of Occurrences (wind toward designation) at 10 to $11 \mathrm{~km}$ above $\mathrm{YM}$}

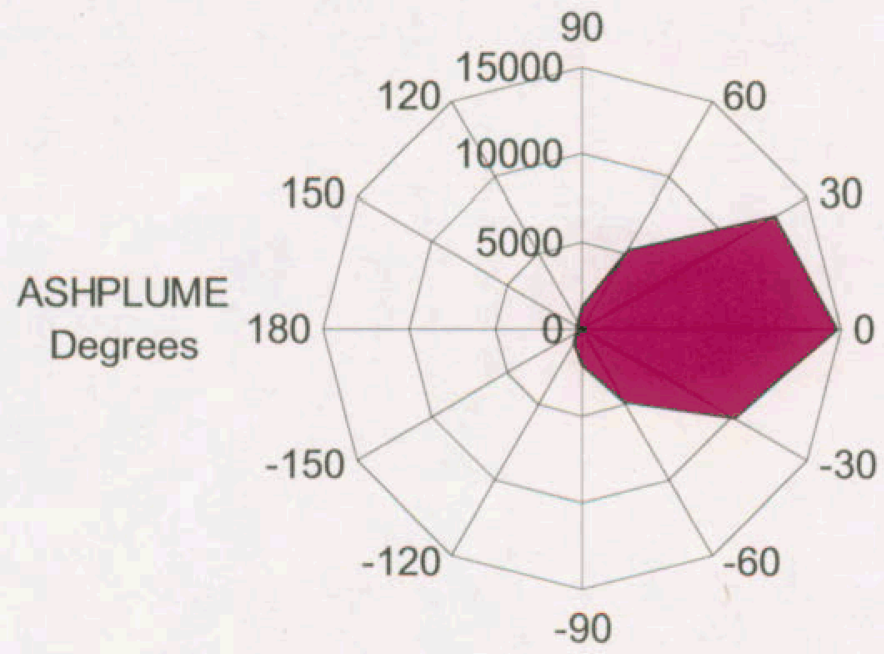

Count

Output DTN: MO0408SPADRWSD.002.

Figure D-13. Wind Rose Frequency of Occurrences at 10 to $11 \mathrm{~km}$ above Yucca Mountain

Table D-34. 11 to $12 \mathrm{~km}$ PDF

\begin{tabular}{|c|c|c|c|}
\hline Compass Degrees & ASHPLUME Degrees & Count & PDF \\
\hline 165 to 195 & 90 & 1113 & 0.0196 \\
\hline 195 to 225 & 60 & 4989 & 0.0876 \\
\hline 225 to 255 & 30 & 13966 & 0.2454 \\
\hline 255 to 285 & 0 & 17353 & 0.3049 \\
\hline 285 to 315 & -30 & 11271 & 0.1980 \\
\hline 315 to 345 & -60 & 4564 & 0.0802 \\
\hline 345 to 15 & -90 & 1701 & 0.0299 \\
\hline 15 to 45 & -120 & 821 & 0.0144 \\
\hline 45 to 75 & -150 & 366 & 0.0064 \\
\hline 75 to 105 & 180 & 192 & 0.0034 \\
\hline 105 to 135 & 150 & 182 & 0.0032 \\
\hline 135 to 165 & 120 & 399 & 0.0070 \\
\hline & Totals & 56917 & 1.0000 \\
\hline
\end{tabular}




\section{Wind Rose Frequency of Occurrences (wind toward designation) at 11 to $12 \mathrm{~km}$ above $\mathrm{YM}$}

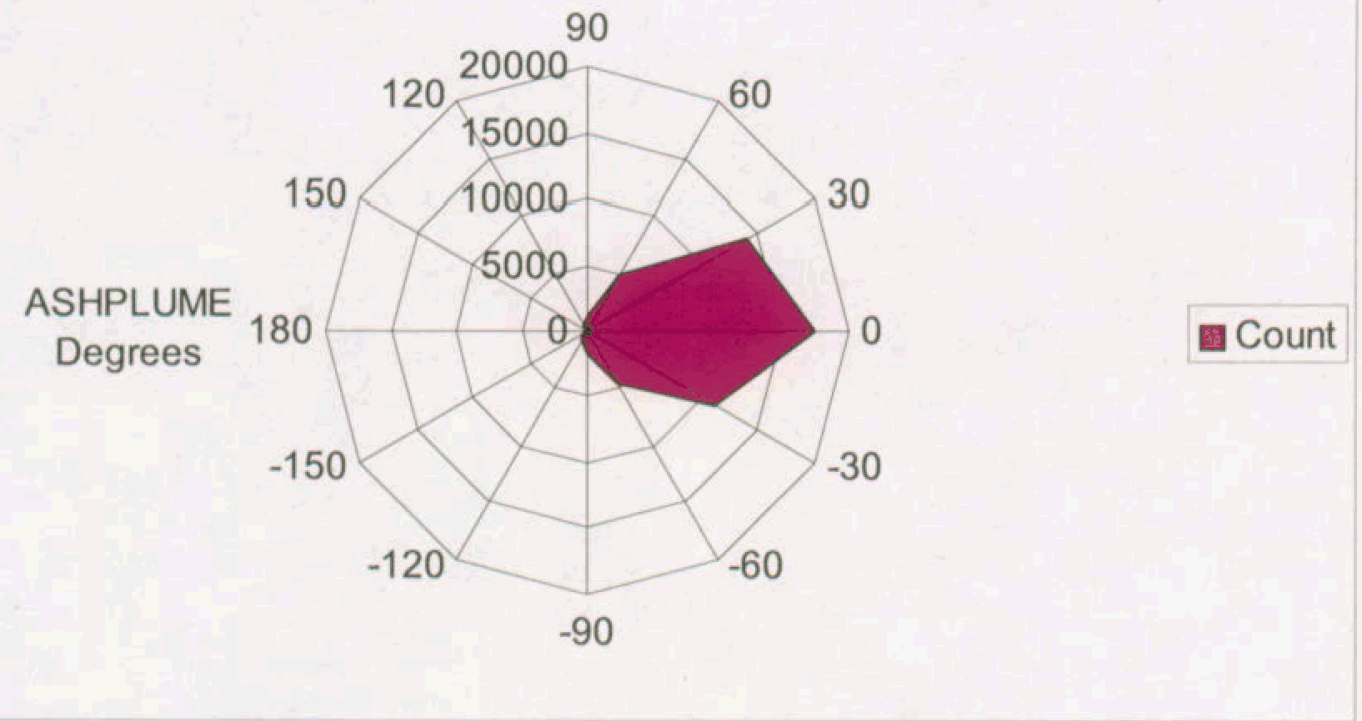

Output DTN: MO0408SPADRWSD.002.

Figure D-14. Wind Rose Frequency of Occurrences at 11 to $12 \mathrm{~km}$ above Yucca Mountain Table D-35. 12 to $13 \mathrm{~km}$ PDF

\begin{tabular}{|c|c|c|c|}
\hline Compass Degrees & ASHPLUME Degrees & Count & PDF \\
\hline 165 to 195 & 90 & 1058 & 0.0205 \\
\hline 195 to 225 & 60 & 4236 & 0.0818 \\
\hline 225 to 255 & 30 & 13274 & 0.2564 \\
\hline 255 to 285 & 0 & 16921 & 0.3268 \\
\hline 285 to 315 & -30 & 10050 & 0.1941 \\
\hline 315 to 345 & -60 & 3528 & 0.0681 \\
\hline 345 to 15 & -90 & 1262 & 0.0244 \\
\hline 15 to 45 & -120 & 472 & 0.0091 \\
\hline 45 to 75 & -150 & 276 & 0.0053 \\
\hline 75 to 105 & 180 & 149 & 0.0029 \\
\hline 105 to 135 & 150 & 191 & 0.0037 \\
\hline 135 to 165 & 120 & 357 & 0.0069 \\
\hline & Totals & 51774 & 1.0000 \\
\hline
\end{tabular}




\section{Wind Rose Frequency of Occurrences (wind toward designation) at 12 to $13 \mathrm{~km}$ above $\mathrm{YM}$}

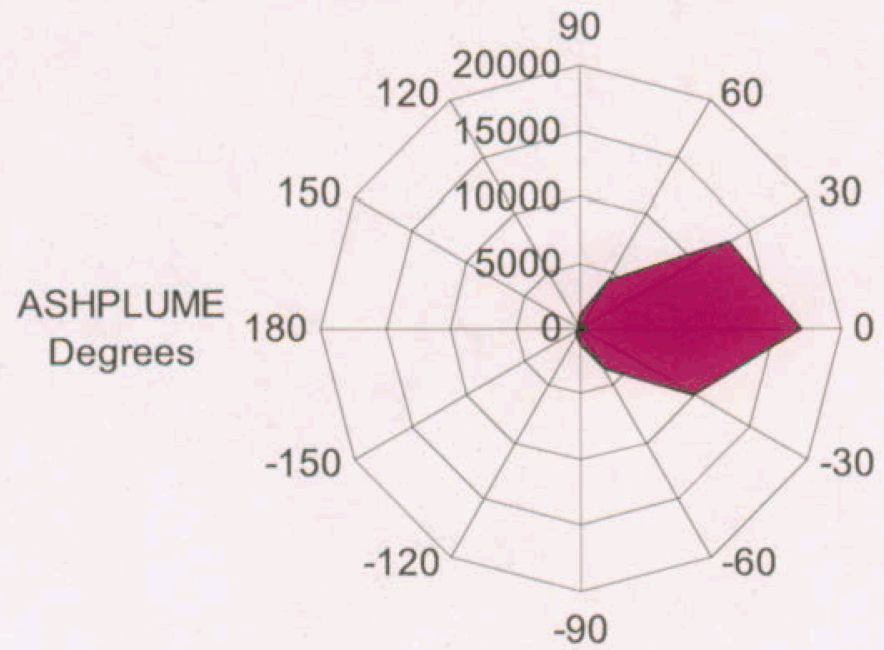

Count

Output DTN: MO0408SPADRWSD.002.

Figure D-15. Wind Rose Frequency of Occurrences at 12 to $13 \mathrm{~km}$ above Yucca Mountain 
APPENDIX E

INPUT VALUES FOR WASTE FORM CONCENTRATION AT THE RMEI LOCATION 


\section{APPENDIX E \\ INPUT VALUES FOR WASTE FORM CONCENTRATION AT THE RMEI LOCATION}

The following tables contain the values of ASHPLUME parameters that were used to calculate the mean concentration at the RMEI used in the ash redistribution model discussed in Section 6.7. Table E-1 contains the fixed (deterministic) values and Table E-2 contains the sampled (stochastic) values for each realization of the GoldSim/ASHPLUME simulation.

Table E-1. Fixed Input Values for ASHPLUME

\begin{tabular}{|c|c|c|}
\hline \multicolumn{2}{|c|}{ Input Parameters } & \multirow[b]{2}{*}{ Value $^{c}$} \\
\hline $\begin{array}{l}\text { Names Used in } \\
\text { ASHPLUME Code }\end{array}$ & $\begin{array}{l}\text { Names } \\
\text { Provided } \\
\text { to TSPA }\end{array}$ & \\
\hline$x \min , x \max (\mathrm{km})$ & $X_{\min }, X_{\max }$ & 0,0 \\
\hline$y \min , y \max (\mathrm{km})$ & $Y_{\min }, Y_{\max }$ & $0,-18$ \\
\hline numptsx & $N_{x}$ & 1 \\
\hline numptsy & $N_{y}$ & 2 \\
\hline ashdenmin & $\Psi_{p}^{\text {low }}$ & 1.04 \\
\hline ashdenmax & $\Psi_{p}^{\text {high }}$ & 2.08 \\
\hline ashrholow & $\rho_{a}^{\text {low }}$ & -3 \\
\hline ashrhohi & $p_{a}^{\text {high }}$ & 0 \\
\hline fshape & $F$ & 0.5 \\
\hline airden & $\Psi_{\mathrm{a}}$ & 0.001117 \\
\hline airvis & $\eta_{\mathrm{a}}$ & 0.0001758 \\
\hline c & $\mathrm{C}$ & 400.0 \\
\hline dmax & $d_{\max }$ & 10 \\
\hline acutoff & Ash Cutoff & $1 e-10$ \\
\hline hmin & $\mathrm{H}_{\min }$ & 0.001 \\
\hline fdmin, fdmean ${ }^{e}$, fdmax & $\begin{array}{l}\rho_{\min }^{f}, \rho_{\text {mode }}^{f}, \\
\rho_{\max }^{f}\end{array}$ & $0.0001,0.0016,0.05$ \\
\hline Rhocut & $p_{c}$ & 0.3 \\
\hline mass of waste $(\mathrm{g})$ & $U$ & $4.01 \mathrm{e} 7^{\mathrm{d}}$ \\
\hline
\end{tabular}

Variable names used in the ASHPLUME code.

' Parameter names provided to TSPA (from Table 8-2) from the mathematical description in section 6.5.1.

c Values used in this modeling exercise, identical to those provided to TSPA in Table 8-2.Table 8-2 includes all but the last value in this table, which is a value developed in TSPA for each realization at run-time.

d Mass of fuel available for entrainment derived from Miscellaneous WasteForm FEPs (CRWMS M\&O 2001 [DIRS 153938], p. 49): 63,000 MTHM emplaced in 7,860 packages $=8.02 \mathrm{E}+06 \mathrm{~g} /$ package; assume 5 waste packages hit (median value from DTN: SN0402T0503303.004 [DIRS 167515].

"Despite the name, "fdmean", this variable contains values of the mode of the waste particle size distribution. 


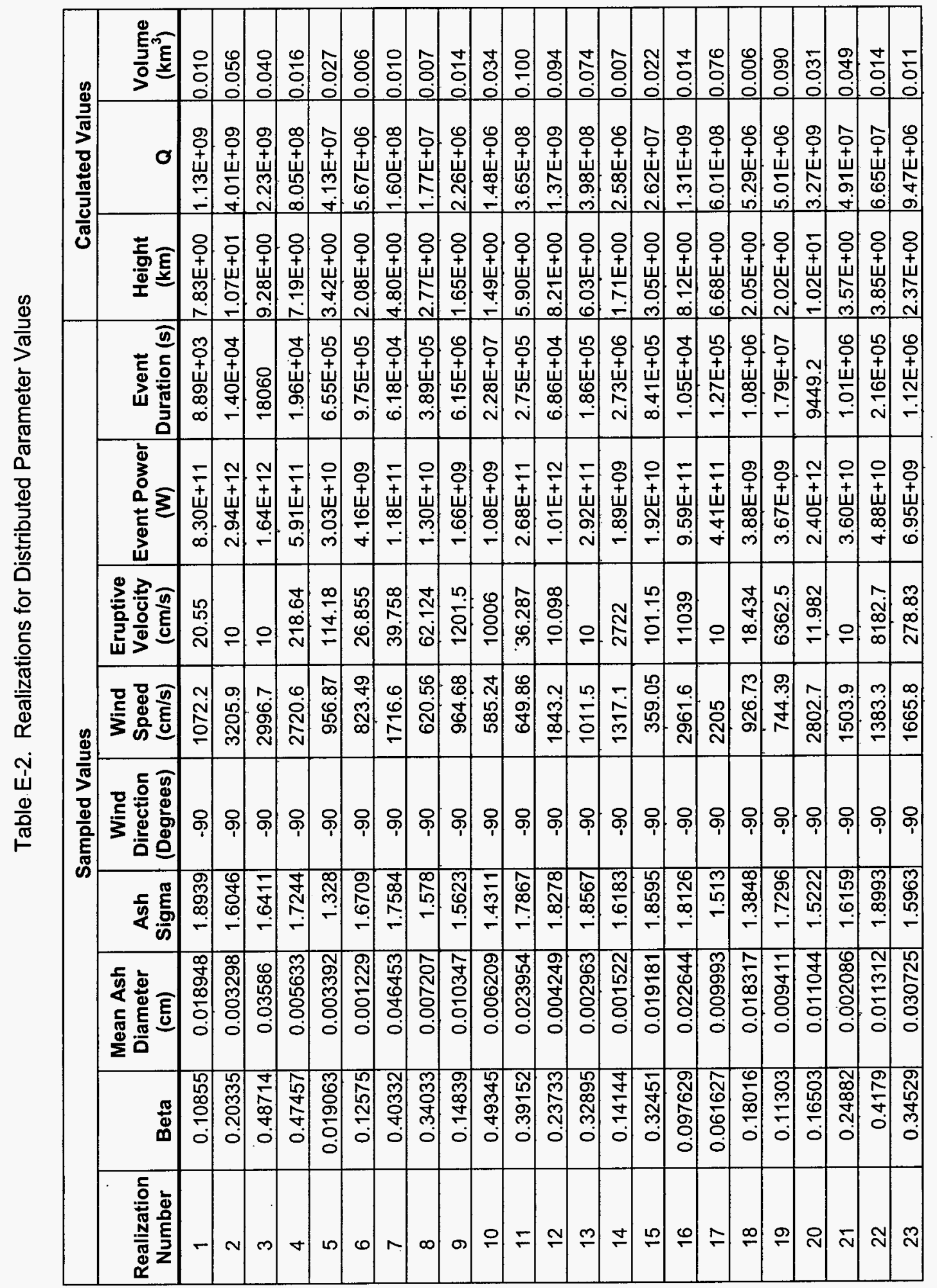




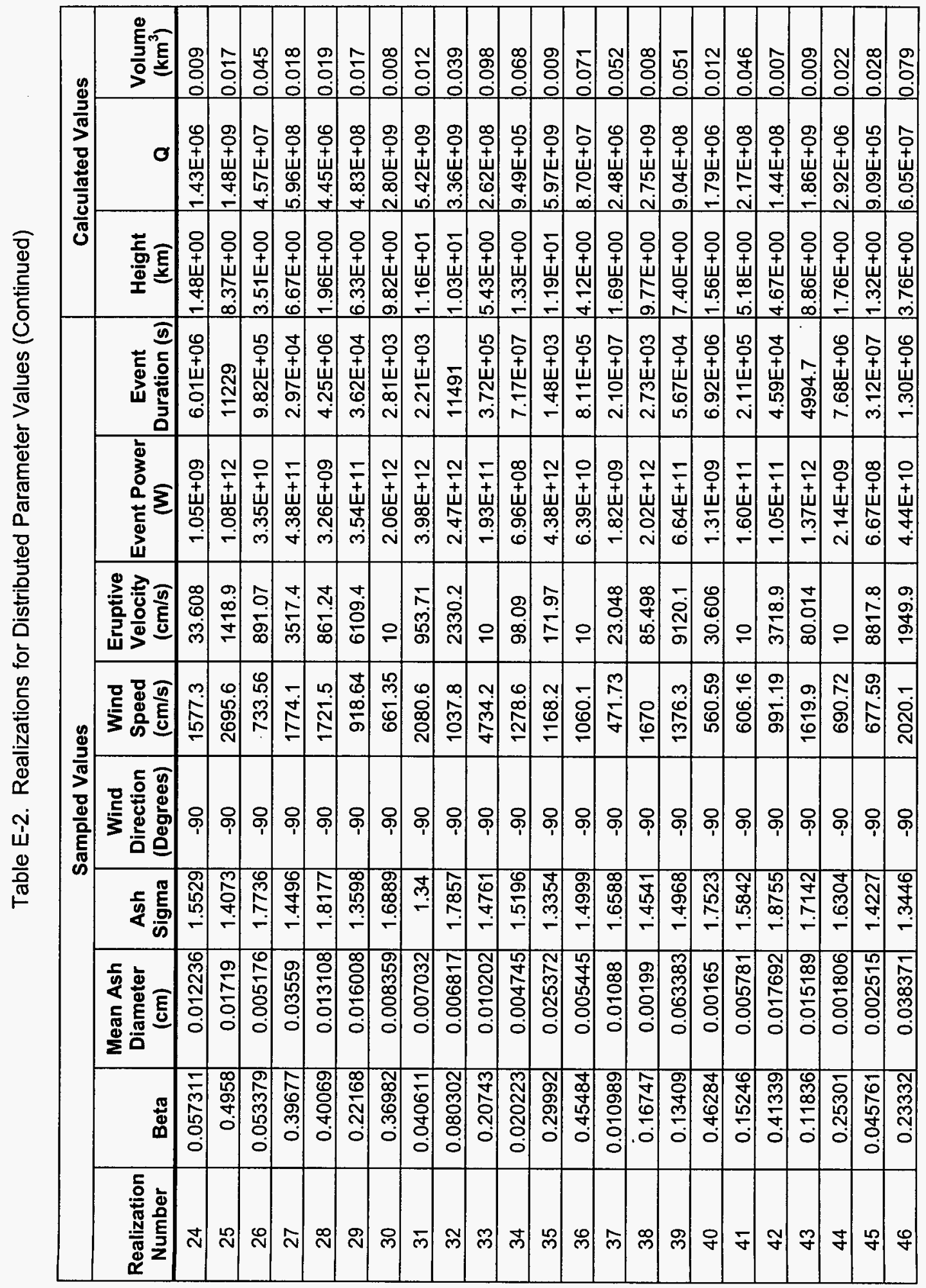




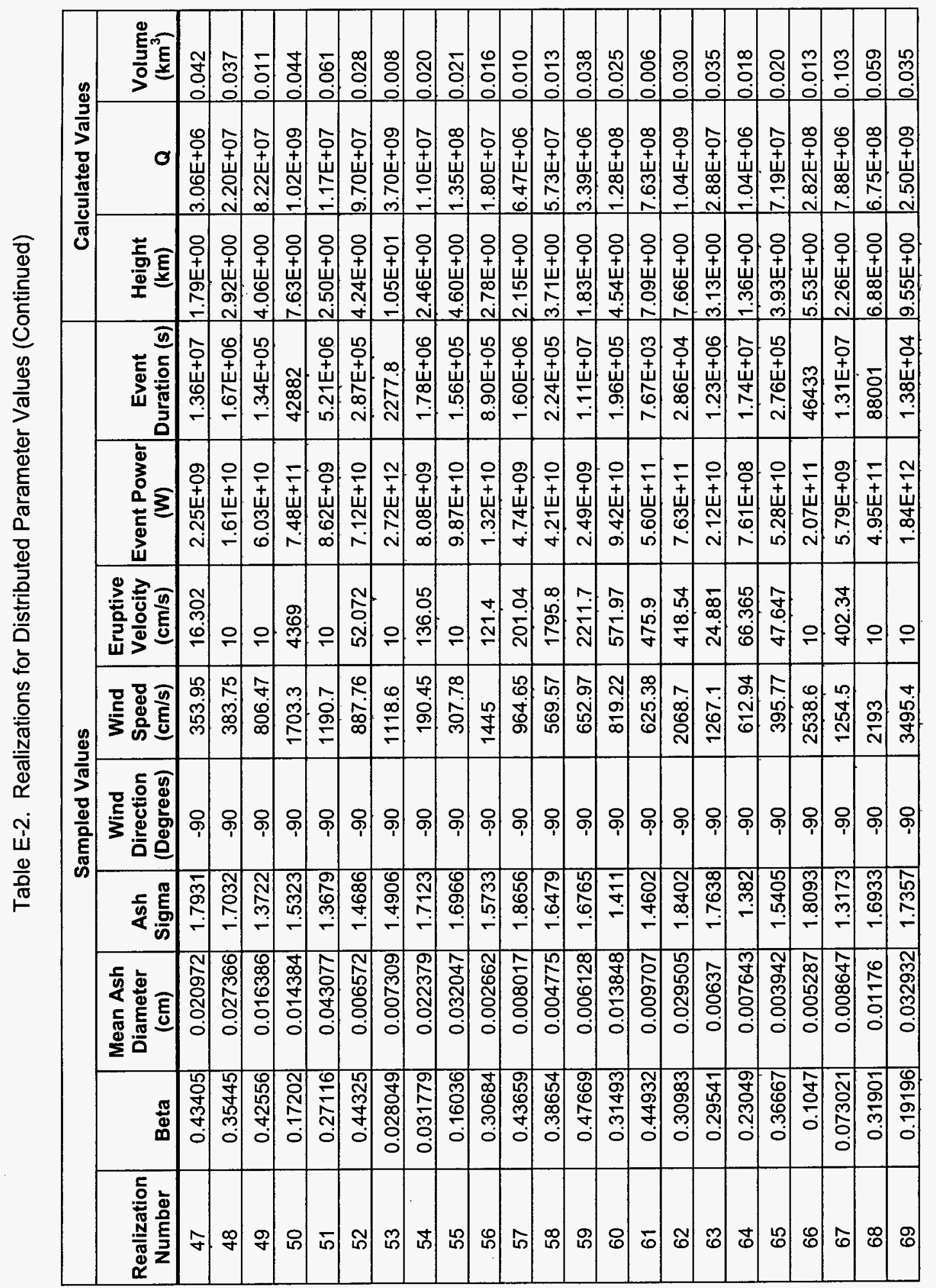




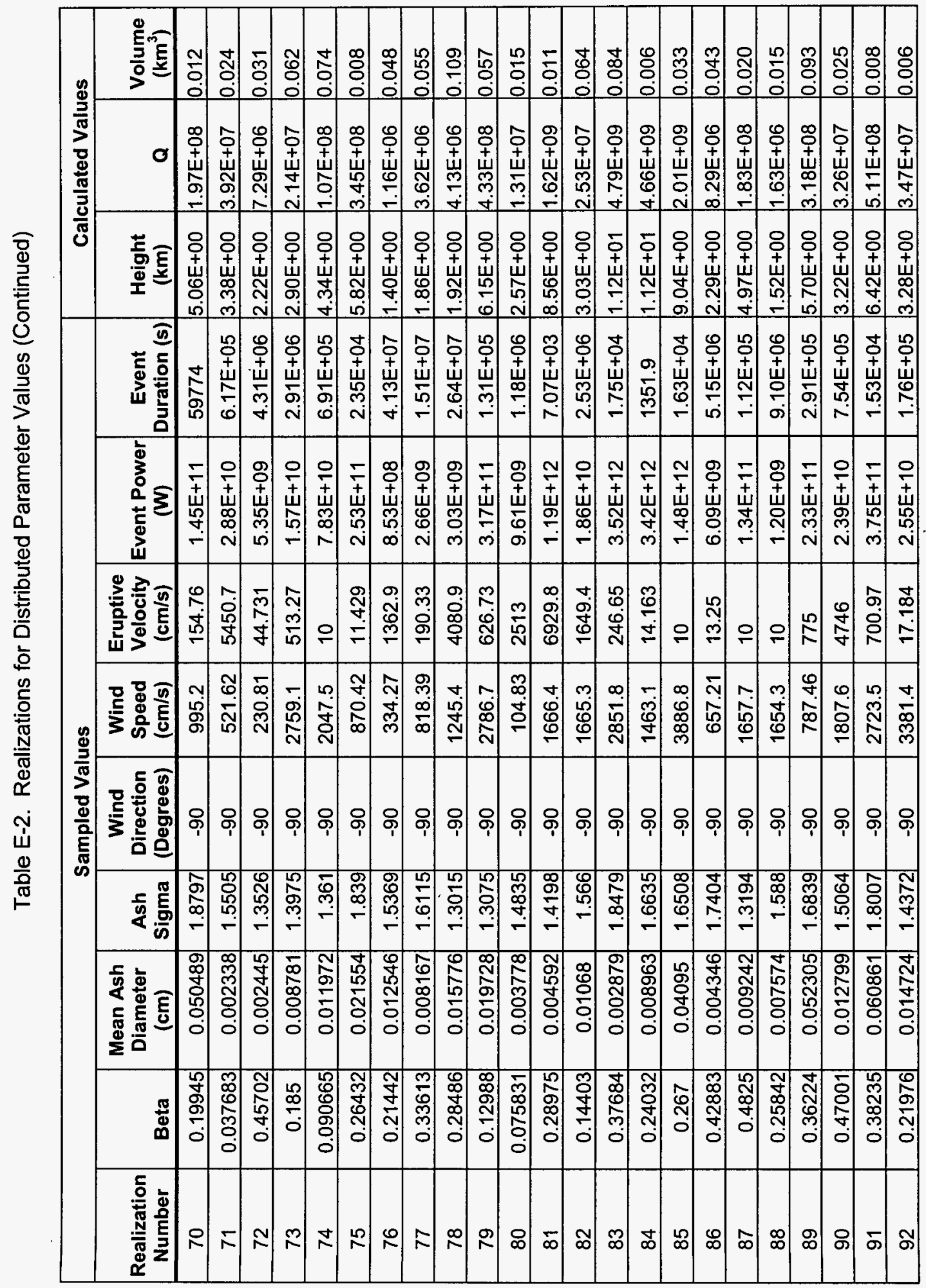




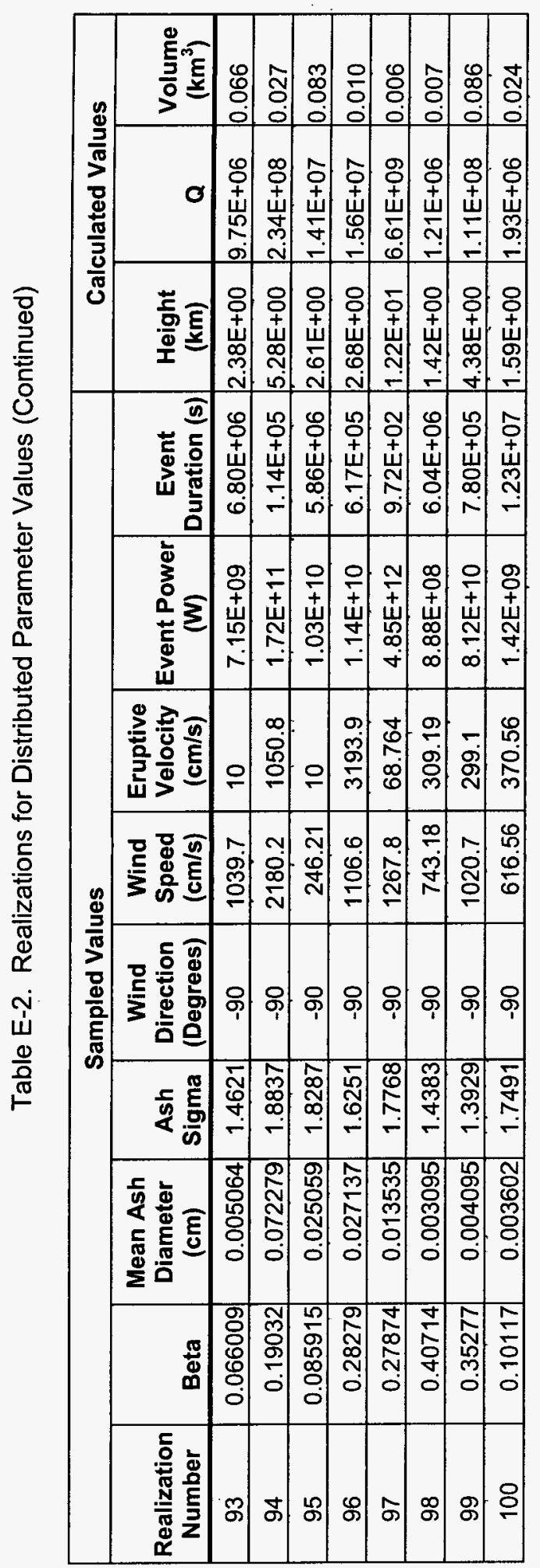




\section{APPENDIX F}

INDEPENDENT TECHNICAL REVIEW OF MDL-MGR-GS 000002 REV 00B CONDUCTED BY DR. FRANK SPERA, UNIVERSITY OF CALIFORNIA, SANTA BARBARA 


\section{APPENDIX F \\ INDEPENDENT TECHNICAL REVIEW OF MDL-MGR-GS 000002 REV 00B}

This document presents a review of Project document MDL-MGR-GS 000002 REV 00B. The structure of this review is based on six review criteria set out in "Exhibit D Amended Scope of Work: Independent Review for Model Validation". The review criteria are listed below as a series of questions. The analysis provided below addresses each of these issues.

1. Is the mathematical model (ASHPLUME) appropriate for representing the conceptual model, i.e., is this model appropriate for its intended use?

2. Are the inputs sufficient.

3. Were all reasonable alternative models identified and adequately treated? If not, what are they, what are their capabilities, and what are their limitations?

4. Are the assumptions appropriate for use in the model.

5. Do the outputs of the model represent the inputs, or are the limitations to the model such that the outputs are not representative of possible future states?

6. Are the outputs of the model a reasonable representation of what may be expected from a volcanic eruption at Yucca Mountain?

No computer codes were run during the course of this review. The review focuses on the conceptual and technical bases of Project work regarding the dispersal of volcanic ash using the computer code ASHPLUME. Results from ASHPLUME are used as input for the TSPA. This review was conducted by F.J. Spera in the period 24 March - April 10, 2003.

Is the mathematical model (ASHPLUME) appropriate for representing the conceptual model, i.e., is this model appropriate for its intended use?

\section{Introduction}

There are a number of ash dispersal mathematical models of differing sophistication. It is beyond the scope of this report to review the history of ash dispersal modeling. ASHPLUME traces its origin back to the model of Suzuki (1983). The Suzuki model applies to a steady eruption (constant eruptive mass flow rate, $\dot{M}$ ) from a circular cross-sectional vent. The fundamental factors governing the fallout distribution of volcanic tephra include the height of the steady state volcanic column $(\mathrm{H})$, which is a function of the eruptive mass flow rate, $\dot{M}$, the total eruptive volume (V) and the spatial and temporal structure of the winds aloft during the eruptive event of duration $t_{d}$. The relationship between the total eruptive volume $(V)$ and the volumetric eruptive rate $(\dot{V})$ for a steady eruption is simply $V=\dot{V} t_{d}$. Because the density of ash $\left(\rho_{\mathrm{e}}\right.$ ) is essentially constant, there is a simple relationship between the eruptive mass flow rate, $\dot{M}$ and the volumetric eruption rate $\dot{V}$. The relationship is $\dot{V}=\dot{M} / \rho_{e}$ where $\rho_{\mathrm{e}}$ is the density of tephra particles at the vent. The size distribution of tephra also plays a role in ash dispersal. The 
distribution of ash particle size is relatively well-known based on granulometric studies of tephra from Strombolian eruptions and varies between reasonably well-defined bounds.

\section{Plume Height (H), Mass Flow ( $\dot{M})$, and Eruptive Volume(V)}

Volcanic plume height $(\mathrm{H})$ scales with the eruptive mass flow rate, $\dot{M}$ according to:

$$
H \propto \dot{M}^{1 / 4}
$$

An example of a quantitative parameterization is the expression:

$$
H=0.24 \dot{M}^{1 / 4}
$$

with $\mathrm{H}$ measured in kilometers and the eruptive mass flow measured in $\mathrm{kg} / \mathrm{s}$. The scaling relation (1) comes from momentum-buoyancy plume theory and rests on a solid fluid dynamical footing. The determination of the constant in eq (2) comes from an empirical calibration using data from a small number $(\sim 10-20)$ of volcanic eruptions for which column height is independently known. Its value may be uncertain by $\pm 20 \%$ due to unsteadiness of column height and the intrinsic difficulty of measuring column height during an eruption. Note that (2) is strictly valid for steady eruptions where $\dot{M}$ (or $\dot{V}$ ) is constant. In fact, no volcanic eruption is truly steady. Variations in mass flow during eruptions give rise to time-varying column heights. For example, during the 1980 eruption at Mount Saint Helens, the mass flow (and hence column height) varied significantly in non-monotonic fashion during the $\sim 10$ hour Plinian phase of the eruption. Although the expected eruptive style at Yucca Mountain is Strombolian and not Plinian, eruptive unsteadiness is typical of all styles of eruption, even eruptive events dominated by lava flows. One way of incorporating unsteadiness into ash dispersal is to model a single eruption as a sequence of smaller eruptive phases each with its own characteristic parameters. In effect one could use the ASHPLUME steady state model serially to evaluate the effects of eruption unsteadiness at least to a first approximation. Whether or not this is important depends on the timescale associated with wind and magma discharge unsteadiness. For example, if the timescale for changes in wind direction are comparable to or shorter than eruptive duration $\left(t_{d}\right)$ then unsteady winds could have a marked effect on the distribution of ash at the surface.

In the model used by the Project, critical input comes from two relations expressed as eqs (7a) and (7b) on p.39 of MDL-MGR-GS 000002 REV 00B. The first is an assumed relationship between the eruptive volume of ash (V) and the duration of the eruption $\left(t_{d}\right)$. This essentially defines the eruptive volume flow rate (and the eruptive mass flow rate) as a function of total eruptive volume (V). That is, eq (7a) may be recast as:

$$
\mathrm{V} / \mathrm{t}_{\mathrm{d}}=\mathrm{e}^{-\mathrm{a}} \mathrm{V}^{1-\mathrm{b}}
$$

with $a=15.29$ and $b=0.527$ and the units of $V$ in $\mathrm{km}^{3}$ and $t_{d}$ in seconds. Because

$$
\dot{V}=\dot{M} / \rho_{e}
$$


it follows from the Project model that the eruptive mass flow rate is a function of eruptive volume:

$$
\dot{M}=k \rho_{e} V^{1-b}
$$

with $k=229, V$ in $\mathrm{km}^{3}, \rho_{e}$ in $\mathrm{kg} / \mathrm{m}^{3}$ and $\dot{M}$ in $\mathrm{kg} / \mathrm{s}$. On p. 44 of MDL-MGR-GS 000002 REV 00B the bounds on $\mathrm{V}$ are set between $0.004 \mathrm{~km}^{3}$ and $0.08 \mathrm{~km}^{3}$. This gives limits for $\dot{M}$ between $2.5 \times 10^{4} \mathrm{~kg} / \mathrm{s}$ and $1.1 \times 10^{5} \mathrm{~kg} / \mathrm{s}$ assuming an ash density of $1500 \mathrm{~kg} / \mathrm{m}^{3}$. These values define bounds that vary by $\sim$ one order of magnitude which seems somewhat on the small side of its potential range. Eruptive mass flow rates in the range $10^{4} \mathrm{~kg} / \mathrm{s}$ to $10^{6} \mathrm{~kg} / \mathrm{s}$ have been cited for Strombolian eruptions by some volcanologists (e.g., see Mastin, 2002; Mastin and Ghiorso, 2000; Mastin and Ghiorso, 2001). On what grounds can eruptions with mass flows $\sim 10^{6} \mathrm{~kg} / \mathrm{s}$ be excluded?

According to eq (7b) on p. 39 of MDL-MGR-GS $000002 \mathrm{REV}$, column heights corresponding to volumes of $0.004 \mathrm{~km}^{3}$ and $0.08 \mathrm{~km}^{3}$ are $2.2 \mathrm{~km}$ and $3.8 \mathrm{~km}$, respectively. Again this is a rather small range and at the low to intermediate end for Strombolian eruptions. According to eq (2), the aforementioned limits $\left(2.5 \times 10^{4} \mathrm{~kg} / \mathrm{s}\right.$ and $\left.1.1 \times 10^{5} \mathrm{~kg} / \mathrm{s}\right)$ for $\dot{M}$ correspond to column heights between $3 \mathrm{~km}$ and $4.3 \mathrm{~km}$ in good agreement with Project calculations.

The main point is that eruptive mass flow rates up to $10^{6} \mathrm{~kg} / \mathrm{s}$ should not be excluded. At $\dot{M}=10^{6} \mathrm{~kg} / \mathrm{s}$, a column height $\mathrm{H}=7.6 \mathrm{~km}$ is predicted from eq (2). Because the a priori assumption in Project ash dispersal calculations is the relationship between eruptive duration and eruptive volume, the range of corresponding eruptive mass flow rates is uniquely defined. It is the opinion of this reviewer that starting off by bounding eruptive mass flow rates $(\dot{M})$ rather than volume (V) might be advantageous partly because it is the correlation between $\dot{M}$ and $\mathrm{H}$ that has some fluid dynamical basis (i.e., unlike the $\mathrm{V}-\mathrm{t}_{\mathrm{d}}$ correlation which is entirely empirical) and partly because the limits on $\dot{M}$ between $\sim 10^{4} \mathrm{~kg} /$ to $10^{6} \mathrm{~kg} / \mathrm{s}$ encompass the range for normal Strombolian eruptions. Violent Strombolian eruption can attain even greater eruptive mass flow rates, up to $10^{7} \mathrm{~kg} / \mathrm{s}$. According to eq (2), a violent Strombolian eruption with $\dot{M}=10^{7} \mathrm{~kg} / \mathrm{s}$ would generate a column height $\mathrm{H}=13 \mathrm{~km}$. It is not argued here that such a value is 'typical.' However, the range 2 to $4 \mathrm{~km}$ considered by the Project seems unduly restrictive. Should the Project wish to consider additional higher mass flow eruptions, it would not be difficult to perform the simulations using Project models.

\section{Structure and Variability of Winds Aloft}

In addition to plume column height, the structure of prevailing winds during an eruption is critical to determination of ash dispersal. In the most detailed model, one can imagine wind velocity (direction and magnitude) prescribed on a three-dimensional grid of specified spatial resolution. Because upper atmosphere winds are often different from low level winds, it is important to get a complete profile of wind versus height from the vent up to the top of the eruption column. The wind velocity (speed and direction) can also vary temporally. Indeed, the eruption used by the Project (see Section 7.4 NATURAL ANALOG STUDY on p. 56 in MDL-MGR-GS 000002 REV) to "ground test" ASHPLUME shows how variations in winds aloft during an eruption influence ash distribution. In the simplest ash dispersal model, the wind 
speed and direction is spatially constant (speed and direction) with no temporal variability during the eruptive interval $\left(t_{d}\right)$. ASHPLUME implements a simple model of constant wind speed and direction and uses the wind vector from a height equal to "upper elevations to which the ash plume reaches." Presumably this corresponds to the height of the eruption column $(\mathrm{H})$ derived from the relationship between eruptive volume (V) and column height $(\mathrm{H})$.

\section{Summary}

ASHPLUME is applicable to steady volcanic eruptions (constant mass flow, $\dot{M}$ ) characterized by eruption columns of fixed height $(\mathrm{H})$. Although no volcanic eruption is truly steady, the state-of-the-art in volcanic plume modeling is not sufficiently advanced to consider eruptions with unsteady discharge. ASHPLUME can be used serially to approximately model discharge unsteadiness and/or variable winds.

Two critical factors affecting ash dispersal are the column height and structure of winds aloft. ASHPLUME uses an empirically calibrated correlation between eruptive volume (V) and column height, $H$. In fluid dynamical terms, the height of an eruption column $(H)$ scales with the mass flow, $\dot{M}$ according to $\mathrm{H} \sim \dot{M}^{1 / 4}$. The eruptive volume (V) as given in eq (3) correlates to $\mathrm{H}$ provided the plume-generating eruption is steady (i.e., $\dot{M}$ is constant) and the density of ash is constant. Regarding the issue of the winds aloft, any single ASHPLUME realization of ash dispersal assumes a constant wind speed and direction. Clearly this is a gross approximation; the vertical structure of the winds will generally depend on height above the vent. On the other hand, predicting the structure of the winds aloft at some time in the future 10,000 years is not easily accomplished. The Monte Carlo method of drawing a constant wind velocity from a meteorologically-based distribution and performing many realizations and then sampled for TSPA purposes is sound.

The range of eruptive volumes leads to a range of eruptive mass flows that are in the low to intermediate range for Strombolian eruptions. Eruptive mass flow rates of $10^{6} \mathrm{~kg} / \mathrm{s}$ cannot be precluded and should be computed.

\section{Are the inputs sufficient?}

discussion is keyed to numbered sections in MDL-MGR-GS 000002 REV 00B

\subsubsection{DATA}

The variation of volcanic ash size distributions for Strombolian eruptions based on granulometric studies of G.P.L. Walker and co-workers beginning in the early 1970 's and continuing to the present today is well known. Although the precise distribution of particle size is unique to a given eruption, the variations are not large. Similarly, waste particle size distributions are adequately known for the purposes of the TSPA given other limitations of the ASHPLUME model. 


\subsubsection{PARAMETERS AND PARAMETER UNCERTAINTY}

The method of developing probability distributions for compatibility with MC methods used in the TSPA is a sound practice.

\subsubsection{OTHER MODEL INPUTS}

Items in Table 4, p. 20 of MDL-MGR-GS 000002 REV 00B are needed to perform ASHPLUME simulations and are commented on here.

The mathematical model of Suzuki is the starting point. The Suzuki model was used by Jarzemba (1997) with an important correction (see eq (2) in Jarzemba) in order to achieve mass conservation, a constraint that must be incorporated in any ash dispersal model. However, the paper by Jarzemba has at least two errors. The first is that eq (1) in Jarzemba (1997) is missing a negative sign in front of the numerator in the exponential term. The second is that there is a missing factor of $g$ in the third term in the denominator of eq (3) in Jarzemba. I note that these errors have been corrected in the Project work; that is, eq (2) and eq (4) on p. 37 and p.38 in MDL-MGR-GS 000002 REV 00B are correct unlike the analogous equations in Jarzemba (1997).

The physical properties used for air (viscosity and density) from Lide (1994) are adequate for the purposes of the TSPA.

\section{Are the Assumptions Justified?}

discussion is keyed to numbered sections in MDL-MGR-GS 000002 REV 00B

\section{$\underline{5.1 .1}$}

The two-dimensional model may be sufficient for the purposes of the TSPA. It is hard to determine the level of confidence one should assign to ASHPLUME results without making a direct comparison between ASHPLUME and a 3-dimensional code such as the one by $\mathrm{G}$. Macedonio and co-workers (Armienti et al, 1988; Macedonia et al, 1988, 1990). Approximations are made in contracting a 3-D model to a 2-D model. The neglect of vertical diffusion is probably justified because vertical advection is many orders-of-magnitude larger than vertical diffusion. In the 2-D models one can increase the $2-\mathrm{D}$ eddy diffusivity to roughly account for 3-D effects. The only way to evaluate the quality of the 2-D approximations is to carry out the full 3-D calculation and compare results. This reviewer has not made this comparison. Presumably, if the Project felt this was important, they could contact the Italian volcanologists mentioned and explore this possibility. Alternatively, the Project can generate 2-D ASHPLUME results and compare these to published 3-D forward models relevant to eruptions at Mount Vesuvius, Italy. My own guess is that for the purposes of the TSPA the 2-D model would suffice. Even with a sophisticated 3-D model, the lack of knowledge of the winds aloft at some time in the future 10000 years may translate into a larger uncertainty in ash thickness at a specific location than that associated with a 2-D rather than $3-\mathrm{D}$ model. But this is speculation on my part. 


\section{$\underline{5.1 .2}$}

This is a very conservative assumption. Inspection of volcanological data suggests the ratio of lava to proximate tephra (cone-building deposits) to distal ash (the deposition that ASHPLUME and like models compute) is of order 1:1:<<1. That is, for the sort of eruption 'expected' at Yucca Mountain, the distal ash will make up only a small portion of the total. Hence the assumption made by the Project, that the entire eruptive volume is processed through a Strombolian column, is conservative. For Lathrop Wells, if the entire eruptive volume of $0.06 \mathrm{~km}^{3}$ is identified with the ash volume (it clearly is not!), then according to expressions used by the Project, the eruptive duration was $\sim 11.5$ days, the eruptive mass flow was $6 \times 10^{4} \mathrm{~kg} / \mathrm{s}$ and the column height was $\mathrm{H} \sim 3.6 \mathrm{~km}$.

\section{$\underline{5.1 .3}$}

Small ash particles cannot host large fuel waste particles. This seems to be a very reasonable assumption in no further need of documentation or explanation.

\section{$\underline{5.2 .1}$}

Even if one knew the future climate, predicting winds aloft and their variation in time and space is most difficult. The present winds aloft structure is as good as any other and is consistent with the level of approximation in ASHPLUME.

\section{$\underline{5.2 .2}$}

Waste is assumed to be unaltered spent commercial fuel. This is an adequate approximation given other uncertainties.

\section{$\underline{5.2 .3}$}

The Project adopts a relationship from Wilson and Head (1981) between vent exit radius $\left(\mathrm{r}_{\mathrm{e}}\right)$ and eruptive velocity $\left(\mathrm{u}_{\mathrm{e}}\right)$, as input for ASHPLUME. Neither the derivation of this relationship nor a discussion of the assumptions upon which it is based is given in MDL-MGR-GS 000002 REV. It is noted here that this "correlation" is based on incompressible flow and assumes specific pressure gradients (based on a density differences between magma and host crust) and magma viscosities. The conditions assumed to generate the values in Table 3 in Wilson and Head (1981) are not generally applicable to the highly compressible high-speed eruption of volatile-charged magma in the inertial regime. Jarzemba (1997) also cites a relationship from Wilson and Head (1981) that provides a correlation amongst vent exit radius $\left(\mathrm{r}_{\mathrm{e}}\right)$, mean density of ash particles $\left(\rho_{\mathrm{p}}\right)$ and eruption mass flow rate $(\dot{M})$ to determine the eruption velocity at the vent exit $\left(u_{e}\right)$. It is important to insure that the Wilson and Head (WH) scaling relation does not implicitly or explicitly involve assumptions inconsistent with other assumed relations (e.g., eq (7a) on p.39 of MDL-MGR-GS $000002 \mathrm{REV}$ ). In particular, the last few sentences of Section 5.2 .3 on p. 26 of MDL-MGR-GS $000002 \mathrm{REV}$ are puzzling. Results plotted on fig. $6 a$ in WH (1981) pertain to specific exsolved magma water contents which are less than those expected for basaltic volcanism at Yucca Mountain (see Final Report of the Igneous Consequences Peer Review Panel, February, 2003). 
From review of the documentation, it appears that the Project develops the input needed for ASHPLUME according to the following scheme. First, a value for the eruptive ash volume (V) is picked from a uniform distribution. Then using eq (7a) on p.39 of MDL-MGR-GS 000002 $R E V$, the eruptive duration, $t_{d}$ is calculated (project literature calls this $T_{d}$; to avoid confusion with the thermodynamic temperature used in some volcanic plume models, although not in ASHPLUME, use is made of the symbol $t_{d}$ here). Once $t_{d}$ and $V$ are known, then eq (7b) on p.39 of MDL-MGR-GS $000002 \mathrm{REV}$ is used to compute the column height, $\mathrm{H}$. Once $\mathrm{V}$ and $\mathrm{t}_{\mathrm{d}}$ are known, $\dot{M}$ and $\mathrm{M}$ (eruptive mass) are easily computed given a density (based on particle size) of ash particles using $\dot{V}=\dot{M} / \rho_{e}$ and $\mathrm{V}=\mathrm{M} / \rho_{\mathrm{e}}$, respectively. (Project uses symbol $\psi_{p}$ for particle density). Then the Project uses the Wilson and Head (WH) scaling relation (discussed above) amongst $\mathrm{r}_{\mathrm{e}}, \dot{M}$ and $\rho_{\mathrm{e}}$ to obtain the vent exit radius, $\mathrm{r}_{\mathrm{e}}$ and finally, from the continuity expression $\dot{M}=\rho_{e} \pi r_{e}^{2} u_{e}$, the eruption velocity at vent exit (labeled $\mathrm{W}_{0}$ by Project and $\mathrm{u}_{\mathrm{e}}$ in this review).

It seems, unless this reviewer is mistaken, that this procedure is redundant. That is, once $\mathrm{V}$ and hence $t_{d}$ are determined, then indeed $\mathrm{H}$ is easily determined. However, implicit in the correlation between $\mathrm{V}$ and $\mathrm{t}_{\mathrm{d}}$ is the value of $\dot{M}$ and hence $\mathrm{M}$, for an assumed ash density. It seems the vent exit velocity is uniquely determined once a value for $r_{e}$ is chosen using the expression $\dot{M}=\rho_{e} \pi r_{e}^{2} u_{e}$. In other words, why does the Project resort to the use of the WH correlation, presumably identical to or a closely related to the one given as eq (14) in Jarzemba (1997)?

First of all, it is not clear that eqs (7a) and (7b) on p.39 of MDL-MGR-GS 000002 REV are consistent with the WH relationship used by the Project. The density of the magmatic mixture depends on the pressure at the vent exit, which in turn depends on the volatile content. Do these considerations affect the $r_{e}-u_{e}$ scaling relationship assumed to obtain input parameters for ASHPLUME? Secondly, and most importantly, it is not clear why the WH scaling correlation is needed at all. Straightforward manipulation of eq (7a) on p.39 of MDL-MGR-GS 000002 REV) gives:

$$
\frac{V}{t_{d}}=e^{-a} V^{1-b}
$$

where $\mathrm{a}$ and $\mathrm{b}$ are constants. Hence eq (6) combined with continuity ( $\left.\dot{M}=\rho_{e} \pi r_{e}^{2} u_{e}\right)$ implies that

$$
\pi r_{e}^{2} u_{e}=e^{-a} V^{1-b}
$$

From eq (7) it appears that given $V$, a unique relationship between $r_{e}$ and $u_{e}$ exists. A selected value for $r_{e}$ completely determines $u_{e}$ without need for an additional WH correlation.

Were all reasonable alternative models identified and adequately treated? If not, what are they, what are their capabilities, and what are their limitations?

The short answer to this question is "No." The Project uses the ASHPLUME model. There has been no systematic comparison of results generated by ASHPLUME with other models. On p. 34 in MDL-MGR-GS 000002 REV 00B there is discussion of other models although no 
detailed comparisons have been made. The models briefly mentioned in MDL-MGR-GS 000002 REV 00B (Gaussian-Plume, PUFF and Gas-Thrust code) suffer limitations and cannot generate the quantitative output needed for the TSPA without modification. A model not mentioned in MDL-MGR-GS 000002 REV 00B called VAFTAD (Hefter and Stunder, 1993) has been found to accurately model the dispersion of volcanic ash in the atmosphere. That is, to predict the motion of airborne ash clouds. Unfortunately, VAFTAD like PUFF offers no prediction of ground-level ash accumulation and therefore unsuitable in its present form for TSPA purposes.

Fortunately, other volcanological ash dispersal models that provide quantitative results for ground-level ash accumulation exist and may be utilized by the Project to build confidence and discover the limitations of ASHPLUME. Perhaps the most cogent model is one developed by Hurst and co-workers (Hurst, 1994) based on the earlier model of G. Macedonio and co-workers (Armienti et al, 1988; Macedonio et al, 1988, 1990). The code developed by the Italian group implements a three-dimensional particle diffusion model with allowance for wind direction and speed as a function of height. The original code was somewhat unwieldy requiring large 3-D arrays and long run times. Motivated by the need for an easy-to-implement Civil Defense tool, Hurst and co-workers developed a code called ASHFALL. This is a 2-dimensional code that accounts for variations in wind speed and direction as a function of altitude and time. Vertical diffusion of ash is neglected (as in ASHPLUME). The output of ASHFALL is the ash thickness at points on a rectangular grid centered on the vent. Details of the model can be found in the report and users guide entitled "ASHFALL- A Computer Program for estimating Volcanic Ash Fallout" by T. Hurst (1994). The characteristics and performance of ASHFALL are documented in the studies of Hurst and Turner (1999). A comparison of ASHFALL predictions with observed ash distributions of three ash-producing events from Ruapehu volcano in the North Island of New Zealand shows that actual ash thickness at any location are generally within a factor of two of that forecast by ASHFALL. The accuracy of the forecast wind direction is the main factor affecting quality of ASHFALL predicted tephra isopachs according to the study by Hurst and Turner (1999).

Finally, mention should be made of the Hybrid Particle and Concentration Transport Model (HYPACT) of Walko and Tremback (1985). HYPACT simulates the motion of atmospheric tracers under the influence of winds and turbulence. Its Lagrangian formulation enables representation of sources of any size and the maintenance of concentrated, narrow plumes until atmospheric dispersion dictates they should broaden. The Lagrangian particle plume can then be converted into a concentration field and advected using a Eulerian formulation. The Lagrangian particles are moved through space and time based on interpolated wind velocities plus a superimposed random motion scaled to the intensity of local turbulence. A spectrum of gravitational settling velocities related to particle size can be specified. The velocity field (all three components), the potential temperature and information regarding the scale of turbulence are necessary input for implementation of HYPACT. HYPACT is the most sophisticated model for following the trajectory of airborne particles known to this reviewer.

In the study of Turner and Hurst (2001) a comparison is made between HYPACT and ASHFALL using the Regional Atmospheric Modeling System (RAMS) for the winds aloft structure as input for both models (see Pielke et al, 1992 for details pertaining to RAMS). Comparison of the performance of RAMS/HYPACT with ASHFALL shows that RAMS/HYPACT provides more accurate spatial and temporal forecasts of ash transport. 
Although the HYPACT model is superior in reproducing the temporal and spatial movement of the ash cloud, it is not suitable in its current form for quantifying the depth of ash. The code would need to be modified in order to determine the distribution of isopachs.

In summary, a detailed comparison should be made between ASHFALL and ASHPLUME. This can be done in two ways. First, one can select representative eruption and winds aloft parameters and compare predictions made by ASHPLUME and ASHFALL. Secondly, one can apply ASHPLUME to the 1995 and 1996 Mount Ruapehu, New Zealand eruptions. These have already been modeled using ASHFALL and results are readily available in the literature. Based on the results of such comparisons, one will be able to develop confidence in the results from ASHPLUME. Because the ASHFALL code is not freely available, Project geoscientists may want to work with Dr. Tony Hurst (T.Hurst@gns.cri.nz). Hurst is the developer of ASHFALL and may be available to run some models in coordination with Project geologists. ASHFALL unlike ASHPLUME can handle a time-varying vertical profile of wind speed and direction perhaps more appropriate to conditions during an eruption. It can also be used in the simpler ASHPLUME-like mode with constant wind speed and direction.

\section{Do the outputs of the model represent the inputs, or are the limitations to the model such that the outputs are not representative of possible future states?}

In general, the output of an ash dispersal model provides the type of information needed for the TSPA. The real issue is the quality of the forward model. Ash dispersal in all its complexity is a problem that has not been fully solved. However, for the purposes of the TSPA and given the state-of-the-art, a two-dimensional model such as ASHPLUME may suffice. However, further work should be accomplished to increase the confidence in ASHPLUME results. One way of doing this is to make a detailed comparison between ASHFALL and ASHPLUME. Another is to apply ASHPLUME to the 1995 and 1996 eruptions at Mount Ruapehu. Typically, these eruptions exhibit column heights $\mathrm{H} \sim 10 \mathrm{~km}$ consistent with eruptive mass flow $\dot{M} \sim 3 \times 10^{6} \mathrm{~kg} / \mathrm{s}$, eruptive volume $\mathrm{V} \sim 0.08 \mathrm{~km}^{3}$ and $\sim 10-\mathrm{hr}$ eruption duration. This is within the range of possibility for Strombolian eruptions at Yucca Mountain. Recall that Strombolian mass flows are generally in the range $10^{4}-10^{6} \mathrm{~kg} / \mathrm{s}$ with very strong so-called 'violent' Strombolian eruptions having $\dot{M}$ up to $\sim 10^{7} \mathrm{~kg} / \mathrm{s}$. The main need is to compare ASHPLUME results to results from another method. This task can probably be accomplished by 3-5 weeks or less if outside expertise (e.g., Dr. Tony Hurst for ASHFALL) contributes to the effort.

\section{Are the outputs of the model a reasonable representation of what may be expected from a volcanic eruption at Yucca Mountain?}

Tentatively the answer to this question is "probably yes." Comparison of ASHPLUME results with other codes would enable one to more definitively answer this question. An explanation of the issue raised in section labeled $\underline{5.2 .3}$ in this review should be provided to insure self-consistency is maintained in application of ASHPLUME.

\section{Other Comments on MDL-MGR-GS 000002, REV 00B.}

p.41. reference to 'Suzuki et al' should be to 'Jarzemba et al (1997)'. 


\section{REFERENCES CITED*}

NOTE: These references were used at part of the technical review and are not reflected in the document input reference system as part of this AMR.

Armienti , P. Macedonio, G. and M. T. Pareschi, A numerical model for the distribution of tephra transport and deposition: applications to May 18, $1980 \mathrm{Mt}$. St. Helens eruption, Jour. Geophys. Res., 93, 6463-6476, 1988.

Hefter, J.L. and B. J. Stunder, Volcanic ash forecast and dispersion (VAFTAD) model, Weather and Forecasting, 8, 533-541, 1993.

Hurst, T. W. and R. W. Turner, Performance of a program for volcanic ashfall forecasting, N. Z. J. Geol. Geophys., 42, 615-622, 1999.

Hurst, T. W. , ASHFALL- a computer program for estimating volcanic ash fallout. Report and user guide. Institute of Geological and Nuclear Sciences Science Report 94/23. 22p., 1994.

Jarzemba, M. S., Stochastic radionuclide distributions after a basaltic eruption for Performance Assessments of Yucca Mountain, Nucl. Tech., 118, 132-142, 1997

Macedonio, G., Pareschi, M. T. and Santacroce, R., A numerical simulation of the plinian fall phase of 79 A.D. eruption of Vesuvius, Jour. Geophys. Res, 93, 14817-14827, 1988.

Macedonio, G., Pareschi, M. T. and Santacroce, R., Renewal of explosive activity at Vesuvius: models for the expected tephra fallout, Jour Volcanol. Geother. Res., 40, 327-342, 1990.

Mastin, L. G., Insights into volcanic conduit flow from an open-source numerical model, Geochem. Geophys. Geosys., 3(7), 10.1029, 2002.

Mastin, L. G., and M. S. Ghiorso, A Numerical Program for Steady-State Flow of Magma-Gas Mixtures Through Vertical Eruptive Conduits, U.S. Geological Survey, Open-File Report 00-209, 2000.

Mastin, L. G., and M. S. Ghiorso, Adiabatic temperature changes of magma-gas mixtures during ascent and eruption, Contributions to Mineralogy \& Petrology, 141, 307-321, 2001.

Pielke, R.A., W.R. Cotton, C. J. Tremback, M.E. Nicholls, M. D. Moran, D. A. Wesley, T.J. Lee and J.H. Copeland, A comprehensive meteorological modeling system-RAMS, Meteor. Atmos. Phys., 49, 69-91, 1992.

Suzuki, T., A theoretical model for dispersion of tephra, In: Shimozuru, D. and I. Yokohama (eds) Arc volcanism: physics and tectonics, p. 95-113, 1983.

Turner, R and T. W. Hurst, Factors influencing volcanic ash dispersal from 1995 and 1996 eruptions of Mount Ruapehu, New Zealand, J. Appl. Meteorol., 40, 56-69, 2001.

Walko, R. L. and C. J. Tremback, HYPACT: The Hybrid Particle and Concentration Transport Model. User's guide, 13pp, 1995 [Available from ASTER Division, Mission Research Corporation, P.O. Box 466, Fort Collins, CO 80522]

Wilson, L. and J.W. Head, Ascent and eruption of basaltic magma on the Earth and Moon, Jour. Geophys. Res., 86, 2971-3001, 1981. 


\author{
APPENDIX G \\ INDEPENDENT TECHNICAL REVIEW OF MDL-MGR-GS 000002, REV 00H \\ ASH REDISTRIBUTION CONCEPTUAL MODEL \\ Included In Appendix G Are The Following: \\ CRITERIAL FOR TECHNICAL REVIEW OF THE ASH REDISTRIBUTION \\ CONCEPTUAL MODEL \\ INDEPENDENT TECHNICAL REVIEW: DR. DAVID BUESCH, \\ U.S. GEOLOGICAL SURVEY \\ INDEPENDENT TECHNICAL REVIEW: DR. DENNIS O'LEARY, \\ U.S. GEOLOGICAL SURVEY
}




\section{APPENDIX G \\ INDEPENDENT TECHNICAL REVIEW OF MDL-MGR-GS 000002, REV O0H ASH REDISTRIBUTION CONCEPTUAL MODEL}

Model validation as stated in the model validation procedure (AP-SIII.10Q) is the process used to establish confidence that the mathematical model (if applicable) and its underlying conceptual model adequately represent with sufficient accuracy the system process, or phenomenon, in question. AP-SIII.10Q identifies a number of methods for validating models that range from simple documentation to peer review. For the ash redistribution conceptual model, the Technical Work Plan (TWP) -- Igneous Activity Assessment for Disruptive Events (TWP-WIS-MD-000007, REV 4), identifies the post development method to achieve the desired level of model validation (Level II):

"Technical review, planned in the applicable TWP, by reviewers independent of the development, checking, and interdisciplinary review of the model documentation (the Originator, Responsible Manager/Lead, Checker, QER, and interdisciplinary reviewers assigned to the model document/activity may not serve as an independent post-development model validation technical reviewer) (Section 5.4.1(c)(5))."

The TWP states that the conceptual model, developed specifically for the Yucca Mountain Project, will be validated under AP-SIII.10Q to develop confidence in its intended use. The draft model report describes the conceptual aspects of the ash redistribution conceptual model. This independent review will focus on the unique application of this model on the Yucca Mountain Project. The intended use of the model is to describe erosion and dilution of contaminated ash as it may affect the RMEI after an eruption of a hypothetical volcanic event intersecting the repository for two end-member scenarios.

The criteria for this independent review are as follows:

1. Is the conceptual model reasonable and appropriate for its intended use?

2. For given inputs, are the outputs of the model reasonable?

3. Are limitations of field and analytical data as well as the conceptual model adequately described?

4. Are there other approaches that may enhance the confidence in use of this model?

5. Are there other alternative models that should be considered? 
Independent Technical Review

Dr. David Buesch, U.S. Geological Survey

November 13, 2003

\section{Independent Technical Review of the Ash Redistribution Conceptual Model}

The "Ash Redistribution Model" is a conceptual component of the "Atmospheric Dispersal and Deposition of Tephra from a Potential Volcanic Eruption at Yucca Mountain, Nevada" AMR. The document on which Dr. David Buesch (USGS) conducted the technical review has a Document Indicator (DI) of "MDL-MGR-GS-000002, REV 00H," and only those parts of the document related to the "Ash Redistribution Model" were reviewed. This part of the independent technical review lists responses to the review criteria and major comments and concerns regarding the data and conceptual model. Comments pertaining to logic flow of the text, presentation and consistency of text and figures, and text editing (or lack thereof) are as annotations on the manuscript.

The criteria for this independent review are as follows:

1. Is the conceptual model reasonable and appropriate for its intended use?

The model lays out several detailed and "big picture" ideas that are based on some data, and in the end it provides some values for input into Total System Performance Analysis (TSPA) models. So, in that respect the model is appropriate for its intended use (i.e., TSPA gets some parameters). Having said that, the model is largely conceptual, so many of the components are not well developed and this diminishes the final intended use of the model (note the use of the word "diminishes", not “excludes").

2. For given inputs, are the outputs or the model reasonable?

The current version of the model is mostly conceptual, but there are a few examples that are based on input data to develop values that are in turn generalized into values for TSPA models. One can follow (possibly even better with a little additional information and editing) the authors ideas for the detailed examples. So for these detailed examples, one can see the logic from input to reasonable output, even though the amount of data is probably less than what one might like to have in order to make solid and defendable arguments for model results.

3. Are limitations of the model adequately described?

Most of the model manuscript is used to explain the conceptual model and present and develop supporting data and ideas, so there is very little explicit discussion on the limitations and uncertainty of the model and results. There are some limitations on the data directed toward the use by TSPA models. 
4. Are there other validation approaches that may enhance the confidence in use of this model?

The current model is mostly conceptual and is pretty sparse on data, so one technique for validation is to acquire additional data to test several of the hypotheses or components of the model. The current model focuses on dilution of ash (and waste) by mechanical erosion and mixing of the sediment during transportation and deposition, and it briefly discusses the possible mechanical process of infiltration into deposits. The data used to evaluate these processes are few and localized, but are used to extrapolate to "full model" conclusion. The authors have shown some interesting initiative using the radionuclide Cs-137 as a tracer (however, the appropriateness of this application must be better understood and described), and there are numerous possibilities of using other radionuclide and non-radionuclide tracers to quantify physical and chemical process. Collection of data that better quantify the processes of erosion, local storage, and flushing of the material through (or farther down) the system would greatly enhance these components of the model and thereby reduce (or at least quantify) uncertainty and enhance confidence. There are atmospheric wind velocity and direction data from numerous sites near Yucca Mountain and Fortymile Wash in addition to regional data, typically from $10 \mathrm{~m}$ above the ground surface (Fransioli and Ambros, 1997). These wind data might be used in conjunction with the distributions of sediment types to determine (calculate) potential for erosion by eolian deflation processes that is part of the Cesium (Cs)-137 study, and that might occur at many locations affected by the potential tephra sheets in the model. Having said all this, one must acknowledge that quantifying wind- and water-related processes in a desert such as at Yucca Mountain is challenging because events are few and far between; therefore, collecting appropriate data and developing it into conceptual and numerical models will probably be one of the few avenues upon which rational discussion and evaluation can take place.

Fransioli, P.M., and Ambros, D.S., 1997, Regional and Local Wind Patterns Near Yucca Mountain: Civilian Radioactive Waste Management System Management \& Operating Contractor, Las Vegas, NV, 200 p. November 20, B00000000-01717-570500081 REVISION 00, MOL.19980204.0319.

5. Are there other alternative models that should be considered?

There are many details on the physical processes that can be included and considered for other models. These processes include refinements to eolian, colluvial, fluvial, pedogenic, mechanical, and chemical processes that result in determining better (and hopefully more realistic) estimates of amounts of materials on the landscape and time during which processes are active. It is the interaction and sum of these processes that can emerge as a model and, which in turn, can be discussed and tested using numerical modeling techniques. The long and short answer to this question is that by focusing more on the diversity of physical processes, collecting appropriate data to evaluate these processes, and integrating them into full-basin and sub-basin models, then another "new" model will emerge, and that model is what should be considered for the redistribution of ash and waste. 
In summary, the conceptual model and the semi-qualitative (semi-quantitative?) results can probably be used for the intended use as input into TSPA models. However, the model should probably be considered as a starting point upon which refinements and enhancements will result in a more rigorous and defendable model.

\section{Major comments and concerns}

There are five major comments and concerns regarding the "Ash Redistribution Model," and although individually none of the concerns result in invalidating the model, together the comments point out some of the gaps in the current model. [Note: the word is "gaps," not "invalidate."] Several of these comments and concerns can probably be initially addressed with additions to the existing document, but others might require additional work to more thoroughly document and substantiate components of the conceptual (and possibly future quantitative and numerical) model. As with many products for the Yucca Mountain Project (AMRs, etc.), there are numerous citations of other reports or data sources rather than providing and developing data with the report so a reader does not have to jump around from product to product.

1. Most of the supporting and component parts of the model focus on two small (scoping?) studies, and these studies are the basis for "scaling up" to the current conceptual model. The Lathrop Wells Cone "ash dilution" consists of nine samples along two transects that are 1 and $2.5 \mathrm{~km}$ long. Additionally, the drainage basin that includes Lathrop Wells Cone has an upstream drainage basin (relative to the tephra sheet) compared to the downsteam drainage area that is expressed as a ratio of $6: 1$. Several (pertinent) reasons are listed for why the Lathrop Wells data should not be directly developed as a simple scaling factor for the ash-dilution values; however, shortly after these statements are made, the Fortymile Wash drainage is expressed in the same type of ratio and a dilution distance is quoted. Observations at Sunset Crater, Arizona, are only briefly described in a scientific notebook; therefore, relations are of limited scope and detail. The Cesium Study for surficial processes consists of 51 samples in approximately a $12 \mathrm{~km} 2$ area south of Highway 95 on the distributary fan of Fortymile Wash. Each of these studies has merit, especially because the Lathrop Wells Cone and the distributary fan of Fortymile Wash are near the typically cited "reasonably maximum exposed individual" (RMEI). However, using these studies as the sole basis for "scaling up" to complete ash redistribution model is, in my opinion, a stretch.

2. The Cesium Study for Surficial Processes in the Fortymile Wash alluvial fan is an interesting use of a radionuclide tracer; however, it is not clear that Cesium (Cs)-137 is an appropriate tracer for the mechanical and possibly chemical processes described or inferred. According to the U.S. Environmental Protection Agency (http://www.epa.gov/radiation/radionuclides/cesium.htm), Cesium (including Cs-137) is one of only three metals that is liquid at about $83^{\circ} \mathrm{F}$ and has a half-life of 30.17 years. These properties raise several issues that need to be addressed.

a. Is Cs-137 transported to the site and deposit as atoms, complexed into molecules, or attached to (or entrained in) particles, and if with particles, then what size are these particles? The physical form of Cs-137 at the time of deposition (or 
"shortly" thereafter) might influence the susceptibility to mechanical erosion or chemical reaction.

b. It is proposed that Cs-137 infiltration can be used as a general proxy for the depth to which fine particles (clay, silt, and ash or sand-sized grains) might transported into the soil. It seems that this proposal assumes mechanical infiltration; however, with a Cs-137 liquidus of about $83^{\circ} \mathrm{F}$ the potential of mechanical and chemical processes must be evaluated and explained.

c. With Cs-137 potentially being deposited during several periods in the 20 years from the mid-1940s to the mid-1960s and a half-life of about 30 years, how might these competing processes of accumulation and decay be manifest in the data? For example, material deposited in the mid-1940s (about 57 years ago) will have undergone almost 2 half-life cycles, so only about 27 percent of the original material is still in the system.

3. On the basis of model results of "ASHPLUME," establishment of two tephra sheets is a good use of end-member distributions where, relative to Yucca Mountain, one sheet is deposited south and the other sheet is deposited to the east. However, how and in what depth these two models are discussed differs greatly.

a. A figure (or two) illustrating these two model distributions should be included early in the Ash Redistribution section of the in the report so the reader can visualize the distribution, thickness, and even gain size in the tephra sheets. Location of the RMEI should be included (as it is, partially, on Figure 5).

b. The tephra sheet deposited to the south of Yucca Mountain would deposit ash on the RMEI area. Although the current model appears to emphasizes only eolian processes, this area contains numerous ridges and basins, including the one in which Lathrop Wells Cone is located, the Fortymile Wash alluvial fan, and both of these sites are described in detail for the fluvial redeposition of material. So, the emphasis on eolian processes in this model distribution under represents the fluvial processes in the area.

c. The tephra sheet deposited to the east of Yucca Mountain would deposit ash across Jackass Flats and in the drainage basin between the Calico Hills and Shoshone Mountain that is drained by Topopah Wash. The current model focuses on the fluvial redistribution of ash along Fortymile Wash. However, after introduction of this model end member, it is rarely described except through inference of colluvial and fluvial processes, in which most of this discussion is associated with the Lathrop Well Cone and Fortymile Wash alluvial fan studies. The discussions on short-duration, intense thunderstorms and the more aerially extensive, long-duration storms are apparently provided in support of the sediment transport into and through Fortymile Wash, but these same storm conditions are applicable throughout the area, including for the south-directed tephra sheet. 
d. The RMEI is typically identified in the area of the Lathrop Wells Cone and Fortymile Wash; however, if the 18-km distance from the proposed repository site is the fundamental criteria, then an arc can be drawn to the east-northeast to where it intersects the southwestern edge of Little Skull Mountain. This minor eastward continuation of the $18-\mathrm{km}$ arc intersects Topopah Wash just north of where this wash transitions into a distributary fan similar to the Fortymile Wash fan. So, the east-directed end-member model should probably include redeposition from the drainage of Topopah Wash and Jackass Flats because most of the tephra sheet would be deposited across these areas. According to Christensen and Spahr (1980), significant parts of Jackass Flats would be affected in 100-year storms, and especially 500-year and maximum flood events. So, eroded ash from the Jackass Flats area and the drainage near Calico Hills might be a contributing source of material to the RMEI area.

Christensen, R.C., and Spahr, N.E., 1980, Flood Potential of Topopah Wash and Tributaries, Eastern Part of Jackass Flats, Nevada Test Site, Southern Nevada: U.S. Geological Survey, Lakewood, CO, Open-File Report 80-963, 22 p. [TIC Catalog Number 203211]

4. Erosion, transportation, and deposition of ash from different types of slopes (orientation and inclination) and substrates (Miocene, densely welded ignimbrite versus colluvial and old or young alluvial surfaces) can differ greatly, but these variations are not discussed. Here are two aspects of how these conditions and processes might be applied to the model.

a. There are some minor discussions of material being eroded from steeper slopes and accumulating in the washes at the base of these slope (possibly during thunderstorms), and at later times (during long-duration regional storms) being flushed farther out into the fluvial system. These processes and times for each process to be active are challenging to quantify, especially in desert environments where there is sparse runoff data; however, estimates of thickness and rates of erosion are provided as "soil redistribution factors" for the TSPA model (Table 7-1). So, there are a few examples of attempts at quantifying amounts and processes, and there are many that have not been addressed.

b. In the discussion on tephra deposits on the RMEI in northern Amargosa Valley (paragraph 2 on page 64) it is stated that because of the strong eolian action in this area, it is "highly unlikely a that tephra deposit ... would remain in place and/or undiluted for more than a few decades". There are other places in the text that complete (or near complete) removal of the tephra deposits is described as part of the model. It is hard to judge if complete (or near complete) removal of the ash in "a few decades" has positive or negative affects on the concentration of ash and waste materials, but it is not clear that these conditions are even appropriate. For example, consider the amount of ash deposited on the highly varied topography near Mount St. Helens, Washington, in 1980, and how much of this ash has been eroded off the slopes in the last 23 years. It is true that Mount St. Helens is in a different climate and environment. It is also true that there are no specific measurements that can be cited (just some oral communication estimates from 
some of those who have worked extensively in the area), but estimates of the amount of eroded 1980 ash vary from about 10 to 20 percent, and this means that 80 to 90 percent of the primary deposit is still on the hillsides. Erosion of the ash is primarily by the formation of rills, and once the rills are established, there is very little lateral cutting to strip of the material that remains on the interfluve ridges. Coming back to the Yucca Mountain area, rills and interfluve ridges are pretty common on many types of slopes and substrates. All this means is that more of the primarily deposited ash might not be eroded in the short time frame inferred in the current model.

5. There is an assumption from the ASHPLUME model that "waste" is incorporated into the ash and the two form individual grains that are deposited to form the tephra sheets; however, this "mixed grain of ash and waste" might not be appropriate for the Ash Redistribution model. I understand that the "mixed grain of ash and waste" has been an assumption in ASHPLUME model for quite a while, and that this is not part of the tasked technical review. However, from a fragmentation process-base mechanistic point of view, I think formation of mingled and mixed grains it is difficult to do and it is very likely that the majority of waste and ash would be erupted as mostly individual particles (this complicates the calculations). If particles deposited in the tephra sheets are mostly individual grains of ash and waste, then each would have very different hydrodynamic and possibly chemical properties. These different properties would affect the erosion, transportation, deposition, and fractionation potential of the particles.

Finally, the intended use of the Ash Redistribution model is to provide some parameters to the TSPA, and that is what the (conceptual-semiqualitative-semiquantitative) model does. However, although the current model is a reasonable start, it only contains a few localized aspects of the physical processes that are likely to affect the redistribution of ash (and waste). Because processes that affect the redistribution of ash and waste operate at a wide variety of scales, a more integrated model is probably in order. For example, there are eolian and aqueous processes, localized processes of erosion on a slope, small drainage basin scales processes of erosion, transportation, and deposition, and full drainage basin scale processes of erosion, transportation, and deposition. Most of the basaltic eruptive (disruptive) processes, including the redistribution of ash and waste materials, are typically considered as post-closure events and there has not been a clear link between these issues and pre-closure issues such as potential flood events. The importance of fluvial and eolian processes described in the current model, and hopefully emphasized in this review, indicates that an integrated, full-basin model of potential flooding and sediment transport (including a few sub-basin models) would be important for evaluating both potential pre- and post-closure events. Such a quantitative model (or submodels) could provide a powerful tool in evaluating the redistribution of ash and waste material. 
Independent Technical Review

Dr. Dennis O'Leary, U.S. Geological Survey

November 19, 2003

\section{Independent Technical Review of the Ash Redistribution Conceptual Model}

I reviewed sections 6.6: Ash Redistribution Conceptual Model, 6.7: Model Results, and 7: Model Validation, in Atmospheric Dispersal and Deposition of Tephra from a Potential Volcanic Eruption at Yucca Mountain, Nevada. I found no fatal flaws or other lapses. The constraints identified from field observations and from analytical data are considered in the report as fully relevant factors in the deposition and redistribution processes of tephra. The conceptual model is appropriate and the discussions and reasoning are presented in adequate detail to support the conclusions and inferences in these sections. Application of ASHPLUME is well reasoned and is appropriate for its intended use. The outputs of the model are reasonable with respect to the given inputs; the outputs adequately explain the distribution of tephra as a basis for analyzing its fate by erosion, fluvial and eolian transport, as described in the text. The limitations of the model are adequately described. I do not know of other validation approaches that may enhance the confidence in the use of the model, and I do not know of other alternative models that should be considered.

The following comments are suggestions pertaining to technical details in the interest of providing a more complete presentation.

1. To give an accurate impression of the distribution of tephra outfall, it should not be described as a sheet; it is actually an attenuated apron deposit continuous with the cone itself, distinguished mainly by the variation in particle size with distance from the vent. The scenarios implicitly assume a tephra dispersion profile based on size-related weight distribution I think more should be said about the presumed waste particle distribution within the single eruption tephra deposit. Namely, will the waste content distribution mimic the tephra particle size distribution or is there a particle size waste adherence limit, as implied in Sec. 6.5.1? I suspect the nature of the waste particle distribution within the tephra distribution might have some bearing on the erosional dispersion of contaminated tephra by wind or water over time. Is windborn volcanic dust, then, ever a hazard?

2. Note that a single flood event in Fortymile Wash (and there have been a couple of bank-to-bank flows within the time I have been on the project) will distribute tephra from A to D (Fig. 2) instantaneously (i.e., within a day). The time lapse will be insignificant in this case but the tephra concentration downstream will probably be as shown in Fig 2. Note also that the amount of tephra contributed to bedload from the slopes of Yucca Mountain may be trivial if the flood event is a result of cloudburst/snowmelt from the Timber Mountain part of the drainage basin. It would seem that Timber Mountain weather would be a much bigger contributor to runoff in the channel than the relatively infrequent Yucca Mountain-wide flank storms. Therefore, the amount of contaminated waste fed to Fortymile Wash may be metered by local storms and fed to a channel that is repeatedly cleared of tephra. It may be 
correct to think of relatively small slugs of contaminated tephra fed to the channel on an infrequent basis but sluiced down to Amargosa Valley in large, relatively frequent homogenizing flood events. If this is true, it would tend to decrease the rate of tephra delivery to RMEI. Fig 5 (p. 76) would be more useful if you could show on it the inferred area of a tephra deposit that would form from a violent strombolian eruption through the repository. Just a glance at Red and Black and Lathrop Wells Comes suggests that a tephra deposit(s) would occupy a small part of the Fortymile Wash drainage basin and that the tributary systems that dominate its delivery to Fortymile Wash would be Yucca, Midway, and Dune Washes. Has any study been done to estimate the sediment contribution these tributaries made to Fortymile Wash in late Pleistocene -Holocene? I recommend you adjust fig. 5 to show the entire Fortymile Wash watershed to the north at Timber Mountain; this will make clear the enormous potential diluting effect available from upstream.

Fig. 2 shows the concentration of tephra in the channel decreasing as a non-linear concave decay curve, notably at A. Is there a basis for this? I would assume a linear decrease incrementally stepped down to the right, each step representing a flood/erosion event (the slope could reflect tributary input of tephra, so I guess the curve would flatten with time as the tephra source becomes depleted or otherwise stabilized upslope). Is there a basis for having the concentrations at $\mathrm{B}, \mathrm{C}$, and $\mathrm{D}$ build to a maximum concentration and then begin to decrease? Since each subsequent flood through A brings down an increasingly diluted tephra load, shouldn't there be a net decrease in tephra at $\mathrm{B}$ and $\mathrm{C}$ after the first flood event (B and $\mathrm{C}$ also suffer erosion during each flood so I don't expect much of an incremental increase in tephra at those points.) $\mathrm{D}$ is harder to understand because it is more clearly an aggrading environment that $\mathrm{C}$ and B. The text says that the plots in fig. 2 are purely conceptual; perhaps some simple flume experiments would help support this concept.

3. Page 73 presents data on a tephra transport and redeposition study. It would be helpful to know the tephra grain size with distance from head of input. The text mentions ash and microscopic analysis, which suggests a fine sand size. How does the ash size in channel samples compare to tephra size at the presumed source (margin of intact tephra deposit)? Has there been appreciable size sorting by stream/erosion transport? Some estimates should be given to the size distribution and agglomeration of fragmented waste to the overall tephra distribution. I suspect that waste particle sizes will form a leptokurtic subpopulation of large particles, and more important, be discriminated by high density. If so, this suggests that contaminated tephra or waste particles will be relatively large and form a distribution of placer deposits and perhaps be strung out as lag deposits within Fortymile Wash rather than being uniformly fed to Amargosa Valley with a light fraction of sediment. Seems to me some large-scale flume experiments are in order. Or were such already performed by you? Another factor that probably should be mentioned is bedload transport abrasion. Most clasts of stream-bed basalt look fairly well-rounded. Has any work been done on rounding with transport distance and mixing? My guess is that the vesicular tephra are susceptible to comminution during stream transport. Does grain fining by abrasion have an effect on your waste travel calculations? I suspect it is insignificant, but we probably should give the impression of having thought of every contingency. Note that this point is 
relevant to statements in Sec 6.7.2.4. On p. 88 (Sec. 6.7.2.4) there is a good discussion of ash removal with time. There is mention of "residual contamination that may have leached into the underlying sediments." This statement implies that there can be significant dissolution of ash during its time in the stream bed, allowing adhered waste particles to either dissolve and precipitate in the substrate, or migrate downward as very fine particles released from the dissolved ash host grains. Should the solubility of ash be discussed here? Is it a significant factor in the migration of waste?

4. I disagree that sediment mixing occurs at higher rates on steeper hillslopes (p. 70) and that drainage channels that form and flow across newly deposited tephra have well-mixed sediment loads after small transport distances (last sentence, first $\uparrow$, p. 70). Unless these streams cut into pre-tephra substrate, no mixing with other sediment types occurs. Drainage on steeper slopes is restricted to relatively narrow rill or gully incisions, and if the slopes are well-graded to the axial channels, upper slope tephra contributions should progressively diminish with time. Higher order channels gather a larger volume of more compositionally heterogeneous sediment, hence mixing is increased with channel size on lower slopes.

5. Sec. 6.7.2.3 p. 87 informs that "a layer of contaminated ash . . . appears immediately following eruption ..." This contradicts the redistribution scenario presented in Sec. 6.6.1.2. You might want to make some appropriate qualification to mitigate this apparent discrepancy.

6. 7.3.1 Why did you use Cerro Negro as an analog instead of Paricutin? I would have chosen Paricutin because of: 1 . its monogenetic eruption behavior is more analogous to the Yucca Mountain volcanoes, 2. It would be a worst-case scenario compared to Yucca Mountain eruptions, 3. the time since eruption ceased is sufficient to give some indication of how ash is being redistributed from a pristine state by erosion in an arid climate comparable to that of the Yucca Mountain area. In light of F. Spera's comment in Sec. 7.4 I would add Paricutin to your analogs. 
APPENDIX H

AN ESTIMATE OF FUEL-PARTICLE SIZES FOR PHYSICALLY DEGRADED SPENT FUEL FOLLOWING A DISRUPTIVE VOLCANIC EVENT THROUGH THE REPOSITORY

CONDUCTED BY

DR. R.J. FINCH, ARGONNE NATIONAL LABORATORY 


\title{
APPENDIX H \\ AN ESTIMATE OF FUEL-PARTICLE SIZES FOR PHYSICALLY DEGRADED SPENT FUEL FOLLOWING A DISRUPTIVE VOLCANIC EVENT THROUGH THE REPOSITORY ${ }^{1}$
}

\author{
Input To "Waste Particle Diameter In Magmatic Environment" (PA-WP-99383.R)
}

\section{INTRODUCTION}

This document addresses estimates of particle-size distributions for spent nuclear fuel exposed to a potential disruptive magmatic event through the proposed repository at Yucca Mountain, Nevada. As stated in the AP3.14Q input request, "Waste Particle Diameter in Magmatic Environment" (PA-WP-99383.R ), the probability distribution for fuel particles should consider mechanical and chemical degradation of the fuel at the time of the disruptive event. A disruptive event may occur at any time while the degradation of fuel due to oxidation and/or aqueous corrosion is expected to increase over time. However, the estimated extent of fuel degradation that will have occurred at the time of the event is not addressed here.

The following discussion is based largely on laboratory examinations of commercial spent nuclear fuels performed at Argonne National Laboratory but conducted for purposes outside the realm of understanding particle size. The aim of the sample preparation, from which much of the discussed information was obtained, was to disaggregate spent-fuel fragments in order to maximize the fuel's surface area before using it in "accelerated" aqueous-corrosion tests. There is no statistical information available for the distribution of particle sizes caused by the disaggregation and grinding of spent $\mathrm{UO}_{2}$ fuels in the laboratory. There is a similar paucity of data for oxidized and corroded fuels. Particle-size estimates reported here, as well as estimates for mean sizes and ranges, are based on a combination of data obtained from intentional crushing and grinding of "unaltered" spent fuel, as well as this author's experience with handling and examining spent commercial fuel in various states of degradation. These observations are augmented by citations to selected open-literature reports on the physical condition of spent commercial fuel, as well as naturally occurring $\mathrm{UO}_{2}$ (the later being considered a useful natural analogue for severely corroded spent commercial fuel). It is emphasized that no formal statistical treatment was performed to justify the mean sizes and ranges reported here.

The following discussion concerns commercial spent $\mathrm{UO}_{2}$-based fuels.

\section{FUEL DEGRADATION}

Three states of fuel degradation can be defined: (1) unaltered fuel (i.e., uncorroded and unoxidized); (2) dry-air oxidized fuel; and (3) aqueous-corroded fuel. Particle sizes are estimated for each below.

\footnotetext{
1 This work was completed in 1999 by Dr. R.J. Finch, Argonne National Laboratory. This text updated by R.J. Finch for this model report in May through August 2004.
} 


\subsection{Unaltered fuel (uncorroded and unoxidized)}

Unaltered spent fuel shows a range of physical characteristics that depend largely on fission-gas release and possibly burnup; however, there is no clear understanding of the relationship between such parameters and the relative ease with which fuel may fragment under stress or the grain sizes that might result from fragmentation. Fission-gas release appears to be a crucial parameter affecting fuel microstructure, including grain growth (Guenther et al. 1988a and 1988b]), a characteristic that could strongly impact the distribution of fuel-particle sizes from a fuel following exposure to a disruptive volcanic event.

When crushing spent $\mathrm{UO}_{2}$ fuel during the preparation of samples for aqueous-corrosion studies on fuel being conducted at Argonne National Laboratory (ANL), it was found that reducing the particle sizes of a fuel of moderate burnup [approved testing material (ATM) 103: $30 \mathrm{MW}-\mathrm{d} / \mathrm{kg}-\mathrm{U}]$ was readily achieved by using a two-step crushing and grinding process. Fuel fragments that had been removed from the cladding (with fragment sizes of several millimeters across) were initially crushed by using a stainless-steel impact tool, followed by sieving the resulting pieces through two stacked sieves with nominal openings of $0.015 \mathrm{~cm}$ and $0.0045 \mathrm{~cm}$ (i.e., 200 and $325 \mathrm{mesh}$, respectively). The largest size fraction $(>0.015 \mathrm{~cm})$ was then placed into a stainless-steel-ball mill [an ANL-designed and built vibratory roller mill cylinder] and ground for a total of 31 minutes. After each grinding step, the fuel was emptied from the ball mill into the stack of three sieves, with the largest size fraction $(>0.015 \mathrm{~cm})$ being returned to the ball mill for re-grinding (Finch 1999a, ANL scientific notebook \#1547, page 9). The distribution of particles sizes obtained after crushing and milling was approximately bimodal, with numerous large $(>0.015 \mathrm{~cm}$ diameter) fragments and material less than $0.0045 \mathrm{~cm}$, which subsequent SEM examination revealed to be approximately single fuel grains (approximately $0.020 \mathrm{~mm}$ diameter). A relatively small number $(\sim 11 \%)$ of fuel particles were between $\sim 0.0045 \mathrm{~cm}$ and $0.015 \mathrm{~cm}$ in diameter. No attempt was made to estimate the relative distribution of these three particle sizes during the initial grinding; however, following the sample preparation procedure, in which the largest fragments $(>0.0075 \mathrm{~cm})$ were crushed and milled a second time, the final distribution of particle sizes obtained after preparation for the ANL tests given in Table 1 was achieved.

A second grinding was performed as part of the same sample preparation for additional tests at ANL (Finch 1999a). The procedure followed was similar to that followed for the first grinding described above; however, the fuel was ground in the ball mill for a total of 55 minutes, nearly twice as long as for Trial 1. Also, masses were determined for only two size fractions following the second grinding procedure: that fraction with particles less than $0.0045 \mathrm{~cm}$, which was $76 \%$ of the total mass, and that with particles larger than $0.0045 \mathrm{~cm}$, which was $24 \%$ of the total mass. The distribution for this second grinding differs slightly from, but is nevertheless consistent with, that reported after the first grinding. That is, most of the crushed and ground fuel was reduced to less than $0.0045 \mathrm{~cm}$ grain sizes $(76 \%)$, much of which consisted of single fuel grains (Finch 1999a, ANL scientific notebook \#1547, page 20). 
Table 1. Final Distribution of Fuel Particle Sizes After All Grinding Cycles (ANL Tests)

\begin{tabular}{|c|l|l|}
\hline Size Fraction (particle diameter) & Mass (gram) & \multicolumn{1}{|c|}{ relative amount $^{\star}$} \\
\hline $\begin{array}{c}<0.0045 \mathrm{~cm} \text { (ave. } \sim 0.0020 \mathrm{~cm} \text { ) } \\
\text { (mostly single fuel grains) }\end{array}$ & 2.3252 & $81 \%$ \\
\hline 0.0045 to $0.015 \mathrm{~cm}$ & 0.3063 & $11 \%$ \\
\hline$>0.015 \mathrm{~cm}$ & 0.2520 & $9 \%$ \\
\hline
\end{tabular}

Source: DTN: LL001104412241.019.

* NOTE: Total relative amounts may exceed $100 \%$ due to rounding.

Several powders of spent $\mathrm{UO}_{2}$ fuels were prepared for flow-through dissolution studies conducted at Pacific Northwest National Laboratory (PNNL) by crushing and grinding de-clad segments, and the results are reported by Gray and Wilson 1995), who reproduce SEM micrographs of the prepared powders. Gray and Wilson (1995) do not discuss what fraction of the crushed fuel had a size fraction exceeding that used in the flow-through studies, and it is assumed here that the distribution is similar to that given in Table 1. The most important factor illustrated by Gray and Wilson (1995), in terms of understanding the potential distribution of particle sizes produced during a disruptive volcanic event, is that not all fuels prepared by them show identical particle size distributions. Several fuels display very small particles - on the order of $0.001 \mathrm{~cm}$ or less. Although SEM examinations of the ANL fuel grains revealed relatively few particles of ATM103 fuel with sizes less than single grains, the PNNL results from a wider variety of fuel types necessitates shifting the potential distribution of grain sizes to smaller particle sizes than that estimated from the ATM103 results alone. We consider here that $0.0001 \mathrm{~cm}$ diameter particles represent a reasonable lower limit on particle sizes for all unaltered fuels exposed to a disruptive volcanic event.

\subsection{Dry-Air Oxidized Fuel}

Spent $\mathrm{UO}_{2}$ fuel that has been oxidized in the absence of moisture may form a series of oxides, with concomitant degradation of the integrity of the fuel meat (i.e., the $\mathrm{UO}_{2}$ pellets only, but not the cladding, stainless steel spacers, and other components that make up a complete fuel bundle). Oxidation up to a stoichiometry of $\mathrm{UO}_{2.4}$ leads to volume reduction of the $\mathrm{UO}_{2}$ matrix. This can open grain boundaries and may result in the disaggregation of the fuel into single fuel grains (Einziger et al. 1992). Further oxidation to $\mathrm{U}_{3} \mathrm{O}_{8}$ and related oxides results in a large volume expansion and potentially extreme degradation of the fuel into a powder with particle sizes less than one micrometer in diameter. SEM examination of spent fuel oxidized to approximately $\mathrm{U}_{3} \mathrm{O}_{8}$ indicates particle sizes of approximately 2.5 micrometers $(0.0025 \mathrm{~cm}$ dia. $)$ with lower limits of approximately 0.5 micrometers $(0.00005 \mathrm{~cm}$ dia.) (Gray and Wilson 1995), with larger particles ranging up to approximately 50 micrometers diameter $(0.005 \mathrm{~cm})$ (Table 2). An estimate of the larger limit on the range of particle sizes is more difficult to make with much certainty. Based on qualitative observations of ATM103 fuel following preparation for the ANL corrosion studies, an upper limit of $0.05 \mathrm{~cm}$ diameter is chosen (Table 2).

\subsection{Aqueous-Corroded Fuel}

SEM examinations of corroded spent fuel following interaction with simulated groundwater at $90^{\circ} \mathrm{C}$ are reported by Finch et al. (1999a). The grain sizes of uranium(VI) alteration products on corroded fuel commonly reach $0.01 \mathrm{~cm}$ (Finch et al. 1999a); however, based on our 
understanding of the physical properties of uranium(VI) compounds, these phases are similar to gypsum or calcite in terms of hardness and fracture toughness. Therefore, a powerful eruptive event will probably fragment nearly all of the larger crystals of secondary $U$ phases, which is why a smaller upper limit of $0.001 \mathrm{~cm}$ diameter is chosen for the range of particle sizes for aqueous-corroded fuel (Table 2). The lower value for the particle-size range is based on the SEM examinations reported in Finch et al. (1999a), who demonstrate the extremely fine-grained nature of many alteration products, with crystal dimensions as small as 0.5 micrometers or less $(\leq 0.00005 \mathrm{~cm})$.

\subsection{Suggested Particle Size Ranges}

Based on the foregoing data, cited sources and experience of the author, a professional judgment of suggested particle-size ranges and average values for particle sizes (based on light-water-reactor fuels) for modeling disaggregation effects such as from a volcanic eruption through the repository are listed in Table 2 . No firm statistical foundation underlies the averages or ranges listed in Table 2; however, based on observation experience with fuels and literature sources, the listed averages are considered reasonable. Limiting values for the ranges are perhaps less-well constrained, but a reasonable estimate is that 80 to 90 percent of the fuel particles will fall within the ranges reported in Table 2 .

Table 2. Estimated Fuel-particle Sizes

\begin{tabular}{|l|l|l|}
\hline \multicolumn{1}{|c|}{ Degradation state } & \multicolumn{1}{c|}{ mean (cm dia.) } & \multicolumn{1}{c|}{ range (cm dia.) } \\
\hline Unaltered fuel & 0.0020 & 0.0001 to 0.050 \\
\hline Oxidized in dry air & 0.00025 & 0.00005 to 0.0005 \\
\hline Corroded fuel & 0.0002 & 0.00005 to 0.001 \\
\hline
\end{tabular}

Sizes indicate particle diameters. Size estimates based on sources cited in the text and the experience of the author.

Based on our current level of understanding, it seems reasonable to treat both categories of altered fuel (dry-air oxidized and aqueous corroded) as identical, since their estimated particle sizes are not very different from each other. The altered fuel is substantially more friable than (most) unaltered fuel, with size distributions that may be skewed to quite small sizes.

\subsection{Other types of spent fuel}

In addition to commercial spent nuclear fuel (CSNF), which constitutes the vast majority of the fuel inventory destined for permanent disposal, there are additional fuel types that may exhibit physical properties that are quite distinct from those of CSNF. These "other" spent fuels include those from research reactors, military-use reactors, and other sources. They are highly variable in their physical characteristics, and include materials from metals to carbides, and may be in a variety of forms, from ingots to granules. No attempt is made here to estimate potential particle sizes for this broad category of fuel types. Furthermore, there are too few data currently available on the physical properties of these fuels following physical and/or chemical degradation that may occur in the repository following their disposal. 


\subsection{Defense High-level Waste (DHLW) Glass}

Whereas DHLW glass will constitute a large volume fraction of the total volume of waste in the repository, it is not the major contributor to total activity. DHLW glass is probably best treated in a manner similar to the Tuff rock, which also consists of a large volume of glass. Similarly, an intrusive, rapidly cooling magma is likely going to be glassy as well.

\section{REFERENCES}

Einziger, R.E.; Thomas, L.E.; Buchanan, H.C.; and Stout, R.B. 1992. “Oxidation of Spent Fuel in Air at 175 to $195^{\circ} \mathrm{C}$." Journal of Nuclear Materials, 190, 53-60.

Finch R.J. 1999a. "Petri-dish Tests. Spent Fuel." ANL-CMT Scientific Notebook 1547. (Argonne National Laboratory)

Finch, R.J.; Buck, E.C.; Finn, P.A.; and Bates, J.K. 1999b. "Oxidative Corrosion of Spent Fuel in Vapor and Dripping Groundwater at $90^{\circ} \mathrm{C}$." Materials Research Society Symposium Proceedings, 556, 431-438.

Gray W.J.; and Wilson, C.N.' 1995. "Spent Fuel Dissolution Studies FY1 1991 to 1994." PNL-10540 (Pacific Northwest National Laboratory, Richland, WA).

Guenther et al. 1988a. "Characterization of spent fuel approved testing material -- ATM-103." PNL--5109-103 (Pacific Northwest National Laboratory, Richland, WA).

Guenther et al. 1988b. "Characterization of spent fuel approved testing material -- ATM-106." PNL--5109-106 (Pacific Northwest National Laboratory, Richland, WA). 
INTENTIONALLY LEFT BLANK 


\section{APPENDIX I}

\section{ALTERNATIVE MODEL FOR ASH REDISTRIBUTION}




\section{APPENDIX I \\ ALTERNATIVE MODEL FOR ASH REDISTRIBUTION}

\section{I1. PURPOSE}

This alternative numerical model for ash and waste redistribution is presented as an enhancement to the existing ash redistribution conceptual model in the main body of this model report. The purpose is to provide TSPA with a basis for calculation of temporal near-surface and at-depth waste concentrations in soil in the RMEI area. The reason for the enhanced numerical model is to provide a more complete representation of the redistribution mechanisms involved, and to eliminate the mass balance conservatism of the existing simplified ash redistribution conceptual model.

\section{I1.1 Scope}

This alternative redistribution model retains the use of model Outcome 1 (ash deposition at the RMEI site) and Outcome 2, (ash redistribution to the RMEI site), as described in Sections 5.1.3 and 6.3.2. However, an opportunity is also identified (see I5.1.1) for enhanced modeling whereby the need for Outcome 1 and Outcome 2 distinction by tephra thickness criteria could be eliminated.

The alternative redistribution model provides computation formulae for alluvial fan stream interchannel divides and for channels. The formulae provide near-surface and at-depth waste concentrations in soil at the RMEI area for any post-eruptive time interval, given a set of initial conditions $(t=0)$. The ASHPLUME model provides the initial ash depth and waste concentration in ash. For ash depths that meet the criterion of Outcome 2 conditions (south westerly winds and ash thickness at $\mathrm{RMEI}<0.001 \mathrm{~cm}$ ), the given initial condition for the RMEI will include redeposition of ash from Fortymile Wash.

\section{I1.2 Model Limitations}

On account of uncertainties, lack of data and avoidance of mathematical complexity that do not provide value commensurate with the model purpose, there are recognized limitations in the capabilities of the alternative redistribution model. Among the recognized limitations are:

- The initial conditions for Outcome 2 include post eruptive event transport during the first TSPA time step, of the more mobile ash and waste from Fortymile Wash to the RMEI before stabilization occurs. Thus, this initial condition might represent the redistribution result from the order of five to ten years after the eruptive event. The model does not permit distinction of Outcome 2 transport within the early years that are banded as the first TSPA time step.

- The alternative model does not include representation for local eolian accumulations such as dune growth on the leeward sides of obstacles.

- The redeposition of waste on the interechannel divides by sheet flooding is not represented. The low frequency of these events, and the dilution of waste that would occur in the redistributed material, support this simplification. 
- The stability of channels in the upper alluvial fan at the RMEI is assumed, and the long-term geologic dynamics of fan interchannel divide and channel interactions are not represented.

\section{QUALITY ASSURANCE}

See Section 2.

I3. USE OF SOFTWARE

\section{I3.1 Software Tracked by Configuration Management}

None.

\section{I3.2 Exempt Software}

Commercial, off-the-shelf software used in support of this model report is listed in Table I-1. This software is exempt from the requirements of LP-SI.11Q-BSC, Software Management.

Table I-1. Exempt Software

\begin{tabular}{|l|l|l|}
\hline $\begin{array}{c}\text { Software Name and } \\
\text { Version (V) }\end{array}$ & \multicolumn{1}{|c|}{ Description } & $\begin{array}{c}\text { Computer and Platform } \\
\text { Identification }\end{array}$ \\
\hline $\begin{array}{l}\text { Microsoft Excel, } \\
2000\end{array}$ & $\begin{array}{l}\text { The commercial software, Microsoft Excel 2000, was used for } \\
\text { plotting graphs and statistical calculations. Only built-in } \\
\text { standard functions in this software were used. }\end{array}$ & PC, Windows 2000/NT \\
\hline
\end{tabular}

\section{I4. INPUTS}

\section{I4.1 Data, Parameters And Other Model Inputs}

\section{I4.1.1 Value for $f$, the Fraction Of Waste Deposited in Fortymile Wash Drainage Basin Redistributed to the RMEI Location}

The parameter $f$ represents the fraction of waste deposited in the Fortymile Wash drainage basin that is transported to the RMEI location by fluvial processes. To calculate $f$ it is assumed that ashfall on active channels and slopes steeper than 10 percent would be transported within the first time step (ten years) following the eruption, while ashfall on hillslopes with less than 10 percent gradient would be permanently stored. The threshold value of 10 percent slope was chosen based on studies by Harrington (2003 [DIRS 164775]) at analog field sites.

Should this alternative mathematical diffusion model be used in the future, drainage-basin analysis would be used to constrain the value of $f$ by identifying the fraction of the Fortymile Wash drainage basin with either active channels, or slopes greater than 10 percent. To do this, a Digital Elevation Model (DEM) for the Yucca Mountain region would be obtained from the USGS National Elevation Dataset. The Fortymile Wash drainage basin upstream of the RMEI location would be extracted from this DEM using standard GIS techniques, and steepest-descent slopes within the drainage basin would then be computed. The fraction of the drainage basin 
with slopes greater than 10 percent would then be computed to estimate the value of $f$. This approach is a standard means of identifying potentially unstable slopes. An example of this approach is described by Pareschi et al. (2002 [DIRS 171394]). Illustrations of the mapping results, applied to assessment of drainage basin hazard potential, are shown in Figures I-1 and I-2 (Pareschi et al. 2002 [DIRS 171394], Figures 7 and 8).

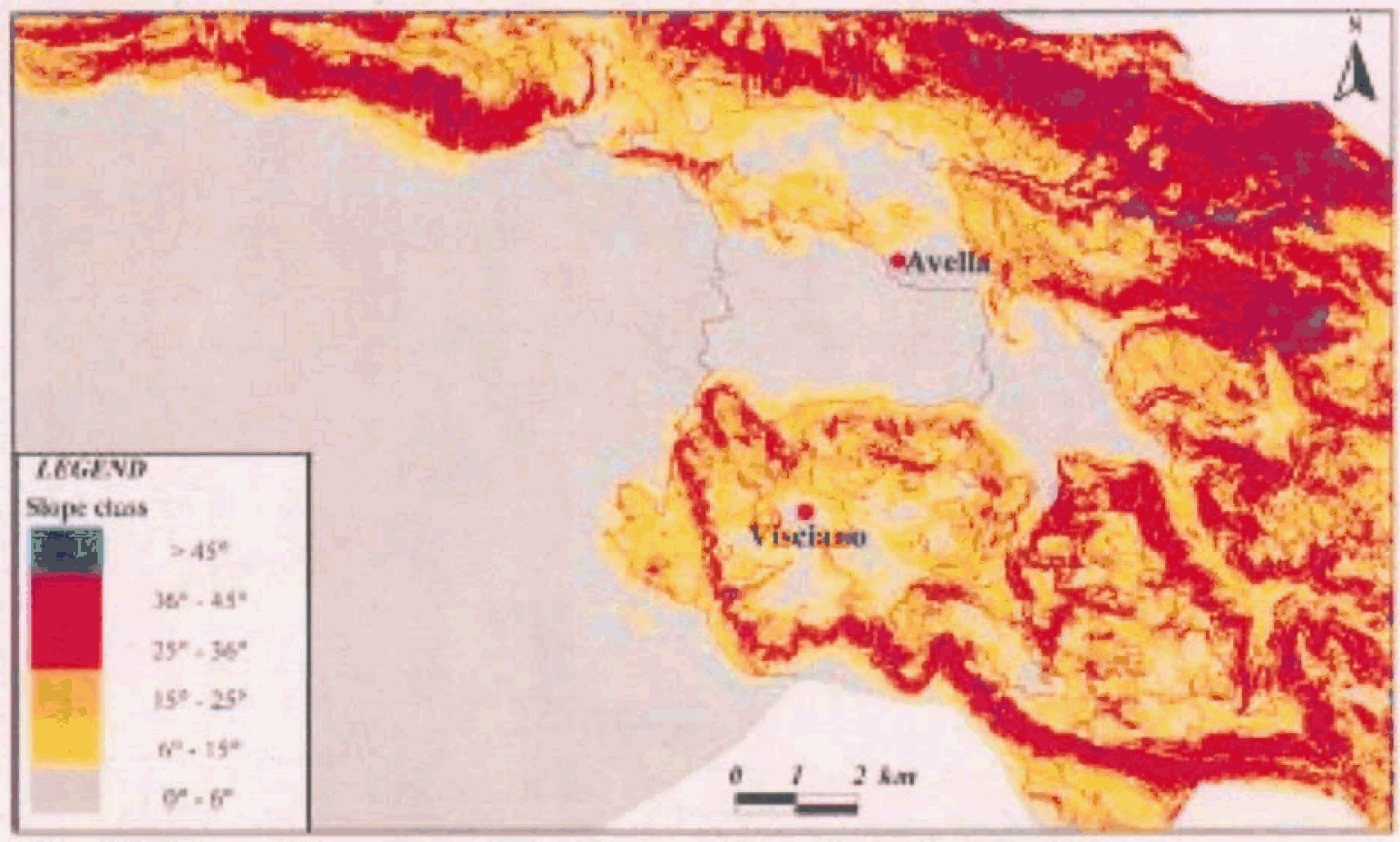

Source: Pareschi et al. 2002 [DIRS 171394], Figure 7.

NOTE: The slope map is derived directly from the DEM.

Figure I-1. Illustration of Drainage Basin Slope Mapping Derived from DEM Dataset 

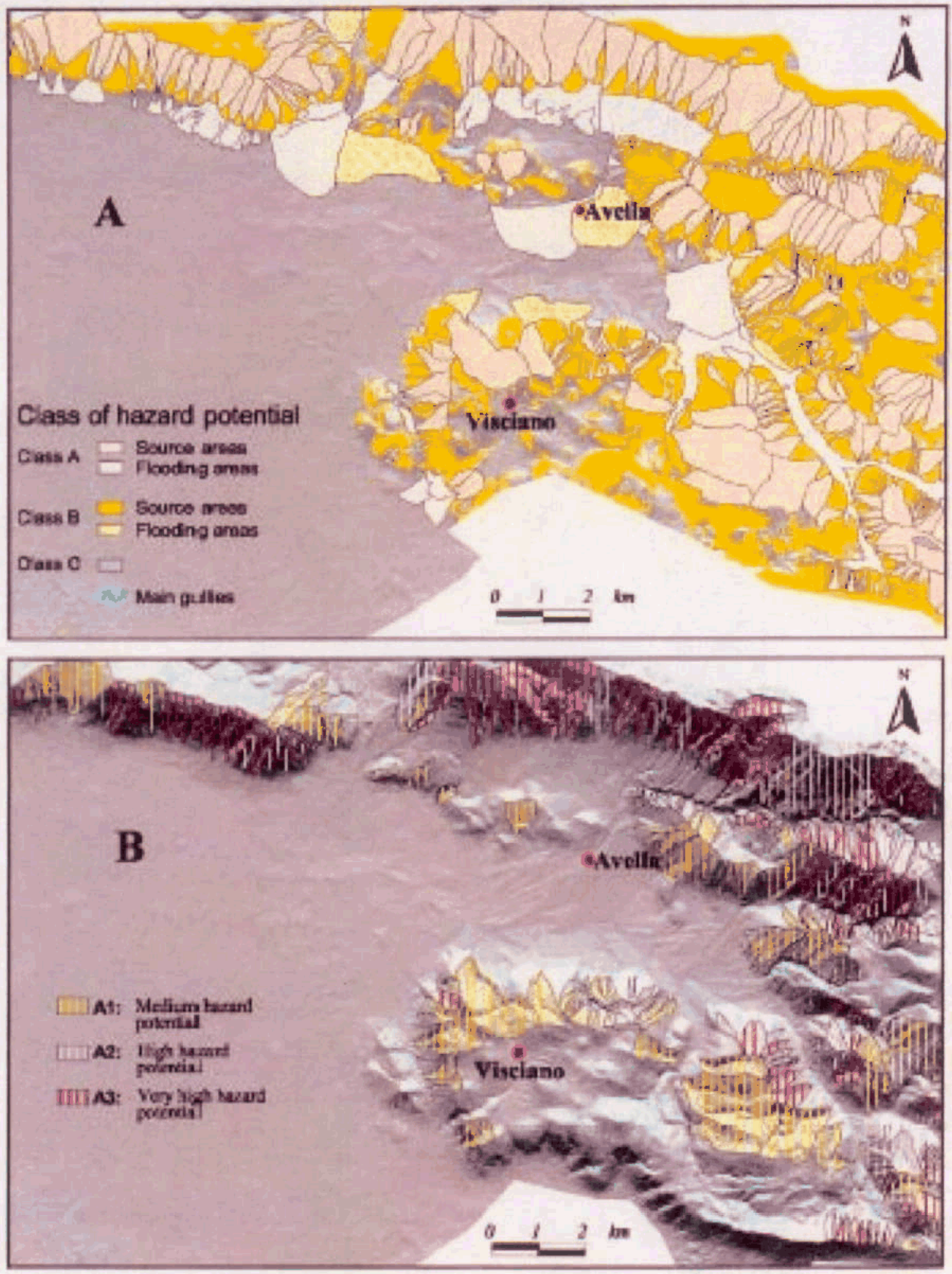

Source: Pareschi et al. 2002 [DIRS 171394], Figure 8.

Figure 1-2. Illustrated Hazard Assessment Use of Drainage Basin Slope Mapping Derived from DEM Dataset 


\section{I4.2 Criteria}

See Section 4.2.

\section{I5. ASSUMPTIONS}

\subsection{Model Assumptions}

\section{I5.1.1 Tephra Sheet Distribution for Ash Redistribution Model}

Assumption-That potential hazard paths characterizing maximum potential exposure to the RMEI can be represented by two bounding model outcomes for tephra sheet distribution and orientation, and that these outcomes can be distinguished by a criterion of minimum primary ash deposition as calculated by Ashplume. This assumption is equivalent to the assumption in Section 5.1.3.

Rationale-See rationale in Section 5.1.3.

Confirmation Status-It is possible that the simplified bounding by the two defined model outcomes could classify as Outcome 1 an event in which an approximately westerly wind placed the primary tephra upstream of the RMEI location, but also provided sufficient ash thickness at the RMEI location to satisfy categorization as Outcome 1 . This would result in omitting an upstream waste redistribution source to the RMEI location.

Although not presently included in the alternative ash redistribution model, an adaptation of the presented model could permit removal of the distinction between Outcomes 1 and 2 in favor of an approach that resolves both the primary ashfall and the ash transported to the RMEI location from the Fortymile Wash drainage basin. The proposed work would include modifications to TSPA in which the entire spatial distribution of primary ashfall is calculated by sampling the ASHPLUME ash thickness on a uniform grid that includes the RMEI area and the entire Fortymile Wash drainage basin. This grid would then be used in a Geographic Information System framework to calculate the thickness of ash deposited on the RMEI area as primary ashfall, and the thickness of the ash deposited upstream in the Fortymile Wash drainage basin.

Transportable ash deposited on the Fortymile Wash drainage basin (i.e., ash that is deposited on steep slopes and in active channels) would be immediately redistributed to the RMEI location and added to the primary ashfall. The proposed work would remove the distinction between Outcomes 1 and 2 by treating both primary ashfall and redeposited tephra from the Fortymile Wash drainage basin. As a conservative measure, it could also be elected that tephra from wind directions (i.e., generally easterly) that do not directly impact the RMEI location or the Fortymile Wash be arbitrarily moved to the Fortymile Wash as a potential secondary source.

Work associated with model development including the enhancement for eliminating the distinction of Outcome 1 and Outcome 2 based on primary tephra thickness at the RMEI location is planned for post-LA.

Where Used-The basic assumption of Outcome 1 and Outcome 2 bounding conditions is used in Section I6.5. 


\subsubsection{Future Climate}

Assumption-The climate through much of the regulatory period will be similar to today's climate and, even with a projected increase in annual precipitation, will have relatively little impact on the Fortymile Wash alluvial fan.

Rationale-See Future Climate Analysis (BSC 2004 [DIRS 170002]). If climate changes to a wetter period the pluvial period is projected to have about $1-1 / 2$ to 2 times the current annual precipitation. However this is seen to require no adjusted use of current data since the expected effects would include more vegetation and this will result in less ash being derived from the hillslopes. It should also be noted that, while total precipitation in pluvial climate would be greater, increased peak discharges or storm intensities would not be expected. The precipitation increase would come primarily in the form of more frequent rainfall events.

Confirmation Status-No confirmation needed.

Where Used-Section I6.5.

\section{I5.1.3 Stability of Distributary Channels and Neglect of Fluvial Erosion and Deposition on Interchannel Divides in the RMEI Location}

Assumption-The model assumes that distributary channels in the RMEI location are stable and do not migrate. Therefore, the areal fraction of channels and interchannel divides does not change with time.

Rational-Alluvial fans are dynamic landforms that can evolve topographically over both long and short time scales. A distinction can be made, however, between the evolution of alluvial fans over time scales of millions of years and the evolution of "entrenched" or "segmented" alluvial fans over shorter time scales. In tectonically-active areas and over time scales of millions of years, alluvial fans aggrade by sedimentation in channels and by channel shifting (avulsion). Over these long time scales, alluvial fans are best considered to be subject to redeposition across the entire fan area. The Quaternary period, however, has caused cycles of channel aggradation and incision on alluvial fans in the western Unites States. As a result of these cycles, fluvial activity on many alluvial fans is confined to a small fraction of the piedmont area near the modern channels. Older "terraces" are commonly preserved from previous episodes of aggradation and incision, but these terraces are no longer subject to fluvial activity, even during extreme events (Bull 1991 [DIRS 102040]). Surficial characteristics observed in the field, including well-developed desert pavement and varnish, provide evidence for the stability of channels and the lack of significant, soil-disruptive flood events on interchannel divides. Harrington (2003 [DIRS 164775]) observed well-developed desert pavements and varnish on interchannel divides in the RMEI location, indicating that most of these interchannel divide surfaces are Pleistocene in age and have not been subject to significant flooding for at least 10,000 years. As a result, they may be considered to be stable over the time scales considered by TSPA.

Confirmation Status-No testing or modeling activities are planned to provide further confirmation of this assumption. 
Where Used-Basis for areal ratio provided in Tables I-2 and I-3.

\section{I5.1.4 Neglect of Eolian Redistribution to the RMEI Location}

Assumption-The model assumes that eolian transport to the RMEI location can be neglected compared with fluvial transport processes.

Rationale-The model distinguishes between two outcomes of ASHPLUME: primary ashfall directly on the RMEI location (Outcome 1), and primary ashfall elsewhere (Outcome 2). Under Outcome 2, the redistribution of primary ashfall to the RMEI location must be considered. This redistribution occurs by a complex combination of eolian and fluvial processes. Redeposition of primary ashfall by eolian processes is neglected because redeposition by fluvial processes can be treated more accurately and results in a bounding case. Fluvial transport is considered to be the predominant process redistribution of primary ashfall for two reasons. First, the prevailing wind is away from the RMEI location and towards the drainage basin, so eolian transport is most likely to redistribute ash into the drainage basin (i.e., away from the RMEI location). Second, fluvial transport processes in a tributary drainage system have the effect of focusing material onto the RMEI location, while eolian processes act to disperse ash by repeated episodes of entrainment, turbulent dispersion in the atmosphere, and redeposition.

It should be noted that eolian redistribution of material at the RMEI location is included in the model using a Monte Carlo approach that assumes an equal probability of erosion and deposition. The neglect of eolian redistribution only applies to the initial redistribution of primary ashfall into the RMEI location under Outcome 2.

Confirmation Status-No testing or modeling activities are planned to provide further confirmation of this assumption.

Where Used-Section I6.5.

\section{I5.2 PARAMETER ASSUMPTIONS}

\section{I5.2.1 Initial Conditions}

Assumption-Initial redistributed tephra is assumed to be undiluted and this is an upper bound of the process. The lower bound would be a well-mixed tephra with no undiluted ash.

Rationale-The lack of dilution data from younger analog volcanoes precludes its use in TSPA so the undiluted upper bound is used.

Confirmation Status-None possible until quantitative dilution data are required as part of the model development plan.

Where Used-Table I-3. 


\subsubsection{Depth to the Impermeable Carbonate Horizon (L Values)}

Assumption-For interchannel divides, ${ }^{137} \mathrm{Cs}$ field data provides upper and lower bounds on net eolian erosion, and typical depths of 9 to $15 \mathrm{~cm}$ of the impermeable carbonate horizon. For the channels, it is assumed that a carbonate horizon can be at soil depths of 1.0 to $1.5 \mathrm{~m}$.

Rationale-Measurements have been made of depth to the carbonate layer on interchannel divides and in channels. Measurements on interchannel divides yield a typical range in depth between 9 and $15 \mathrm{~cm}$. No extensive measurements were made for channel carbonate layers. In two locations modern channels overlay older channels. In these older channels, a carbonate layer was observed at depths of 1.0 to $1.5 \mathrm{~m}$.

Confirmation Status-These data are taken from Ash and Soil Redistribution Studies Scientific Notebook (Harrington 2003 [DIRS 164775]). Confirmation would be part of the model development plan.

Where Used-Equations I-4, I-5, I-6, and I-8 through I-12.

\subsubsection{Rates of Eolian Erosion (E Values):}

Assumption-Eolian erosion and deposition is assumed to take place with equal probability during each time step. The magnitude of surface change over the ten ten-year time step used by TSPA is uniformly distributed between -0.04 and $0.04 \mathrm{~cm} / \mathrm{year}$.

Rationale $-{ }^{137}$ Cs studies at the RMEI location (Harrington 2003 [DIRS 164775).

Confirmation Status-This data is taken from Ash and Soil Redistribution Studies Scientific Notebook (Harrington 2003 [DIRS 164775]).

Where Used-Equations I-4, I-5, I-6, and I-8 through I-12.

\section{I6. MODEL DISCUSSION}

The potential consequences of an igneous event intersecting the repository (BSC 2004 [DIRS 169989]) require consideration of both the eruption and deposition of pyroclastic material and redistribution of that pyroclastic material after initial deposition. Section 6 presents the objectives, technical bases, and application of the two models that represents the eruption, deposition, and redistribution of volcanic ash. This section presents an alternative model for redistribution of the ash and the contained waste. Section 16 presents the modeling objectives. Section I6.2 presents the applicable features, events, and processes addressed by the models. Sections I6.3 to I6.5 provide the technical basis for the redistribution of waste-contaminated volcanic ash through sedimentary processes. 


\section{I6.1 MODELING OBJECTIVES}

The overall objectives of the alternative ash redistribution model are to:

- Represent the processes and the associated potential consequences related to redistribution of contaminated ash to and at the RMEI location

- Provide representative abstractions of the models with bounding conditions for inclusion in the post TSPA-LA application of the TSPA model.

The consequences of a volcanic eruption include consideration of the potential increase in dose at the location of the RMEI from the transport of radioactive-waste-contaminated ash through sedimentary processes. This potential consequence is described in Section I6.2 as a specific disruptive events FEP (FEP 1.2.04.07.0C).

The objective of the alternative ash redistribution model is to numerically represent the range of conditions that allow for the transport of waste-contaminated volcanic ash to the location of the RMEI by sedimentary processes that include both eolian and alluvial transport mechanisms. The alternative ash redistribution model also addresses the temporal near-surface and at-depth concentrations of waste in soil conditions at the location of the RMEI.

\section{I6.2 BASIS OF ALTERNATIVE REDISTRIBUTION MODEL}

The alternative ash redistribution model considers two bounding outcomes of ash atmospheric dispersion and settlement to the ground as calculated by ASHPLUME within the TSPA GoldSim calculations. Numerical abstractions from the alternative ash redistribution model would be provided for post TSPA-LA use by the TSPA GoldSim model for the purpose of calculating initial ash layer thickness and ground surface concentration at the RMEI location, as well as for calculating changes in these parameters over the regulatory period.

The bounding TSPA model outcomes one and two are already described in Section 6.3.2. Outcome 1 is defined as including eruptions for which primary tephra thickness at the RMEI location is greater than or equal to the minimum ash particle size, $0.001 \mathrm{~cm}$. Realizations in which the primary tephra thickness is less than $0.001 \mathrm{~cm}$ are then treated as examples of Outcome 2. Outcome 2 is also defined as corresponding with all ash dispersion and settlement within the Fortymile Wash basin (consistent with prevailing southwesterly winds), which is the source for potential downstream redistribution towards the RMEI location.

While the same concept of the two bounding model outcomes is used for the current presentation of the alternative ash redistribution model an improved approach, that will eliminate the dependency on outcome definition by primary ash thickness criterion, is outlined in the rationale of Section I5.1.1. This improved approach would take greater advantage of the numerical modeling capabilities of the alternative model and would be evaluated as part of the model development plan.

The outputs of the alternative as redistribution model are proposed as an abstraction for the post TSPA-LA use of the TSPA model for the purpose of combining with BDCFs to calculate the dose at the RMEI location. 


\section{I6.3 CONSIDERATION OF OTHER ALTERNATIVE REDISTRIBUTION MODELS}

Apart from the ash redistribution conceptual model described in Section 6.6, the resolution of this modeling requirement is unique.

\section{I6.4 DESCRIPTION OF THE ALTERNATIVE REDISTRIBUTION MODEL}

This section describes the concepts of the proposed alternative ash redistribution model (Section I6.5.1) and the numerical aspects (Section I6.5.2).

\section{I6.4.1 Primary Redistribution to RMEI Location Following an Eruption}

As described in Section 16.2, initial conditions for ash redistribution are distinguished by two bounding outcomes of the TSPA GoldSim model. Outcome 1 is that of the primary tephra sheet deposited at the location of the RMEI. Outcome 2 has the tephra sheet deposited within the Fortymile Wash drainage basin (consistent with prevailing southwesterly winds) at some distance upstream from the RMEI location. In the conceptual redistribution model currently used by TSPA, waste concentrations decrease at a specified rate with time. In the alternative redistribution model, the TSPA model outcomes affect the initial waste concentration only. The evolution of the waste concentration through time in the alternative model is calculated using process-based transport models to the greatest extent possible.

The initial ash thickness for Outcome 1 is given by the ash layer thickness calculated by the ASHPLUME code in the TSPA model. The waste concentration is the geometric mean waste concentration in ash, calculated by ASHPLUME at the $18-\mathrm{km}$ distance corresponding with the RMEI location. This applies to both channels and interchannel divides.

In Outcome 2, ash is redistributed to the RMEI area from the Fortymile Wash drainage basin by fluvial transport processes (eolian transport is assumed to be negligible). Fluvial processes are assumed to act only on the distributary channels of the RMEI location, so the interchannel divides of the RMEI location are ash-free in this outcome. The initial ash-layer thickness in the distributary channels is calculated by assuming that ash is distributed uniformly over the entire Fortymile Wash drainage basin upstream of the RMEI location. Fluvial transport is modeled by assuming that all ash deposited in channels and on steep ( $>10$ percent) slopes is immediately transported to the RMEI location in the manner described in Section I4.1.1.

\section{I6.4.1.1 Distinction Between Channels and Interchannel Divides in the RMEI Area}

The alternative ash redistribution model follows the conceptual ash redistribution model distinction of channels and interchannel divides, and tracking the waste in each landform type separately. Channels comprise $18 \%$ of the RMEI area, while interchannel divides comprise 82 percent (Harrington 2003 [DIRS 164775]).

\section{I6.4.1.2 Redistribution in the Soil Column}

Physical processes of waste redistribution and mixing in the soil column are modeled with the diffusion equation. Diffusion is a commonly used empirical model for hydrodynamic dispersion of solutes in porous media (Dagan 1989 [DIRS 147409], Sections 2.12.1, local scale; and 4.1, 
field scale). Confidence building in the use of the diffusion equation for radionuclide redistribution is described in Section I7. A single value of diffusivity is applied to waste, representing all radionuclides. Support for this assumption comes from Anspaugh et al. (2002 [DIRS 169793]), who noted that measurements indicate that different radionuclide species are dispersed in the soil column at similar rates (Anspaugh et al. 2002 [DIRS 169793]).

Redistribution on interchannel divides occurs within a permeable layer of depth $L$, where $L$ is the depth to the petrocalcic horizon, also known as the caliche layer. Soils in arid environments develop a petrocalcic horizon by solution and reprecipitation of calcium carbonate over time scales of tens to hundreds of thousands of years (Machette 1985 [DIRS 104660]). Deposition of calcium carbonate at depth in the soil decreases permeability locally until an impermeable layer forms. Petrocalcic horizons were observed at $8-10 \mathrm{~cm}$ depth on interchannel divides in the RMEI location where ${ }^{137}$ Cs samples were collected (Harrington 2003 [DIRS 164775]).

In channels, a finite permeable layer is also assumed because petrocalcic horizons are also observed in channels of the RMEI location. However, a different range of $L$ values is used for channels than for interchannel divides. In channels of the RMEI location, petrocalcic horizons were observed at depths of 1.0 to $1.5 \mathrm{~m}$ (Harrington 2003 [DIRS 164775]).

\section{I6.4.1.3 Redistribution by Eolian Transport}

It is assumed that eolian erosion and deposition takes place with equal probability during each time step. The magnitude of surface change over the ten-year time step used by TSPA is uniformly distributed between -0.04 and $0.04 \mathrm{~cm} /$ year, based on ${ }^{137} \mathrm{Cs}$ studies at the RMEI location (Harrington 2003 [DIRS 164775]). Material eroded from the surface is assumed to be transported out of the RMEI location without redeposition.

The effects of erosion and deposition are quantified separately for the surface concentration and the total waste in the soil column. In this portion of the model, the waste is considered to be completely mixed within the soil column. This assumption is necessary because diffusion with moving boundaries cannot be computed analytically. Therefore, as a simplifying assumption, the total waste in the subsurface is treated as being uniformly mixed. The assumption of fully-mixed waste is appropriate because erosion and deposition take place over time scales much greater than mixing. For example, complete mixing of waste in a $10-\mathrm{cm}$ deep soil column requires time scales of several centuries with diffusivity, $D=0.1 \mathrm{~cm}^{2} /$ year, while significant soil erosion or deposition over the same depth requires millennia or longer.

\section{I6.4.1.4 Redistribution by Fluvial Transport}

It is assumed that no fluvial erosion or deposition takes place on interchannel divides in the RMEI location. The presence of well-developed desert pavements in these areas suggests that they have not received sufficient flow depths to entrain soil material for time scales of thousands of years or longer (Harrington 2003 [DIRS 164775]). In channels, fluvial erosion and deposition is not explicitly included in the model, but its effect on the migration rate of radionuclides is implicitly included in the mixing rates, or diffusivities, inferred from radionuclide concentrations measured in channels at the RMEI location (Harrington 2003 [DIRS 164775]). 


\section{I6.4.2 Mathematical Description of the Alternative Ash Redistribution Model}

\section{I6.4.2.1 Definition of Model Variables}

$z$-depth in the soil profile relative to the surface elevation

$t_{1}-$ time

$C_{0}$ - initial concentration of waste

$d_{\mathrm{w}}$ - initial thickness of ash/waste

$C\left(z, t_{1}\right)$ - waste concentration at location $x$ and time $t_{1}$

$C_{\mathrm{T}}\left(t_{1}\right)$ - total waste in soil column at time $t_{1}$

$L$ - depth to impermeable boundary (i.e., petrocalcic horizon)

$L_{0}-$ initial depth to impermeable boundary

$E$ - rate of eolian erosion (positive $E$ ) and deposition (negative $E$ )

$D$ - diffusivity

$A$ - area of upper fan where RMEI is located

$f$ - fraction of ash deposited in Fortymile Wash drainage basin redistributed to the RMEI location

\section{I6.4.2.2 Initial Conditions}

Outcome 1 (primary ashfall)-The initial ash thickness and waste concentration at the RMEI location are calculated by ASHPLUME in the TSPA model. The same values are used for channels and interchannel divides.

Outcome 2 (primary ashfall elsewhere, redistribution to the RMEI location)-Fluvial transport of ash from the Fortymile Wash drainage basin to the RMEI location is the focus of the redistribution model under Outcome 2. Fluvial transport is considered to be the predominant process for redistributing large quantities of ash to the RMEI location for two reasons. First, the prevailing wind is away from the RMEI location and towards the drainage basin, so eolian transport is most likely to redistribute ash into the drainage basin or within the drainage basin in Outcome 2. Second, fluvial transport processes have the effect of focusing material onto the RMEI location, while eolian processes are most likely to disperse ash by repeated episodes of entrainment, turbulent dispersion in the atmosphere, and redeposition. For this reason, an assumption of $100 \%$ fluvial transport is likely to represent an upper bound for ash thickness redistributed to the RMEI location.

The erupted mass under Outcome 2 is assumed to be deposited entirely within the Fortymile Wash drainage basin. The prevailing wind direction and large size of the drainage basin are consistent with this assumption. Not all of the ash will be transported out of the drainage basin, however. Field observations and measurements suggest that ash layers can remain stored on low-gradient hillslopes for tens of thousands of years or longer (Harrington 2003 [DIRS 164775]). Long-term storage can occur for many reasons, but one reason is that the fluvial system often responds to a pulse of sediment by localized fluvial incision. Incision quickly excavates sediment within a narrow, channelized region, but stores the remaining material as an abandoned fluvial terrace. The persistent storage of mining waste is one example of long-term storage in perturbed fluvial systems (Marcus et al. 2001 [DIRS 171177]). 
To account for long-term storage of ash within the drainage basin, the volume of erupted ash is multiplied by a fluvial transport fraction $f$. The value of $f$ is a function of the drainage basin morphology, with increasing values for basins with steep slopes and high drainage densities. To calculate the value of $f$ for the Fortymile Wash drainage basin, it was assumed that all of the ashfall on active channels and slopes steeper than $10 \%$ would be transported out of the basin within the first 10 years following the eruption. Conversely, ashfall on hillslopes less that $10 \%$ is assumed to be permanently stored. The value of $f$ for the Fortymile Wash drainage basin was calculated to be 27.6 percent in the scoping exercise analysis of Section I4.

Ash transported by sheetflow to the RMEI location is assumed to be deposited with uniform thickness across the upper fan of Fortymile Wash as shown in Figure 6-1. This assumption was used to take into account the possibility that channels may fill with ash and avulse onto the interchannel divides. Also, this assumption represents a conservative or bounding case, since ash concentrated in the channels would have a lower areally-averaged surface concentration compared with ash distributed uniformly across the upper fan.

Expressed mathematically, the ash-layer thickness for Outcome 2 is given by

$$
d_{w}=\frac{Q f}{A \Psi_{p}}
$$

according to this conceptual model, where $\mathrm{Q}$ is the total mass of erupted material, and $\Psi_{p}$ is the ash particle density. The waste concentration is given by the geometric mean $18-\mathrm{km}$ ASHPLUME concentration. The waste concentration will likely be lower than this value due to mixing of the ash with uncontaminated sediment during transport to the RMEI location. However, this effect cannot be readily quantified without additional measurements from analog sites, so dilution is not included in the model at this time. The initial conditions are summarized in Table I-2.

Table I-2. Initial Conditions for the Alternative Redistribution Model

\begin{tabular}{|c|c|c|}
\hline & Interchannel Divides & Distributary Channels \\
\hline AREAL RATIO (\%) & 0.82 & 0.18 \\
\hline $\begin{array}{l}\text { Outcome } 1 \\
\text { Primary tephra (ash } \\
\text { fall) in the vicinity of } \\
\text { the RMEI location. }\end{array}$ & $\begin{array}{l}\text { Ash-layer (tephra) thickness calculated } \\
\text { by ASHPLUME in the TSPA model. } \\
\text { Initial waste areal concentration } \\
\text { calculated in TSPA for the ash layer at } \\
\text { the location of the RMEI. }\end{array}$ & $\begin{array}{l}\text { Ash-layer (tephra) thickness calculated } \\
\text { by ASHPLUME in the TSPA model. } \\
\text { Initial waste areal concentration } \\
\text { calculated in TSPA for the ash layer at } \\
\text { the location of the RMEI. }\end{array}$ \\
\hline $\begin{array}{l}\text { Outcome } 2 \\
\text { No primary tephra fall } \\
\text { on or near the RMEI } \\
\text { location. Primary } \\
\text { tephra deposition in } \\
\text { upper Fortymile } \\
\text { Wash drainage } \\
\text { basin. }\end{array}$ & $\begin{array}{l}\text { Ash-layer (tephra) thickness calculated } \\
\text { with Eq. I-1: } \\
d_{w}=\frac{Q f}{A \Psi_{p}} \\
\text { Initial waste concentration: geometric } \\
\text { mean 18-km ASHPLUME volumetric } \\
\text { concentration (see Table 6-4). }\end{array}$ & $\begin{array}{l}\text { Ash-layer (tephra) thickness calculated } \\
\text { with Eq. I-1: } \\
d_{w}=\frac{Q f}{A \Psi_{p}} \\
\text { Initial waste concentration: geometric } \\
\text { mean 18-km ASHPLUME volumetric } \\
\text { concentration (see Table 6-4). }\end{array}$ \\
\hline
\end{tabular}




\section{I6.4.2.3 Redistribution in the Soil Column}

Redistribution in the soil column is modeled as a diffusion process, so the concentration of radionuclides is given by the solution to the one-dimensional diffusion equation in a finite layer from $z=0$ to $z=L$, with no-flux boundary conditions and a waste mass of $C_{0} d_{\mathrm{w}}$ input at $z=0$ at $t_{1}=0$ :

$$
C\left(z, t_{1}\right)=C_{0} d_{w}\left(\frac{1}{L}+\frac{2}{L} \sum_{n=1}^{\infty} \cos \left(\frac{n \pi z}{L}\right) \mathrm{e}^{-n^{2} \pi^{2} D t_{1} / L^{2}}\right) .
$$

This solution is given by Carslaw and Jaeger (1959 [DIRS 100968], Section 14.3, eq. (7)), who applied the diffusion equation to the transport of heat in solids. Mathematical solutions to the diffusion equation are general, however, and can be applied to both heat and mass diffusion. Therefore, the solution given by Carslaw and Jaeger (1959 [DIRS 100968], Section 14.3, eq. (7)) also holds for radionuclide dispersion in soils, as long as diffusion is an appropriate model for this process.

Figure I-3 illustrates the behavior of the model for representative values of $D=0.1 \mathrm{~cm}^{2} /$ year and $L=10 \mathrm{~cm}$. This figure shows that the distribution of waste behaves as a spreading bell curve. A uniform, steady-state radionuclide distribution is reached approximately 200 years for these parameter values. The steady-state concentration is given by

$$
C(z, \infty)=\frac{C_{0} d_{w}}{L}
$$

\subsubsection{Redistribution by Eolian Erosion and Deposition}

Eolian erosion and deposition is considered to be the predominant process of active aggradation and degradation on alluvial-fan surfaces older than 10,000 years (Wells et al., 1995 DIRS 171051]). For this reason, interchannel divides in our model are assumed to evolve by eolian processes only; fluvial erosion and deposition is neglected. Eolian erosion and deposition is highly spatially and temporally variable (Whicker et al., 2002 [DIRS 171050]). Direct measurements of erosion and deposition on the Fortymile Wash fan (Harrington 2003 [DIRS 164775]) reflect this variability. Measurements of ${ }^{137} \mathrm{Cs}$ concentrations from the Fortymile Wash alluvial fan indicate that fan surfaces have eroded by $0-0.04 \mathrm{~cm} /$ year during the past fifty years (Harrington 2003 [DIRS 164775]). Over geologic time, however, silt has been deposited on many surfaces beneath the desert pavement. These silt deposits, or A zone vesicular $\left(A_{v}\right)$ soil horizons, generally increase in thickness with age where they are found. The thickness of $A_{v}$ horizons does not increase linearly with age, however. Instead, a ten-fold increase in surface age may lead to only a doubling of $A_{v}$ horizon thickness. Not all older surfaces have $A_{v}$ horizons; some have been stable or have undergone net erosion (Reheis et al. 1995 [DIRS 106658]). 


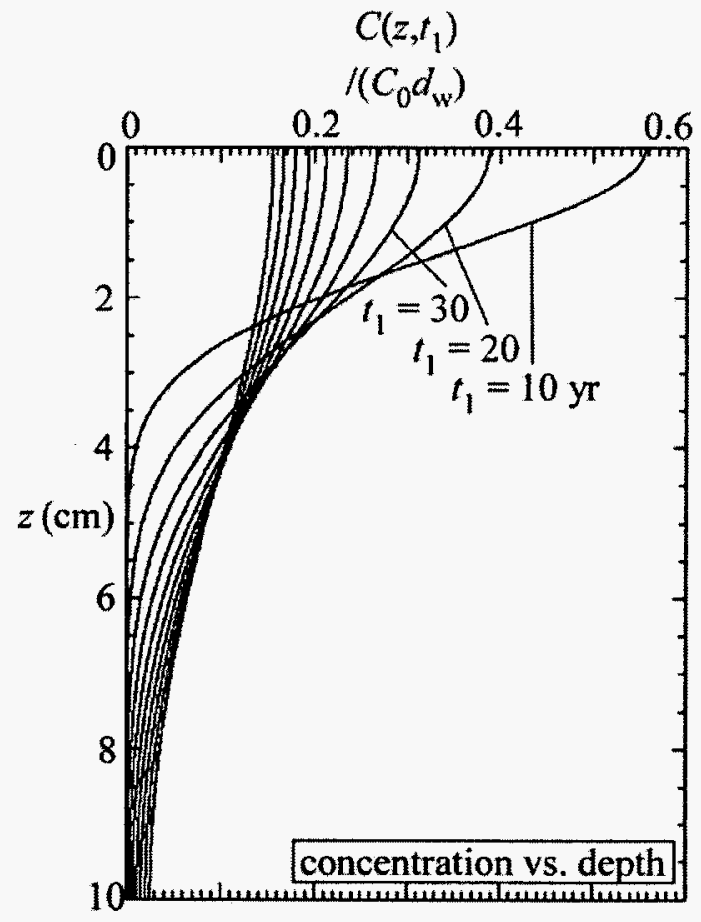

Source: Harrington 2004 [DIRS 171907], pp. 82-94.

NOTES: Model parameters are $L=10 \mathrm{~cm}$ and $D=0.1 \mathrm{~cm}^{2} / \mathrm{yr}$. Early phase of model evolution (e.g., 10-100 years) is dominated by dispersion of the waste within the soil column. The waste becomes uniformly mixed after about 200 years.

Figure 1-3. Plots of Concentration (Normalized to Initial Concentration) vs. Depth for a Range of Values of Time $\left(t_{1}\right)$

To account for the temporal variability of erosion and deposition on alluvial-fan surfaces, erosion and deposition are assumed to occur with equal probability during each time step in the TSPA model. The erosion rate $E$ was sampled from a uniform distribution between $-0.04 \mathrm{~cm} /$ year (deposition) and $0.04 \mathrm{~cm} /$ year (erosion). This range of magnitudes for $E$ is constrained by ${ }^{137} \mathrm{Cs}$ measurements made at the RMEI location (Harrington 2003 [DIRS 164775]).

The implications of this model for long-term erosion and deposition on the fan can be determined by considering the behavior of a Brownian motion. A Brownian motion is a function with increments that are random and have a mean of zero. Erosion and deposition on the fan surface is a random variable with zero mean, so the surface elevation is a Brownian motion. Two realizations of a Brownian motion are given in Figure I-4 at three different time scales. At the longest time scale $\left(10^{6}\right.$ years), one surface has aggraded by approximately $5 \mathrm{~cm}$ and the other surface has eroded by the same amount. On shorter time scales $\left(10^{5}\right.$ and $10^{4}$ years $)$, the net elevation changes are smaller, but they are not linear with the time scale. For example, the surface changes by about $1 \mathrm{~cm}$ in $10^{4}$ years, a much larger change per unit time than the $5 \mathrm{~cm}$ observed over $10^{6}$ years.

This behavior illustrates an important trait of Brownian motion that is similar to the observed behavior of alluvial fan surfaces: the rate of net change decreases with the time scale. The 
average or expected value of the surface elevation change according to the Brownian motion model is derived from van Kampen (1997 [DIRS 151889], Section 8.3, p. 201)

$$
\left\langle\left|L\left(t_{1}\right)-L_{0}\right|\right\rangle=\langle|E|\rangle t_{1}^{1 / 2}
$$

where the brackets denote the average value. To compute the rate of net elevation change, Equation I-4 is divided by $t_{1}$ to give

$$
\frac{\left\langle\left|L\left(t_{1}\right)-L_{0}\right|\right\rangle}{t_{1}}=\langle|E|\rangle t_{1}^{-1 / 2} .
$$

Equation I-5 is plotted in Figure I-4B as the solid line (note the logarithmic scales on both axes). Also plotted are the silt accumulation rates measured by Taylor (1986 [DIRS 102864]) for alluvial-fan surfaces in Fortymile Wash and Yucca Wash ranging from $10^{4}$ years to $10^{6}$ years in age. The Brownian motion model predicts somewhat higher rates of net erosion and deposition than those inferred by Taylor (1986 [DIRS 102864]). This could mean that erosion rates measured for the past fifty years are anomalously high, or that geomorphic surfaces are somewhat more stable than the predictions of the Brownian motion model over geologic time scales. Better agreement with the long-term rates could be achieved by choosing a smaller range of values for $E$, for example. Choosing a smaller range would lower the line in Figure I-4B to better overlap with the geologic data.

Eolian erosion and deposition control the waste concentration in the soil by removing it from the soil column and burying it at greater depths, respectively. Therefore, the first effect of erosion and deposition is to make the soil depth $L$ a time-dependent variable. The value of $L$ at a given time step $t_{1}$ is equal to the initial value $L_{0}$ plus the integral of erosion and deposition up to time $t_{1}$ :

$$
L\left(t_{1}\right)=L_{0}+\int_{0}^{t_{1}} E(t) d t
$$

An ideal model for the effects of erosion and deposition with diffusion in the soil column would use Equation I-6 with a generalized version of Equation I-2 applicable to the case with moving boundaries (i.e., a surface undergoing erosion and deposition). The diffusion equation is not analytically solvable with most types of moving boundaries, however, so a simplifying assumption is made. The waste is assumed to be uniformly mixed within the soil column. This assumption reduces the time-dependent radionuclide distribution (Equation I-4) to the steady-state distribution (Equation I-5) for the purposes of erosion and deposition. The appropriateness of this assumption is strongly supported by the wide separation of time scales between diffusion, which occurs over time scales of centuries, and significant erosion and deposition, which occur over time scales of $10^{4}-10^{6}$ years.

In all cases it is assumed that the impermeable lower soil boundary (petrocalcic horizon) is stationary. This is a good assumption considering both the impermeable nature of the boundary (i.e., it cannot migrate downward by dissolution and reprecipitation) and because of the time required $\left(\approx 10^{5}\right.$ years) to form impermeable petrocalcic horizons. Significant silt deposition 
would likely cause the petrocalcic horizon to thicken and aggrade, but the time scale for this process is too long to significantly affect the model behavior.

Erosion and deposition affect the surface concentration and total waste differently. First, the effects of erosion, shown schematically in Figure I-6, are considered. Erosion removes waste from the soil column, so the total waste in the column decreases. The surface concentration, however, is unchanged because the permeable soil thickness and the total waste both decrease by an amount proportional to the erosion depth $\Delta z$. If the surface erodes by an amount $\Delta z$, the total waste decreases by a ratio of $\Delta z / L$, or

$$
\Delta C_{T}=-\frac{\Delta z}{L} C_{T}
$$

Using $\Delta z / \Delta t=E$ and taking the limit as $\Delta t \rightarrow 0$, Eq. I- 8 becomes

$$
\frac{\partial C_{T}(t)}{\partial t}=-\frac{E}{L} C_{T}
$$

The solution to Equation I-8 is

$$
C_{T}\left(t_{1}\right) \propto \mathrm{e}^{-\int_{0}^{1} \frac{E}{L} d t} .
$$

The effects of silt deposition are shown schematically in Figure I-6. In contrast to eolian erosion, silt deposition does not change the total waste mass in the soil column. It does, however, decrease the surface concentration by burying some waste deeper in the column. The effect of deposition on the surface concentration is mathematically identical to the effect of erosion on the total concentration. Therefore, Equation I-9 can be used to quantify the effect of deposition on the surface concentration. The only required change is to introduce a negative sign in front of $E$ in Equation I-9 to cancel the negative values for $E$.

Equations I-8 and I-9 are appropriate for continuous erosion and deposition only. To generalize these equations for unsteady erosion and deposition, it is necessary to introduce the Heavyside function, given by

$$
H(E)=\left\{\begin{array}{lll}
E & \text { if } & E>0 \\
0 & \text { if } & E<0
\end{array}\right\}
$$



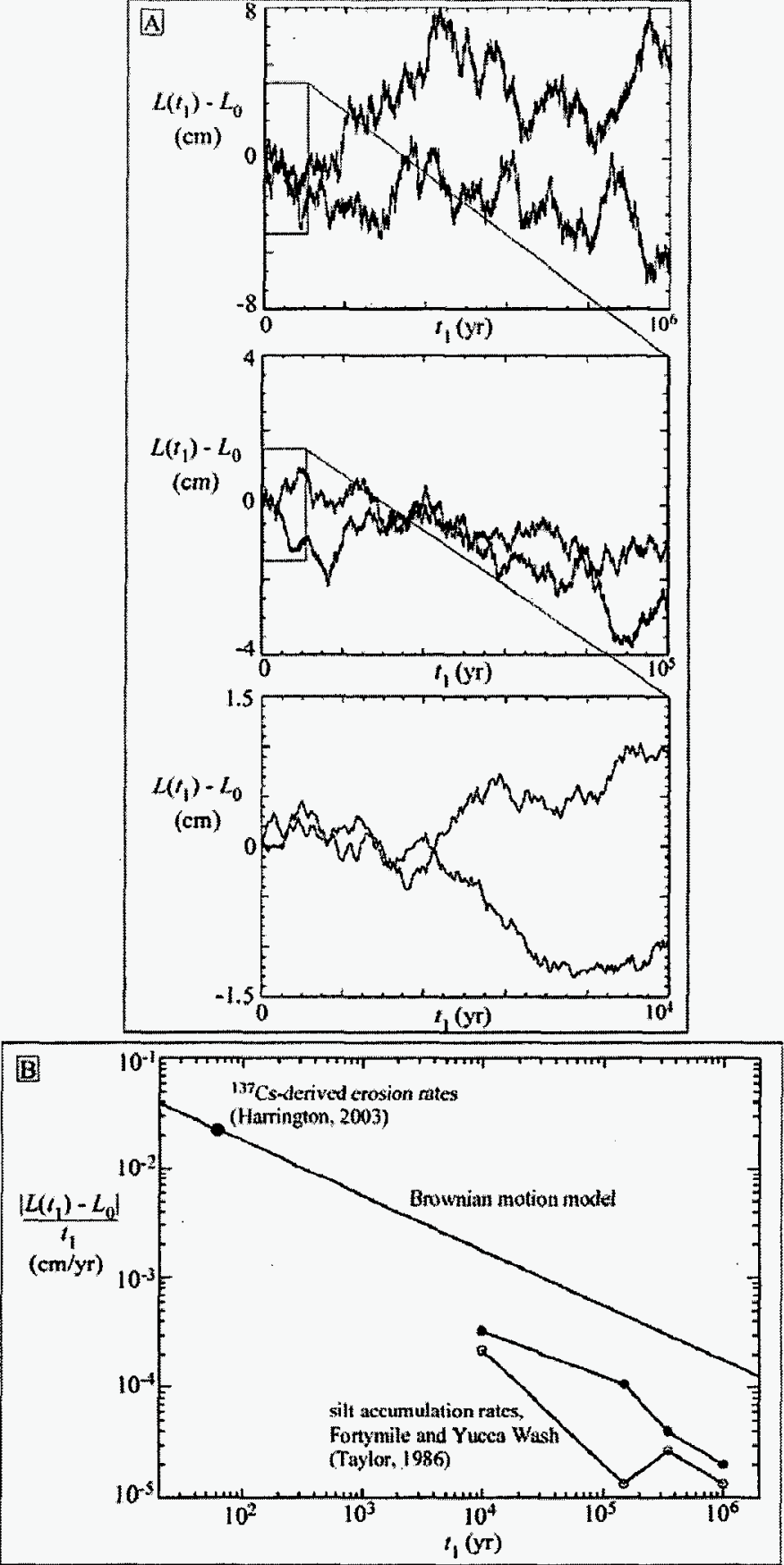

NOTE: (A) Two realizations of a Brownian motion, shown over time scales of $10^{6}$ years (top), $10^{5}$ years (middle), and $10^{4}$ years (bottom). (B) Plot of rate of net surface elevation change versus time scale. Solid line represents the prediction of a Brownian motion constrained to match the ${ }^{137} \mathrm{Cs}$-derived erosion rates of Harrington (2003 [DIRS 164775]). Also shown are silt-accumulation rates for alluvial-fan surfaces ranging in age from $10^{4}-10^{6}$ years from Taylor (1986 [DIRS 102864]).

Figure 1-4. Illustration of the Brownian Motion Model for Erosion and Deposition 


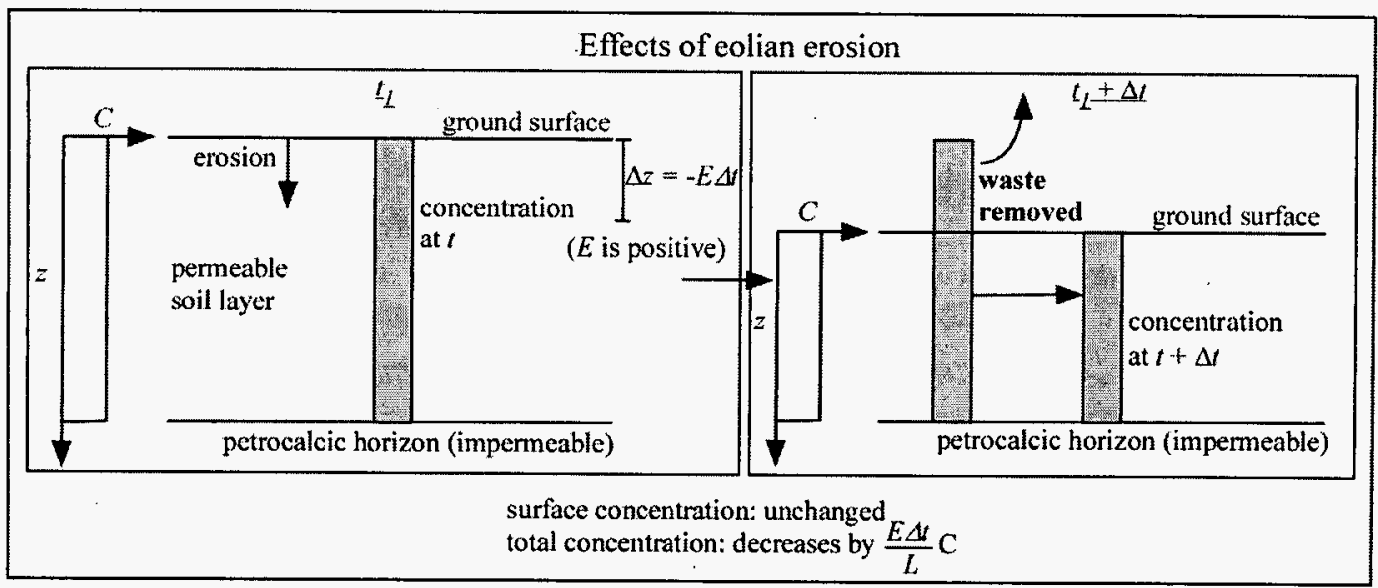

For illustration purposes only.

NOTE: Erosion decreases the total waste in the soil column but leaves the surface concentration unchanged. Diagrams show soil-layer geometry and concentration profiles at $t$ (left) and $t+\Delta t$ (right).

Figure 1-5. Schematic Illustration of the Dilution Effect During Eolian Erosion

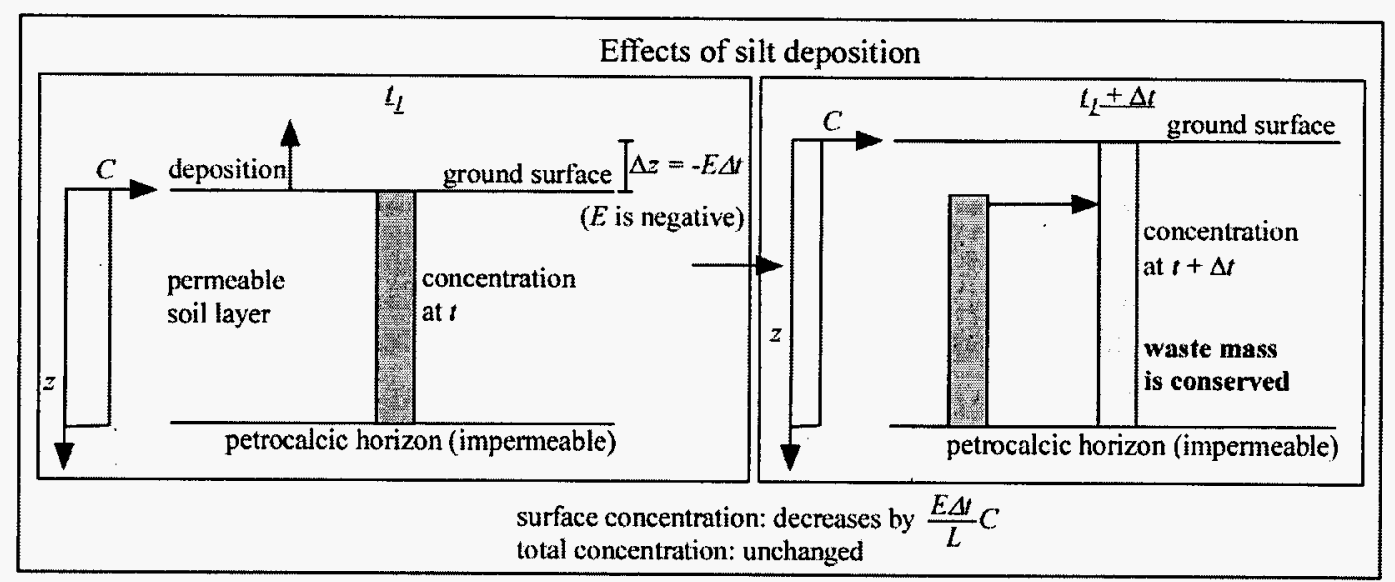

For illustration purposes only.

NOTE: Deposition decreases the surface concentration but leaves the total concentration unchanged.

Figure 1-6. Schematic Illustration of the Dilution Effect of Silt Deposition

The Heavyside function allows integration of the effects of erosion or deposition through time, taking into account only instances where net erosion (or deposition) takes place. Using Equation (I-11), the total waste mass is given by

\section{Total waste mass:}

$$
C_{T}\left(t_{1}\right)=C_{0} d_{w} \mathrm{e}^{-\int_{0}^{t} \frac{H(E)}{L} d t}
$$


and the surface concentration is given by

\section{Surface concentration:}

$$
C\left(0, t_{1}\right)=C_{0} d_{w} \mathrm{e}^{\int_{0}^{t} \frac{H(-E)}{L} d t}\left(\frac{1}{L_{0}}+\frac{2}{L_{0}} \sum_{n=1}^{\infty} \mathrm{e}^{-n^{2} \pi^{2} D t_{1} / L_{0}^{2}}\right) .
$$

Equation I-12 includes the dilutionary effects of deposition through the integral term, and the dispersion effects through Equation I-4, evaluated for $z=0$.

\section{I6.5 MODEL RESULTS AND ABSTRACTIONS}

This section provides the model abstraction for ash redistribution for use in the TSPA model.

The proposed output parameters of the alternative ash redistribution model for use in TSPA are summarized in Table I-3 in terms of the two tephra fall/redistribution outcomes described in Section I6.2, as well as the two main geomorphic features at the RMEI location (interchannel divides and distributary channels). The format of Table I-3 is parallel to that of Table 6-5, which describes the abstraction of the existing conceptual ash redistribution model. For the purposes of TSPA, the distinction between Outcomes 1 and 2 is consistent with the conceptual ash redistribution model and is made on the basis of the presence of non-negligible thickness of ash at the RMEI location (also see potential improvement, rationale of Section I5.1.1). Non-negligible ash thickness should be defined as greater than or equal to the smallest mean ash particle diameter of $0.001 \mathrm{~cm}$. This thickness, or greater, of ash constitutes ash fall at the RMEI location (Outcome 1); less than $0.001 \mathrm{~cm}$ constitutes Outcome 2.

\section{I7. MODEL VALIDATION}

Should this alternative mathematical diffusion model be used in the future, it must be validated for its intended use. Validation should proceed by correlating observed radionuclide concentrations in soils from several appropriate analog sites with predictions by the alternative ash redistribution model. The objective of the validation tests would be to assess how well the diffusion model predicts the concentration-depth profiles of radionuclides. Selection and/or assessment of compared $D$ values would require consideration for differences in climate and soil type. Data identified as available for use in this analysis include ${ }^{137} \mathrm{Cs}$ data from the Ukraine after the Chernobyl accident (Likhtarev et al. 2002 [DIRS 169810]), and ${ }^{137}$ Cs data from a field experiment in the UK (Gale et al. 1964 [DIRS 169807]). Other considerations for suitable sites would include a search for natural radionuclide tracer analogs involving alluvial sedimentation and climate appropriate to that of the YMR. 
Table I-3. Abstraction of Ash Redistribution Model for TSPA

\begin{tabular}{|c|c|c|}
\hline & Interchannel Divide & Distributary Channels \\
\hline AREAL WEIGHT & 0.82 & 0.18 \\
\hline $\begin{array}{l}\text { Outcome } 1 \\
\text { Primary tephra (ash } \\
\text { fall) in the vicinity of } \\
\text { the RMEI location. }\end{array}$ & $\begin{array}{l}\text { Initial condition } \\
\text { Ash-layer (tephra) thickness } \\
\text { calculated by ASHPLUME in the } \\
\text { TSPA model. } \\
\text { Initial waste areal concentration } \\
\text { calculated in TSPA for the ash } \\
\text { layer at the location of the RMEI. } \\
\text { Temporal Values at the RMEI } \\
\text { Numerical expressions will be } \\
\text { provided for calculation of, } \\
\text { a) Near-surface waste } \\
\text { concentration in soil column } \\
\text { b) Areal concentrations of waste in } \\
\text { soil } \\
\text { c) At-depth concentrations of waste } \\
\text { in soil column }\end{array}$ & $\begin{array}{l}\text { Initial condition } \\
\text { Ash-layer (tephra) thickness calculated by } \\
\text { ASHPLUME in the TSPA model. } \\
\text { Initial waste areal concentration calculated in } \\
\text { TSPA for the ash layer at the location of the } \\
\text { RMEI. } \\
\text { Temporal Values at the RMEI } \\
\text { Numerical expressions will be provided for } \\
\text { calculation of, } \\
\text { a) Near-surface waste concentration in soil } \\
\text { column } \\
\text { b) Areal concentrations of waste in soil } \\
\text { c) At-depth concentrations of waste in soil } \\
\text { column }\end{array}$ \\
\hline $\begin{array}{l}\text { Outcome } 2 \\
\text { No primary tephra } \\
\text { fall on or near the } \\
\text { RMEI location. } \\
\text { Primary tephra } \\
\text { deposition in upper } \\
\text { Fortymile Wash } \\
\text { drainage basin. }\end{array}$ & $\begin{array}{l}\text { Initial condition } \\
\text { Ash-layer (tephra) thickness } \\
\text { calculated with Eq. I-1: } \\
d_{w}=\frac{Q f}{A \Psi_{p}} \\
\text { Initial waste concentration: Mean } \\
\text { primary waste concentration (see } \\
\text { Table 6-4). } \\
\text { Temporal Values at the RMEI } \\
\text { Same as for Outcome } 1\end{array}$ & $\begin{array}{l}\text { Initial condition } \\
\text { Ash-layer (tephra) thickness calculated with } \\
\text { Eq. l-1: } \\
d_{w}=\frac{Q f}{A \Psi_{p}} \\
\text { Initial waste concentration: Mean primary } \\
\text { waste concentration (see Table 6-4). } \\
\text { Temporal Values at the RMEI } \\
\text { Same as for Outcome } 1\end{array}$ \\
\hline
\end{tabular}

Source: Areal weights are developed in Harrington (2004 [DIRS 171345], p. 77).

\section{I8. CONCLUSIONS}

Summary Of Modeling Activity-The mathematical model of this appendix is presented as an alternative to the conceptual model of this AMR. The model explicitly includes redistribution within the soil column and eolian erosion and deposition within and out of the RMEI location. Fluvial erosion and deposition within channels in the RMEI location is not considered explicitly, but+- is implicitly included by enhanced mixing in the soil column of channel environments. Redistribution in the soil column is governed by the diffusion equation.

Eolian erosion and deposition is a complex process characterized by temporal variability at all scales. This variability is captured naturally within Monte Carlo model framework; however, by assuming that erosion and deposition occur with equal probability during each time step. This approach is consistent with both short-term (decadal-scale) measurements of eolian erosion and long-term $\left(10^{4}-10^{6}\right.$ years) rates of net erosion or deposition on the Fortymile Wash alluvial fan.

The primary simplifications of the model are associated with the initial redistribution of tephra to the RMEI location shortly following the eruption (i.e., within the initial ten-year TSPA time step following the eruption). Ideally, all of the ash initially deposited on the landscape would be calculated by Ashplume and would be tracked within a three-dimensional process-based 
geospatial model, including eolian, fluvial, and soil processes. The version of Ashplume currently used within TSPA does not model the full, two-dimensional pattern of deposition, however, and no calibrated geospatial model is readily available for modeling eolian and fluvial transport in the area surrounding the YMR. In place of such a model, the initial redistribution to the RMEI location is treated using a simple either/or approach (dependent on the location of initial plume deposition), and the subsequent redistribution within and out of the RMEI location is treated in more detail. The initial redistribution to the RMEI location is determined by whether primary ashfall occurs on the RMEI location (Outcome 1) or whether it occurs elsewhere (Outcome 2). In the case of outcome 1, no additional tephra is transported to the RMEI area. In Outcome 2, fluvial transport from the Fortymile Wash drainage basin is considered to be the dominant process of transport to the RMEI location.

It is recognized that the waste mass redistributed to the RMEI location in Outcome 2 should represent a bounding case. Fluvial transport of ash from the Fortymile Wash drainage basin is assumed to be responsible for transporting most of the ash under outcome 2 . This is consistent with the fact that fluvial transport is highly concentrative while eolian redistribution is dispersive. Fluvial transport and deposition is highly complex, but analog field sites would provide constraints on the amount of ash that may be redistributed to the RMEI location from an initial deposition site upstream. Based on observations by Harrington, 2003 [DIRS 164775], it is expected that the proposed further studies will suggest that ash can be readily mobilized from steep slopes (e.g., greater than 10 percent gradient) and stored for tens to hundreds of thousands of years on shallower slopes. In that case, the tephra mass from slopes greater than 10 percent gradient would be assumed to be transported and deposited in the channels of the RMEI location. Some of the tephra would likely be transported through the RMEI location further downstream. By assuming all of the mass is deposited at the RMEI location the initial condition defined in this manner would be a bounding case.

\section{SUPPLEMENTARY SUPPORTING DATA}

\section{I9.1 Description of Redistribution of Radionuclides In Soil Criteria}

The health physics community has studied the processes of radionuclide migration into soils since the advent of the atomic age, mostly from the point of view of resuspension of radionuclides for airborne transport and potential human dose. It was early recognized that one of the factors controlling the concentration of radionuclides available for resuspension is its "weathering," in which the radionuclides becomes less erodible (Anspaugh et al. 1975 [DIRS 151548], p. 576). This weathering process includes mixing with surface soil and vertical migration into the soil (Anspaugh et al. 2002 [DIRS 169793], p. 677). From the body of work summarized in Anspaugh et al. (2002 [DIRS 169793], p. 677) and others where noted, the following are general statements that reflect the state of knowledge about radionuclide migration into soil:

- Radionuclides deposited in soil immediately experience a surface-roughness process that is equivalent to shielding by a 1-mm layer of soil.

- Radionuclides move to an average depth of about $1 \mathrm{~cm}$ within one month. 
- Within a year radionuclides move to a depth of $3 \mathrm{~cm}$ and slowly move to greater depths.

- Results for ${ }^{129} \mathrm{I},{ }^{137} \mathrm{Cs},{ }^{239} \mathrm{Pu}$, and ${ }^{240} \mathrm{Pu}$ studies after the Chernobyl accident indicate that all of these radionuclides move into the soil at the same rate and that their distributions in the soil were essentially identical. Anspaugh et al. (2002 [DIRS 169793]) conclude that the process of radionuclide migration into soil is essentially a physical, rather than chemical process, and although data are limited on other radionuclides, the ${ }^{235} \mathrm{U}$ data from the Nevada Test Site (Gilbert and Eberhardt 1976 [DIRS 169808]) seem to follow similar migration rates.

- Local climate and soil conditions may result in significant differences in radionuclide migration rates.

- Vertical migration of radionuclides in montmorillonite and illite-bearing soils (like those at the Nevada Test Site) is due to freeze/thaw and wet/dry cycles that granulate the soil by aggregation and dispersion, enhancing the mechanical movement and downward migration of high-density particles. Migration of radionuclides in solution in infiltrating water is considered less important (Romney et al. 1970 [DIRS 169811], pp. 488-489).

Radionuclide concentrations measured in the field are bulk measurements. Rather than measure point concentrations, the concentration within different depth intervals is usually measured (BSC 2004 [DIRS 169980], Table 6-8). For the purposes of extracting model parameters from observed data, it is most accurate to represent measured data cumulatively as the fraction of total concentration to a given depth. To compare the diffusion-model predictions to this normalized cumulative curve, it is necessary to integrate the solution to the diffusion equation in a semi-infinite column with a no-flux boundary condition at the surface and a waste mass of $C_{0} d_{\mathrm{w}}$ input at $z=0$ at $t_{1}=0$ (Carslaw and Jaeger 1959 [DIRS 100968] Chapter 14.2, eq. (1)):

$$
\frac{C\left(z, t_{1}\right)}{C_{0} d_{w}}=\frac{1}{\sqrt{\pi D t_{1}}} \mathrm{e}^{-z^{2} / 4 D t_{1}},
$$

to give

$$
\int_{0}^{z} \frac{C\left(\zeta, t_{1}\right)}{C_{0} d_{w}} d \zeta=\operatorname{erf}\left(\frac{z}{\sqrt{4 D t_{1}}}\right)
$$

where erf is the error function and $\zeta$ is an integration variable for depth. Equations I-13 and I-14 approximate the permeable soil layer as semi-infinite. This is an accurate approximation, even in a soil with a petrocalcic horizon at depth, because radionuclides do not penetrate far into the soil over time scales of several decades (the maximum time scale for man-made radionuclides). As such, near-surface concentrations are not affected by the presence of an impermeable barrier at $10 \mathrm{~cm}$ depth. It should also be noted that radioactive decay need not be considered explicitly in this analysis because decay does not affect the spatial distribution of radionuclide concentration for a normalized cumulative curve. 
${ }^{137} \mathrm{Cs}$ distributions measured by Harrington (2003 [DIRS 164775]) were used to calibrate values of the radionuclide diffusivity $D$. To calculate $D$, the fraction of total activity at $3 \mathrm{~cm}$ was first computed by dividing the activity from $0-3 \mathrm{~cm}$ by the total activity from $0-6 \mathrm{~cm}$ (column 2 in table I-4). Equation I-14 was then used to infer the value of the error function argument, equal to $z / \sqrt{4 D t_{1}}$, corresponding to the fraction of activity at $3 \mathrm{~cm}$ after $50 \mathrm{yr}$ of diffusion following nuclear testing (column 3 in table I-4). A table of calculated error function values was used for this purpose. This value was then used to solve for $D$ (column 4 in table I-4).

Table 1-4. Calibration Values for $D$

\begin{tabular}{|c|c|c|c|}
\hline Sample ID & $\begin{array}{c}\text { fraction at } 3 \mathbf{c m}= \\
\left.\text { erf(3 cm/(4D 50 } \mathbf{y r})^{1 / 2}\right)\end{array}$ & $3 \mathbf{c m} /(\mathbf{4 D} 50 \mathbf{~} \mathbf{r r})^{1 / 2}$ & $D\left(\mathbf{c m}^{2} / \mathbf{y r}\right)$ \\
\hline Cs-071702-A & 0.8274 & 0.965 & 0.0468 \\
\hline Cs-071702-B & 0.5387 & 0.521 & 0.165 \\
\hline Cs-071702-C & 0.8100 & 0.929 & 0.052 \\
\hline Cs-071702-E & 0.7644 & 0.839 & 0.063 \\
\hline Cs-071702-G & 0.9593 & 1.448 & 0.021 \\
\hline Cs-071802-H & 0.9695 & 1.530 & 0.019 \\
\hline Cs-071802-I & 0.9614 & 1.463 & 0.021 \\
\hline Cs-071802-J & 0.6387 & 0.643 & 0.108 \\
\hline Cs-071802-K & 0.9558 & 1.423 & 0.022 \\
\hline Cs-071802-N & 0.9082 & 1.192 & 0.031 \\
\hline Cs-071802-P & 0.9428 & 1.345 & 0.024 \\
\hline Cs-071802-Q & 0.9951 & 1.990 & 0.011 \\
\hline Cs-071802-R & 0.9578 & 1.437 & 0.021 \\
\hline Cs-071802-S & 0.8807 & 1.101 & 0.037 \\
\hline Cs-071802-U & 0.5488 & 0.533 & 0.158 \\
\hline Cs-071802-V & 0.9938 & 1.938 & 0.012 \\
\hline Cs-071802-W & 0.7185 & 0.762 & 0.077 \\
\hline Cs-071802-X & 0.8771 & 1.092 & 0.037 \\
\hline Cs-071802-Y & 0.6616 & 0.684 & 0.096 \\
\hline Cs-071802-Z & 0.7547 & 0.822 & 0.066 \\
\hline Cs-071802-AA & 0.9450 & 1.359 & 0.024 \\
\hline Cs-071802-BB & 0.7943 & 0.895 & 0.056 \\
\hline
\end{tabular}

Corroboration of the calibrated values for $D$ was obtained by analyzing ${ }^{239} \mathrm{Pu}$ and ${ }^{235} \mathrm{U}$ radionuclide profiles in soils at the Nevada Test Site (Anspaugh et al. 1975 [DIRS 151548]; Gilbert and Eberhardt 1976 [DIRS 169808]; Romney et al. 1970 [DIRS 169811]). These measurements expand the list of radionuclides analyzed, and also increase the range of time scales to those as small as 1.3 years.

The Nevada Test Site is considered the best available analog for the RMEI location. Datasets for the concentration of ${ }^{239} \mathrm{Pu}$ and ${ }^{235} \mathrm{U}$ were measured by Romney et al. (1970 [DIRS 169811]) and Anspaugh et al. (1975 [DIRS 151548]), and concentrations of ${ }^{235} \mathrm{U}$ were measured by Gilbert and Eberhardt (1976 [DIRS 169808]) at the Nevada Test Site. In all of these literature sources, the concentration is measured in three or more depth intervals. Only the first depth interval and the 
total activity were used, however, to reduce the analysis to the error function value at a single point (analogous to the calibration data in Table I-4). Proposed work includes a more complete analysis, including nonlinear curve fitting of Equation I-14 to the complete measured profiles.

Romney et al. (1970) data-Romney et al. (1970 [DIRS 169811], table 1) provided three profiles measured over two different time scales: 1.3 years and 10.8 years. The inferred $D$ values are comparable despite the order-of-magnitude difference in time scale. This provided confidence that the diffusion model was accurately reproducing the temporal evolution of the migration process.

Table I-5. Inferred $D$ Values from Romney et al. (1970)

\begin{tabular}{|c|c|c|c|}
\hline Radionuclide, $\mathrm{t}_{1}$ & $\begin{array}{c}\text { fraction at } \mathbf{3} \mathbf{~ c m =} \\
\text { erf }\left(\mathbf{3} \mathbf{~ c m} /\left(\mathbf{4 D t _ { 1 }}\right)^{1 / 2}\right)\end{array}$ & $\begin{array}{c}\mathbf{3} \\
\mathbf{c m} /\left(\mathbf{4 D t _ { 1 }}\right)^{1 / 2}\end{array}$ & $\mathbf{D}\left(\mathbf{c m}^{2} / \mathbf{y r}\right)$ \\
\hline${ }^{239} \mathrm{Pu}, 1.3 \mathrm{yr}$ & 0.9231 & 1.251 & 1.105 \\
\hline${ }^{239} \mathrm{Pu}, 10.8 \mathrm{yr}$ & 0.8007 & 0.908 & 0.252 \\
\hline${ }^{239} \mathrm{Pu}, 10.8 \mathrm{yr}$ & 0.7151 & 0.757 & 0.363 \\
\hline
\end{tabular}

Anspaugh et al. (1975) data-Anspaugh et al. (1975 DIRS 151548]) measured one profile in detail approximately 20 years after nuclear testing. The best-fit $D$ value is $0.01 \mathrm{~cm}^{2} /$ year, or more than an order-of-magnitude less than the values obtained for Romney et al. (1970 [DIRS 169811]) for the same radionuclide.

Table I-6. Inferred $D$ Values from Anspaugh et al. (1975)

\begin{tabular}{|c|c|c|c|}
\hline Radionuclide, $t_{1}$ & $\begin{array}{l}\text { fraction at } 0.5 \mathrm{~cm}= \\
\operatorname{erf}\left(0.5 \mathrm{~cm} /\left(4 D \mathrm{t}_{1}\right)^{1 / 2}\right)\end{array}$ & $\begin{array}{c}0.5 \\
\mathrm{~cm} /\left(4 D \mathrm{t}_{1}\right)^{1 / 2}\end{array}$ & $D\left(\mathrm{~cm}^{2} / \mathrm{yr}\right)$ \\
\hline${ }^{239} \mathrm{Pu}, 20 \mathrm{yr}$ & 0.6009 & 0.596 & 0.0088 \\
\hline
\end{tabular}

Gilbert and Eberhardt (1976) data-Gilbert and Eberhadt (1976 [DIRS 169808], table 8, site A, area 11) also measured one profile in detail. The best-fit $D$ value is $0.060 \mathrm{~cm}^{2} /$ year. The inferred $D$ values from Anspaugh et al., (1975) and Gilbert and Eberhardt (1976) using ${ }^{239} \mathrm{Pu}$ and ${ }^{235} \mathrm{U}$ are comparable to the calibration values obtained using the ${ }^{137} \mathrm{Cs}$ profiles of Harrington (2003 [DIRS 164775]).

Table 1-7. Inferred $D$ Values from Gilbert and Eberhardt (1976)

\begin{tabular}{|c|c|c|c|}
\hline Radionuclide, $\mathrm{t}_{1}$ & $\begin{array}{c}\text { fraction at } 2.5 \mathrm{~cm}= \\
\left.\text { erf(2.5 cm/(4Dt } 1)^{1 / 2}\right)\end{array}$ & $\begin{array}{c}2.5 \\
\mathrm{~cm} /(4 \mathrm{dt})^{1 / 2}\end{array}$ & $D\left(\mathrm{~cm}^{2} / \mathrm{yr}\right)$ \\
\hline${ }^{235} \mathrm{U}, 20 \mathrm{yr}$ & 0.8920 & 1.138 & 0.060 \\
\hline
\end{tabular}

These results indicate that $D$ values do not differ systematically between radionuclides, indicating that different radionuclide species become mixed within the soil profile at comparable rates. This result is consistent with the conclusions of Anspaugh et al. (2002 [DIRS 169793]). Individual profiles do show large variability, however, from a minimum of $0.008 \mathrm{~cm}^{2} / \mathrm{yr}$ to a maximum of $1.1 \mathrm{~cm}^{2} / \mathrm{yr}$. Some of this variability could reflect geomorphic position (i.e. 
channels vs. interchannel divides). It is difficult to test this hypothesis, however, because only limited information on sample position is provided in these NTS reports.

\section{I9.2 Depth of Impermeable Soil Horizon}

\section{I9.2.1 $\quad L_{0}$ values for Interchannel Divides}

The depth to petrocalcic horizons is correlated with mean annual precipitation (Arkley 1963 [DIRS 171102]). This correlation provides a regional context for the $L_{0}$ values appropriate for interchannel divides. Arkley (1963) [DIRS 171102] developed an equation to describe this relationship using aridisols in Nevada and California. He obtained

$$
P=3.73 L_{0}+106
$$

where $P$ is the mean annual precipitation in $\mathrm{mm}$ and $L_{0}$ is in $\mathrm{cm}$. Using an appropriate range for $P$ at the RMEI location of between 6 and $7.5 \mathrm{in} / \mathrm{yr}, L_{0}$ is expected to be between 10 and $20 \mathrm{~cm}$ according to Equation I-15.

Harrington (2003 [DIRS 164775]) directly measured $L_{0}$ values to be between 7 and $12 \mathrm{~cm}$ depth. These values are consistent with the predicted values based on the regional calibration of Equation I-15. Therefore, an appropriate range for $L_{0}$ is between 7 and $12 \mathrm{~cm}$.

\subsection{2 $L_{0}$ values for Channels}

In channels, frequent erosion and deposition prevents the formation of a petrocalcic horizon in the near subsurface. At greater depths, petrocalcic horizons may or may not exist depending on the geomorphic history of the particular location. As a result of this dependence on local geomorphic history, there is no regional calibration available for $L_{0}$ values in channels, so a direct measurement is the best means of constraining these values. In the RMEI location, Harrington (2003 [DIRS 164775]) observed petrocalcic horizons at 1.0 to $1.5 \mathrm{~m}$ depth in several locations. At other locations, no petrocalcic horizon was observed down to $2 \mathrm{~m}$ depth. Therefore, an appropriate range for $L_{0}$ in channels is 1 to $2 \mathrm{~m}$ until further field measurements are made. 
ILLEGIBILITY STATEMENT

The illegibility and/or cutoff information does not impact the technical meaning or content of the record or create a condition adverse to quality.

$\underset{\text { Denise Gibson }}{\text { Gibson }}$

$11 / 02 / 04$ 